\title{
Vascular function and metabolic health in humans
}

Citation for published version (APA):

Joris, P. (2016). Vascular function and metabolic health in humans: effects of diet and weight loss.

[Doctoral Thesis, Maastricht University]. https://doi.org/10.26481/dis.20160708pj

Document status and date:

Published: 01/01/2016

DOI:

10.26481/dis.20160708pj

Document Version:

Publisher's PDF, also known as Version of record

\section{Please check the document version of this publication:}

- A submitted manuscript is the version of the article upon submission and before peer-review. There can be important differences between the submitted version and the official published version of record.

People interested in the research are advised to contact the author for the final version of the publication, or visit the DOI to the publisher's website.

- The final author version and the galley proof are versions of the publication after peer review.

- The final published version features the final layout of the paper including the volume, issue and page numbers.

Link to publication

\footnotetext{
General rights rights.

- You may freely distribute the URL identifying the publication in the public portal. please follow below link for the End User Agreement:

www.umlib.nl/taverne-license

Take down policy

If you believe that this document breaches copyright please contact us at:

repository@maastrichtuniversity.nl

providing details and we will investigate your claim.
}

Copyright and moral rights for the publications made accessible in the public portal are retained by the authors and/or other copyright owners and it is a condition of accessing publications that users recognise and abide by the legal requirements associated with these

- Users may download and print one copy of any publication from the public portal for the purpose of private study or research.

- You may not further distribute the material or use it for any profit-making activity or commercial gain

If the publication is distributed under the terms of Article $25 \mathrm{fa}$ of the Dutch Copyright Act, indicated by the "Taverne" license above, 
Vascular function and metabolic health in humans:

Effects of diet and weight loss 

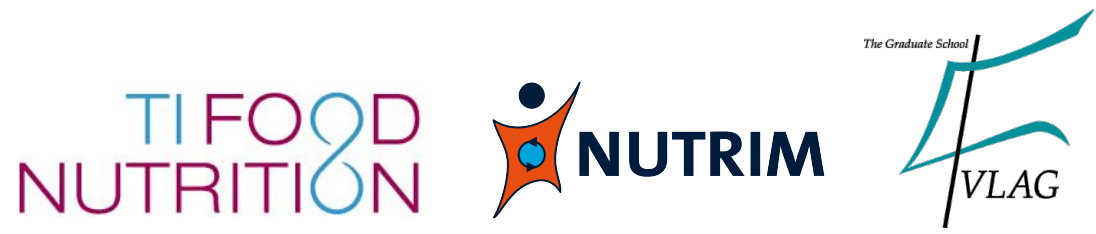

The studies presented in this thesis were performed within the framework of TI Food and Nutrition and within NUTRIM School of Nutrition and Translational Research in Metabolism, which participates in the Graduate School VLAG (Food Technology, Agrobiotechnology, Nutrition and Health Sciences), accredited by the Royal Netherlands Academy of Arts and Sciences.

Cover design: Joris Thys Layout: Peter Jozef Joris

Printed by: Proefschriftmaken.nl || Uitgeverij BOXPress

(c) Copyright Peter Jozef Joris, Maastricht 2016 


\title{
Vascular function and metabolic health in humans: Effects of diet and weight loss
}

\author{
PROEFSCHRIFT \\ ter verkrijging van de graad van doctor \\ aan de Universiteit Maastricht \\ op gezag van de Rector Magnificus, \\ Prof. dr. L.L.G. Soete \\ volgens het besluit van het College van Decanen, \\ in het openbaar te verdedigen \\ op vrijdag 8 juli 2016 om 12.00 uur
}

door

\section{Peter Jozef Joris}

geboren te Hasselt op 3 maart 1988 


\section{Promotores}

Prof. dr. ir. R.P. Mensink

Prof. dr. J. Plat

\section{Beoordelingscommissie}

Prof. dr. M.K.C. Hesselink (voorzitter)

Prof. dr. A. Bast

Dr. R. Draijer (Unilever R\&D, Vlaardingen, The Netherlands)

Prof. dr. J.M. Geleijnse (Wageninen UR, Wageningen, The Netherlands)

Prof. dr. A.A. Kroon 
Table of Contents

Chapter 1 General introduction

Chapter 2 Effect of dietary fatty-acid intake on cardiovascular disease

Chapter 3 Beetroot juice improves in overweight and slightly obese men postprandial endothelial function after consumption of a mixed meal

Chapter 4 Effects of supplementation with the fat-soluble vitamins $E$ and $D$ on fasting flow-mediated vasodilation in adults:

A meta-analysis of randomized controlled trials

Chapter 5 Weight loss improves fasting flow-mediated vasodilation in adults: A meta-analysis of intervention studies

Chapter 6 Diet-induced weight loss not only improves cardiometabolic risk markers, but also markers of vascular function:

A randomized controlled trials in abdominally obese men

Chapter 7 Long-term magnesium supplementation improves arterial 109 stiffness in overweight and obese adult: Results of a randomized, double-blind, placebo-controlled intervention trial

Chapter 8 General discussion

Summary

Samenvatting

Valorisation

Dankwoord 



\title{
CHAPTER 1
}

\author{
General introduction
}




\section{CHAPTER 1}

\section{Cardiovascular disease}

Cardiovascular disease (CVD) remains the leading cause of morbidity and mortality globally, accounting for $31 \%$ (17.5 million) of all deaths in 2012 [1]. The number of global cardiovascular deaths is expected to increase to 23 million in the year 2030 [2]. CVD related costs are high. In fact, annual costs are more than 196 billion Euros in Europe [3]. The disease is caused by disorders of the heart and blood vessels that involve a group of clinical syndromes, including coronary heart disease (CHD; angina pectoris and myocardial infarction), cerebrovascular disease (stroke and transient ischemic attacks) and peripheral arterial disease (intermittent claudication). The underlying pathological feature of all these syndromes is atherosclerosis. Atherosclerosis is a slowly progressing chronic disease that is characterized by plaque development inside large and medium-sized arterial walls. These atherosclerotic lesions, which may partially or totally block the blood flow through an artery, consist of different major components. The first component is a collection of migrated vascular smooth muscle cells (VSMCs) and inflammatory cells (macrophages and lymphocytes). The second major component is the connective tissue matrix and an accumulation of (modified) extracellular lipids. The third component is intracellular lipid accumulated within macrophages that eventually leads to the formation lipid-laden foam cells. Even though CVD has a strong genetic component, the onset and progress of atherosclerosis are modified by dietary habits and lifestyle approaches. In fact, dietary factors may be the most modifiable CVD risk factors [4]. A healthy diet has indeed been associated with a reduced risk of CVD [5-7]. However, the number of large randomized controlled trials (RCTs) with appropriate follow-up periods and CHD events as endpoints is limited. Alternatively, the effects of dietary interventions on surrogate risk markers of CVD can be studied, such as vascular function markers. Vascular markers have been related to CVD risk. In addition, dietary factors may improve cardiovascular health based on beneficial effects on vascular function.

\section{Vascular function and cardiovascular disease}

Various vascular function markers exist along the pathway between diet and CVD, each addressing a different aspect of the vasculature. These markers can be used to assess vascular endothelial function, arterial stiffness or microvascular structure [Figure 1.1]. In addition, vascular function can be determined by measuring plasma biomarkers. Many of the vascular markers used in the present disseration (i) are sensitive to dietary factors; (ii) can be assessed non-invasively in humans with sufficient reproducibility; and (iii) may be used as predictors of long-term CVD outcomes [8].

\section{Vascular endothelial function}

The vascular endothelium is a thin monolayer of cells lining the interior surface of all blood vessels. These endothelial cells line the entire circulatory system from the heart to the capillaries and cover a total surface area of approximately 1 to $7 \mathrm{~m}^{2}$ in human adults. The endothelium, that is composed of about 1 to $6 \times 10^{13}$ cells, responds to numerous stimuli and performs many essential physiological functions 
throughout the vasculature. It acts as a physical barrier, plays a central role in blood coagulation and inflammation, and regulates vascular tone and hemodynamics [9]. Changes in endothelial responses or function that are inappropriate with regard to the preservation of vascular function can be defined as endothelial dysfunction. Endothelial dysfunction, which is in an initial state still reversible, mediates the initiation and progression of atherosclerosis and is therefore an important target to prevent or reverse the process of plaque development in arterial walls. Importantly, vascular endothelial function may indeed be a key mechanism though which a healthy diet improves the risk of CVD outcomes.

\section{Markers of vascular endothelial function}

Vascular endothelial function can be assessed in many different ways. Flowmediated vasodilation (FMD) of the brachial artery, which is a functional marker measured by ultrasonography, is considered a robust [10] and the current noninvasive gold standard technique [11] to assess endothelial function. Celermajert and colleagues introduced the assessment of FMD in 1992 [12] and up till now most research on endothelial function still comprises the measurement of FMD since it is the most accepted and established method. This technique basically quantifies the capacity of the vascular endothelium to induce brachial artery dilation following an ischemia-induced blood flow increase. This reactive hyperemic response triggers the release of vasodilators from the endothelium like the gas nitric oxide (NO), that is recognized as a key determinant of vascular health since it exerts vasodilatory, anti-inflammatory, antithrombotic, anti-proliferative and antiadhesive properties [13]. FMD is normal with values above $3 \%$ of the baseline diameter, but can also be abnormal or absent in patients with values between $0 \%$ and $2 \%$ [14]. Importantly, brachial FMD is inversely associated with future CVD events and a recent meta-analysis of prospective epidemiologic trials has suggested that each $1 \%$ increase in FMD is associated with a $8 \%$ lower risk of overall CVD [15]. In addition, the European Food Safety Authority (EFSA) considers an increase in fasting FMD following dietary interventions a beneficial physiological effect [16]. However, assessments of FMD are technically challenging and the within-subject variability is relatively large [17]. There are also various physiological, methodological and technical factors that adversely affect comparability between FMD trials. Peripheral arterial tonometry (PAT), which is recorded by pneumatic probes placed on the index fingers, is another functional measure of endothelial function that is easier to use and may provide better reproducibility. The EndoPAT device basically measures changes in finger arterial pulse wave amplitude following reactive hyperemic responses. Importantly, both methods for investigation of vascular endothelial function target different arterial systems. However, the utility and value of PAT assessments are less established than of FMD measures [18]. Plasma biomarkers are also measured as an indirect approach to determine vascular endothelial function. Vascular cell adhesion molecule (VCAM-1), intercellular adhesion molecule (ICAM-1) and endothelial selectin (E-selectin) are adhesion molecules expressed by endothelial cells that mediate the activation and recruitment of leukocytes. The soluble variants of these molecules are shed from the vascular wall into the circulation after cleavage at the cell membrane through proteolysis. In addition, the glycoprotein von Willebrand 


\section{CHAPTER 1}

factor (vWf) can be found in higher amounts in plasma after the activation of endothelial cells. Increased circulating concentrations of these endothelial cell markers represent vascular endothelial dysfunction and have been associated with a greater risk of future cardiovascular events [19].

\section{Arterial stiffness}

Arterial stiffening represents another mechanism that has been associated with CVD [20, 21]. The pathogenesis of cardiovascular events caused by stiffer arteries involves an elevation of the travel speed of the pulse pressure wave throughout the arterial tree. This eventually leads to an increased pulse pressure, to reduced coronary perfusion and to increased left ventricular hypertrophy. These alterations caused by stiffer arteries can culminate into cardiovascular events, such as myocardial infarction and stroke [22]. In fact, arterial stiffness may also be caused by endothelial dysfunction and represents another pathway between endothelial dysfunction and CVD events. Indeed, endothelial dysfunction may cause increased functional arterial stiffness (short-term effect: days to weeks), which is in an initial state still reversible, through diminished NO bioavailability and increased activity of vasoconstrictors that lead to the induction of vasoconstriction by VSMCs [23]. In addition, vascular endothelial dysfunction may also lead to increased structural arterial stiffness (longer-term effect: months), which is in an initial state also still reversible, via the induction of processes that involve the formation of cross-links, the replacement of elastin fibers with collagen fibers and the deposition of calcium that alters structural proteins in the arterial wall [24].

\section{Markers of arterial stiffness}

Arterial stiffness as determined by carotid-femoral pulse wave velocity $\left(P W V_{c-f}\right)$ is considered the current gold standard method for measuring regional arterial stiffness [25]. Basically, $\mathrm{PWV}_{\text {c-f }}$ is the speed of the pulse pressure wave travelling along the aorta to the femoral artery. A faster $P W V_{c-f}$ is indicative of greater arterial stiffness and has been associated with CVD. Further, the presence of a velocity above $13 \mathrm{~m} / \mathrm{s}$ is a strong predictor of cardiovascular mortality [26] and a metaanalysis showed that CVD risk was reduced by $14 \%$ when $P W V_{c-f}$ decreases by 1 $\mathrm{m} / \mathrm{s}$ [20]. The augmentation index (Alx) is another non-invasive measure of arterial stiffness and a lower Alx is associated with a lower risk of CVD [27]. The Alx was defined as the difference between the first and second peak of the arterial waveform, which is acquired with an applanation tonometer (SphygmoCor v9; AtCor Medical, West Ryde, Australia), and expressed as a percentage of the pulse pressure and corrected for heart rate.

\section{Microvascular structure}

The microcirculation in the retina is accessible to non-invasive measurement and retinal images can be obtained to determine microvascular structure of the eye. Retinal images can be taken digitally without pharmacological pupil dilation with a Topcon TRC-NW-300 camera (Topcon Co., Tokyo, Japan). Beneficial changes in retinal vessel diameters are associated with a decreased risk of CVD events [28, 29]. McGeechan and colleagues suggested that the risk of $\mathrm{CHD}$ outcomes 
decreases by $17 \%$ when mean arterial diameters increase by $20 \mu \mathrm{m}$ in women, but not in men. In the meta-analysis, it was further calculated that the risk of CHD was significantly reduced by $16 \%$ when venular diameters decreased by $20 \mu \mathrm{m}$ in women [29].

Flow-mediated vasodilation $\quad$ Pulse wave velocity

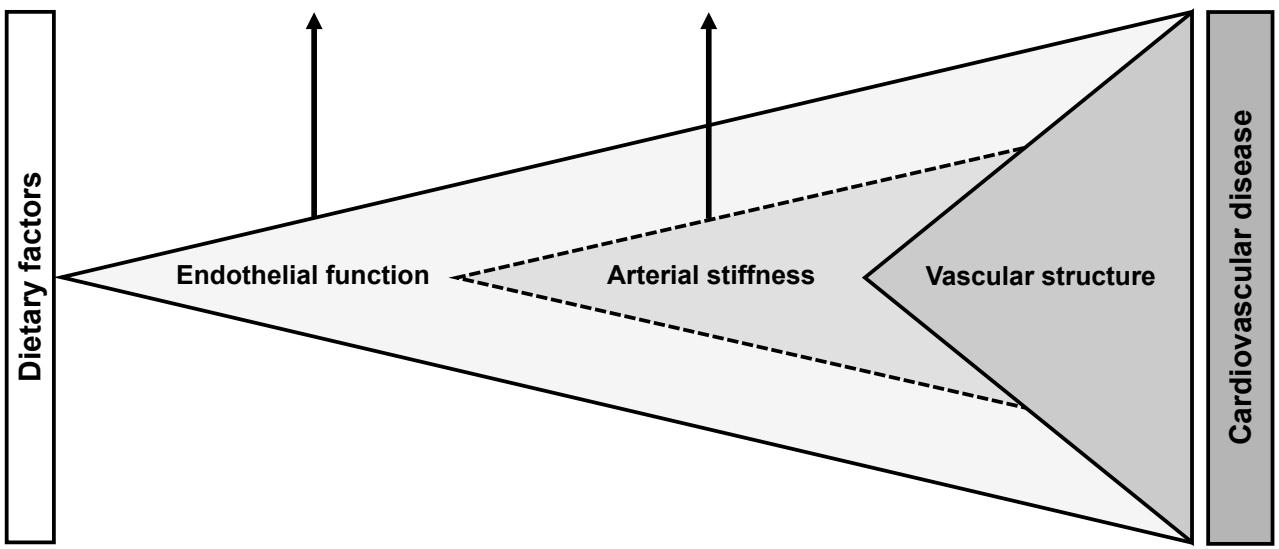

Figure 1.1. Various vascular function markers exist at different stages on the pathway between dietary factors and cardiovascular disease, each addressing a different aspect of the vasculature. This thesis focused on non-invasive markers that can be used to assess vascular endothelial function (e.g. brachial artery flow-mediated vasodilation) or arterial stiffness (e.g. carotid-femoral pulse wave velocity).

\section{Dietary factors and vascular function}

The vasculature is continuously exposed to a changing environment, such as observed after successive food intake. Emerging evidence suggest an important role of dietary factors in modulating vascular function. Several factors, such as high loads of dietary fat or carbohydrate, have been classified as harmful stressors for the endothelium, whereas others have been classified as beneficial [30]. Model dietary components used in the present thesis (i) may affect selected vascular function markers in realistic doses; and (ii) have indications for a relation with CVD outcomes.

\section{Dietary stressors}

A high load of fat is considered a nutritional stressor for the vasculature since the intake of dietary fat transiently impairs vascular endothelial function [31, 32]. Even though the precise underlying mechanism remains to be elucidated, diminished bioavailability of $\mathrm{NO}$ is considered to be a major cause. The NO bioavailability may reduce via an increased production of reactive oxygen species during the postprandial state and stimulatory effects of plasma triglyceride-rich lipoproteins on pro-coagulation and pro-inflammatory pathways in endothelial cells [33]. The intake of dietary carbohydrate may also relate to impaired vascular endothelial function, but effects are less pronounced than those of high loads of fat [34]. The ability to 


\section{CHAPTER 1}

respond to dietary stressors during the postprandial state can be seen as a measurement of endothelial flexibility. Postprandial challenges may thus be used as tools to assess early perturbations in endothelial function, even before these can be measured under fasting conditions. In addition, since a significant part of the day is spent in the postprandial state, identification of strategies to counteract the transient impairment of postprandial endothelial function may be of major importance to decrease the risk of cardiovascular outcomes.

\section{Dietary model components}

There is increasing evidence that a diet rich in fruit and vegetables has beneficial effects on CVD risk [35, 36]. Therefore, more attention has been directed towards the effects on vascular health of the various nutrients found in these diets, such as inorganic nitrate $\left(\mathrm{NO}_{3}{ }^{-}\right)$. Via bioconversion to nitrite $\left(\mathrm{NO}_{2}{ }^{-}\right)$, inorganic nitrate supplementation has been shown to increase NO bioavailability, which results in improved endothelial function. In fact, these effects have been observed following consumption of nitrate-rich beetroot juice [37]. The effects of the fat-soluble vitamins $E$ and vitamin $D$ on selected vascular function markers and CVD outcomes are less established as compared with inorganic nitrate. However, observational studies have found inverse associations between the use of fatsoluble vitamin supplements and CVD outcomes [38]. Furthermore, vitamin E supplementation may lower the quenching effect of free radicals on NO [39], thereby improving NO bioavailability and endothelial function. A role of vitamin D supplements on vascular endothelial function has also been suggested based on in vitro and animal studies [40]. Lifestyle changes leading to weight loss are also of major interest. Weight loss can be considered as a powerful dietary effector of vascular function. The potential beneficial effects of diet-induced weight loss on vascular endothelial function may relate to decreased secretion of adipose tissuederived adipokines [41] and other vasoactive factors. Further, significant evidence exists to suggest that lifestyle changes leading to weight reduction improve CVD risk. The essential mineral magnesium is the final dietary model component used in the present dissertation. Evidence suggests that high dietary magnesium intakes play a protective role in CVD. In addition, magnesium has defined effects on blood pressure [42] since it acts as a calcium antagonist, thereby causing vasorelaxation by VSMCs and subsequent decreases in systemic vascular resistance [43]. Except for blood pressure, the essential mineral magnesium may also beneficially affect other cardiovascular risk markers, but it still remains to be investigated whether these effects translate into improved vascular function.

\section{Study populations}

The primary target is the large part of the population that is at increased cardiovascular risk, but not diagnosed with disease or under drug treatment. Therefore, the present thesis focused on healthy overweight and (abdominally) obese volunteers in randomized trials. In these intervention trials, only men and postmenopausal women were included. This may reduce the external validity, but excludes possible variations in the outcomes due to hormonal effects. Further, two thorough meta-analyses were used to compare results between these and other study populations. 


\section{Outline of the thesis}

The main aim of the present thesis was to investigate the effects of dietary interventions on selected vascular markers. First, chapter 2 briefly summarizes the relation between vascular function markers and cardiovascular risk. Then, the effects of dietary fatty acids on these cardiovascular risk markers and on CVD risk itself are discussed. The next two chapters describe the effects of specific nutritional factors on endothelial function. It is investigated in the study described in chapter 3 whether beetroot juice, which is rich in inorganic nitrate, may counteract in overweight and slightly obese men the postprandial impairment of FMD associated with the ingestion of a mixed meal. In chapter 4 , a meta-analysis is performed to quantify the effects of supplementation with the fat-soluble vitamin $\mathrm{E}$ and vitamin $\mathrm{D}$ on fasting FMD in adults. In the next two chapters, the effects of weight loss on vascular function markers are investigated. The effects of weight loss on fasting FMD in adults are first quantified [chapter 5] in a thorough metaanalysis. Then, a randomized trial is performed, specially designed to investigate (i) the effects of diet-induced weight loss on different vascular function markers and (ii) differences between normal-weight and abdominally obese male subjects at baseline and after weight loss [chapter 6 ]. In chapter 7 , the results are described of a long-term human intervention study in which the effects of magnesium citrate supplementation on arterial stiffness are investigated. Arterial stiffness was determined by $P W V_{c-f}$, while the study was performed in healthy overweight and slightly obese adults. Finally chapter 8 summarizes the major findings of the different studies and meta-analyses described in the present thesis. The main results from the previous chapters are discussed in a broader perspective, and some leads for future research are provided. 


\section{CHAPTER 1}

\section{References}

1. World Health Organization. Cardiovascular diseases (CVDs) fact sheet No. 317, January 2015. Available from: http://www.who.int/mediacentre/factsheets/fs317/en/.

2. Mathers CD, Loncar D. Projections of global mortality and burden of disease from 2002 to 2030. PLoS Med 2006;3:e442.

3. European Heart Network. European cardiovascular disease statistics 2012, January 2015. Available from: http://www.ehnheart.org/cvd-statistics.html.

4. Lichtenstein AH, Appel LJ, Brands M, Carnethon M, Daniels S, et al. Diet and lifestyle recommendations revision 2006: a scientific statement from the American Heart Association Nutrition Committee. Circulation 2006;114:82-96.

5. Harriss LR, English DR, Powles J, Giles GG, Tonkin AM, Hodge AM, et al. Dietary patterns and cardiovascular mortality in the Melbourne Collaborative Cohort Study. Am J Clin Nutr 2007;86:221-9.

6. Hu FB, Rimm EB, Stampfer MJ, Ascherio A, Spiegelman D, Willett WC. Prospective study of major dietary patterns and risk of coronary heart disease in men. Am J Clin Nutr 2000;72:912-21.

7. Knoops KT, de Groot LC, Kromhout D, Perrin AE, Moreiras-Varela O, Menotti A, et al. Mediterranean diet, lifestyle factors, and 10-year mortality in elderly European men and women: the HALE project. JAMA 2004;292:1433-9.

8. Cohn JN, Quyyumi AA, Hollenberg NK, Jamerson KA. Surrogate markers for cardiovascular disease: functional markers. Circulation 2004;109:IV31-46.

9. Cines DB, Pollak ES, Buck CA, Loscalzo J, Zimmerman GA, McEver RP, et al. Endothelial cells in physiology and in the pathophysiology of vascular disorders. Blood 1998;91:352761.

10. Donald AE, Charakida M, Cole TJ, Friberg P, Chowienczyk PJ, Millasseau SC, et al. Noninvasive assessment of endothelial function: which technique? J Am Coll Cardiol 2006;48:1846-50.

11. Ellins EA, Halcox JP. Where are we heading with noninvasive clinical vascular physiology? Why and how should we assess endothelial function? Cardiol Res Pract 2011;2011:870132.

12. Celermajer DS, Sorensen KE, Gooch VM, Spiegelhalter DJ, Miller OI, Sullivan ID, et al. Non-invasive detection of endothelial dysfunction in children and adults at risk of atherosclerosis. Lancet 1992;340:1111-5.

13. Jin RC, Loscalzo J. Vascular Nitric Oxide: Formation and Function. J Blood Med 2010;2010:147-62.

14. Moens AL, Goovaerts I, Claeys MJ, Vrints CJ. Flow-mediated vasodilation: a diagnostic instrument, or an experimental tool? Chest 2005;127:2254-63.

15. Ras RT, Streppel MT, Draijer R, Zock PL. Flow-mediated dilation and cardiovascular risk prediction: a systematic review with meta-analysis. Int J Cardiol 2013;168:344-51.

16. EFSA. Scientific Opinion on the substantiation of a health claim related to cocoa flavanols and maintenance of normal endothelium-dependent vasodilation pursuant to Article 13(5) of Regulation (EC) No. 1924/2006. EFSA Journal 2012.

17. De Roos NM, Bots ML, Schouten EG, Katan MB. Within-subject variability of flow-mediated vasodilation of the brachial artery in healthy men and women: implications for experimental studies. Ultrasound Med Biol 2003;29:401-6.

18. Poredos P, Jezovnik MK. Testing endothelial function and its clinical relevance. J Atheroscler Thromb 2013;20:1-8.

19. Morange PE, Simon C, Alessi MC, Luc G, Arveiler D, Ferrieres J, et al. Endothelial cell markers and the risk of coronary heart disease: the Prospective Epidemiological Study of Myocardial Infarction (PRIME) study. Circulation 2004;109:1343-8. 
20. Vlachopoulos C, Aznaouridis K, Stefanadis C. Prediction of cardiovascular events and allcause mortality with arterial stiffness: a systematic review and meta-analysis. J Am Coll Cardiol 2010;55:1318-27.

21. Laurent S, Boutouyrie P, Asmar R, Gautier I, Laloux B, Guize L, et al. Aortic stiffness is an independent predictor of all-cause and cardiovascular mortality in hypertensive patients. Hypertension 2001;37:1236-41.

22. Safar ME. Handbook of Hypertension: Arterial Stiffness in Hypertension. Amsterdam, Netherlands: Elsevier B.V. 2006.

23. Wilkinson IB, Qasem A, McEniery CM, Webb DJ, Avolio AP, Cockcroft JR. Nitric oxide regulates local arterial distensibility in vivo. Circulation 2002;105:213-7.

24. Greenwald SE. Ageing of the conduit arteries. J Pathol 2007;211:157-72.

25. Laurent S, Cockcroft J, Van Bortel L, Boutouyrie P, Giannattasio C, Hayoz D, et al. Expert consensus document on arterial stiffness: methodological issues and clinical applications. Eur Heart J 2006;27:2588-605.

26. Blacher J, Asmar R, Djane S, London GM, Safar ME. Aortic pulse wave velocity as a marker of cardiovascular risk in hypertensive patients. Hypertension 1999;33:1111-7.

27. Vlachopoulos C, Aznaouridis K, O'Rourke MF, Safar ME, Baou K, Stefanadis C. Prediction of cardiovascular events and all-cause mortality with central haemodynamics: a systematic review and meta-analysis. Eur Heart J 2010;31:1865-71.

28. McGeechan K, Liew G, Macaskill P, Irwig L, Klein R, Klein BE, et al. Prediction of incident stroke events based on retinal vessel caliber: a systematic review and individual-participant meta-analysis. Am J Epidemiol 2009;170:1323-32.

29. McGeechan K, Liew G, Macaskill P, Irwig L, Klein R, Klein BE, et al. Meta-analysis: retinal vessel caliber and risk for coronary heart disease. Ann Intern Med 2009;151:404-13.

30. Brown AA, Hu FB. Dietary modulation of endothelial function: implications for cardiovascular disease. Am J Clin Nutr 2001;73:673-86.

31. Vogel R, Coretti M, Plotnick G. Effect of a single high-fat meal on endothelial function in healthy subjects. Am J Cardiol 1997;79:350-4.

32. Gaenzer H, Sturm W, Neumayr G, Kirchmair R, Ebenbichler C, Ritsch A, et al. Pronounced postprandial lipemia impairs endothelium-dependent dilation of the brachial artery in men. Cardiovasc Res 2001;52:509-16.

33. Nappo F, Esposito K, Cioffi M, Giugliano G, Molinari A, Paolisso G, et al. Postprandial endothelial activation in healthy subjects and in type 2 diabetic patients: role of fat and carbohydrate meals. J Am Coll Cardiol 2002;39:1145-50.

34. Kawano H, Motoyama T, Hirashima O, Hirai N, Miyao Y, Sakamoto T, et al. Hyperglycemia rapidly suppresses flow-mediated endothelium-dependent vasodilation of brachial artery. $\mathrm{J}$ Am Coll Cardiol 1999;34:146-54.

35. Joshipura KJ, Hu FB, Manson JE, Stampfer MJ, Rimm EB, Speizer FE, et al. The effect of fruit and vegetable intake on risk for coronary heart disease. Ann Intern Med 2001;134:1106-14

36. Joshipura KJ, Ascherio A, Manson JE, Stampfer MJ, Rimm EB, Speizer FE, et al. Fruit and vegetable intake in relation to risk of ischemic stroke. JAMA 1999;282:1233-9.

37. Webb A, Patel N, Loukogeorgakis S, Okorie M, Aboud Z, Misra S, et al. Acute blood pressure lowering, vasoprotective, and antiplatelet properties of dietary nitrate via bioconversion to nitrite. Hypertension 2008;51:784-90.

38. Lichtenstein AH. Nutrient supplements and cardiovascular disease: a heartbreaking story. J Lipid Res 2009;50:S429-33.

39. Paolisso G, Tagliamonte MR, Barbieri M, Zito GA, Gambardella A, Varricchio G, et al. Chronic vitamin $\mathrm{E}$ administration improves brachial reactivity and increases intracellular magnesium concentration in type II diabetic patients. J Clin Endocrinol Metab 2000;85:10915.

40. Dalan R, Liew H, Tan AW, Chew DE, Leow MK. Vitamin D and the endothelium: basic, translational and clinical research updates. IJC Metab Endocr 2014;4:4-17. 


\section{CHAPTER 1}

41. Gu P, Xu AM. Interplay between adipose tissue and blood vessels in obesity and vascular dysfunction. Rev Endocr Metab Disord 2013;14:49-58.

42. Kass L, Weekes J, Carpenter L. Effect of magnesium supplementation on blood pressure: a meta-analysis. Eur J Clin Nutr 2012;66:411-8.

43. Bo S, Pisu E. Role of dietary magnesium in cardiovascular disease prevention, insulin sensitivity and diabetes. Curr Opin Lipidol 2008;19:50-6. 


\title{
CHAPTER 2
}

\section{Effect of dietary fatty-acid intake on cardiovascular disease}

\author{
Peter J. Joris and Ronald P. Mensink
}

Functional Dietary Lipids, $1^{\text {st }}$ Edition: Food formulation, Consumer Issues and Innovation for Health. Woodhead Publishing 2015: 177-191 


\title{
CHAPTER 2
}

\begin{abstract}
Dietary recommendations to lower cardiovascular disease (CVD) risk are focused on reducing the intake of dietary saturated fatty acids (SFAs). However, the number of randomized controlled trials with cardiovascular events as endpoints is limited, which makes it difficult to define the most optimal substitute for the dietary SFAs. The effects of dietary fatty-acid intake on cardiovascular risk markers, such as serum lipid and lipoprotein cholesterol concentrations and non-invasive vascular function markers, can then be studied as an alternative approach. This chapter first summarizes the relation between these lipid-sensitive markers and cardiovascular risk. Then, the effects of dietary fatty acids on serum lipids and lipoproteins, noninvasive vascular function markers, and CVD risk are discussed.
\end{abstract}




\section{Introduction}

Worldwide, cardiovascular disease (CVD) is the leading cause of death. In 2012, over 17 million people died from CVD, representing $31 \%$ of all deaths [1]. This number is expected to increase to 23 million in 2030 [2]. A frequent underlying pathology of CVD is atherosclerosis that can cause a group of clinical syndromes, including coronary heart disease (CHD; angina pectoris and myocardial infarction), cerebrovascular disease (stroke and transient ischemic attacks) and peripheral arterial disease (intermittent claudication). The onset and progress of atherosclerosis, which is characterized by plaque development inside arterial walls, are modified by dietary habits. In fact, a major focus of dietary recommendations to lower CHD risk is to reduce the intake of saturated fatty acids (SFAs) [3]. However, it is difficult to define the most optimal substitute for SFAs, as the number of randomized controlled trials (RCTs) with CHD events as endpoints is limited. Alternatively, the effects of dietary fatty-acid interventions on validated risk markers of CVD can be studied.

Many biomarkers have been related to the risk of CVD. It is well known that these markers may be interrelated or interact with each other. This chapter will focus on validated risk markers that exist along the pathway between dietary lipid intake and CVD, such as serum lipids and lipoproteins, and non-invasive vascular function markers [Figure 2.1]. First, the relation between these markers and CVD risk is discussed. Then, the effects of dietary fatty-acid intake on risk markers and on CVD risk itself will be summarized. In the last paragraph, general conclusions will be formulated.

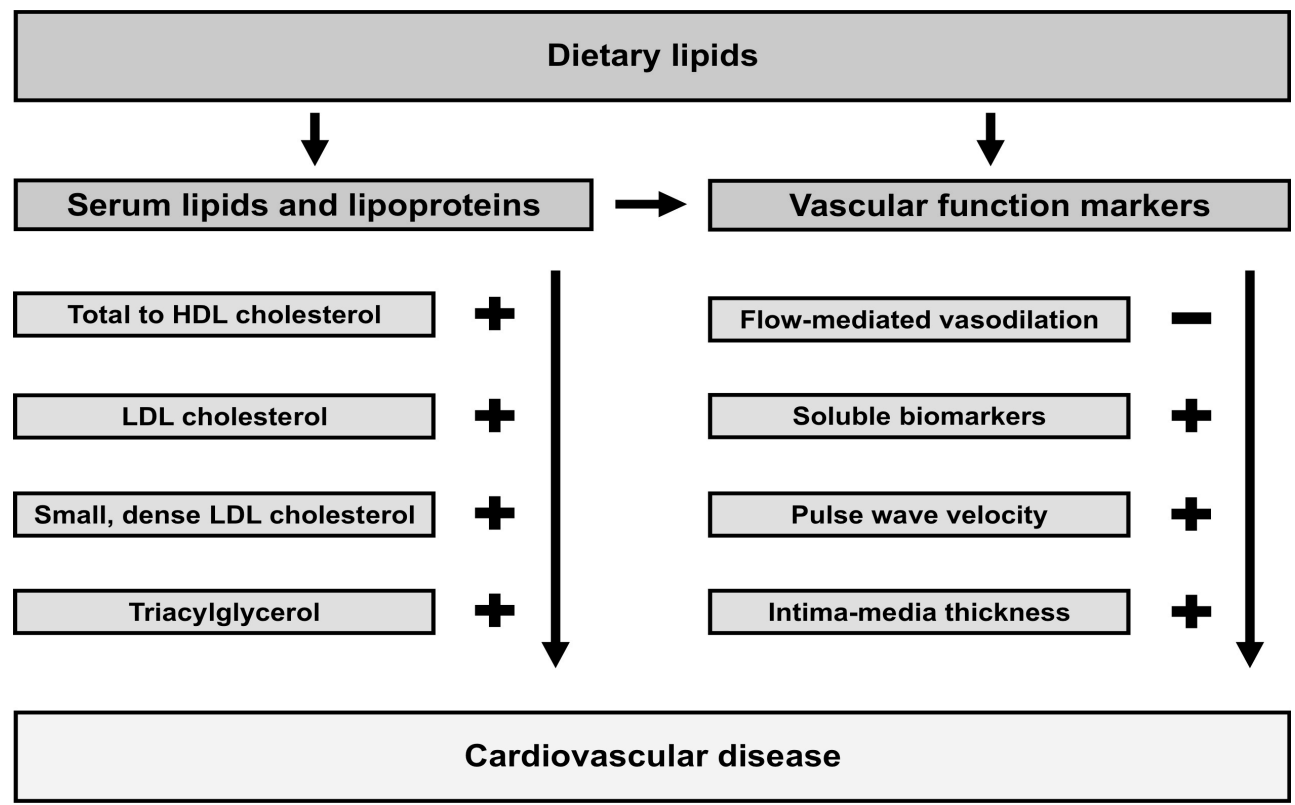

Figure 2.1. Many cardiovascular risk markers exist along the pathway between dietary lipid intake and cardiovascular disease (CVD), such as serum lipids and lipoproteins, and non-invasive vascular function markers. These markers may be interrelated or interact with each other, and have been positively (+) or inversely (-) related to the risk of CVD. 


\section{CHAPTER 2}

\section{Lipid-sensitive markers and risk of cardiovascular disease}

\section{Serum lipids and lipoproteins}

Cholesterol is the major component of the lipid core of the lipoproteins that transport cholesterol into and out of the arterial wall. It therefore plays a central role in the development of atherosclerotic plaques in arteries. The two major cholesterol-transporting lipoproteins are the atherogenic low-density lipoproteins (LDL) and the high-density lipoproteins (HDL) that may protect against atherosclerosis. These lipoproteins carry respectively $60 \%$ to $70 \%$ and $20 \%$ to $30 \%$ of the total amount of cholesterol in blood. The evidence suggesting a causal relationship of LDL cholesterol with CHD is well established and supported by numerous clinical trials. It has been estimated that a decrement of $0.10 \mathrm{mmol} / \mathrm{L}$ in LDL cholesterol results in a decrease of $3.7 \%$ in coronary events [4]. HDL cholesterol concentrations are inversely associated with the risk of coronary disease. However, a causal relation between HDL cholesterol and CHD is uncertain and the concept that intervention-induced improvements in HDL cholesterol reduce cardiovascular risk (the classic HDL cholesterol hypothesis) has been challenged. These challenges are driven by data derived from human genetics studies and RCTs that have failed to relate drug-induced increases in HDL cholesterol with a reduction in cardiovascular events. Therefore, the classic HDL cholesterol hypothesis is gradually being replaced by the HDL function hypothesis and future research is required to determine the impact of improved aspects of HDL function on cardiovascular outcomes [5]. The total to HDL cholesterol ratio may be a more sensitive and specific risk predictor than individual lipoprotein cholesterol concentrations and epidemiological observations suggest a decrease in the risk of myocardial infarction by $5.3 \%$ for each 0.10 unit decrease in the ratio [6]. Serum triacylglycerol concentrations represent another, but lessvalidated, cardiovascular risk marker. Triacylglycerol, which is found mainly in very-low-density lipoproteins (VLDL), is positively related with CVD endpoints in the general population and a $0.10 \mathrm{mmol} / \mathrm{L}$ decrease in triacylglycerol is associated with a $1.4 \%$ decrease in cardiovascular risk for men and a $3.7 \%$ decrease for women [7]. A concentration of serum triacylglycerol between $1.5 \mathrm{mmol} / \mathrm{L}$ and 1.7 $\mathrm{mmol} / \mathrm{L}$ has also been suggested as a critical threshold for the formation of small, dense low-density lipoproteins (sdLDL) that may be more atherogenic than normalsized LDL. Prospective cohort studies indeed indicated that increased sdLDL concentrations at baseline were associated with a 3.6 fold increase in the risk of $\mathrm{CHD}$, independent of concomitant variations in other serum lipid and lipoprotein cholesterol concentrations [8]. Like for HDL cholesterol, however, RCTs specifically designed to study the relationship of serum triacylglycerol and sdLDL cholesterol with coronary risk are needed to establish a causal link between these two biomarkers and CHD.

\section{Vascular function markers}

Many different vascular function markers exist, each addressing different aspects of the vasculature. Some of these markers can be used to assess vascular endothelial function, stiffness or structure, whereas vascular dysfunction can also be characterized indirectly by measuring circulating biomarkers. All these vascular 
markers are used to demonstrate CVD benefits [9]. Flow-mediated vasodilation (FMD) of the brachial artery is considered the non-invasive gold standard technique to assess vascular endothelial function [10]. This technique quantifies the arterial response to dilate in response to an ischemia-induced blood flow increase (reactive hyperemia) that triggers the release of vasodilators from the endothelium like nitric oxide. FMD is normal with values above $6 \%$ of the baseline diameter in healthy people, but is mildly abnormal ( $2 \%$ to $6 \%)$ or even abnormal to absent in patients with values between $0 \%$ and $2 \%$ [11]. Importantly, FMD is inversely associated with future CVD events and results from prospective epidemiologic studies have suggested that CVD risk decreases by about $8 \%$ per $1 \%$ higher FMD [12]. However, assessing endothelial function via FMD is complex and comparability of FMD measurements between research centers is low due to differences in methodological and technical factors that affect these measurements. Circulating biomarkers are also measured as an indirect approach to characterize vascular endothelial function. Vascular cell adhesion molecule 1 (VCAM-1), intercellular adhesion molecule 1 (ICAM-1) and endothelial selectin (Eselectin) are expressed by the endothelium and mediate the attachment of leukocytes to vascular endothelial cells. The soluble variants of these adhesion molecules, which are shed into the circulation after cleavage at the cell membrane through the process of proteolysis, can be analyzed in plasma and higher concentrations of these endothelial cell markers have been associated with future cardiovascular events [13]. Arterial stiffness can be determined either regionally or locally. Regional arterial stiffness determined by carotid-femoral pulse wave velocity $\left(P W V_{c-f}\right)$ is considered the non-invasive gold standard method for measuring arterial stiffness [14]. $P W V_{c-f}$ is basically the velocity of the pulse pressure wave travelling along the aorta to the femoral artery. A faster $P W V_{\text {c-f }}$ is indicative of greater arterial stiffness, which has been associated with CVD. In fact, the presence of a velocity above $13 \mathrm{~m} / \mathrm{s}$ is a strong predictor of cardiovascular mortality [15]. In a meta-analysis, it was further found that the risk of cardiovascular events was reduced by $14 \%$ when $\mathrm{PWV}_{\text {c-f }}$ decreased by $1 \mathrm{~m} / \mathrm{s}$ [16]. Finally, carotid intima-media thickness (IMT), which is an ultrasound measurement of the thickness of the tunica intima and tunica media of the artery wall, reflects structural changes and is widely used as a surrogate marker of early atherosclerosis. According to guidelines, IMT values below $0.9 \mathrm{~mm}$ are considered normal [17]. Importantly, carotid IMT has a strong prognostic value for future vascular events and it has been estimated that the future risk of myocardial infarction decreases by $10 \%$ to $15 \%$ for an absolute IMT difference of $0.1 \mathrm{~mm} \mathrm{[18]}$.

\section{Dietary lipid intake and lipid-sensitive markers}

\section{Serum lipids and lipoproteins}

The various fatty acids affect serum lipid and lipoprotein cholesterol concentrations differently. It is well known that body weight is an important determinant of serum lipid concentrations. Therefore, to study the effects of fatty acids on the serum lipoprotein profile, one cannot simply add fats and oils to a diet. With that approach, serum lipids would also change due to changes in energy intake and consequently body weight. Therefore, meta-analyses investigating the effects of 


\section{CHAPTER 2}

fatty-acid intakes balanced changes in the SFA, monounsaturated fatty acids (MUFA), polyunsaturated fatty acids (PUFA) or carbohydrate composition of the diet by opposite isocaloric changes in one or more of the other macronutrients. Protein intake was constant. As a result, the effects of dietary fatty acids on the serum lipoprotein profile are generally expressed relative to those of an isocaloric amount of dietary carbohydrates.

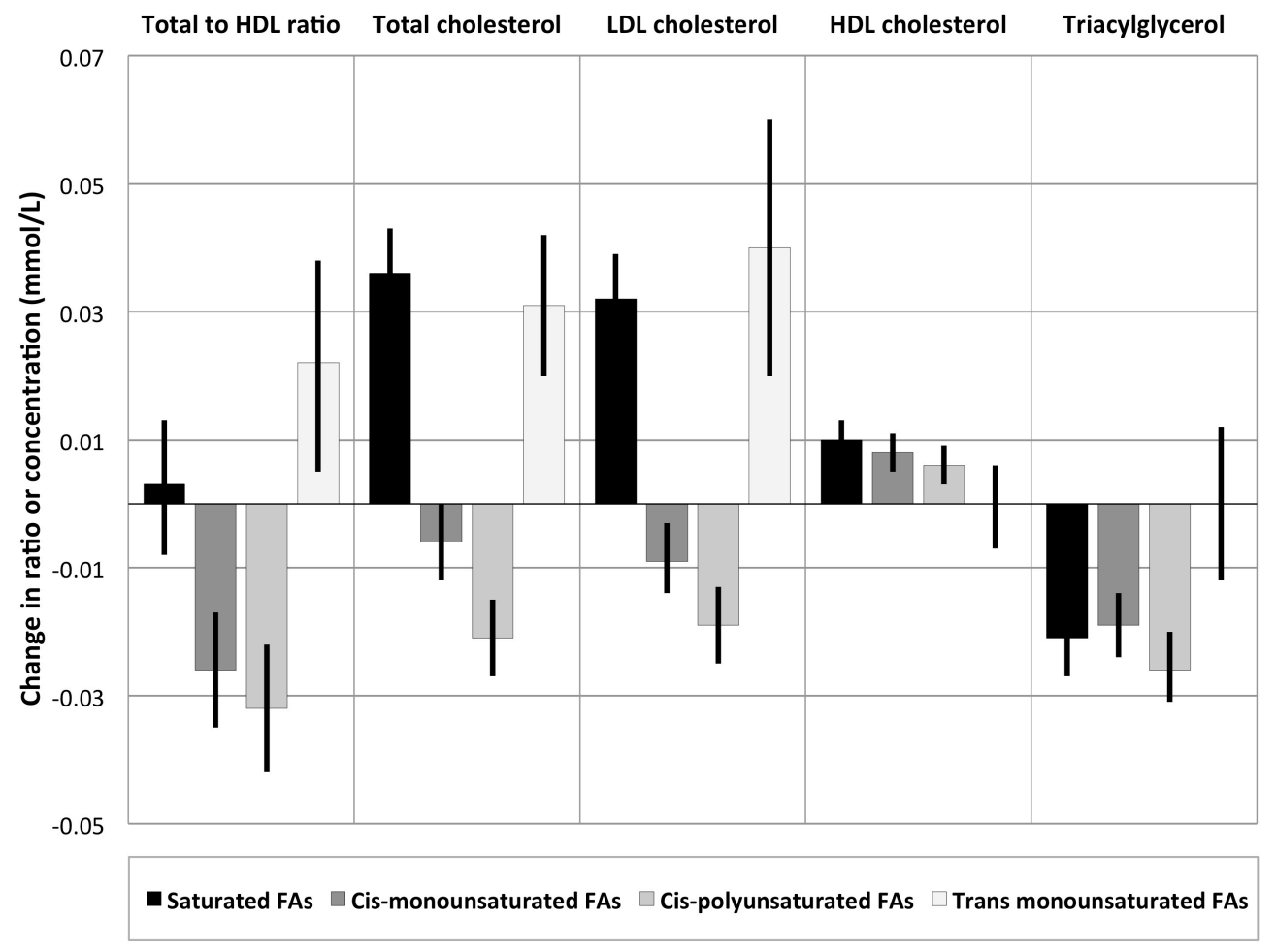

Figure 2.2. Predicted mean changes (and 95\% Cls) in serum lipid and lipoprotein cholesterol concentrations when carbohydrates constituting $1 \%$ of energy were replaced with an isocaloric amount of one of the major dietary fatty acids (FAs) [19].

Saturated, cis-monounsaturated and cis-polyunsaturated fatty acids

A meta-analysis of 60 RCTs, that involved 1672 adult volunteers, calculated the effects of the major dietary fatty acids on serum lipid and lipoprotein cholesterol levels when carbohydrates were replaced by fatty acids under isoenergetic conditions [Figure 2.2]. In the test diets, the mean daily intakes of SFAs, cisMUFAs, and cis-PUFAs were $10.2 \%$ of energy, $13.5 \%$ of energy, and $8.8 \%$ of energy, respectively. Replacing $1 \%$ of energy of carbohydrates by SFAs increased $\mathrm{LDL}$ and $\mathrm{HDL}$ cholesterol concentrations by $0.03 \mathrm{mmol} / \mathrm{L}$ and $0.01 \mathrm{mmol} / \mathrm{L}$, respectively. The total to HDL cholesterol ratio was not affected. The cis-MUFAs, mainly oleic acid, caused a decrease of $0.01 \mathrm{mmol} / \mathrm{L}$ in $\mathrm{LDL}$ cholesterol and an increase of $0.01 \mathrm{mmol} / \mathrm{L}$ in $\mathrm{HDL}$ cholesterol relative to carbohydrates. 
Replacement of carbohydrates by cis-PUFAs caused a more pronounced decrease of $0.02 \mathrm{mmol} / \mathrm{L}$ in $\mathrm{LDL}$ cholesterol, but had a comparable effect on HDL cholesterol as cis-MUFAs. Changes were related to changes in the intakes of linoleic acid and to a lesser extent to those of $\alpha$-linolenic acid, as studies that focused on $n$-3 PUFAs from fatty fish and fish oils were excluded. Further, the total to HDL cholesterol ratio decreased after replacement of carbohydrates by oils rich in cis-unsaturated fatty acids such as rapeseed, soybean, sunflower, and olive oils. The effects of cis-PUFAs were not statistically different from those of cis-MUFA, and the level of serum triacylglycerol decreased independent of the class of fatty acid [19]. Also, the fatty-acid composition of the background diet may affect the response to dietary cholesterol. It has been reported that changes in serum LDL cholesterol to a decrease in dietary cholesterol are less pronounced in studies with a background diet low in SFA and high in cis-PUFA as compared with a background diet high in SFA and low in cis-PUFA [20]. Finally, in most [21], but not all [22] studies, increasing the intake of fat at the expense of carbohydrates also increased the proportion of large LDL particles, which may be less atherogenic than the smaller LDL particles.

Based on these data, the most favorable serum lipid profile is achieved after replacement of a mixture of SFAs by cis-unsaturated fatty acids, with a slightly better profile for cis-PUFAs than for cis-MUFAs.

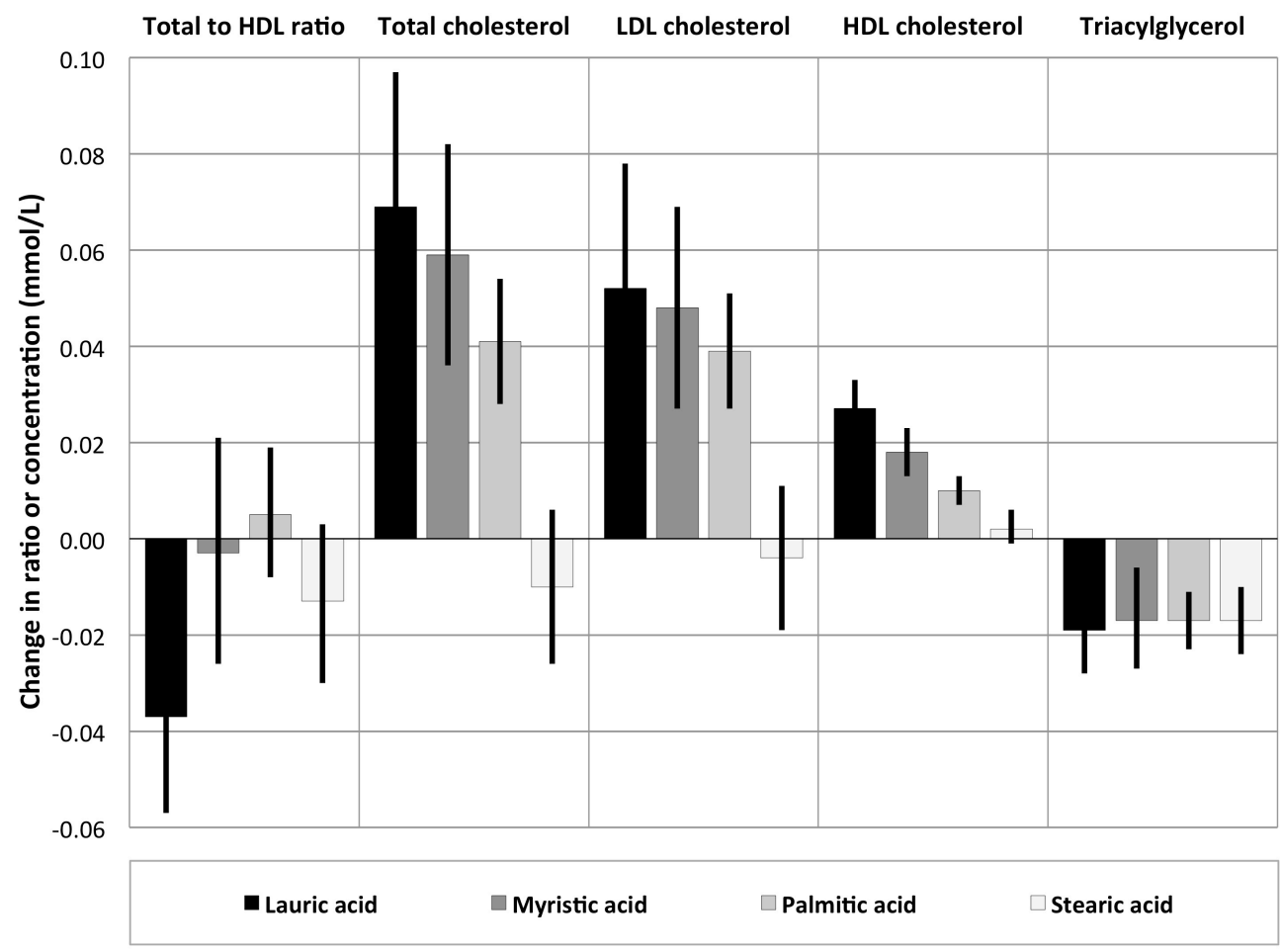

Figure 2.3. Predicted mean changes (and 95\% Cls) in serum lipid and lipoprotein cholesterol concentrations when carbohydrates constituting $1 \%$ of energy were replaced with an isocaloric amount of one of the dietary saturated fatty acids (FAs) [19]. 


\section{CHAPTER 2}

Lauric, myristic, palmitic and stearic acid

The effects of the various SFAs on the serum lipoprotein profile were also examined in the meta-analysis based on intakes of the individual SFAs reported by 35 RCTs [Figure 2.3]. In these diets, the mean daily intakes of lauric acid (C12:0), myristic acid (C14:0), palmitic acid (C16:0), and stearic acid (C18:0) were $1.1 \%$ of energy, $1.3 \%$ of energy, $6.2 \%$ of energy, and $3.0 \%$ of energy, respectively. Lauric acid, myristic acid and palmitic acid all increased LDL and HDL cholesterol concentrations as compared with carbohydrates. These effects decreased with increasing chain length, while no effects of stearic acid were found. Further, replacing $1 \%$ of energy from carbohydrates by lauric acid significantly lowered the total to HDL cholesterol ratio by 0.04 , while no effects on the ratio were found after replacement with myristic acid, palmitic acid or stearic acid. As a result, lauric acid, which is a major component of tropical oils such as palm kernel and coconut fat, had a more favorable effect on the total to HDL cholesterol ratio than other fatty acids. Still, effects of the tropical oils were less favorable than those of oils rich in cis-unsaturated fatty acids. Finally, replacement of carbohydrates with the different SFAs decreased serum triacylglycerol concentrations to the same extent [19].

\section{$n-3$ polyunsaturated fatty acids}

The cis-PUFAs, linoleic acid and $\alpha$-linolenic acid, are essential fatty acids that must be obtained from the diet. The $n-6$ PUFA linoleic acid, which is the most abundant essential fatty acid in the diet, serves as the dietary precursor for arachidonic acid synthesis. Eicosapentaenoic acid (EPA) can be synthesized from the plant-derived $n$-3 PUFA a-linolenic acid and can be converted into docosahexaenoic acid (DHA) [23]. However, for many people the most important sources of the $n$-3 long-chain PUFAs EPA and DHA in the body are fatty fish and fish oils. A meta-analysis summarized the results of 25 randomized trials representing about 8000 participants to examine the effects of $n-3$ PUFA intake on the serum lipid profile. Across different daily $n-3$ long-chain PUFA doses ranging from 800 to $5400 \mathrm{mg}$, it was found that fatty fish and fish oil consumption decreased serum triacylglycerol concentrations by $0.31 \mathrm{mmol} / \mathrm{L}$, while $\mathrm{HDL}$ and $\mathrm{LDL}$ cholesterol significantly increased by $0.04 \mathrm{mmol} / \mathrm{L}$ and $0.16 \mathrm{mmol} / \mathrm{L}$, respectively. Further, a doseresponse relationship was found and Balk et al. estimated that each increase of $1000 \mathrm{mg}$ in daily fish oil intake was associated with a significant decrease of 0.09 $\mathrm{mmol} / \mathrm{L}$ in serum triacylglycerol concentrations. Effects on serum lipids were more pronounced when baseline triacylglycerol levels were higher (i.e., above 3.32 $\mathrm{mmol} / \mathrm{L}$ ) and in these studies an increase of $1000 \mathrm{mg}$ in fish oil dose was associated with a much larger reduction of $0.21 \mathrm{mmol} / \mathrm{L}$ in serum triacylglycerol concentrations. Five studies reported effects of plant-derived $\alpha$-linolenic acid consumption on serum lipids, but these studies were mostly of poor quality and results were inconsistent [24].

Whether EPA and DHA have different effects is uncertain. However, in one study, EPA and DHA reduced serum triacylglycerol concentrations to the same extent, while only DHA appeared to increase LDL and HDL cholesterol levels [25]. Finally, even though the plant-derived $n-3$ long-chain PUFAs increased LDL cholesterol concentrations, most of the available data suggested a decrease in serum sdLDL cholesterol [26]. 


\section{DIETARY LIPIDS AND CARDIOVASCULAR DISEASE}

Trans fatty acids

Trans fatty acids are unsaturated fatty acids that are found in fats from ruminant animals and in partially hydrogenated vegetable oils. The daily intake is declining and varies between $0.5 \%$ and $2.0 \%$ of energy in Europe [27]. Many studies have shown unfavorable effects of these fatty acids on serum lipid and lipoprotein concentrations. A meta-analysis estimated that replacing $1 \%$ of energy from carbohydrates by trans MUFAs increased the level of serum LDL cholesterol by $0.04 \mathrm{mmol} / \mathrm{L}$, while serum $\mathrm{HDL}$ cholesterol and serum triacylglycerol concentrations remained unchanged [Figure 2.2]. The total to HDL cholesterol ratio significantly increased by 0.02 , which is the equivalent of replacing more than $7 \%$ of energy from carbohydrates by SFAs [19]. Further, the consumption of diets with increasing amounts of trans fatty acids was also associated with a significant dose-dependent increase in serum sdLDL concentrations as compared with a diet enriched with SFA [28].

In all these studies, trans fatty acids were derived from partially hydrogenated oils. The effects of trans fatty acids from ruminant fats on serum lipoprotein concentrations are more difficult to study, mainly because amounts in food products are much lower than those of industrial-derived trans MUFAs. A recent meta-analysis of $39 \mathrm{RCTs}$, however, compared the effects of ruminant trans fatty acids and conjugated trans linoleic acid (CLA) with those of industrial trans fatty acids. It was concluded that effects on serum lipoprotein concentrations between these type of trans fatty acids were not statistically different [29]. In summary, fatty acids with one or more bonds in the trans configuration adversely affect the serum lipoprotein profile irrespective of their origin or structure.

\section{Vascular function markers}

Except for the $n-3$ long-chain PUFAs EPA and DHA from fatty fish and fish oils, the effects of dietary lipid intake on vascular function markers have not been studied extensively. Only a few studies were designed to directly compare changes in the SFA, MUFA, PUFA or carbohydrate composition of the diet by opposite isocaloric changes in one or in one or more of the other macronutrients. Therefore, studies that compared diets or meals enriched with one of the major fatty acids will also be discussed.

Saturated, cis-monounsaturated and cis-polyunsaturated fatty acids

The impact of dietary fatty-acid intake on vascular function markers has been reviewed recently. Most studies included healthy men. It was concluded that the number of studies was in general too limited to draw firm conclusions regarding the longer-term effects of dietary lipid intake on measures of vascular function. However, a modest improvement in fasting FMD of the brachial artery was suggested in both healthy and diseased individuals when diets high in carbohydrates or cis-MUFAs were compared with diets enriched with dietary SFAs, while no differences were found between diets rich in carbohydrates and cisMUFAs [30]. However, in a recent study with insulin-resistant men and women, replacement of dietary SFAs by cis-MUFAs or carbohydrates did not affect fasting FMD. In addition, no changes in arterial stiffness, as assessed by $\mathrm{PWV}_{\text {c-f, }}$, were 


\section{CHAPTER 2}

observed [31]. Evidence regarding the longer-term effects of diets high in $n-6$ PUFAs is very limited. For acute studies, FMD of the brachial artery may impair during the postprandial phase following the consumption of SFA-rich meals, whereas results for cis-unsaturated fatty acids were inconsistent. Given these uncertainties, it was therefore concluded that future well-designed RCTs are needed to compare changes in the dietary SFA composition of the diet by opposite isocaloric changes in one of the other macronutrients on vascular function markers in adult [30]. Finally, limited numbers of angiographic studies have been carried out to investigate the effects of a modified fat diet on the progression of atherosclerosis. In one of the studies, it was found that lumen diameters of coronary arteries significantly increased following for three years a dietary intervention, which was low in dietary SFAs and high in cis-PUFAs, as compared with usual care [32].

\section{$n-3$ polyunsaturated fatty acids}

Recently, the effects of the $n-3$ long-chain PUFAs EPA and DHA on fasting FMD of the brachial artery have been quantitatively summarized. Compared with placebo, results from fifteen RCTs involving 821 participants showed a significant improvement in FMD by $2.30 \%$. Daily doses ranged from 450 to $4500 \mathrm{mg}$ and the median value of study duration was 56 days. These effects were more pronounced when participants had a poor health status. Although a higher intake of EPA plus DHA had a more pronounced effect on FMD, no linear dose-response relationship was evident. A similar improvement in FMD by $2.30 \%$ was found in one study that investigated the effect of $\alpha$-linolenic acid supplementation [33]. Further, not enough studies have been carried out to provide unambiguous evidence whether EPA and DHA have different effects on vascular endothelial function [25]. Pase and colleagues performed a meta-analysis of human randomized studies to quantify the effects of $n-3$ long-chain PUFA supplementation on arterial stiffness. A total of 550 subjects participated in ten trials. Study durations ranged from 6 to 105 weeks, while daily doses varied between 640 and $3000 \mathrm{mg}$ of combined EPA and DHA that was administered through capsules. It was found that $n-3$ long-chain PUFA supplementation significantly improved fasting PWV vs. control by $0.33 \mathrm{~m} / \mathrm{s}$ in absence of significant changes in blood pressure or heart rate [34]. In addition, more pronounced effects on arterial stiffness were found with combined EPA and DHA supplementation as compared with isolated EPA supplementation [35]. However, a recent yearlong randomized trial, that was not included in the metaanalysis, was unable to demonstrate an effect of supplementation with encapsulated $n-3$ long-chain PUFAs at three different daily doses $(450,900$ and $1800 \mathrm{mg}$ ) on fasting $\mathrm{PWV}_{\mathrm{c}-\mathrm{f}}$ in older males and females. It was suggested that at lower intakes much longer intervention periods might be necessary to detect significant differences on the progress of arterial stiffening [36].

Trans fatty acids

Hardly any data are available on the effects of trans fatty acids on vascular function. Five weeks of trans fatty acid consumption ( $8 \%$ of total energy intake) increased plasma E-selectin levels by $10 \%$ as compared with equivalent calories from carbohydrates [37]. In addition to these effects on circulation biomarkers of 
endothelial dysfunction, trans fatty acids may affect functional measures of endothelial function. Four weeks of trans fatty acid intake ( $9 \%$ of total energy intake) indeed significantly impaired fasting FMD as compared with SFAs [38]. In contrast, no postprandial impairment in brachial FMD was found after the consumption of a meal rich in trans fatty acids [39].

\section{Dietary lipid intake and risk of cardiovascular disease}

Dietary recommendations to lower $\mathrm{CHD}$ risk are focused on reducing the intake of SFAs. Indeed, dietary intervention studies have demonstrated that replacing SFAs with cis-MUFAs or cis-PUFAs improves the serum lipid profile, but also decreases $\mathrm{CHD}$ risk. Due to methodological aspects to estimate dietary fatty-acid intakes, the association between dietary SFA intake and CHD incidence may become attenuated, contributing to conflicting results. Important sources of variability in estimating dietary fatty-acid intake are (i) variability in the composition of food products, (ii) errors in estimating quantities of the foods consumed and (iii) remembering what was actually consumed [40]. Therefore, the focus will be on RCTs in this paragraph, that evidently suffer not or less from sources of error in estimating dietary fatty acids.

\section{Saturated, cis-monounsaturated and cis-polyunsaturated fatty acids}

Sacks and Katan predicted that replacing $10 \%$ of energy from SFAs with an isocaloric amount of cis-unsaturated fatty acids would decrease coronary events by $19 \%$ in men and by $16 \%$ in women [41]. Mozaffarian carried out a systematic review and meta-analysis of eight RCTs to quantify the effects of increasing cisPUFA consumption in place of dietary SFAs on CHD outcomes. In the metaanalysis, that involved a total of 1042 coronary events among nearly 14,000 participants, the mean daily intakes of cis-PUFAs were $14.9 \%$ of energy in intervention groups vs. 5.0\% of energy in control groups. It was found that each $5 \%$ energy increase in cis-PUFA at the expense of SFA significantly reduced the risk of CHD by $10 \%$ [Figure 2.4]. Studies of longer duration showed greater benefits [42]. The effect of replacing dietary SFAs by cis-PUFAs on CHD outcomes should be attributed to the combined effects of $n$-3 PUFAs, involving a-linolenic acid and/or EPA plus DHA, and n-6 PUFAs. Interestingly, the estimate was consistent with the effect that would be predicted based on changes in the ratio of total to HDL cholesterol (i.e., 9\% reduced CHD risk for each $5 \%$ energy of increased cis-PUFA). The replacement of dietary SFAs for carbohydrates was investigated in the Women's Health Initiative RCT carried out in 48,835 women. Over eight years of follow-up, replacement of about $3 \%$ of energy from dietary SFAs with carbohydrates did not lower the risk of CHD [Figure 4] in this large longterm dietary intervention study [43]. This finding was also in agreement with the predicted effects based on changes in the ratio of total to HDL cholesterol. The effects of replacing dietary SFAs with cis-MUFAs have never been evaluated in the randomized trials [Figure 2.4]. 


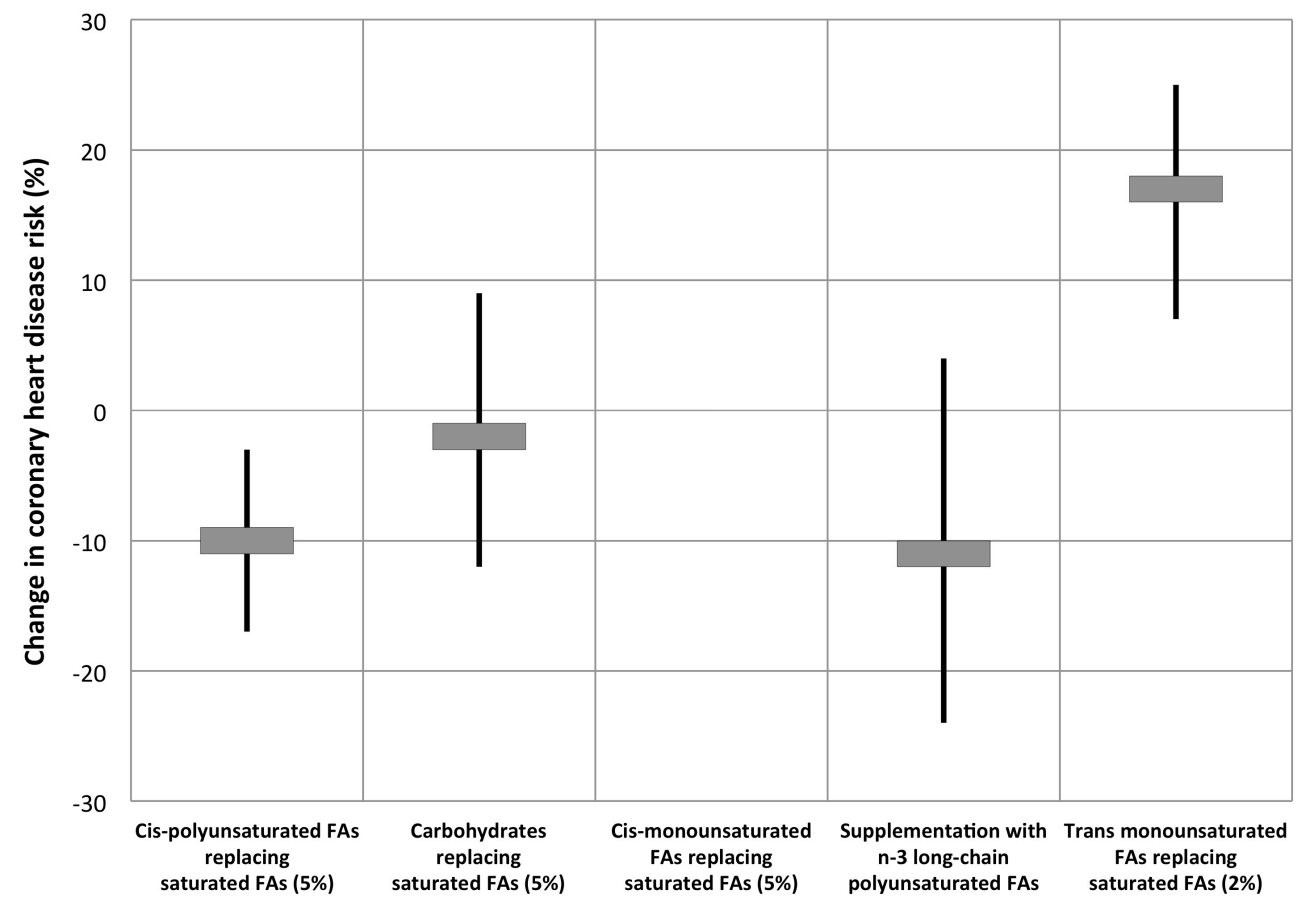

Figure 2.4. Summary of the results of randomized controlled trials on dietary fatty acid intake and coronary heart disease risk [42-44]. The effects of replacing saturated fatty acids (FAs) with cismonounsaturated FAs have never been evaluated in the randomized trials. Effects on coronary events of consuming trans monounsaturated FAs in place of dietary saturated FAs were based on prospective cohort studies [47].

\section{n-3 polyunsaturated fatty acids}

A recent meta-analysis of 20 randomized trials, that involved 68,680 adult participants, estimated the effects of $n-3$ long-chain PUFA supplementation achieved through diet or supplements on CHD events. The mean study duration was 2 years and a total of 1837 myocardial infarctions were reported across the various patient groups, who were at increased cardiovascular risk. No RCTs for the primary prevention of $\mathrm{CHD}$ were found. The meta-analysis reported no significant association with myocardial infarction [Figure 2.4] or other major CVD events [44]. The RCTs of the plant-derived $n$-3 PUFA $\alpha$-linolenic acid and CHD risk were also secondary prevention intervention studies conducted among patients with established CHD. However, several of these trials had important methodological limitations and conclusions regarding the effects of dietary a-linolenic acid on incidence of CHD could not be drawn [45]. Therefore, these data from RCTs did not show benefits of $n-3$ PUFA supplementation for the secondary prevention of $\mathrm{CHD}$. As many of the participants in these studies were taking medications, it is thought that drug treatment may have masked the effects of $n-3$ PUFA supplementation on the incidence of major cardiovascular events. Indeed, Eussen and colleagues have reported that $n-3$ PUFAs may reduce the risk of 
cardiovascular outcomes in patients who are not treated with statins, while no effects were found in statin users [46].

\section{Trans fatty acids}

No RCTs have been carried out to examine the effects of dietary trans fatty acids on the risk of CHD. However, a meta-analysis of four prospective cohort studies, that involved 5215 CHD events among nearly 140,000 participants, estimated that replacing $2 \%$ of energy from carbohydrates with an isocaloric amount of trans fatty acids was associated with a $23 \%$ increase in the incidence of CHD events. In addition, it was also calculated in the meta-analysis that each $2 \%$ energy replacement of SFAs, cis-MUFAs and cis-PUFAs with an isocaloric amount of dietary trans fatty acids significantly increased the risk of $\mathrm{CHD}$ events by $17 \%$ [Figure 2.4], 21\% and 24\%, respectively [47].

\section{Conclusions}

This chapter focused on the effects of dietary fatty acids on serum lipid and lipoprotein cholesterol concentrations, non-invasive vascular function markers, and CVD. The most favorable serum lipoprotein profile is achieved after replacement of trans fatty acids and SFAs by a mixture of cis-unsaturated fatty acids. In addition, the consumption of fatty fish and fish oils decreased serum triacylglycerol concentrations. The effects of dietary fatty acids on vascular endothelial function and arterial stiffness have not been studied extensively. An exception, however, are the $n-3$ long-chain PUFAs EPA and DHA, which may improve vascular endothelial function and arterial stiffness.

The number of RCTs with CHD events as endpoints is limited. Replacement of dietary SFAs by cis-PUFAs lowered CHD risk, but future research is warranted to evaluate the effects of replacing SFAs with carbohydrates or cisMUFAs. The intake of trans fatty acids from hydrogenated oils should be as low as possible independent of the macronutrient that is replacing. Finally, a recent metaanalysis of randomized trials showed no benefit of $n-3$ PUFA supplementation for the secondary prevention of CHD. However, many of the subjects were taking medication that may have masked the effects of $n-3$ PUFA supplementation. 


\section{CHAPTER 2}

\section{References}

1. World Health Organization. Cardiovascular diseases (CVDs) fact sheet No. 317, January 2015. Available from: http://www.who.int/mediacentre/factsheets/fs317/en/.

2. Mathers CD, Loncar D. Projections of global mortality and burden of disease from 2002 to 2030. PLoS Med 2006;3:e442.

3. Morrison LM. Reduction of mortality rate in coronary atherosclerosis by a low cholesterollow fat diet. Am Heart J 1951;42:538-45.

4. Briel M, Ferreira-Gonzalez I, You JJ, Karanicolas PJ, AkI EA, Wu P, et al. Association between change in high density lipoprotein cholesterol and cardiovascular disease morbidity and mortality: systematic review and meta-regression analysis. BMJ 2009;338:b92.

5. $\quad$ Rader DJ, Hovingh GK. HDL and cardiovascular disease. Lancet 2014;384:618-25.

6. Stampfer MJ, Sacks FM, Salvini S, Willett WC, Hennekens CH. A prospective study of cholesterol, apolipoproteins, and the risk of myocardial infarction. $\mathrm{N}$ Engl $\mathrm{J}$ Med 1991;325:373-81.

7. Hokanson JE, Austin MA. Plasma triglyceride level is a risk factor for cardiovascular disease independent of high-density lipoprotein cholesterol level: a meta-analysis of population-based prospective studies. J Cardiovasc Risk 1996;3:213-9.

8. Lamarche B, Tchernof A, Moorjani S, Cantin B, Dagenais GR, Lupien PJ, et al. Small, dense low-density lipoprotein particles as a predictor of the risk of ischemic heart disease in men. Prospective results from the Quebec Cardiovascular Study. Circulation 1997;95:6975.

9. Cohn JN, Quyyumi AA, Hollenberg NK, Jamerson KA. Surrogate markers for cardiovascular disease: functional markers. Circulation 2004;109:IV31-46.

10. Ellins EA, Halcox JP. Where are we heading with noninvasive clinical vascular physiology? Why and how should we assess endothelial function? Cardiol Res Pract 2011;2011:870132.

11. Moens AL, Goovaerts I, Claeys MJ, Vrints CJ. Flow-mediated vasodilation: a diagnostic instrument, or an experimental tool? Chest 2005;127:2254-63.

12. Ras RT, Streppel MT, Draijer R, Zock PL. Flow-mediated dilation and cardiovascular risk prediction: a systematic review with meta-analysis. Int J Cardiol 2013;168:344-51.

13. Morange PE, Simon C, Alessi MC, Luc G, Arveiler D, Ferrieres J, et al. Endothelial cell markers and the risk of coronary heart disease: the Prospective Epidemiological Study of Myocardial Infarction (PRIME) study. Circulation 2004;109:1343-8.

14. Laurent S, Cockcroft J, Van Bortel L, Boutouyrie P, Giannattasio C, Hayoz D, et al. Expert consensus document on arterial stiffness: methodological issues and clinical applications. Eur Heart J 2006;27:2588-605.

15. Blacher J, Asmar R, Djane S, London GM, Safar ME. Aortic pulse wave velocity as a marker of cardiovascular risk in hypertensive patients. Hypertension 1999;33:1111-7.

16. Vlachopoulos C, Aznaouridis K, Stefanadis C. Prediction of cardiovascular events and allcause mortality with arterial stiffness: a systematic review and meta-analysis. J Am Coll Cardiol 2010;55:1318-27.

17. Mancia G, Laurent S, Agabiti-Rosei E, Ambrosioni E, Burnier M, Caulfield MJ, et al. Reappraisal of European guidelines on hypertension management: a European Society of Hypertension Task Force document. J Hypertens 2009;27:2121-58.

18. Lorenz MW, Markus HS, Bots ML, Rosvall M, Sitzer M. Prediction of clinical cardiovascular events with carotid intima-media thickness: a systematic review and meta-analysis. Circulation 2007;115:459-67.

19. Mensink RP, Zock PL, Kester AD, Katan MB. Effects of dietary fatty acids and carbohydrates on the ratio of serum total to HDL cholesterol and on serum lipids and apolipoproteins: a meta-analysis of 60 controlled trials. Am J Clin Nutr 2003;77:1146-55. 


\section{DIETARY LIPIDS AND CARDIOVASCULAR DISEASE}

20. Weggemans RM, Zock PL, Katan MB. Dietary cholesterol from eggs increases the ratio of total cholesterol to high-density lipoprotein cholesterol in humans: a meta-analysis. Am J Clin Nutr 2001;73:885-91.

21. Siri PW, Krauss RM. Influence of dietary carbohydrate and fat on LDL and HDL particle distributions. Curr Atheroscler Rep 2005;7:455-9.

22. Jebb SA, Lovegrove JA, Griffin BA, Frost GS, Moore CS, Chatfield MD, et al. Effect of changing the amount and type of fat and carbohydrate on insulin sensitivity and cardiovascular risk: the RISCK (Reading, Imperial, Surrey, Cambridge, and Kings) trial. Am J Clin Nutr 2010;92:748-58.

23. Goyens PL, Spilker ME, Zock PL, Katan MB, Mensink RP. Compartmental modeling to quantify alpha-linolenic acid conversion after longer term intake of multiple tracer boluses. $\mathrm{J}$ Lipid Res 2005;46:1474-83.

24. Balk EM, Lichtenstein AH, Chung M, Kupelnick B, Chew P, Lau J. Effects of omega-3 fatty acids on serum markers of cardiovascular disease risk: a systematic review. Atherosclerosis 2006;189:19-30.

25. Cottin SC, Sanders TA, Hall WL. The differential effects of EPA and DHA on cardiovascular risk factors. Proc Nutr Soc 2011;70:215-31.

26. Jacobson TA. Role of $n-3$ fatty acids in the treatment of hypertriglyceridemia and cardiovascular disease. Am J Clin Nutr 2008;87:1981S-90S.

27. van Poppel G. Intake of trans fatty acids in western Europe: the TRANSFAIR study. Lancet 1998;351:1099.

28. Mauger JF, Lichtenstein AH, Ausman LM, Jalbert SM, Jauhiainen M, Ehnholm C, et al. Effect of different forms of dietary hydrogenated fats on LDL particle size. Am J Clin Nutr 2003;78:370-5.

29. Brouwer IA, Wanders AJ, Katan MB. Effect of animal and industrial trans fatty acids on HDL and LDL cholesterol levels in humans-a quantitative review. PloS one 2010;5:e9434.

30. Vafeiadou K, Weech M, Sharma V, Yaqoob P, Todd S, Williams CM, et al. A review of the evidence for the effects of total dietary fat, saturated, monounsaturated and $n-6$ polyunsaturated fatty acids on vascular function, endothelial progenitor cells and microparticles. Br J Nutr 2012;107:303-24.

31. Sanders TA, Lewis FJ, Goff LM, Chowienczyk PJ, Group RS. SFAs do not impair endothelial function and arterial stiffness. Am J Clin Nutr 2013;98:677-83.

32. Watts GF, Lewis B, Brunt JN, Lewis ES, Coltart DJ, Smith LD, et al. Effects on coronary artery disease of lipid-lowering diet, or diet plus cholestyramine, in the St Thomas' Atherosclerosis Regression Study (STARS). Lancet 1992;339:563-9.

33. Wang Q, Liang X, Wang L, Lu X, Huang J, Cao J, et al. Effect of omega-3 fatty acids supplementation on endothelial function: a meta-analysis of randomized controlled trials. Atherosclerosis 2012;221:536-43.

34. Pase MP, Grima NA, Sarris J. Do long-chain n-3 fatty acids reduce arterial stiffness? A meta-analysis of randomised controlled trials. Br J Nutr 2011;106:974-80.

35. Pase MP, Grima NA, Sarris J. The effects of dietary and nutrient interventions on arterial stiffness: a systematic review. Am J Clin Nutr 2011;93:446-54.

36. Sanders TA, Hall WL, Maniou Z, Lewis F, Seed PT, Chowienczyk PJ. Effect of low doses of long-chain n-3 PUFAs on endothelial function and arterial stiffness: a randomized controlled trial. Am J Clin Nutr 2011;94:973-80.

37. Baer DJ, Judd JT, Clevidence BA, Tracy RP. Dietary fatty acids affect plasma markers of inflammation in healthy men fed controlled diets: a randomized crossover study. Am J Clin Nutr 2004;79:969-73.

38. de Roos NM, Bots ML, Katan MB. Replacement of dietary saturated fatty acids by trans fatty acids lowers serum HDL cholesterol and impairs endothelial function in healthy men and women. Arterioscler Thromb Vasc Biol 2001;21:1233-7. 


\section{CHAPTER 2}

39. de Roos NM, Siebelink E, Bots ML, van Tol A, Schouten EG, Katan MB. Trans monounsaturated fatty acids and saturated fatty acids have similar effects on postprandial flow-mediated vasodilation. Eur J Clin Nutr 2002;56:674-9.

40. Kromhout D, Geleijnse JM, Menotti A, Jacobs DR, Jr. The confusion about dietary fatty acids recommendations for CHD prevention. Br J Nutr 2011;106:627-32.

41. Sacks FM, Katan M. Randomized clinical trials on the effects of dietary fat and carbohydrate on plasma lipoproteins and cardiovascular disease. Am J Med 2002;113:13S24S.

42. Mozaffarian D, Micha R, Wallace S. Effects on coronary heart disease of increasing polyunsaturated fat in place of saturated fat: a systematic review and meta-analysis of randomized controlled trials. PLoS Med 2010;7:e1000252.

43. Howard BV, Manson JE, Stefanick ML, Beresford SA, Frank G, Jones B, et al. Low-fat dietary pattern and weight change over 7 years: the Women's Health Initiative Dietary Modification Trial. JAMA 2006;295:39-49.

44. Rizos EC, Ntzani EE, Bika E, Kostapanos MS, Elisaf MS. Association between omega-3 fatty acid supplementation and risk of major cardiovascular disease events: a systematic review and meta-analysis. JAMA 2012;308:1024-33.

45. Pan A, Chen M, Chowdhury R, Wu JH, Sun Q, Campos H, et al. alpha-Linolenic acid and risk of cardiovascular disease: a systematic review and meta-analysis. Am J Clin Nutr 2012;96:1262-73.

46. Eussen SR, Geleijnse JM, Giltay EJ, Rompelberg CJ, Klungel OH, Kromhout D. Effects of $\mathrm{n}-3$ fatty acids on major cardiovascular events in statin users and non-users with a history of myocardial infarction. Eur Heart J 2012;33:1582-8.

47. Mozaffarian D, Clarke R. Quantitative effects on cardiovascular risk factors and coronary heart disease risk of replacing partially hydrogenated vegetable oils with other fats and oils. Eur J Clin Nutr 2009;63:S22-33. 


\section{CHAPTER 3}

Beetroot juice improves in overweight and slightly obese men postprandial endothelial function after consumption of a mixed meal

Peter J. Joris and Ronald P. Mensink

Atherosclerosis 2013; 231: 78-83 


\section{CHAPTER 3}

\section{Abstract}

Background: Through effects on nitric oxide (NO) bioavailability, endothelial function is improved after the intake of beetroot juice - which is rich in inorganic nitrate -, but decreased after the intake of a meal.

Objective: The objective of this study was to examine if beetroot juice could counteract the impairment of endothelial function associated with the ingestion of a mixed meal.

Methods: Twenty healthy overweight and slightly obese men with a BMI between 28 and $35 \mathrm{~kg} / \mathrm{m}^{2}$ received in random order a mixed meal providing $56.6 \mathrm{~g}$ of fat with beetroot juice or a control drink. The beetroot juice $(140 \mathrm{~mL})$ provided approximately $500 \mathrm{mg}$ dietary nitrate. Flow-mediated dilation (FMD) of the brachial artery was measured before and two hours after meal consumption. Blood was sampled at regular intervals.

Results: Postprandial changes in serum triacylglycerol (TAG) $(P=0.69)$, plasma glucose $(P=0.84)$ and insulin $(P=0.67)$ concentrations were comparable between the meals. After consumption of beetroot juice, the postprandial impairment in FMD following a standardized mixed meal was improved $(P=0.030)$ compared with the control drink $(-0.37 \pm 2.92 \%$ versus $-1.56 \pm 2.90 \%)$. Following beetroot juice consumption, plasma concentrations of the circulating NO pool were higher at T60, T120, and T240 ( $P<0.001$ at all time points).

Conclusion: In healthy overweight and slightly obese men a single dose of beetroot juice attenuates the postprandial impairment of FMD following a mixed meal, possibly through increases in plasma NO concentrations. 


\section{Introduction}

Chronically impaired endothelial function can be characterized by a decreased arterial response to stimuli that triggers the release of vasodilators from the endothelium like nitric oxide (NO). It may predict long-term atherosclerotic disease progression and cardiovascular event rates [1]. However, endothelial dysfunction has also been reported as an acute and reversible event. Fat intake, for example, transiently impairs endothelial function [2, 3]. Although the mechanisms of decreased postprandial endothelial function have not been fully elucidated, diminished NO bioavailability is considered to be a major cause [4]. During the postprandial state, the bioavailability of NO may reduce via an increased production of reactive oxygen species and stimulatory effects of chylomicron remnants and/or free fatty acids on pro-coagulant and pro-inflammatory signaling pathways in the endothelium [5]. Diminished NO bioavailability can be assessed by the circulating pool of bioactive $\mathrm{NO}(\mathrm{NOx})$, that is comprised of both plasma nitrite $\left(\mathrm{NO}_{2}{ }^{-}\right)$and nitroso/nitrosyl NO species (RXNOs) [6].

It is known that overweight and slightly obese male subjects have a disturbed postprandial metabolism [7]. Since a significant part of the day is spent in the postprandial state, strategies to counteract the transient impairment of postprandial endothelial function may be important to decrease the cardiovascular risk associated with overweight and obesity. Recently, more attention has been directed towards the effects on endothelial function of the various nutrients found in diets rich in fruits and vegetables such as inorganic nitrate $\left(\mathrm{NO}_{3}{ }^{-}\right)$. Via bioconversion to $\mathrm{NO}_{2}^{-}$, inorganic nitrate supplementation has been shown to increase NO bioavailability, which results in a decreased systolic (SBP) and diastolic blood pressure (DBP), and improved endothelial function [8]. In fact, these effects have been observed following consumption of beetroot juice, a high nitratecontaining vegetable [9]. Therefore, the objective of the current study was to investigate whether beetroot juice could counteract the impairment of endothelial function associated with the ingestion of a mixed meal [2, 3]. Flow-mediated dilation (FMD) of the brachial artery was used as a non-invasive method to assess endothelial function, while the study was performed in healthy overweight and slightly obese male subjects.

\section{Subjects and methods}

\section{Study population}

Apparently healthy men were recruited by advertisements in local newspapers or among participants who had participated in earlier studies. Women were excluded to avoid any possible variations in postprandial responses due to hormonal effects. Participants were invited for 2 screening visits if they met the following inclusion criteria: aged between 18 and 70 years, BMI between 28 and $35 \mathrm{~kg} / \mathrm{m}^{2}$, stable body weight (weight gain or loss $<3 \mathrm{~kg}$ within the previous 3 months), no use of medication known to affect serum lipid metabolism, no diabetes, or receiving antidiabetic or anti-hypertensive medication, and no participation in another biochemical trial during the past 30 days. Twenty-one men were included. They had fasting serum concentrations $\leq 1.7 \mathrm{mmol} / \mathrm{L}$ for triacylglycerol (TAG); no 


\section{CHAPTER 3}

indications for treatment with cholesterol-lowering drugs according to the Dutch Cholesterol Consensus [10]; no active cardiovascular disease like congestive heart failure or cardiovascular event, such as an acute myocardial infarction or cerebro vascular accident; no inflammatory disease; and no drug or alcohol abuse. All participants gave written informed consent before entering the study. The study was approved by the Medical Ethics Committee of Maastricht University and registered at ClinicalTrials.gov (NCT 01559441).

\section{Study design}

Each participant received two interventions in randomized order with an interval of at least 1-week. On the day preceding each postprandial test, subjects were asked not to consume high-fat foods or alcohol, or to perform any strenuous physical exercise. During the study, subjects were requested not to change their food intake pattern, physical activity level or use of alcohol.

After an overnight fast (from 10.00 PM), subjects arrived at the Department by public transport or car to standardize measurements as much as possible. After resting for 20 minutes in the supine position, vascular function measurements were performed. After an intravenous cannula was inserted into a vein and a fasting venous blood sample (T0) was obtained, subjects had to consume within 10 minutes a standardized mixed meal. Subsequent blood samples were collected 15 min (T15), $30 \mathrm{~min}$ (T30), $45 \mathrm{~min}$ (T45), $60 \mathrm{~min}$ (T60), $90 \mathrm{~min}$ (T90), $120 \mathrm{~min}$ (T120), $180 \mathrm{~min}$ (T180), and $240 \mathrm{~min}$ (T240) after meal consumption. After sampling, the cannula was rinsed with $1 \mathrm{~mL} 1 \%$ heparin (LEO Pharma, Ballerup, Denmark) in $0.9 \% \mathrm{NaCl}$. Assessment of vascular function was repeated two hours after meal consumption, immediately after taking the T120 blood sample.

\section{Test meals}

The test meals consisted of two muffins (containing $56.6 \mathrm{~g}$ fat) and $140 \mathrm{~mL}$ of either concentrated beetroot juice (Beet it, James White drinks Ltd., Ipswich, UK) or a control drink. Both test meals [Supplemental Table 3.1] had a comparable energy content $(4695 \mathrm{~kJ})$ and macronutrient composition $(56.6 \mathrm{~g}$ fat, of which 33.9 $\mathrm{g}$ saturated fatty acids, $14.5 \mathrm{~g}$ monounsaturated fatty acids, and $2.7 \mathrm{~g}$ polyunsaturated fatty acids; $137.0-138.5 \mathrm{~g}$ carbohydrates; and $41.5 \mathrm{~g}-46.5 \mathrm{~g}$ protein). A single dose $(140 \mathrm{~mL})$ of concentrated beetroot juice has an average listed content of dietary nitrate of approximately $500 \mathrm{mg}$. One batch of muffins was made for the entire study. After baking the muffins at $180^{\circ} \mathrm{C}$ in a fan-assisted oven for 20 minutes and cooling down, the muffins were packaged per portion and frozen at $-20^{\circ} \mathrm{C}$.

\section{Blood analyses}

NaF-containing 2-mL vacutainer tubes (Becton Dickinson, Erembodegem, Belgium) and lithium heparin-containing 4-mL vacutainer tubes (Becton Dickinson) were placed on ice directly after blood sampling. To obtain plasma, the plasma tubes were centrifuged at $1300 \times \mathrm{g}$ for 15 minutes at $4{ }^{\circ} \mathrm{C}$. Blood drawn in $3.5-\mathrm{mL}$ vacutainer serum tubes (Becton Dickinson) was allowed to clot for 30 minutes at $21^{\circ} \mathrm{C}$. To obtain serum, the serum tubes were centrifuged at $1300 \times \mathrm{g}$ for 15 
minutes at $21^{\circ} \mathrm{C}$. Following centrifugation, plasma and serum aliquots were directly frozen in liquid nitrogen and stored at $-80^{\circ} \mathrm{C}$ until analysis at the end of the study.

Plasma glucose (Roche Diagnostic Systems, Hoffmann-La Roche) concentrations were measured in $\mathrm{NaF}$ plasma at all time points and those of insulin with a human insulin-specific RIA kit (Linco Research) in NaF plasma samples collected at T0, T30, T60, T90, T120 and T240. Serum TAG (GPO Trinder; Sigma-Aldrich) with correction for free glycerol was measured hourly. Concentrations of nitrite and RXNOs, referred to as the circulating NO pool (NOx), were determined using a triiodide/ozone-based chemiluminescence assay as described [11]. RXNO and nitrite analyses were carried out in lithium heparin plasma samples collected at T0, 60, 120 and 240.

\section{Anthropometric and vascular measurements}

Height was measured during screening using a wall-mounted stadiometer. Body weight without shoes and heavy clothing were measured before the start of each postprandial test. SBP, DBP and heart rate were monitored hourly using a MobilO-Graph blood pressure monitor. Measurements were assessed in fourfold at the left arm. The first measurement was discarded and the last three were averaged.

All vascular measurements were performed in a quiet and darkened room. Room was temperature controlled at $22^{\circ} \mathrm{C}$. FMD was assessed by echo-Doppler (Sonos 5500, Hewlett-Packard) at baseline and two hours after the meal by using a 7.5-MHz transducer and recording of echo images on DVD. After a 3-minute reference period, the pneumatic cuff placed around the participant's forearm was inflated $50 \mathrm{mmHg}$ above systolic pressure for 5 minutes, causing distal (forearm) hypoxia. Upon cuff-release reactive hyperemia ensued. The echo images were processed automatically to determine the diameter profiles over the entire 13 minutes of the FMD measurement using a custom-written Matlab program (MyFMD, Prof. A.P. Hoeks, Department of Biomedical Engineering, Maastricht University, Maastricht, the Netherlands). The FMD response was quantified as the maximal percentage change in post occlusion arterial diameter relative to baseline diameter. Radial pulse wave analysis (PWA) was performed, in triplicate, with a tonometer (SphygmoCor v9, AtCor Medical) applied to the radial artery near the wrist of the arm. The central arterial waveform was derived from the peripheral waveform using a validated transfer function. Peripheral and central augmentation indices (AIX) were defined as the difference between the first and second peak of the arterial waveform, expressed as a percentage of the pulse pressure. Using the same tonometer, pulse wave velocity (PWV) was determined by measuring the arrival of the pulse wave and the delay to the R-wave of the ECG at the carotid and femoral artery. Carotid-femoral PWV ( $\left.P W V_{c-f}\right)$ was calculated by the program of the manufacturer after entering $80 \%$ of the direct carotid-femoral distance [12]. Alx and $\mathrm{PWV}_{\mathrm{c}-\mathrm{f}}$ were measured at baseline and 3 hours after the meal.

\section{Statistical analyses}

Results are presented as mean $\pm S D$, unless otherwise indicated. Before the start of the study, it was calculated that the statistical power to detect a true treatment difference of at least $1.75 \%$ in FMD with 20 participants was $80 \%$ when an $\alpha$ of 0.05 and intra-subject variability of $2.82 \%$ were used [13]. Differences in baseline 


\section{CHAPTER 3}

values between test days were tested using a paired Student's $t$ test. Changes were analyzed using paired Student's $t$ tests or linear mixed models with diet and time as fixed factors and with diet * time as interaction term. If the interaction term was not significant, it was omitted from the model. If the interaction term or factor time was significant, post hoc tests with Bonferroni correction were conducted. The incremental area under the curve (iAUC; the area above baseline (T0) concentrations) was calculated using the trapezoidal rule [14]. Pearson correlation coefficients were determined to examine the relationship between changes in FMD and the iAUC during the first 2 hours for TAG or glucose. Differences were considered statistically significant at $P<0.05$. Statistical analyses were performed using SPSS 20.0 software for Mac (SPSS Incorporated, Chicago, IL, USA).

\section{Results}

\section{Study participants}

Of the 28 subjects screened, 7 men were excluded because of fasting serum TAG concentrations above $1.7 \mathrm{mmol} / \mathrm{L}$. Twenty-one men started the study and completed both postprandial tests. One of these participants was excluded from the statistical analyses due to a large difference between fasting FMD values (2.83 vs. $13.04 \%)$ for which we had no explanation. The mean age of the participants was $61 \pm 7$ years and their average BMI was $30.1 \pm 1.9 \mathrm{~kg} / \mathrm{m}^{2}$. Baseline characteristics of the participants who completed the study are shown in Table 3.1.

Table 3.1. Baseline characteristics of the overweight and slightly obese men who completed the study ${ }^{1}$

\begin{tabular}{lc}
\hline \hline & Study Participants \\
\hline Age $(\mathrm{y})$ & $61 \pm 7^{2}$ \\
$\mathrm{BMI}\left(\mathrm{kg} / \mathrm{m}^{2}\right)$ & $30.1 \pm 1.9$ \\
Total cholesterol $(\mathrm{mmol} / \mathrm{L})$ & $5.17 \pm 1.27$ \\
TAG $(\mathrm{mmol} / \mathrm{L})$ & $1.28 \pm 0.35$ \\
Systolic BP $(\mathrm{mmHg})$ & $135.2 \pm 18.2$ \\
Diastolic BP $(\mathrm{mmHg})$ & $93.2 \pm 12.0$ \\
\hline
\end{tabular}

${ }^{1} n=20$. TAG: triacylglycerol; BP: blood pressure.

${ }^{2}$ Values are means \pm SD.

\section{Postprandial lipemia and glycemia}

Fasting serum TAG were comparable between the test days $(P=0.99)$. After meal consumption, postprandial TAG concentrations were significantly higher at T120T240 from baseline ( $P<0.001$ at all time points) [Figure 3.1]. Changes in TAG concentrations did not differ between the meals $(P=0.69$ for diet effect).

Plasma glucose $(P=0.84)$ and insulin $(P=0.67)$ concentrations at baseline did not differ between the test days. Following meal consumption, there was a rapid increase in both glucose and insulin, which was significant for the factor time $(P<0.001)$ [Figure 3.1]. After adjustment for multiple comparisons, 


\section{BEETROOT JUICE AND POSTPRANDIAL ENDOTHELIAL FUNCTION}

glucose concentrations differed during the first 2 hours $(P<0.01$ at all time points) and insulin concentrations at T30-T240 from baseline $(P<0.05$ at all time points) after both interventions. The plasma glucose $(P=0.86)$ and insulin $(P=0.73)$ responses did not differ between the meals.
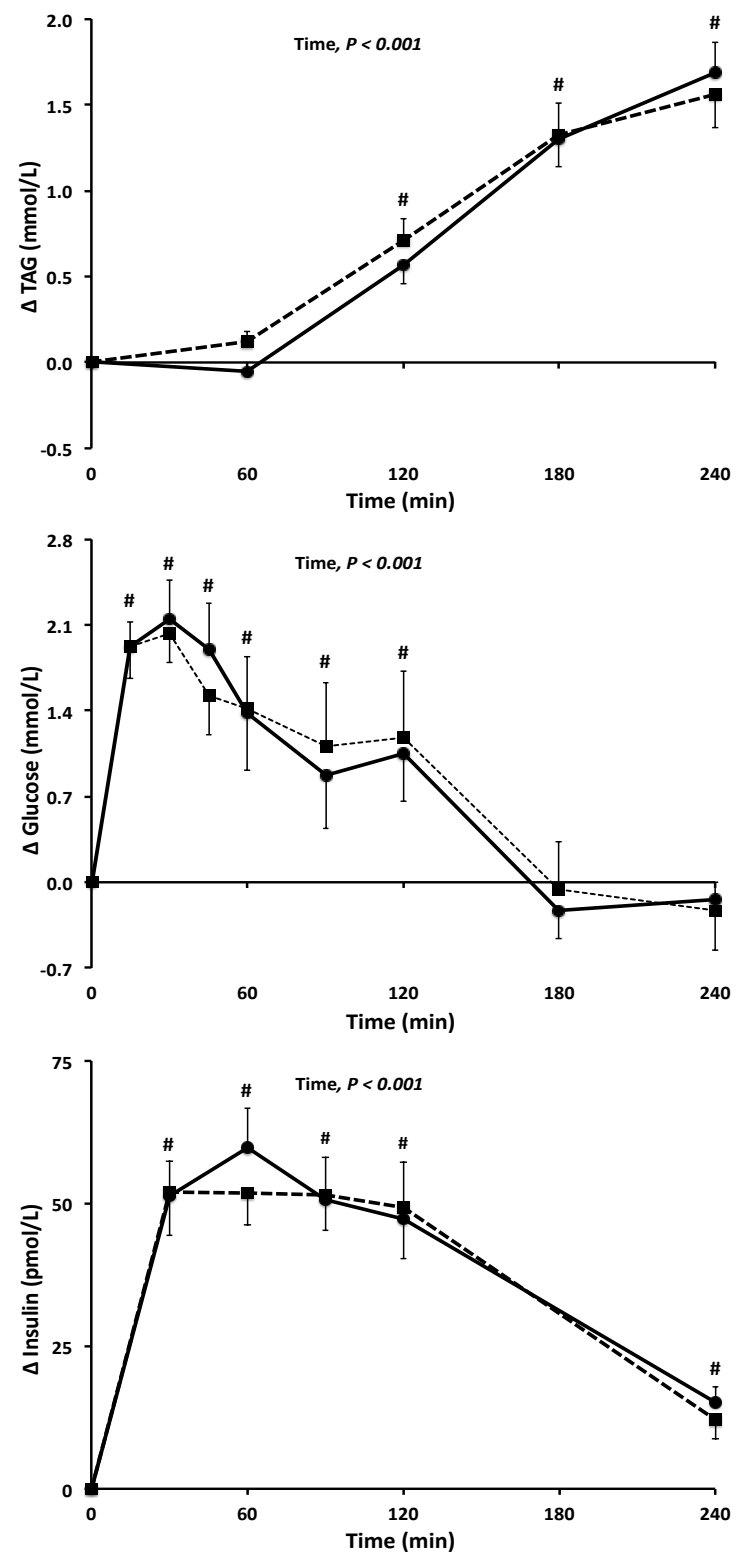

Figure 3.1. Mean changes ( \pm SEM) in serum triacylglycerol (TAG) and plasma glucose and insulin concentrations following a mixed meal with either concentrated beetroot juice $(\boldsymbol{O})$ or a control drink ( $\boldsymbol{\square})$ in a randomized crossover study with overweight and slightly obese men $(n=20)$. Data were analyzed using linear mixed models. Following meal consumption, there was an increase in TAG, glucose and insulin, which was significant for the factor time $(P<0.001)$. Values between the meals did not differ $(P$ $>0.05)$. "After Bonferroni's correction significantly different from baseline, $P<0.05$. 


\section{CHAPTER 3}

\section{The circulating NO pool}

Baseline concentrations of the circulating NO pool $(P=0.82)$ were comparable between the test days. As shown in Figure 3.2, there was a statistically significant diet ${ }^{*}$ time interaction for plasma concentrations of NOx during the postprandial period $(P<0.001)$. After Bonferroni's correction, NOx concentrations were significantly higher at T60-T240 following a mixed meal with concentrated beetroot juice $(P<0.001$ at all time points).

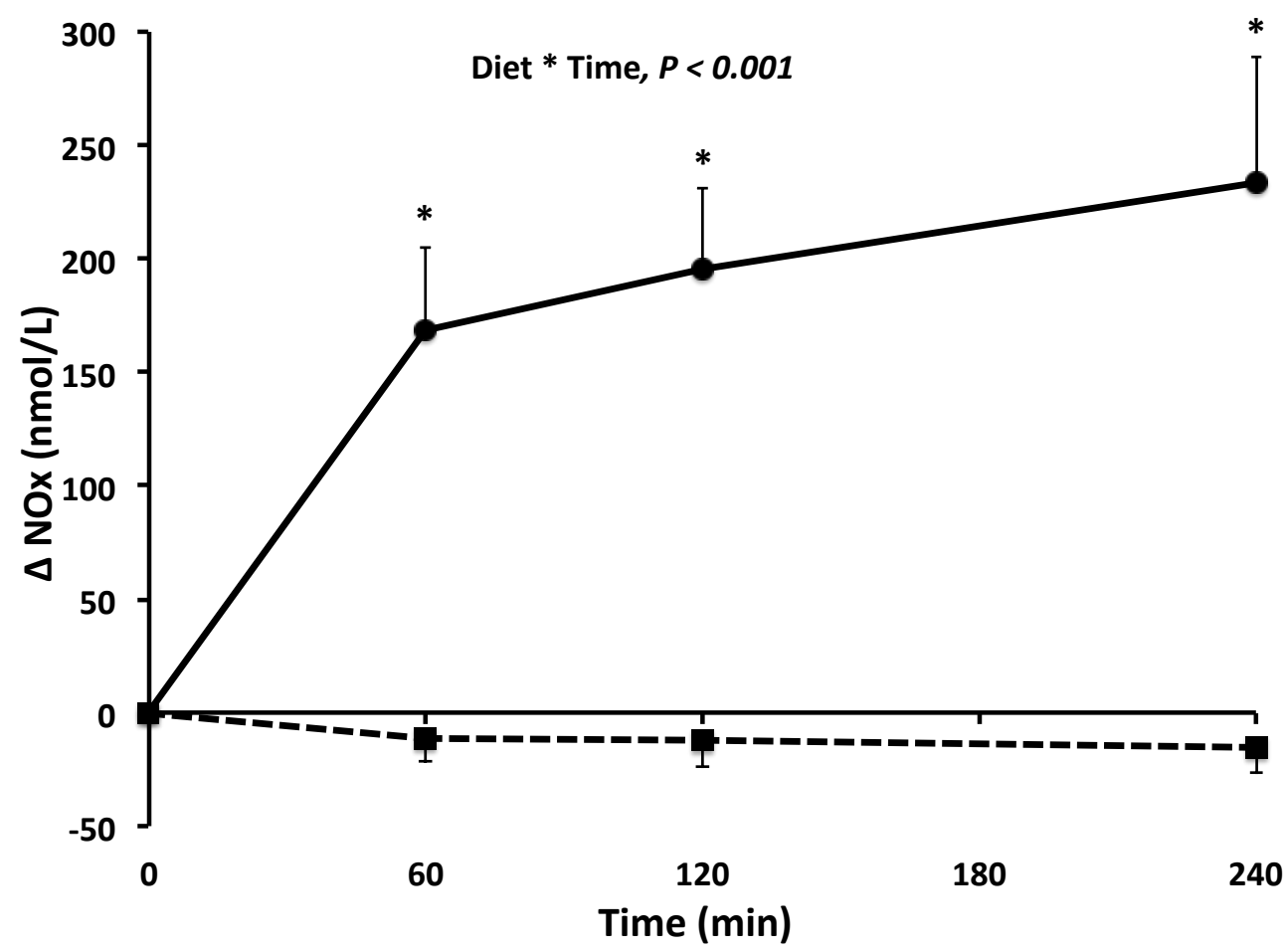

Figure 3.2. Mean changes ( \pm SEM) in concentrations of the circulating nitric oxide pool (NOx) following a mixed meal with either concentrated beetroot juice $(\boldsymbol{O})$ or a control drink $(\boldsymbol{\square})$ in a randomized crossover study with overweight and slightly obese men $(n=20)$. Data were analyzed using linear mixed models. There was a statistically significant diet * time interaction for plasma concentrations of NOx during the postprandial period $(P<0.001)$. ${ }^{*}$ After Bonferroni's correction significantly different from meal with control drink, $P<0.001$.

\section{Vascular function}

Baseline brachial artery diameters (data not shown) did not differ between test meals $(P=0.78)$ and did not change from fasting values 2 hours after consumption of either meal. In addition, baseline FMD levels did not differ between the test days $(P=0.42)$ and correlated significantly $(r=0.68, P=0.001)$. FMD [Figure 3.3] was reduced from fasting values at 2 hours following the meal with control drink $(P=$ $0.026)$, but did not change following the meal with beetroot juice $(P=0.58)$. After consumption of beetroot juice, the postprandial impairment in FMD was reduced 
compared with the control drink $(-0.37 \pm 2.92 \%$ versus $-1.56 \pm 2.90 \% ; P=0.030)$. We found no correlation between the postprandial change in FMD and the iAUC during the first 2 hours for TAG $(r=-0.04, P=0.88$ and $r=0.03, P=0.91$ after consumption of beetroot juice and the control drink, respectively) or for glucose ( $r=$ $0.19, P=0.42$ and $r=0.10, P=0.69$ after consumption of beetroot juice and the control drink, respectively).

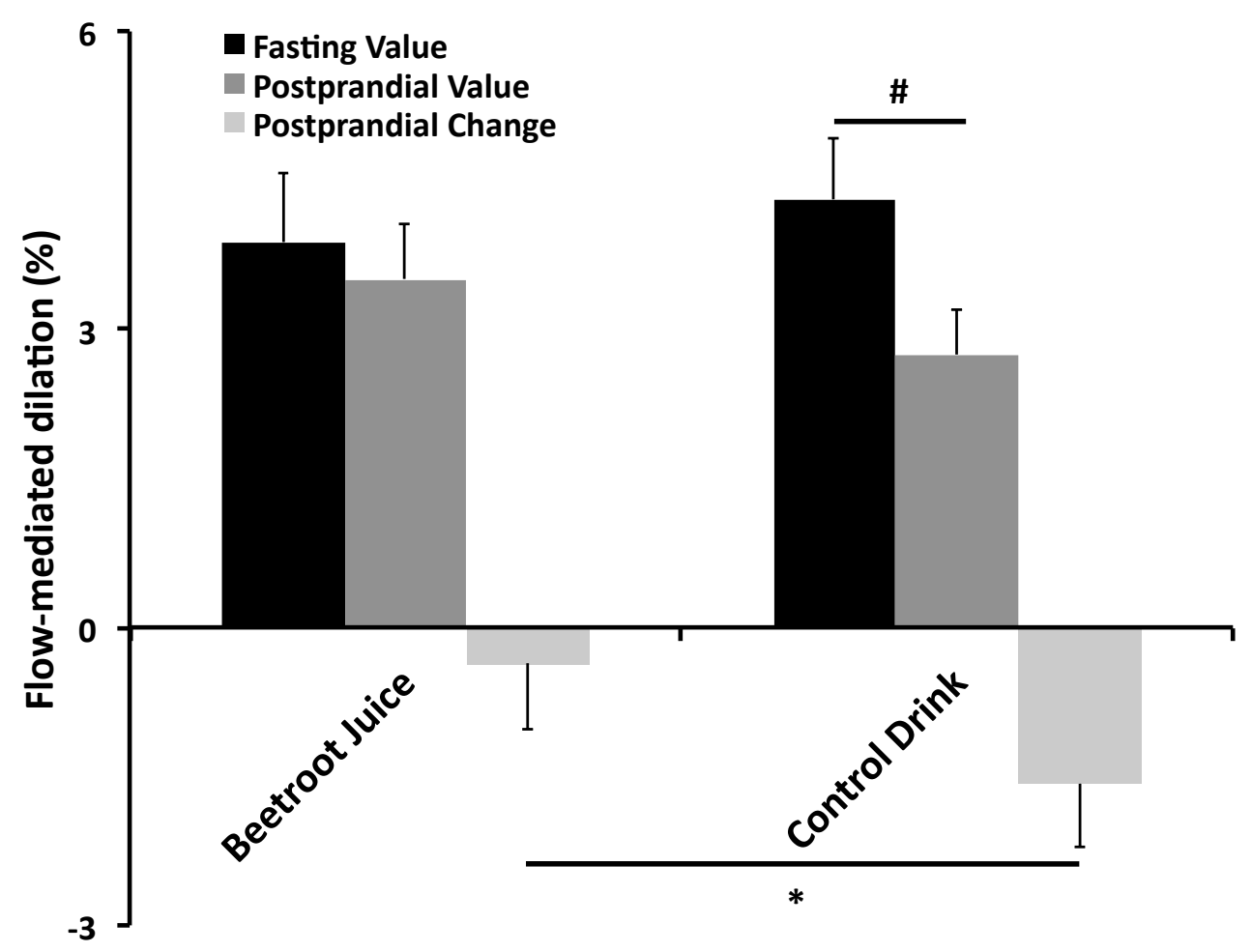

Figure 3.3. Mean flow-mediated dilation ( \pm SEM) before and after a mixed meal with either concentrated beetroot juice or a control drink in a randomized crossover study with overweight and slightly obese men $(n=20)$. * Significantly different from meal with control drink, $P<0.05$ (paired Student's $t$ test). \# Significantly different from baseline, $P<0.05$ (paired Student's $t$ test).

As indicated by $P W V_{c-f}$ [Table 3.2], there were no differences in arterial stiffness. However, the peripheral Alx, central Alx and central Alx adjusted for heart rate (CAlxHR75) [Table 3.2] were significantly reduced following the meals $(P<0.001)$, but changes did not differ between test meals. Following meal consumption, DBP decreased $(P<0.001$ for time effect) at T60-T240 from baseline $(P<0.05$ at all time points). SBP did not differ significantly between meals $(P=0.46)$ and did not change over time $(P=0.48)$ [Supplemental Figure 3.1]. Results were not significantly related to BMI, or baseline SBP or DBP levels. 


\section{CHAPTER 3}

Table 3.2. Vascular stiffness measurements before and after a mixed meal with either beetroot juice or a control drink in a randomized crossover study with overweight and slightly obese men

\begin{tabular}{|c|c|c|c|c|c|c|}
\hline & \multicolumn{3}{|c|}{ Beetroot Juice } & \multicolumn{3}{|c|}{ Control Drink } \\
\hline & Baseline & $3 \mathrm{~h}$ & Delta & Baseline & $3 \mathrm{~h}$ & Delta \\
\hline PAlx, \% & $-13.0 \pm 12.5^{2}$ & $-21.8 \pm 12.6^{\#}$ & $-8.7 \pm 6.5$ & $-14.1 \pm 10.9$ & $-22.0 \pm 13.2^{\#}$ & $-8.0 \pm 6.7$ \\
\hline CAlx, \% & $30.0 \pm 7.4$ & $24.6 \pm 8.3^{\#}$ & $-5.4 \pm 5.0$ & $30.3 \pm 7.0$ & $24.1 \pm 8.5^{\#}$ & $-6.2 \pm 4.5$ \\
\hline CAIxHR75, \% & $21.2 \pm 5.6$ & $16.2 \pm 6.9^{\#}$ & $-5.0 \pm 4.2$ & $21.1 \pm 6.1$ & $15.2 \pm 7.5^{\#}$ & $-5.9 \pm 4.0$ \\
\hline$P W V_{c-f}, m / s$ & $9.9 \pm 1.8$ & $9.8 \pm 1.6$ & $-0.1 \pm 1.2$ & $9.8 \pm 1.5$ & $9.8 \pm 1.8$ & $-0.1 \pm 1.1$ \\
\hline
\end{tabular}

\section{Discussion}

In this study with healthy overweight and slightly obese men, we found that concentrated beetroot juice counteracted the decrease in FMD associated with the intake of a mixed meal. Beetroot juice is rich in $\mathrm{NO}_{3}{ }^{-}$, which can be converted into $\mathrm{NO}_{2}^{-}$by facultative bacteria from the dorsal surface of the tongue. Once in the circulation, $\mathrm{NO}_{2}^{-}$can be further reduced to $\mathrm{NO}$ in the vasculature [15], thereby increasing concentrations of the circulating NO pool [16]. This pathway is of particular interest when vascular NO bioavailability is disturbed, as observed after the intake of dietary fat [4].

Several previous dietary intervention studies have already investigated whether improvements in endothelium-dependent vasodilation measured as FMD were related to increased concentrations of the circulating $\mathrm{NO}$ pool. Webb and colleagues found that dietary nitrate through the intake of $\mathrm{NO}_{3}{ }^{-}$-rich beetroot juice improved FMD during ischemia as a result of bioconversion to NO [9]. Other studies have reported that consumption of flavanol-rich cocoa [17] and flavonoidrich apples with nitrate-rich spinach [18] were associated with acute elevations of circulating NO concentrations and an improved FMD response. In agreement, we found that beetroot juice increased plasma NO concentrations. In contrast, postprandial lipemia was related to impaired endothelial function and decreased postprandial $\mathrm{NO}_{2}^{-}$plasma concentrations [19], possibly due to an increased production of reactive oxygen species. Oxygen free radicals, such as superoxide anions $\left(\mathrm{O}_{2}^{-}\right)$, can react directly with $\mathrm{NO}$ forming peroxynitrites (ONOO$\left.{ }^{-}\right)$, causing loss of vasodilators released from the endothelium. Additionally, the accumulation of $\mathrm{O}_{2}^{-}$and $\mathrm{ONOO}^{-}$leads to an inhibition of endothelial NO synthase (eNOS), the enzyme responsible for endogenous endothelial NO production [5]. Some studies have indeed reported a negative correlation between the magnitude of lipemia and the change in endothelial function [20, 21]. However, like several other studies [2224], we found no significant correlation. Differences in meal composition and experimental design may explain some of the discrepancies between studies. It should be noted, however, that in our study postprandial increases in serum TAG concentrations were comparable between both meals, which contained the same amount of fat and had a similar fatty acid composition. Therefore, differences in postprandial lipemia between the experimental conditions cannot explain our 
results. Although effects of dietary fat intake on acute impairment of endothelial function are more pronounced than those of carbohydrates [2, 25], postprandial hyperglycemia may also relate to impaired endothelial function [26, 27]. In the present study, postprandial glucose concentrations increased rapidly following the meals, containing the same carbohydrate content. However, no correlation between glucose and FMD responses was detected, while plasma glucose and insulin responses were comparable between the test meals.

Beetroot juice is thought to improve postprandial endothelial function primarily via the exogenous nitrate-nitrite-NO pathway as described. This alternative pathway for NO generation was abolished when the entero-salivary circulation was interrupted by spitting out the saliva for 3 hours following beetroot juice ingestion [9] or by using an antibacterial mouthwash [28]. Also, the finding that plasma nitrite concentrations increased dose-dependently after the intake of potassium nitrate $\left(\mathrm{KNO}_{3}\right)$ capsules or beetroot juice [8], indicates that the effects observed on $\mathrm{NO}$ bioavailability and endothelial function are due to $\mathrm{NO}_{3}{ }^{-}$. Alternatively, potassium may account for some of the effects of diets rich in fruits and vegetables on the cardiovascular system [16] and it is possible that the effects we observed were caused by the potassium from the beetroot juice. However, Kapil et al. [8] did not observe significant changes on endothelial function after potassium chloride $(\mathrm{KCl})$ supplementation. In contrast, ingestion of $\mathrm{KNO}_{3}$ capsules improved endothelial function following ischemia-reperfusion-induced depression of the FMD response. Therefore, it is unlikely that potassium underlies the effects observed after the acute intake of beetroot juice. Finally, it cannot be excluded that antioxidants present in beetroot juice such as polyphenols [29] have contributed to the effects observed.

The level of dietary or supplemental $\mathrm{NO}_{3}{ }^{-}$tested in previous studies ranged from approximately 500 to $1500 \mathrm{mg} /$ day in longer-term studies and from 400 to $2400 \mathrm{mg} /$ day in acute studies [8, 9]. In the current study, a single dose (140 mL) of concentrated beetroot juice was given with an average listed content of dietary $\mathrm{NO}_{3}{ }^{-}$of approximately $500 \mathrm{mg}$, which can be provided by $200-300 \mathrm{~g}$ of fresh spinach or beetroot [30]. Our intake exceeds the World Health Organization's (WHO) Acceptable Daily Intake (ADI) of $3.7 \mathrm{mg}$ per $\mathrm{kg}$ body weight [31], which equals approximately $350 \mathrm{mg}$ for our study population. However, evidence for adverse effects of $\mathrm{NO}_{3}{ }^{-}$in humans is weak [32], and epidemiological data do not provide evidence to restrict $\mathrm{NO}_{3}{ }^{-}$consumption [33]. Moreover, the intake of dietary $\mathrm{NO}_{3}{ }^{-}$provided by $140 \mathrm{~mL}$ of concentrated beetroot juice is more than two times below the intake reached by making an appropriate selection of $\mathrm{NO}_{3}^{-}$-rich vegetables and fruit as part of the Dietary Approaches to Stop Hypertension (DASH) diet [34] and below the reference dose for chronic oral exposure set by the United States Environmental Protection Agency (EPA) of $7.0 \mathrm{mg}$ per $\mathrm{kg}$ body weight per day for a 95-kg individual [35].

Irrespective of the intervention, we observed postprandial decreases in DBP and peripheral Alx, which are measures of arterial tone and reflect vasodilation of peripheral vessels. Previous studies with high-fat and highcarbohydrate meals have also reported postprandial peripheral vasodilatation [22, 36-38]. This may be caused by the insulin response [36, 37], which induces peripheral vasodilatation via endothelial-independent mechanisms and may explain the similar reductions in diastolic BP and peripheral Alx after the meals, despite differences in FMD. A direct endothelial-independent vasodilator effect of a 


\section{CHAPTER 3}

meal on the brachial artery diameters would also result in a reduced FMD from fasting values [39-40]. However, since baseline brachial artery diameters after the meals were not affected, this could not explain differences in FMD observed in our study.

In summary, our data indicate that in healthy overweight and slightly obese men a single dose of beetroot juice attenuates the postprandial impairment of FMD following a mixed meal, possibly through increases in plasma NO concentrations. However, although brachial FMD at baseline is inversely associated with future cardiovascular disease events [41] and the magnitude of impairment of endothelial function predicts adverse cardiovascular events [1], it remains to be investigated whether improvement of the frequent but transient postprandial lowering of the FMD response beneficially affects health.

\section{Acknowledgements}

The present study was supported by research grant $\mathrm{CH} 001$ from the Top Institute of Food and Nutrition (TIFN), Wageningen, The Netherlands. We also thank M. Hulsbosch and P. Hollman for their technical support. Finally, we thank our volunteers for their cooperation and enthusiasm.

The authors' responsibilities were as follows; P.J.J.: designed and conducted the study, performed the statistical analyses, interpreted the data, and wrote the manuscript; and R.P.M.: designed the study, interpreted the data, had overall responsibility for the study, and wrote the manuscript. Neither of the authors had any financial or personal conflicts of interest.

\section{Supplemental data}

Supplemental Table 3.1. Energy content and macronutrient composition of the test meals ${ }^{1}$

\begin{tabular}{lcccc}
\hline \hline & Mixed Meal & Beetroot Juice & Control Drink & Total \\
\hline Energy (kJ) & 4095 & 600 & 600 & 4695 \\
Energy (kcal) & 980 & 142 & 142 & 1122 \\
Protein (g) & 41.5 & 5.0 & 0.0 & $41.5-46.5$ \\
Carbohydrates (g) & 103.0 & 34.0 & 35.5 & $137.0-138.5$ \\
Sucrose (g) & 60.0 & 34.0 & 35.5 & $94.0-95.5$ \\
Total fat (g) & 56.6 & & & 56.6 \\
Saturated FA (g) & 33.9 & & & 33.9 \\
Trans FA (g) & 2.2 & & & 2.2 \\
Monounsaturated FA (g) & 14.5 & & & 14.5 \\
Polyunsaturated FA (g) & 2.7 & & & 2.7 \\
Cholesterol (mg) & 349 & & & 349 \\
\hline FA: fatty acids. & & & &
\end{tabular}


BEETROOT JUICE AND POSTPRANDIAL ENDOTHELIAL FUNCTION
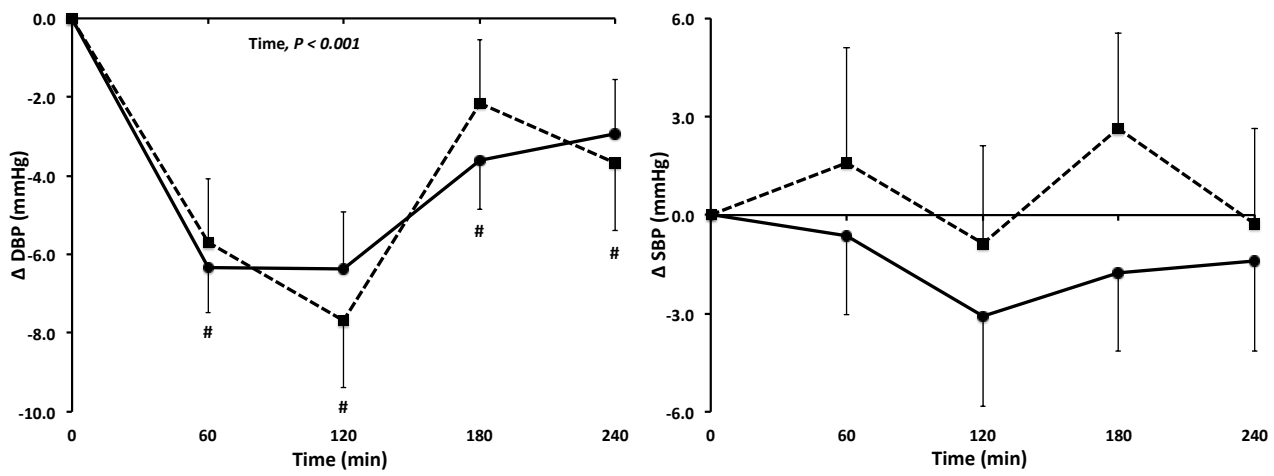

Supplemental Figure 3.1. Mean changes $( \pm$ SEM) in systolic (SBP) and diastolic blood pressure (DBP) following a mixed meal with either concentrated beetroot juice $(\mathbf{O})$ or a control drink ( $\boldsymbol{\square})$ in a randomized crossover study with overweight and slightly obese men $(n=20)$. Data were analyzed using linear mixed models. Following meal consumption, DBP decreased $(P<0.001$ for time effect). There were no significant time effects for SBP $(P>0.05)$. Values between the meals did not differ $(P>$ 0.05). \# After Bonferroni's correction significantly different from baseline, $P<0.05$. 


\section{CHAPTER 3}

\section{References}

1. Schachinger V, Britten M, Zeiher A. Prognostic impact of coronary vasodilator dysfunction on adverse long-term outcome of coronary heart disease. Circulation 2000;101:1899-906.

2. Vogel R, Coretti M, Plotnick G. Effect of a single high-fat meal on endothelial function in healthy subjects. Am J Cardiol 1997;79:350-4.

3. Gaenzer H, Sturm W, Neumayr G, Kirchmair R, Ebenbichler C, Ritsch A, Föger B, Weiss G, Patsch J. Pronounced postprandial lipemia impairs endothelium-dependent dilation of the brachial artery in men. Cardiovasc Res 2001;52:509-16.

4. Westphal S, Taneva E, Kästner S, Martens-Lobenhoffer J, Bode-Böger S, Kropf S, Dierkes J, Luley C. Endothelial dysfunction induced by postprandial lipemia is neutralized by addition of proteins to the fatty meal. Atherosclerosis 2006;185:313-9.

5. Nappo F, Esposito K, Cioffi M, Giugliano G, Molinari A, Paolisso G, Marfella R, Giugliano D. Postprandial endothelial activation in healthy subjects and in type 2 diabetic patients: role of fat and carbohydrate meals. J Am Coll Cardiol 2002;39:1145-50.

6. Balzer J, Heiss C, Schroeter H, Brouzos P, Kleinbongard P, Matern S, Lauer T, Rassaf T, Kelm M. Flavanols and cardiovascular health: effects on the circulating NO pool in humans. J Cardiovasc Pharmacol 2006;47:S122-S7.

7. Couillard C, Bergeron N, Prud'homme D, Bergeron J, Tremblay A, Bouchard C, Mauriège $\mathrm{P}$, Després J. Postprandial triglyceride response in visceral obesity in men. Diabetes 1998;47:953-60.

8. Kapil V, Milsom A, Okorie M, Maleki-Toyserkani S, Akram F, Rehman F, Arghandawi S, Pearl V, Benjamin N, Loukogeorgakis S, et al. Inorganic nitrate supplementation lowers blood pressure in humans. Hypertension 2010;56:274-81.

9. Webb A, Patel N, Loukogeorgakis S, Okorie M, Aboud Z, Misra S, Rashid R, Miall P, Deanfield J, Benjamin $\mathrm{N}$, et al. Acute blood pressure lowering, vasoprotective, and antiplatelet properties of dietary nitrate via bioconversion to nitrite. Hypertension 2008;51:784-90.

10. Utrecht: Netherlands Centraal Begeleidingsorgaan voor de Intercollegiale Toetsing. Behandeling en preventie van coronaire hartziekten door verlaging van de plasma cholesterolconcentratie 1998.

11. Rassaf T, Preik M, Kleinbongard P, Lauer T, Heiss C, Strauer B, Feelisch M, Kelm M. Evidence for in vivo transport of bioactive nitric oxide in human plasma. J Clin Invest 2002;109:1241-8.

12. Van Bortel L, Laurent S, Boutouyrie P, Chowienczyk P, Cruickshank J, De Backer T, Filipovsky J, Huybrechts S, Mattace-Raso F, Protogerou A, et al. Expert consensus document on the measurement of aortic stiffness in daily practice using carotid-femoral pulse wave velocity. J Hypertens 2012;30:445-8.

13. De Roos N, Bots M, Schouten E, Katan M. Within-subject variability of flow-mediated vasodilation of the brachial artery in healthy men and women: implications for experimental studies. Ultra Med Biol 2003;29:401-6.

14. Matthews J, Altman D, Campbell M, Royston P. Analysis of serial measurements in medical research. Brit Med J 1990;300:230-5.

15. Kapil V, Webb A, Ahluwalia A. Inorganic nitrate and the cardiovascular system. Heart 2010;96:1703-9.

16. Adrogué $\mathrm{H}$, Madias $\mathrm{N}$. Sodium and potassium in the pathogenesis of hypertension. New Eng J Med 2007;356:1966-78.

17. Schroeter H, Heiss C, Balzer J, Kleinbongard P, Keen C, Hollenberg N, Sies H, Kwik-Uribe $\mathrm{C}$, Schmitzz H, Kelm M. Epicatechin mediates beneficial effects of flavanol-rich cocoa on vascular function in humans. PNAS 2006;103:1024-9.

18. Bondonno C, Yang X, Croft K, Considine M, Ward N, Rich L, Puddey I, Swinny E, Mubarak A, Hodgson J. Flavonoid-rich apples and nitrate-rich spinach augment nitric oxide status 


\section{BEETROOT JUICE AND POSTPRANDIAL ENDOTHELIAL FUNCTION}

and improve endothelial function in healthy men and women: a randomized controlled trial. Free Rad Biol Med 2012;52:95-102.

19. Ramirez-Vélez R. Postprandial lipemia induces endothelial dysfunction and higher insulin resistance in healthy subjects. Endocrinol Nutr 2011;58:529-35.

20. Bae J, Bassenge E, Kim K, Kim Y, Kim K, Lee H, Moon K, Lee M, Park K, Schwemmer M. Postprandial hypertriglyceridemia impairs endothelial function by enhanced oxidant stress. Atherosclerosis 2001;155:517-23.

21. Marchesi S, Lupattelli G, Schillaci G, Pirro M, Siepi D, Roscini A, Pasqualini L, Mannarino E. Impaired flow-mediated vasoactivity during post-prandial phase in young healthy men. Atherosclerosis 2000;153:397-402.

22. Berry S, Tucker S, Banerji R, Jiang B, Chowienczyk P, Charles S, Sanders T. Impaired postprandial endothelial function depends on the type of fat consumed by healthy men. $\mathrm{J}$ Nutr 2008;138:1910-4.

23. Steer P, Sarabi D, Karlström B, Basu S, Berne C, Vessby B, Lind L. The effect of a mixed meal on endothelium-dependent vasodilation is dependent on fat content in healthy humans. Clin Sci (Lond) 2003;105:81-7.

24. Williams M, Sutherland W, McCormick M, de Jong S, Walker R, Wilkins G. Impaired endothelial function following a meal rich in used cooking fat. J Am Coll Cardiol 1999;33:1050-5.

25. Ong P, Dean T, Hayward C, Della Monica P, Sanders T, Collins P. Effect of fat and carbohydrate consumption on endothelial function. The Lancet 1999;354:2134.

26. Kawano H, Motoyama T, Hirashima O, Hirai N, Miyao Y, Sakamoto T, Kugiyama K, Ogawa $\mathrm{H}$, Yasue $\mathrm{H}$. Hyperglycemia rapidly suppresses flow-mediated endothelium-dependent vasodilation of brachial artery. J Am Coll Cardiol 1999;34:146-54.

27. Title L, Cummings P, Giddens K, Nassar B. Oral glucose loading acutely attenuates endothelium-dependent vasodilation in healthy adults without diabetes: An effect prevented by vitamins C and E. J Am Coll Cardiol 2000;36:2185-91.

28. Govoni M, Jansson E, Weitzberg E, Lundberg J. The increase in plasma nitrite after a dietary nitrate load is markedly attenuated by an antibacterial mouthwash. Nitric Oxide 2008;19:333-7.

29. Wootton-Beard P, Ryan L. A beetroot juice shot is a significant and convenient source of bioaccessible antioxidants. J Funct Foods 2001;3:329-34.

30. Lundberg J, Govoni M. Inorganic nitrate is a possible source for systemic generation of nitric oxide. Free Rad Biol Med 2004;37:395-400.

31. Alexander J, Benford D, Cockburn A, Cravedi J, Dogliotti E, Di Domenico A, FernandezCruz M, Fink-Gremmels J, Fürst P, Galli C, et al. Nitrate in vegetables: Scientific opinion of the Panel on Contaminants in the Food Chain. EFSA Journal 2008;689:1-79.

32. Katan MB. Nitrate in foods: harmful or healthy? Am J Clin Nutr 2009;90:11-2.

33. Milkowski A, Garg H, Coughlin J, Bryan N. Nutritional epidemiology in the context of nitrix oxide biology: a risk-benefit evaluation for dietary nitrite and nitrate. Nitric Oxide 2010;22:110-9.

34. Hord N, Tang Y, Bryan N. Food sources of nitrates and nitrites: the physiologic context for potential health benefits. Am J Clin Nutr 2009;90:1-10.

35. U.S. Environmental Protection Agency. Integrated Risk Information System (IRIS): Nitrate 1991, July 2013. Available from: http://www.epa.gov/iris/subst/0076.htm.

36. Raitakari O, Lai N, Griffiths K, McCredie R, Sullivan D, Celermajer D. Enhanced peripheral vasodilation in humans after a fatty meal. J Am Coll Cardiol 2000;36:417-22.

37. Greenfield J, Samaras K, Chisholm D, Campbell L. Effect of postprandial insulinemia and insulin resistance on measurement of arterial stiffness (augmentation index). Int $\mathrm{J}$ Cardiol 2007;114:50-6.

38. Gokce N, Duffy S, Hunter L, Keaney J, Vita J. Acute hypertriglyceridemia is associated with peripheral vasodilation and increased basal flow in healthy young adults. Am J Cardiol 2011;88:153-9. 


\section{CHAPTER 3}

39. Djoussé L, Ellison R, McLennan C, Cupples L, Lipinska I, Tofler G, Gokce N, Vita J. Acute effects of a high-fat meal with and without red wine on endothelial function in healthy subjects. Am J Cardiol 1999;84:660-4.

40. Gokce N, Hunter L, Vita J. Impaired flow-mediated dilation following a high fat meal is due to a change in basal tone. Circulation 1998;98:I-242.

41. Ras R, Streppel M, Draijer R, Zock P. Flow-mediated dilation and cardiovascular risk prediction: A systematic review with meta-analysis. Int J Cardiol 2013;168:344-351. 


\section{CHAPTER 4}

Weight loss improves fasting flow-mediated vasodilation in adults: A meta-analysis of intervention studies

Peter J. Joris, Maurice P. Zeegers and Ronald P. Mensink

Atherosclerosis 2015; 239: 21-30 


\section{CHAPTER 4}

\section{Abstract}

Background: Obesity is associated with vascular endothelial dysfunction. Effects of weight loss on endothelial function are however not clear. Therefore, we performed a meta-analysis to quantify effects of weight loss on flow-mediated vasodilation (FMD) of the brachial artery, a measurement of endothelial function.

Methods: Studies with experimental (RCTs) and quasi-experimental designs published before June 2014 were identified by a systematic search. Changes in FMD were defined as the difference between measurements before and after the study. For RCTs, changes were corrected for those in the no-weight loss control group. Summary estimates of weighted mean differences (WMDs) in FMD and $95 \%$ confidence intervals (Cls) were calculated using random-effect metaanalyses. The impact of subject characteristics, type of weight-loss treatment, and dietary composition on changes in FMD was also investigated.

Results: Four RCTs involving 265 subjects were included. Weight loss increased FMD vs. control by $3.29 \%(95 \% \mathrm{Cl}$ : $0.98-5.59 \% ; P=0.005$; mean weight loss: 8.6 $\mathrm{kg})$. A total of 1517 subjects participated in 33 studies with 49 relevant study arms. It was estimated that each $10 \mathrm{~kg}$ decrease in body weight increased fasting FMD by $1.11 \%(95 \% \mathrm{Cl}: 0.47-1.76 \% ; P=0.001)$. Effects were more pronounced when participants had coexisting obesity-related morbidities. Also, effects may be larger when subjects received low-fat diets or weight-reduction regimens including exercise therapy or weight-loss medication.

Conclusion: Weight loss significantly improves fasting FMD in adults, which is a risk marker for cardiovascular disease. Effects may depend on subject characteristics, type of weight-loss treatment, and dietary composition. 


\section{Introduction}

Overweight and obese people have an increased risk to develop multiple metabolic disorders such as dyslipidemia, hypertension, and insulin resistance. All these metabolic risk markers are associated with vascular endothelial dysfunction, which is characterized by a decreased arterial response to stimuli that triggers the release of vasodilators from the endothelium, and predicts long-term atherosclerotic disease progression and cardiovascular event rates [1, 2]. Although the mechanisms underlying the association between excess adipose tissue and reduced endothelial function [3-5] have not been fully elucidated, enhanced oxidative stress and inflammatory cytokines may play an important role. In addition, resistance to the vasomotor function of insulin and leptin, activation of the renin-angiotensin-aldosterone system (RAAS), and direct adverse effects of several adipokines and other vasoactive factors may be involved [3-7].

In two reviews, it was concluded that lifestyle changes leading to weight reduction may improve vascular endothelial function [8, 9]. Results, however, were not quantitatively summarized and results of recent large clinical trials were not included. In addition, effects of weight loss on endothelial function were not consistent between studies. It was therefore concluded $[8,9]$ that the impact of subject and treatment characteristics on the outcomes warranted further research. We therefore performed a meta-analysis of human intervention studies on the effects of weight loss on flow-mediated vasodilation (FMD) of the brachial artery, the current gold standard [10] and a robust [11] non-invasive measurement of vascular endothelial function. Objectives were (i) to quantitatively summarize for the first time the effects of weight loss on FMD and (ii) to examine sources of heterogeneity between studies to identify the impact of subject characteristics, type of weight-loss treatment, and dietary composition.

\section{Methods}

The PRISMA statement checklist for this meta-analysis is available online as supporting information [Supplemental Checklist 4.1].

\section{Search strategy}

Potentially relevant studies published before June 2014 were identified by a systematic search of the database PubMed (http://www.ncbi.nlm.nih.gov/pubmed). The following search terms were used to search in titles and abstracts: (weight loss or weight reduction or weight change or BMI loss or BMI reduction or BMI change or diet) and (flow mediated vasodilation (or vasodilatation or dilation or dilatation) or endothelial (or endothelium) dependent vasodilation (or vasodilatation or dilation or dilatation) or endothelial (or endothelium) function (or dysfunction) or FMD or vascular reactivity or brachial artery). The search was limited to studies in humans and to the English language. Reference lists from the selected articles were also screened manually for potentially relevant publications. 


\section{CHAPTER 4}

\section{Selection of trials}

Human intervention studies, that investigated the relationship between weight loss and fasting FMD of the brachial artery with experimental (RCTs) and quasiexperimental (before-and-after design) designs, were selected.

The selection was performed in two steps. First, titles and abstracts were screened. Studies were selected if they met the following inclusion criteria: human intervention study with adults, intervention with weight loss as experimental variable, no intentional co-intervention that made it impossible to estimate the effect of weight loss, and assessment of fasting vascular endothelial function by measuring FMD. In the second step, full-texts of the selected articles were read and studies were excluded based on the following criteria: missing data on FMD, no appropriate measures of variability reported, and no suitable diet-induced weight-loss intervention (i.e. weight loss achieved by exercise alone or no statistically significant weight change). Two of the authors (P.J.J. and R.P.M.) completed the literature search independently. When inconclusive, eligibility was discussed until consensus was reached.

\section{Data extraction}

For each of the selected studies, data were extracted using a custom-made database including identification of the study (first author's name and year of publication), study design (experimental or quasi-experimental), subject characteristics (sample size, age, gender, body mass index (BMI), waist circumference, baseline FMD level, and health status), treatment characteristics (type of weight-loss treatment, duration and amount of weight reduction, and dietary composition) and FMD values including measures of variance.

\section{Statistical analysis}

Statistical analyses were performed using Stata 12.0 software (Stata Corporation, College Station, TX, USA). The FMD response was quantified as the maximal percentage change in post occlusion arterial diameter relative to baseline diameter, which is the diameter of the brachial artery before the introduction of a flow stimulus in the artery. The post occlusion arterial diameter is the diameter observed within minutes of reperfusion following the release of an inflated cuff.

For RCTs including a no-weight loss control group, changes in the experimental group were first corrected for those in the no-weight loss control group. Changes in FMD were then calculated as the difference between measurements after the study (end-of-the-study values). For RCTs and intervention studies with quasi-experimental designs that did not include a noweight control group, changes in FMD were calculated as the difference between measurements before (start-of-the-study values) and after the study (end-of-thestudy values). For trials that performed FMD measurements more than one time during the study, only results of the last measurement were used.

Summary estimates of weighted mean differences (WMDs) in FMD and 95\% confidence intervals (Cls) were calculated using fixed-effect meta-analyses and visualized using forest plots. The inverse of the variance $\left(1 / \mathrm{SE}^{2}\right)(\mathrm{SE}=$ between-subject variance) was used as a weight factor. Heterogeneity was 
evaluated using the Cochran's $Q$ test $(P<0.1$ indicates statistical significant heterogeneity) and quantified using the $I^{2}$ statistic [12-14], i.e. the percentage of variability in effect estimate that is due to heterogeneity rather than sampling error. An $l^{2}$ value above $50 \%$ indicates relevant heterogeneity between studies [15]. In case of heterogeneity, random-effect meta-analyses were used as described by DerSimonian and Laird [13].

As the number of RCTs was limited, a subgroup analysis to identify sources of heterogeneity between studies could only be performed for studies without a no-weight loss control group. As it was evident that the amount of weight loss was an important source of heterogeneity, first a lower-weight loss and a higher-weight loss group were defined. For this, the median value of weight loss for the entire group was used as cut-off point. Subgroup analyses were performed within each weight-loss group by comparing the summary results of the study arms grouped by baseline BMI, baseline FMD level, health status (healthy or coexisting obesity-related morbidities), mean age, population size, study duration, type of weight-loss treatment (diet alone, diet and exercise, diet and weight-loss medication or surgery), and dietary composition (low-fat defined as $\leq 30 \%$ of energy from fat or low-carbohydrate defined as $\leq 45 \%$ of energy from carbohydrates [16]). Median values of continuous variables in both weight-loss groups were used as cutoff values to create the binary variables. Univariate metaregression analyses were performed to investigate the relationships between changes in body weight or waist circumference with changes in FMD. A cumulative meta-analysis was performed to evaluate the change in summary effects of weight loss on FMD over time. For this, studies were chronologically ordered by publication year, and then the cumulative WMDs were calculated at the end of each year. For all statistical analyses, two-sided tests were used. A $P$-value $<0.05$ was considered as statistically significant.

Publication bias was evaluated visually by inspecting the symmetry of funnel plots. The degree of funnel plot asymmetry was assessed with the Egger's weighted regression test. Absence of publication bias is reflected in an intercept close to 0 with a corresponding $P \geq 0.05$ [17]. The nonparametric (rank-based) trim-and-fill method was used to adjust the analysis for the possible effects of publication bias [18].

\section{Results}

\section{Search results and study characteristics}

A total of 1120 potentially relevant papers were retrieved with the systematic search. Based on the predefined selection criteria, 1076 papers were excluded for different reasons [Supplemental Figure 4.1]. The full text of the remaining 44 articles was reviewed and seven papers were excluded for the following reasons: missing data for FMD [19], no appropriate measures of variability reported [20], weight loss achieved by exercise alone [21], or no statistically significant weight change [22-25]. A total of 37 human intervention studies with experimental and quasi-experimental designs met all the inclusion criteria and was included in the meta-analysis [Table 4.1]. 


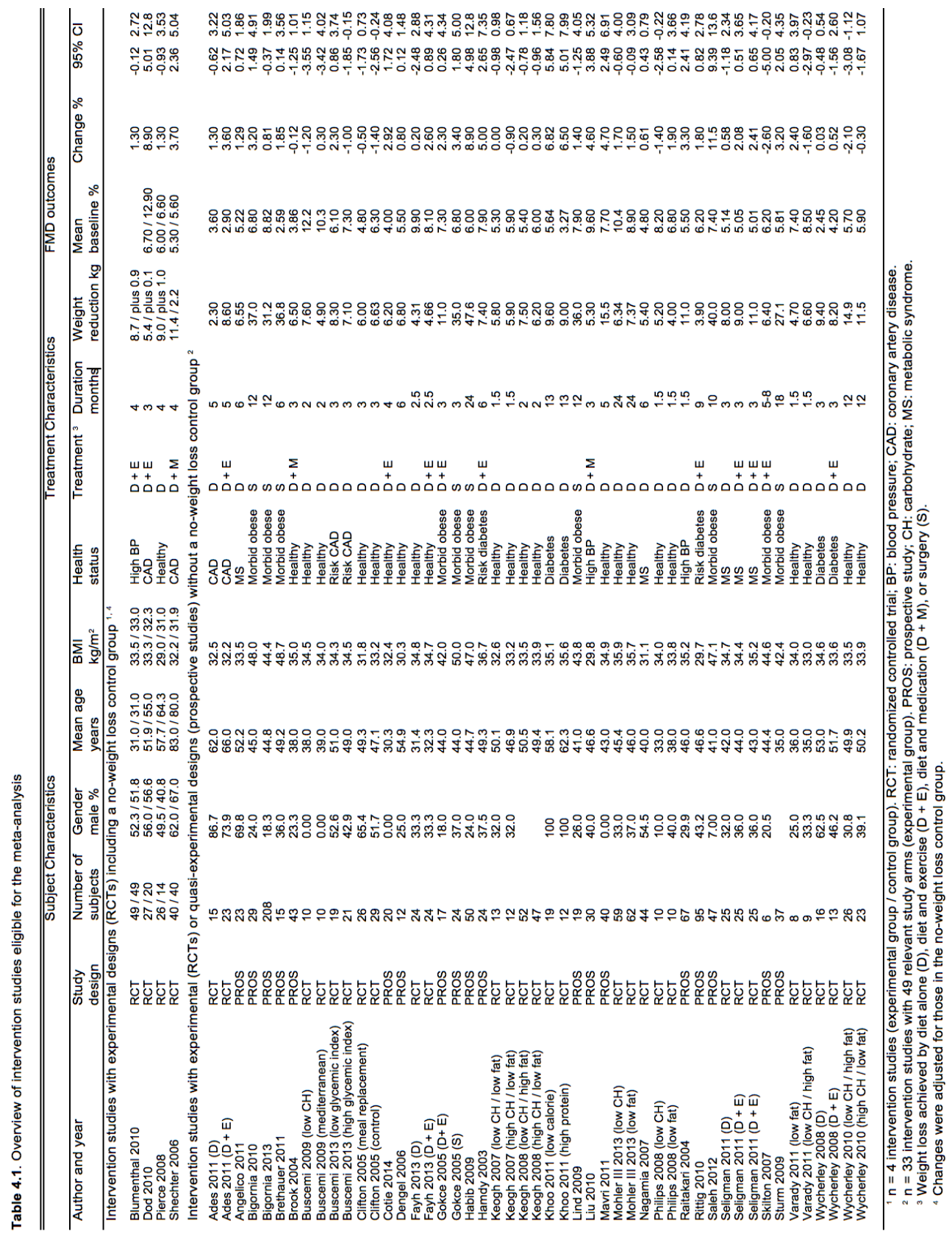




\section{WEIGHT LOSS AND FLOW-MEDIATED VASODILATION}

Four of the studies were RCTs [26-29] with a no-weight loss control group. In these studies 265 subjects participated, 142 in the intervention group and 123 in the noweight loss control group. The mean age of the subjects was 55.7 years (range: 45.5 to 64.5 years) and more than half of the study population was men. In one study, healthy adults were included [28], in one study subjects with uncomplicated high blood pressure (BP) [26], whereas in two studies [27, 29] participants had coronary artery disease (CAD). Study duration varied between three and four months, and weight loss between 5.5 and $10.0 \mathrm{~kg}$. In all studies, all subjects were overweight or slightly obese with a mean BMI between 29.0 and $33.5 \mathrm{~kg} / \mathrm{m}^{2}$.

A total of 1517 subjects participated in 33 experimental or quasiexperimental studies that did not include a no-weight control group [30-62] with 49 relevant study arms. The number of subjects per study arm ranged from 6 to 208, mean age from 30.3 to 66.0 years, and BMl from 29.7 to $50.0 \mathrm{~kg} / \mathrm{m}^{2}$. One study included only men [47], whereas three studies included only women [37, 39, 50]. In the remaining studies, except for two studies that did not report gender [46, 59], the proportion of men ranged from 7.0 to $86.7 \%$. In 13 studies, healthy overweight or obese subjects were included [35, 37-41, 45, 46, 50, 51, 53, 60,61]; the other studies included subjects with high BP $[49,54]$, the metabolic syndrome $[31,52$, 57], morbid obesity [32-34, 42, 43, 48, 56, 58, 59], (an increased risk of) type II diabetes [44, 47, 55, 62] or (an increased risk of) CAD [30, 32]. Study duration varied between two months and two years, and weight loss - achieved by diet alone $(n=29)$, diet and exercise $(n=10)$, diet and weight-loss medication $(n=2)$ or surgery $(n=8)$ - between 2.3 and $47.6 \mathrm{~kg}$. The mean baseline FMD was $6.38 \%$ (range: 2.45 to $12.20 \%$; Table 4.1).

Study

ID

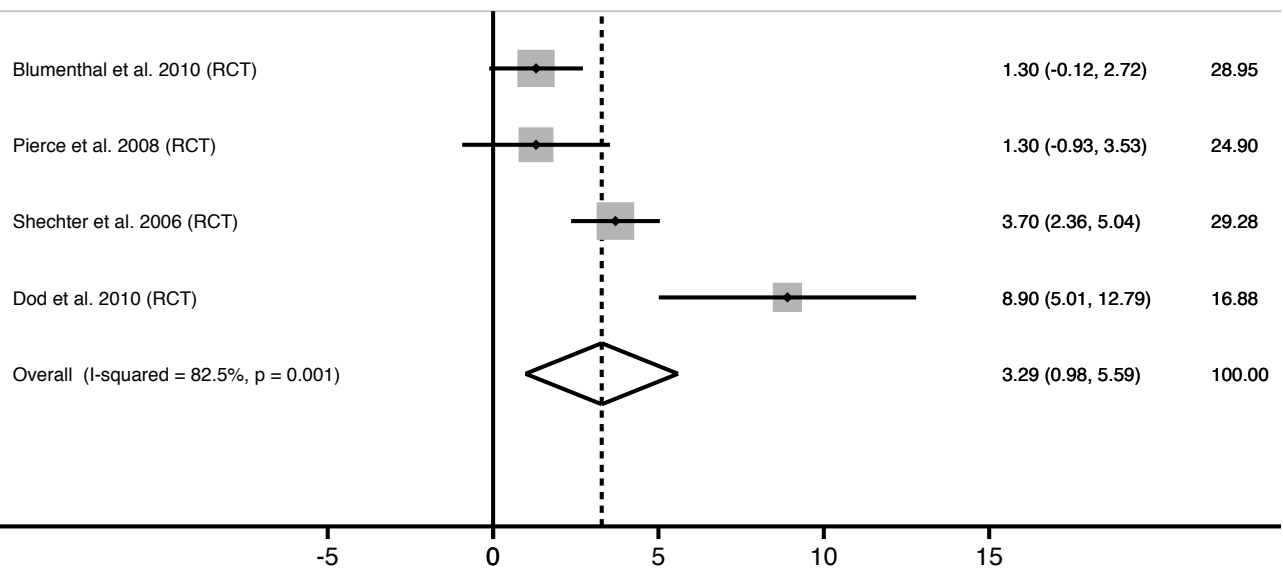

Figure 4.1. Forest plot of random controlled trials (RCTs) including a no-weight loss control group that investigated the effect of weight loss on flow-mediated vasodilation (FMD). The solid squares represent the weight of individual studies and the diamond represents the weighted mean difference (WMD) in FMD (calculated using random-effect meta-analyses). In all studies combined, weight loss increased FMD vs. control by $3.29 \%(95 \% \mathrm{Cl}: 0.98-5.59 \% ; P=0.005$; mean weight loss: $8.6 \mathrm{~kg})$. 


\section{CHAPTER 4}

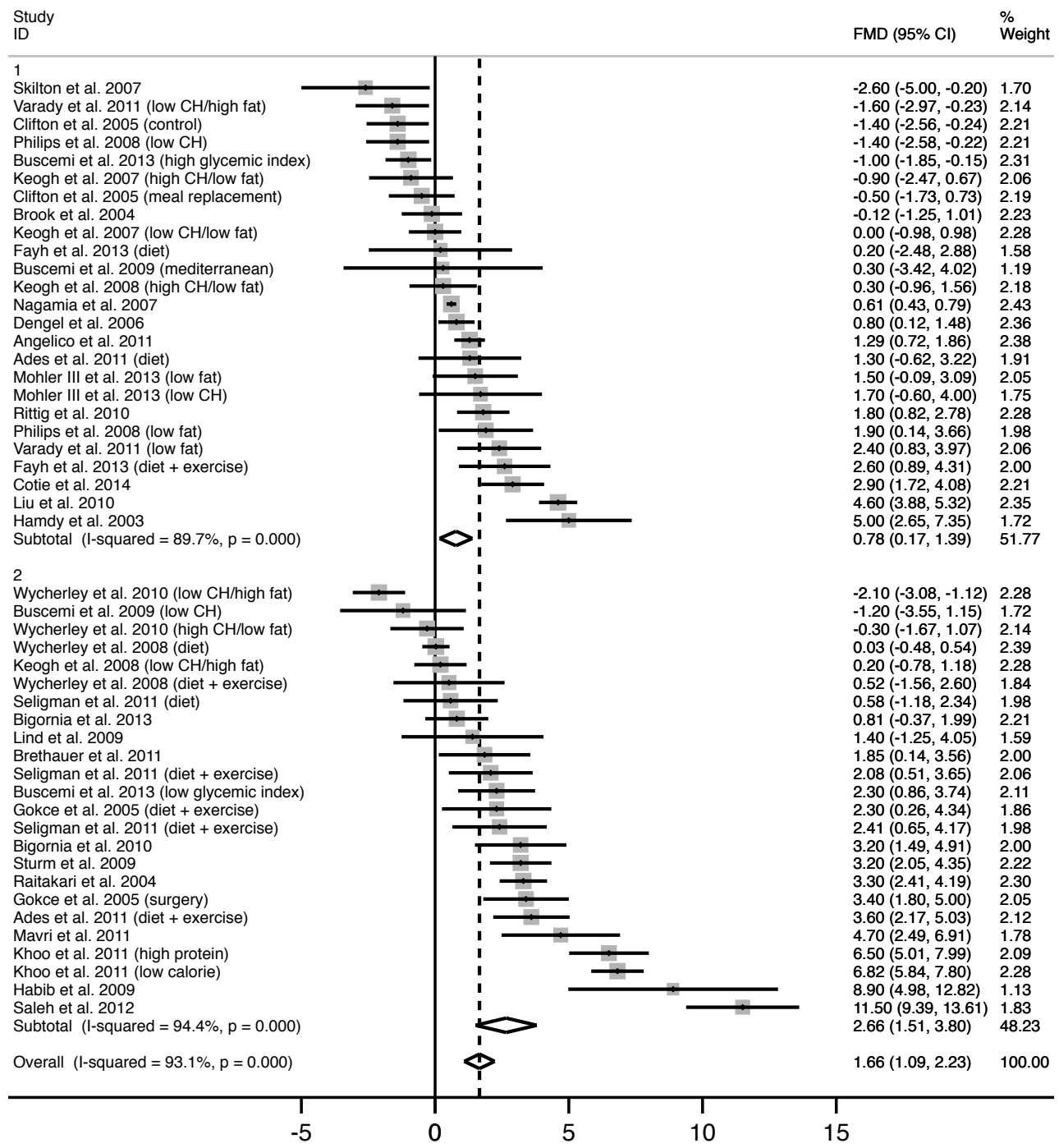

Figure 4.2. Forest plot of studies with experimental or quasi-experimental designs without a no-weight loss control group that investigated the effect of weight loss on flow-mediated vasodilation (FMD). The solid squares represent the weight of individual study arms and the diamond represents the weighted mean difference (WMD) in FMD (calculated using random-effect meta-analyses). When weight loss was below the median level (1), FMD improved by $0.78 \%(95 \% \mathrm{Cl}: 0.17-1.39 \% ; P=0.012$; mean weight loss: $5.7 \mathrm{~kg}$ ) as opposed to $2.66 \%(95 \% \mathrm{Cl}: 1.51-3.80 \% ; P<0.001$; mean weight loss: $18.8 \mathrm{~kg})$ in the groups with weight loss above the median level (2). In case of multiple study arms, intervention details are specified between brackets. $\mathrm{CH}$ : carbohydrate.

\section{Effects of weight loss on FMD}

After correction for changes in the no-weight loss control group, weight loss in the RCTs showed a statistically significant effect on FMD in two individual studies [27, 29]. In all studies combined, weight loss increased FMD vs. control by $3.29 \%$ (95\% 
Cl: 0.98-5.59\%; $P=0.005$; mean weight loss: $8.6 \mathrm{~kg}$ ) [Figure 4.1]. However, significant heterogeneity was found between trials $\left(I^{2}=82.5 \%, P=0.001\right)$. After excluding the study with the most pronounced effect [26], the overall WMD in FMD was still statistically significant $(2.19 \% ; 95 \% \mathrm{Cl}$ : $0.46-3.92 \% ; P=0.013$; mean weight loss: $9.6 \mathrm{~kg})$. Although heterogeneity decreased, it remained significant $\left(I^{2}=\right.$ $70.8 \%, P=0.032$ ).

Thirty-three intervention studies without a no-weight control group were included with 49 study arms. Weight loss significantly improved FMD by $1.66 \%$ $(95 \% \mathrm{Cl}: 1.09-2.23 \% ; P<0.001)$ [Figure 4.2 ], corresponding to a relative improvement of approximately $25 \%$ compared to baseline levels. Between-study heterogeneity was significant $\left(I^{2}=93.1 \%, P<0.001\right)$ and was partly explained by the amount of weight loss after the intervention period. Higher weight loss was associated with greater FMD improvements $(P$ for subgroup difference $=0.013$ ). When weight loss was below the median level $(7.4 \mathrm{~kg})$, FMD improved by $0.78 \%$ (95\% Cl: $0.17-1.39 \% ; P=0.012$; mean weight loss: $5.7 \mathrm{~kg}$ ) as opposed to $2.66 \%$ (95\% Cl: $1.51-3.80 \% ; P<0.001$; mean weight loss: $18.8 \mathrm{~kg}$ ) in the groups with weight loss above the median level [Figure 4.2]. Results of the meta-regression analysis suggested that each $10 \mathrm{~kg}$ decrease in body weight was associated with a significant increase of $1.11 \%(95 \% \mathrm{Cl}: 0.47-1.76 \% ; P=0.001)$ in fasting $\mathrm{FMD}$ [Figure 4.3]. Further, it was estimated that each $5 \mathrm{~cm}$ decrease in waist circumference was associated with an increase of $1.17 \%(95 \% \mathrm{Cl}: 0.45-1.86 \% ; P$ $=0.003$ ) in fasting FMD [Supplemental Figure 4.2] .

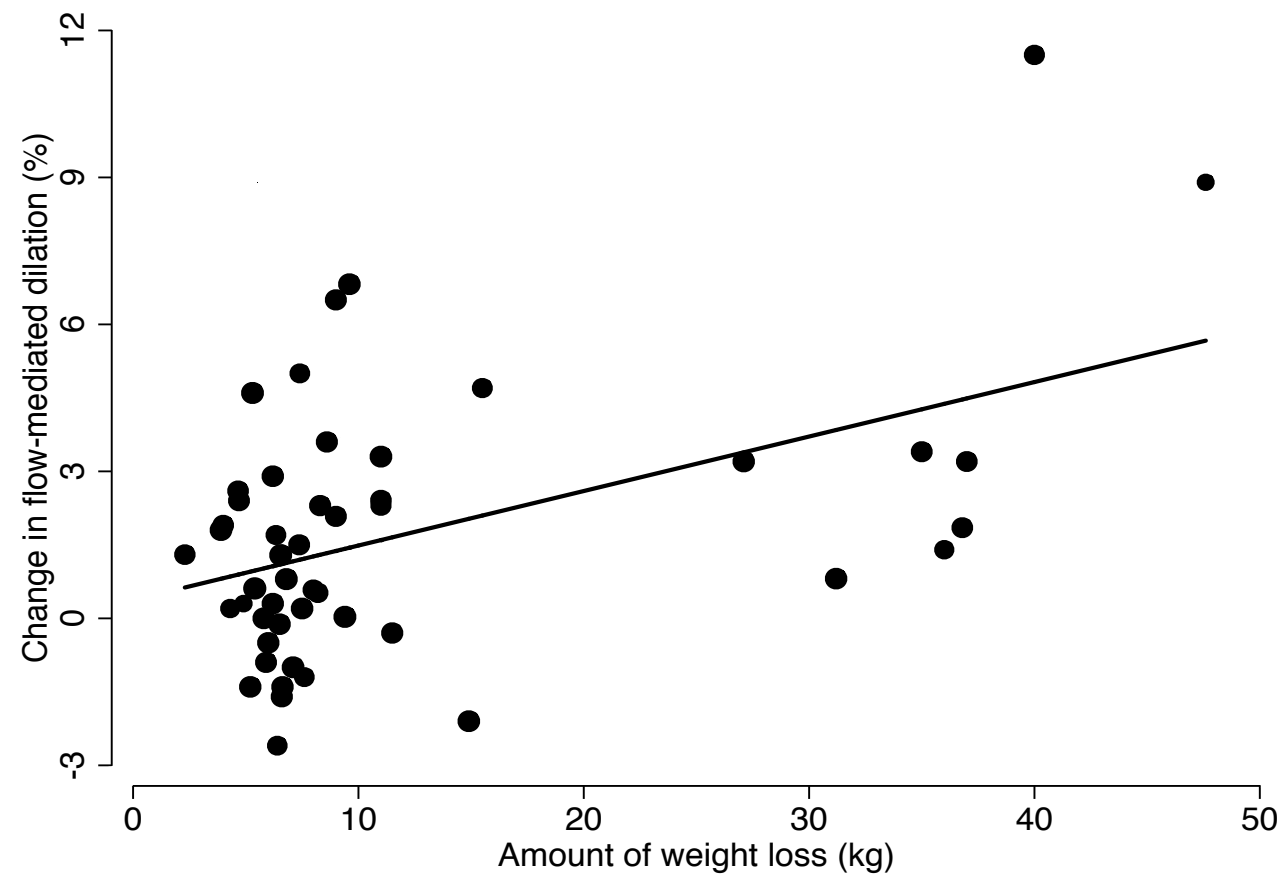

Figure 4.3. Relationship between the change in FMD and the amount of weight loss. The size of each circle is proportional to the inverse of the variance of the change in FMD, and the line represents the regression line determined by meta-regression analysis. Each $10 \mathrm{~kg}$ decrease in body weight was associated with a significant increase of $1.11 \%$ in fasting FMD of the brachial artery. 


\section{CHAPTER 4}

A cumulative meta-analysis was carried out to evaluate the cumulative WMD in FMD over time (data not shown). In 2003, Hamdy and colleagues [44] reported a significant improvement in FMD by 5\% $(P<0.001)$. Between 2003 and 2009, 17 study arms were added, resulting in a non-significant WMD of $0.55 \%(95 \% \mathrm{Cl}$ : 0.01 to $1.11 \%$ ). From 2009 to June 2014, 31 more study arms were published, resulting in an overall WMD in FMD of $1.66 \%(95 \% \mathrm{Cl}: 1.09-2.23 \%)$.

\section{Subgroup analyses}

After stratification for weight loss, significant heterogeneity remained. Therefore, further subgroup analyses were performed in each group to evaluate if subject or treatment characteristics were related to the effects of weight loss on FMD [Table 4.2]. Heterogeneity between studies further decreased after stratification for health status, suggesting larger effects of weight loss on FMD when weight loss was above the median value and participants had coexisting obesity-related morbidities ( $P$ for subgroup difference $=0.040$ ), such as the metabolic syndrome, type II diabetes or CAD. The type of weight-loss treatment was also related to the observed effects, suggesting more pronounced effects in the lower-weight loss group when exercise therapy $(P$ for subgroup difference $=0.033$ ) or weight-loss medication $(P$ for subgroup difference $=0.062$ ) was part of the weight-loss regime. Finally, increases in FMD were more pronounced in the higher-weight loss group when subjects consumed low-fat diets as compared with low-carbohydrate diets $(P$ for subgroup difference $=0.048$ ). None of the other predefined variables (e.g. baseline FMD, mean age, population size or study duration) resulted in significantly different effects of weight loss on FMD.

\section{Publication bias}

Visual evaluation of the funnel plot for the RCTs did not indicate presence of publication bias [Supplemental Figure 4.3]. Egger's weighted regression test also showed no funnel plot asymmetry $(P=0.49)$, indicating absence of publication bias. The funnel plot for the effect of weight-loss programs in the non-RCTs revealed possible presence of publication bias and the Egger's test $(P=0.052)$ tended to reach statistical significance [Supplemental Figure 4.4]. The trim-and-fill correction analysis, however, did not suggest that more studies were needed and did not change the results (WMD: $1.66 \% ; 95 \% \mathrm{Cl}: 1.09-2.23 \%$; $P<0.001$ ). 


\section{WEIGHT LOSS AND FLOW-MEDIATED VASODILATION}

Table 4.2. Subgroup analyses for the effect of weight loss on flow-mediated dilation (FMD) after stratification for weight loss group ${ }^{1}$

\begin{tabular}{|c|c|c|c|c|c|c|c|}
\hline Study characteristic & Mean & $\begin{array}{l}\text { Stratification } \\
\text { variable }\end{array}$ & $\begin{array}{l}\text { No of } \\
\text { study arms }\end{array}$ & $\begin{array}{l}\text { WMD } \\
(\%)\end{array}$ & \multicolumn{2}{|c|}{$995 \% \mathrm{Cl}$} & \multirow{2}{*}{$\begin{array}{l}\begin{array}{l}P \text {-value } \\
\text { differen }\end{array} \\
\text { group }^{2}\end{array}$} \\
\hline \multicolumn{7}{|c|}{ Study arms with experimental or quasi-experimental designs. Lower-weight loss $(\leq 7.4 \mathrm{~kg})$ group $^{2}$} & \\
\hline \multirow[t]{2}{*}{ Baseline BMI $\left(\mathrm{kg} / \mathrm{m}^{2}\right)^{3}$} & 33.8 & $\leq 33.8$ & 13 & 0.87 & 0.05 & 1.69 & 0.827 \\
\hline & & $>33.8$ & 12 & 0.68 & -0.36 & 1.72 & \\
\hline \multirow[t]{2}{*}{ Baseline FMD (\%) ${ }^{3}$} & 6.84 & $\leq 6.30$ & 13 & 0.45 & -0.06 & 0.96 & 0.190 \\
\hline & & $>6.30$ & 12 & 1.35 & -0.25 & 2.94 & \\
\hline \multirow[t]{2}{*}{ Health Status } & - & Healthy & 17 & 0.46 & -0.24 & 1.15 & 0.247 \\
\hline & & $\mathrm{CM}$ & 8 & 1.40 & 0.15 & 2.65 & \\
\hline \multirow[t]{2}{*}{ Mean age (years) ${ }^{3}$} & 43.7 & $\leq 46.0$ & 13 & 0.69 & -0.10 & 1.48 & 0.792 \\
\hline & & $>46.0$ & 12 & 0.89 & -0.22 & 1.99 & \\
\hline \multirow[t]{2}{*}{ Population size ${ }^{3}$} & 27.0 & $\leq 23.0$ & 13 & 0.31 & -0.51 & 1.13 & 0.180 \\
\hline & & $>23.0$ & 12 & 1.31 & 0.24 & 2.38 & \\
\hline \multirow[t]{2}{*}{ Study duration (months) ${ }^{3}$} & 5.18 & $\leq 3$ & 15 & 0.35 & -0.85 & 1.55 & 0.157 \\
\hline & & $>3$ & 10 & 1.38 & 0.73 & 2.03 & \\
\hline \multirow[t]{2}{*}{ Type of treatment } & - & Diet only & 18 & 0.22 & -0.26 & 0.70 & 0.033 \\
\hline & & Diet and exercise & 5 & 2.02 & 0.34 & 3.69 & \\
\hline \multirow[t]{2}{*}{ Type of treatment } & - & Diet only & 18 & 0.22 & -0.26 & 0.70 & 0.062 \\
\hline & & Diet and medication & 2 & 2.26 & -2.36 & 6.89 & \\
\hline \multirow[t]{2}{*}{ Dietary composition } & - & Low carbohydrate & 3 & -0.71 & -2.31 & 0.89 & 0.180 \\
\hline & & Low fat & 10 & 0.53 & -0.07 & 1.13 & \\
\hline
\end{tabular}

Study arms with experimental or quasi-experimental designs. Higher-weight loss $(>7.4 \mathrm{~kg})$ group ${ }^{2}$

\begin{tabular}{|c|c|c|c|c|c|c|c|}
\hline \multirow[t]{2}{*}{ Baseline BMI $\left(\mathrm{kg} / \mathrm{m}^{2}\right)^{3}$} & $38.7^{*}$ & $\leq 35.2$ & 12 & 1.44 & -0.14 & 3.01 & 0.045 \\
\hline & & $>35.2$ & 12 & 3.90 & 2.47 & 5.33 & \\
\hline \multirow[t]{2}{*}{ Baseline FMD (\%) ${ }^{3}$} & 5.90 & $\leq 5.76$ & 12 & 2.15 & 0.53 & 3.77 & 0.410 \\
\hline & & $>5.76$ & 12 & 3.20 & 1.54 & 4.87 & \\
\hline \multirow[t]{2}{*}{ Health Status } & - & Healthy & 5 & 0.14 & -1.68 & 1.95 & 0.040 \\
\hline & & $\mathrm{CM}$ & 19 & 3.31 & 2.05 & 4.57 & \\
\hline \multirow[t]{2}{*}{ Mean age (years) ${ }^{3}$} & 47.4 & $\leq 44.9$ & 12 & 3.20 & 1.57 & 4.84 & 0.412 \\
\hline & & $>44.9$ & 12 & 2.15 & 0.54 & 3.77 & \\
\hline \multirow[t]{2}{*}{ Population size ${ }^{3}$} & 35.0 & $\leq 24.5$ & 12 & 2.31 & 0.61 & 4.02 & 0.581 \\
\hline & & $>24.5$ & 12 & 3.02 & 1.32 & 4.71 & \\
\hline \multirow[t]{2}{*}{ Study duration (months) ${ }^{3}$} & 7.65 & $\leq 5$ & 13 & 1.86 & 0.86 & 2.83 & 0.169 \\
\hline & & $>5$ & 11 & 3.69 & 1.35 & 6.04 & \\
\hline \multirow[t]{2}{*}{ Type of treatment } & - & Diet only & 11 & 1.89 & 0.12 & 3.67 & 0.834 \\
\hline & & Diet and exercise & 5 & 2.33 & 1.37 & 3.28 & \\
\hline \multirow[t]{2}{*}{ Type of treatment } & - & Diet only & 11 & 1.89 & 0.12 & 3.67 & 0.173 \\
\hline & & Surgery & 8 & 4.10 & 1.95 & 6.25 & \\
\hline \multirow[t]{2}{*}{ Dietary composition } & - & Low carbohydrate & 3 & -1.01 & -2.72 & 0.70 & 0.048 \\
\hline & & Low fat & 5 & 2.24 & 0.49 & 4.00 & \\
\hline
\end{tabular}

\footnotetext{
${ }^{1}$ Lower-weight loss group: $\leq 7.4 \mathrm{~kg}$; higher-weight loss group: $>7.4 \mathrm{~kg}$.

${ }^{2} \mathrm{n}=33$ intervention studies with 49 relevant study arms. CM: coexisting obesity-related morbidities.

${ }^{3}$ For continuous variables, studies arms were divided in subgroups based on their medians.

* Significantly different from lower-weight loss group, $P<0.05$ (unpaired Student's $t$ test).
} 


\section{CHAPTER 4}

\section{Discussion}

In this meta-analysis, we found in overweight and obese adults a significant linear relationship between weight loss and fasting FMD of the brachial artery, indicating an improvement in vascular endothelial function. It was estimated that each $10 \mathrm{~kg}$ decrease in body weight was associated with a significant increase of $1.11 \%$ in fasting FMD. Results from prospective epidemiological studies have suggested that CVD risk decreases by $8 \%$ when FMD increases by $1 \%$ [63], underlining the clinical relevance of our findings.

Although the mechanisms for the beneficial effects of weight loss on FMD have not been fully elucidated, decreased secretion of adipose tissue-derived adipokines and other vasoactive factors may be a major cause [64]. Reducing adipose tissue, a metabolically active endocrine organ, lowers the production of proinflammatory and proatherogenic cytokines that have detrimental effects on the endothelium [65]. In fact, it has been shown that adipocytokine levels may be independent predictors of FMD in the circulation of healthy subjects [66]. Moreover, increased adipokine release induces the production of reactive oxygen species (ROS) in obesity, generating oxidative stress [67] that may reduce vascular endothelial function in patients with peripheral arterial disease [68].

Because significant heterogeneity was found between trials, the impact of treatment and subject characteristics on the effect of weight loss on FMD was examined. As expected, this was partly due to differences in weight loss between studies. In fact, a significant linear relationship between weight loss and FMD was found. Even a modest weight change of on average $5.7 \mathrm{~kg}$ resulted in positive effects on the vascular endothelium. Waist circumference as an estimate of visceral fat was also a good predictor of the improvement in FMD. Excess visceral fat is characterized by central obesity, metabolically more active [69], and closely linked to endothelial dysfunction and altered arterial homeostasis [70]. Unfortunately, robust measures of body composition were in general missing to analyze into more detail the effects of changes in total body fat and fat distribution on FMD.

Another source of heterogeneity was health status, as effects of weight loss on FMD were larger in the higher-weight loss group when participants had coexisting obesity-related morbidities. This was not related to differences in baseline FMD levels at the start of the study, as this was not related to the effects observed. It is more likely that in this group part of the additional increase in FMD is related to improvements of obesity-related metabolic abnormalities that are stronger related to increased FMD responses. Results also depend on the type of weight-loss treatment, suggesting additional effects when exercise therapy or weight-loss medication was part of the weight-loss regime. Indeed, exercise alone is well known to improve vascular endothelial function in patients and healthy subjects [71]. Also, the RCT with the most pronounced effect on FMD indeed investigated the effect of caloric-restriction with exercise [27]. Repeated episodes of elevated blood flow and shear stress that occur during exercise episodes are likely to be a key mechanism for adaption in vascular endothelial function and the positive remodeling that results from exercise training [72]. Finally, increases in FMD may be larger when subjects consumed low-fat diets as compared with lowcarbohydrate diets. This finding is in agreement with a previous meta-analysis that combined results of studies under hypocaloric and isocaloric conditions [73]. 
However, the impact of the dietary composition on the change in FMD under isocaloric conditions warrants further research. Further, to what extent differences are confounded by differences in the intake of other nutrients such as protein, fiber and minerals also remains to be determined.

There are several limitations in the present meta-analysis. First, significant heterogeneity was found among the included studies. Although heterogeneity decreased in subgroup analyses, a substantial amount of heterogeneity remained. Factors, including position of cuff and time of occlusion may also have contributed to the heterogeneity among the studies. Overall, the number of studies included in this meta-analysis was too limited and the range in FMD outcomes, especially in the lower-weight loss group, too small to allow a thorough analysis of sources of heterogeneity. Also, low reproducibility in FMD measurements may be a source of heterogeneity. Although FMD is a widely used technique, there are many physiological, methodological and technical factors that affect comparability between FMD studies. Better standardization of the FMD technique, as discussed [74], is required to reduce between study variability. Second, only intervention studies with adults were selected. Studies in children and adolescents are limited. Results may differ from weight-loss studies in adults, suggesting with the same amount of weight loss more beneficial on FMD in obese children due to a better vascular plasticity [75]. The systematic search was also limited to the English language. However, no evidence of systematic bias from the use of language restrictions in meta-analyses was found [76]. Finally, possible presence of publication bias was found for intervention studies without a no-weight loss control group in the current meta-analysis. However, the Egger's weighted regression test only tended to reach statistical significance $(P=0.052)$ and the trim-and-fill correction analysis did not suggest that more studies were needed.

In summary, our meta-analysis in overweight and obese adults indicates that weight loss improves vascular function, as indicated by improvement of fasting FMD of the brachial artery. These effects were related to the amount of weight loss and change in waist circumference, rather than study duration. After stratification for weight loss, subgroup analyses suggested that effects may be larger when subjects received low-fat diets or weight-reduction regimens including exercise therapy or weight-loss medication. However, well-designed RCTs are still needed to investigate the true impact of these two treatment characteristics on the change in FMD. Finally, effects were more pronounced when participants had coexisting obesity-related morbidities.

\section{Acknowledgements}

The present study is funded by research grant $\mathrm{CH} 001$ from the $\mathrm{Tl}$ Food and Nutrition, a public-private partnership on precompetitive research in food and nutrition. The public partners are responsible for the study design, data collection and analysis, decision to publish, and preparation of the manuscript. The private partners have contributed to the project through regular discussion.

The authors' responsibilities were as follows; P.J.J.: designed the study and conducted the literature review, performed the statistical analyses, interpreted the data, and wrote the manuscript; M.P.Z.: performed the statistical analyses, 


\section{CHAPTER 4}

interpreted the data, and wrote the manuscript; and R.P.M.: designed the study and conducted the literature review, interpreted the data, had overall responsibility for the study, and wrote the manuscript. All authors read and approved the final manuscript. The authors have declared that no competing interests exist.

\section{Supplemental data}

Supplemental Checklist 4.1. The PRISMA statement checklist

\begin{tabular}{|c|c|c|c|}
\hline Section/topic & $\#$ & Checklist item & $\begin{array}{l}\text { Reported } \\
\text { on page \# }\end{array}$ \\
\hline \multicolumn{4}{|l|}{ 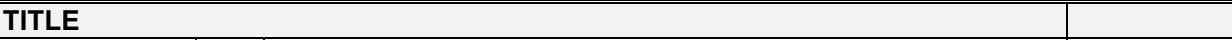 } \\
\hline Title & 1 & Identify the report as a systematic review, meta-analysis, or both. & Title page \\
\hline \multicolumn{4}{|l|}{ ABSTRACT } \\
\hline $\begin{array}{l}\text { Structured } \\
\text { summary }\end{array}$ & 2 & $\begin{array}{l}\text { Provide a structured summary including, as applicable: background; } \\
\text { objectives; data sources; study eligibility criteria, participants, and } \\
\text { interventions; study appraisal and synthesis methods; results; } \\
\text { limitations; conclusions and implications of key findings; systematic } \\
\text { review registration number. }\end{array}$ & Abstract \\
\hline \multicolumn{4}{|c|}{ INTRODUCTION } \\
\hline Rationale & 3 & $\begin{array}{l}\text { Describe the rationale for the review in the context of what is already } \\
\text { known. }\end{array}$ & Introduction \\
\hline Objectives & 4 & $\begin{array}{l}\text { Provide an explicit statement of questions being addressed with } \\
\text { reference to participants, interventions, comparisons, outcomes, and } \\
\text { study design (PICOS). }\end{array}$ & Introduction \\
\hline \multicolumn{4}{|l|}{ METHODS } \\
\hline $\begin{array}{l}\text { Protocol and } \\
\text { registration }\end{array}$ & 5 & $\begin{array}{l}\text { Indicate if a review protocol exists, if and where it can be accessed } \\
\text { (e.g., Web address), and, if available, provide registration information } \\
\text { including registration number. }\end{array}$ & - \\
\hline Eligibility criteria & 6 & $\begin{array}{l}\text { Specify study characteristics (e.g., PICOS, length of follow-up) and } \\
\text { report characteristics (e.g., years considered, language, publication } \\
\text { status) used as criteria for eligibility, giving rationale. }\end{array}$ & $\begin{array}{l}\text { Search } \\
\text { strategy }\end{array}$ \\
\hline $\begin{array}{l}\text { Information } \\
\text { sources }\end{array}$ & 7 & $\begin{array}{l}\text { Describe all information sources (e.g., databases with dates of } \\
\text { coverage, contact with study authors to identify additional studies) in } \\
\text { the search and date last searched. }\end{array}$ & $\begin{array}{l}\text { Search } \\
\text { strategy }\end{array}$ \\
\hline Search & 8 & $\begin{array}{l}\text { Present full electronic search strategy for at least one database, } \\
\text { including any limits used, such that it could be repeated. }\end{array}$ & $\begin{array}{l}\text { Search } \\
\text { strategy }\end{array}$ \\
\hline Study selection & 9 & $\begin{array}{l}\text { State the process for selecting studies (i.e., screening, eligibility, } \\
\text { included in systematic review, and, if applicable, included in the meta- } \\
\text { analysis). }\end{array}$ & $\begin{array}{l}\text { Selection } \\
\text { of trials }\end{array}$ \\
\hline $\begin{array}{l}\text { Data collection } \\
\text { process }\end{array}$ & 10 & $\begin{array}{l}\text { Describe method of data extraction from reports (e.g., piloted forms, } \\
\text { independently, in duplicate) and any processes for obtaining and } \\
\text { confirming data from investigators. }\end{array}$ & $\begin{array}{c}\text { Data } \\
\text { extraction }\end{array}$ \\
\hline Data items & 11 & $\begin{array}{l}\text { List and define all variables for which data were sought (e.g., PICOS, } \\
\text { funding sources) and any assumptions and simplifications made. }\end{array}$ & $\begin{array}{c}\text { Data } \\
\text { extraction }\end{array}$ \\
\hline $\begin{array}{l}\text { Risk of bias in } \\
\text { individual } \\
\text { studies }\end{array}$ & 12 & $\begin{array}{l}\text { Describe methods used for assessing risk of bias of individual studies } \\
\text { (including specification of whether this was done at the study or } \\
\text { outcome level), and how this information is to be used in any data } \\
\text { synthesis. }\end{array}$ & $\begin{array}{l}\text { Statistical } \\
\text { analysis }\end{array}$ \\
\hline $\begin{array}{l}\text { Summary } \\
\text { measures }\end{array}$ & 13 & $\begin{array}{l}\text { State the principal summary measures (e.g., risk ratio, difference in } \\
\text { means). }\end{array}$ & $\begin{array}{l}\text { Statistical } \\
\text { analysis }\end{array}$ \\
\hline $\begin{array}{l}\text { Synthesis of } \\
\text { results }\end{array}$ & 14 & $\begin{array}{l}\text { Describe the methods of handling data and combining results of } \\
\text { studies, if done, including measures of consistency }\left(\text { e.g., }\left.\right|^{2}\right) \text { for each } \\
\text { meta-analysis. }\end{array}$ & $\begin{array}{l}\text { Statistical } \\
\text { analysis }\end{array}$ \\
\hline
\end{tabular}


WEIGHT LOSS AND FLOW-MEDIATED VASODILATION

\begin{tabular}{|c|c|c|c|}
\hline Section/topic & $\#$ & Checklist item & $\begin{array}{l}\text { Reported on } \\
\text { page \# }\end{array}$ \\
\hline $\begin{array}{l}\text { Risk of bias } \\
\text { across studies }\end{array}$ & 15 & $\begin{array}{l}\text { Specify any assessment of risk of bias that may affect the } \\
\text { cumulative evidence (e.g., publication bias, selective reporting } \\
\text { within studies). }\end{array}$ & Statistical analysis \\
\hline $\begin{array}{l}\text { Additional } \\
\text { analyses }\end{array}$ & 16 & $\begin{array}{l}\text { Describe methods of additional analyses (e.g., sensitivity or } \\
\text { subgroup analyses, meta-regression), if done, indicating which } \\
\text { were pre-specified. }\end{array}$ & Statistical analysis \\
\hline \multicolumn{4}{|l|}{ RESULTS } \\
\hline Study selection & 17 & $\begin{array}{l}\text { Give numbers of studies screened, assessed for eligibility, and } \\
\text { included in the review, with reasons for exclusions at each stage, } \\
\text { ideally with a flow diagram. }\end{array}$ & $\begin{array}{l}\text { Search results } \\
\text { Suppl. Fig. } 4.1\end{array}$ \\
\hline $\begin{array}{l}\text { Study } \\
\text { characteristics }\end{array}$ & 18 & $\begin{array}{l}\text { For each study, present characteristics for which data were } \\
\text { extracted (e.g., study size, PICOS, follow-up period) and provide } \\
\text { the citations. }\end{array}$ & $\begin{array}{l}\text { Study } \\
\text { characteristics } \\
\text { Table } 4.1\end{array}$ \\
\hline $\begin{array}{l}\text { Risk of bias } \\
\text { within studies }\end{array}$ & 19 & $\begin{array}{l}\text { Present data on risk of bias of each study and, if available, any } \\
\text { outcome level assessment (see item 12). }\end{array}$ & $\begin{array}{c}\text { Effects on FMD } \\
\text { Fig. 4.1-4.2, Table } 4.1\end{array}$ \\
\hline $\begin{array}{l}\text { Results of } \\
\text { individual } \\
\text { studies }\end{array}$ & 20 & $\begin{array}{l}\text { For all outcomes considered (benefits or harms), present, for each } \\
\text { study: (a) simple summary data for each intervention group (b) } \\
\text { effect estimates and confidence intervals, ideally with a forest plot. }\end{array}$ & Fig. 4.1-4.2 \\
\hline $\begin{array}{l}\text { Synthesis of } \\
\text { results }\end{array}$ & 21 & $\begin{array}{l}\text { Present results of each meta-analysis done, including confidence } \\
\text { intervals and measures of consistency. }\end{array}$ & $\begin{array}{l}\text { Effects on FMD } \\
\text { Fig. 4.1-4.2 }\end{array}$ \\
\hline $\begin{array}{l}\text { Risk of bias } \\
\text { across studies }\end{array}$ & 22 & $\begin{array}{l}\text { Present results of any assessment of risk of bias across studies } \\
\text { (see Item 15). }\end{array}$ & $\begin{array}{l}\text { Publication bias } \\
\text { Suppl. Fig. } 4.3-4.4\end{array}$ \\
\hline $\begin{array}{l}\text { Additional } \\
\text { analysis }\end{array}$ & 23 & $\begin{array}{l}\text { Give results of additional analyses, if done (e.g., sensitivity or } \\
\text { subgroup analyses, meta-regression [see Item 16]). }\end{array}$ & $\begin{array}{l}\text { Effects on FMD } \\
\text { Subgroup analyses } \\
\text { Fig. } 4.3 \text {, Table } 4.2 \\
\text { Suppl. Fig. } 4.2\end{array}$ \\
\hline \multicolumn{4}{|l|}{ DISCUSSION } \\
\hline $\begin{array}{l}\text { Summary of } \\
\text { evidence }\end{array}$ & 24 & $\begin{array}{l}\text { Summarize the main findings including the strength of evidence for } \\
\text { each main outcome; consider their relevance to key groups (e.g., } \\
\text { healthcare providers, users, and policy makers). }\end{array}$ & Discussion \\
\hline Limitations & 25 & $\begin{array}{l}\text { Discuss limitations at study and outcome level (e.g., risk of bias), } \\
\text { and at review-level (e.g., incomplete retrieval of identified research, } \\
\text { reporting bias). }\end{array}$ & Discussion \\
\hline Conclusions & 26 & $\begin{array}{l}\text { Provide a general interpretation of the results in the context of } \\
\text { other evidence, and implications for future research. }\end{array}$ & Discussion \\
\hline \multicolumn{4}{|l|}{ FUNDING } \\
\hline Funding & 27 & $\begin{array}{l}\text { Describe sources of funding for the systematic review and other } \\
\text { support (e.g., supply of data); role of funders for the systematic } \\
\text { review. }\end{array}$ & Acknowledgements \\
\hline
\end{tabular}




\section{CHAPTER 4}

Potentially relevant papers retrieved with the literature search or by hand searching

Studies $n=1120$
Studies excluded due to following reasons:

- No intervention study $(n=521)$

- No adults $(n=221)$

- No FMD measures reported $(n=73)$

- No suitable intervention $(n=258)$

- Double references $(n=3)$
Potentially relevant human intervention studies after first selection

Studies $n=44$
Studies excluded due to following reasons:

- Missing FMD data $(\mathrm{n}=2)$

- No suitable intervention $(n=5)$
Human intervention studies included in the meta-analysis

Studies $\mathrm{n}=37$

Supplemental Figure 4.1. Flow diagram showing the study selection procedure of human intervention studies for the meta-analysis of weight loss and endothelial function as measured by flow-mediated vasodilation (FMD), with the specification of reasons.

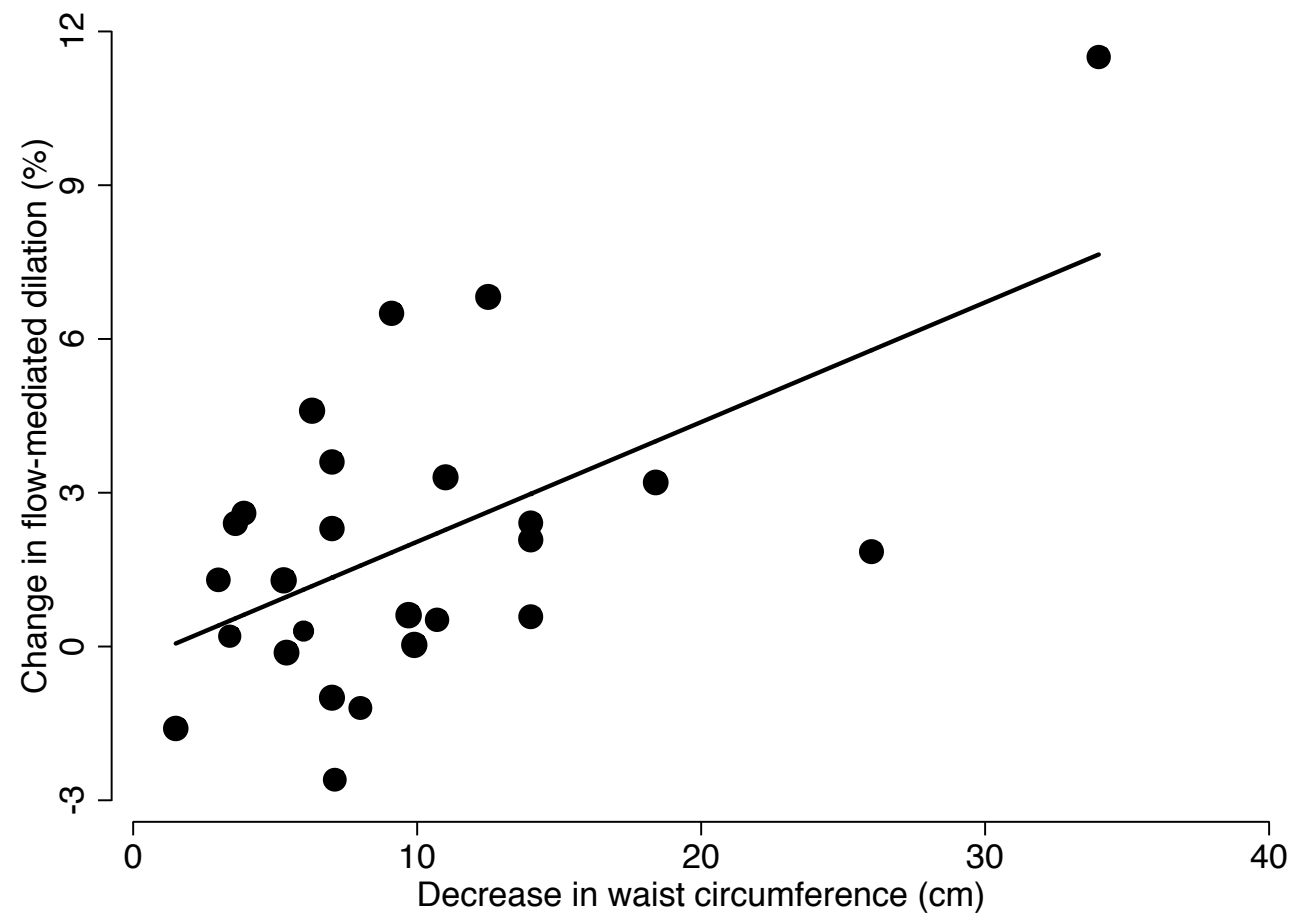

Supplemental Figure 4.2. Relationship between the change in FMD and the decrease in waist circumference. The size of each circle is proportional to the inverse of the variance of the change in FMD, and the line represents the regression line determined by meta-regression analysis. Each $5 \mathrm{~cm}$ decrease in waist circumference was associated with a significant increase of $1.17 \%$ in fasting FMD of the brachial artery. 


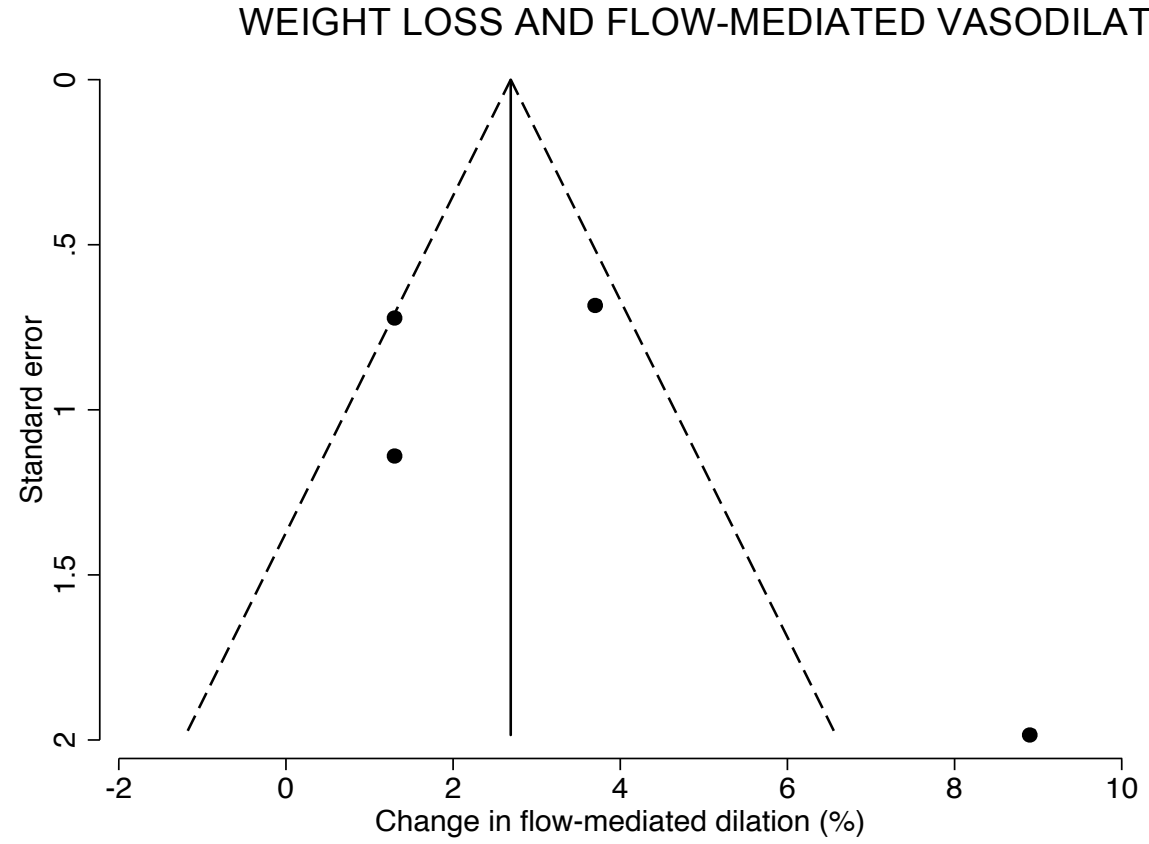

Supplemental Figure 4.3. Funnel plot for the effect of weight loss on flow-mediated vasodilation (FMD) in random controlled trials (RCTs) including a no-weight loss control group. Changes in FMD were plotted on the horizontal axis and the standard errors (s.e.) on the vertical axis. Visual evaluation of the funnel plot did not indicate presence of publication bias.

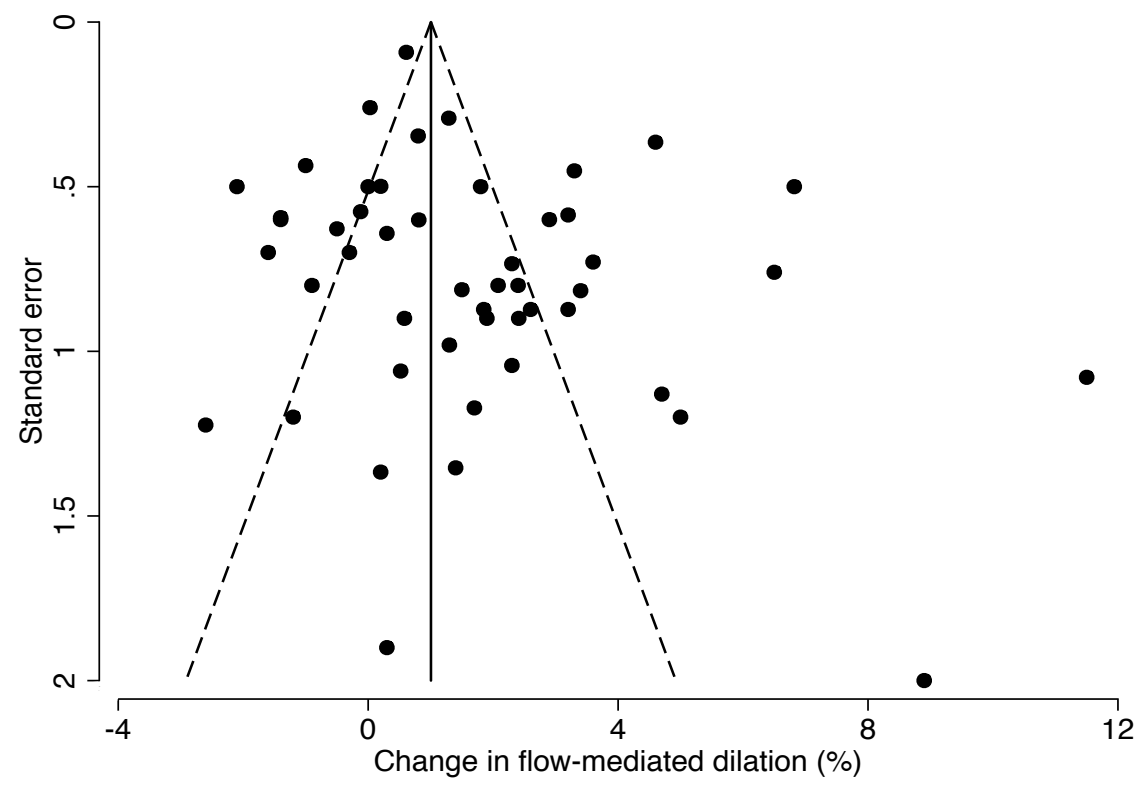

Supplemental Figure 4.4. Funnel plot for the effect of weight loss on flow-mediated vasodilation (FMD) in studies with experimental or quasi-experimental designs without a no-weight loss control group. Changes in FMD were plotted on the horizontal axis and the standard errors (s.e.) on the vertical axis. Visual evaluation of the funnel plot did indicate presence of publication bias. 


\section{CHAPTER 4}

\section{References}

1. Schachinger V, Britten MB, Zeiher AM. Prognostic impact of coronary vasodilator dysfunction on adverse long-term outcome of coronary heart disease. Circulation 2000;101:1899-906.

2. Van Gaal LF, Mertens IL, De Block CE. Mechanisms linking obesity with cardiovascular disease. Nature 2006;444:875-80.

3. Al Suwaidi J, Higano ST, Hamasaki S, Holmes DR, Lerman A. Association between obesity and coronary atherosclerosis and vascular remodeling. Am J Cardiol 2001;88:1300-3.

4. Arcaro G, Zamboni M, Rossi L, Turcato E, Covi G, Armellini F, et al. Body fat distribution predicts the degree of endothelial dysfunction in uncomplicated obesity. Int $\mathrm{J}$ Obes Relat Metab Disord 1999;23:936-42.

5. Brook RD, Bard RL, Rubenfire M, Ridker PM, Rajagopalan S. Usefulness of visceral obesity (waist/hip ratio) in predicting vascular endothelial function in healthy overweight adults. Am J Cardiol 2001;88:1264-9.

6. Fornoni A, Raij L. Metabolic syndrome and endothelial dysfunction. Curr Hypertens Rep 2005;7:88-95.

7. Ritchie SA, Ewart MA, Perry CG, Connell JM, Salt IP. The role of insulin and the adipocytokines in regulation of vascular endothelial function. Clin Sci (Lond) 2004;107:51932.

8. Brook RD. Obesity, weight loss, and vascular function. Endocrine 2006;29:21-5.

9. Kerr SM, Livingstone MB, McCrorie TA, Wallace JM. Endothelial dysfunction associated with obesity and the effect of weight loss interventions. Proc Nutr Soc 2011;70:418-25.

10. Ellins EA, Halcox JP. Where are we heading with noninvasive clinical vascular physiology? Why and how should we assess endothelial function? Cardiol Res Pract 2011;2011:870132.

11. Donald AE, Charakida M, Cole TJ, Friberg P, Chowienczyk PJ, Millasseau SC, et al. Noninvasive assessment of endothelial function: which technique? J Am Coll Cardiol 2006;48:1846-50.

12. Cochran WG. The combinations of estiamtes from different experiments. Biometrics 1954;10:101-29.

13. DerSimonian R, Laird N. Meta-analysis in clinical trials. Control Clin Trials 1986;7:177-88.

14. Higgins JP, Thompson SG. Quantifying heterogeneity in a meta-analysis. Stat Med 2002;21:1539-58.

15. Higgins JP, Thompson SG, Deeks JJ, Altman DG. Measuring inconsistency in metaanalyses. BMJ 2003;327:557-60.

16. Hu T, Mills KT, Yao L, Demanelis K, Eloustaz M, Yancy WS, Jr., et al. Effects of lowcarbohydrate diets versus low-fat diets on metabolic risk factors: a meta-analysis of randomized controlled clinical trials. Am J Epidemiol 2012;176:S44-54.

17. Egger M, Davey SG, Schneider M, Minder C. Bias in meta-analysis detected by a simple, graphical test. BMJ 1997;315:629-34.

18. Duval S, Tweedie R. Trim and fill: a simple funnel-plot-based method of testing and adjusting for publication bias in meta-analysis. Biometrics 2000;56:455-63.

19. Pontiroli AE, Pizzocri P, Paroni R, Folli F. Sympathetic overactivity, endothelial dysfunction, inflammation, and metabolic abnormalities cluster in grade III (World Health Organization) obesity: reversal through sustained weight loss obtained with laparoscopic adjustable gastric banding. Diabetes Care 2006;29:2735-8.

20. Williams IL, Chowienczyk PJ, Wheatcroft SB, Patel AG, Sherwood RA, Momin A, et al. Endothelial function and weight loss in obese humans. Obes Surg 2005;15:1055-60.

21. Bemelmans RH, Coll B, Faber DR, Westerink J, Blommaert PP, Spiering W, et al. Vascular and metabolic effects of 12 days intensive walking to Santiago de Compostela. Atherosclerosis 2010;212:621-7. 


\section{WEIGHT LOSS AND FLOW-MEDIATED VASODILATION}

22. Fuentes F, Lopez-Miranda J, Sanchez E, Sanchez F, Paez J, Paz-Rojas E, et al. Mediterranean and low-fat diets improve endothelial function in hypercholesterolemic men. Ann Intern Med 2001;134:1115-9.

23. Miyazaki S, Hiasa Y, Takahashi T, Tobetto Y, Chen H, Mahara K, et al. Waist circumference reduction is more strongly correlated with the improvement in endothelial function after acute coronary syndrome than body mass index reduction. J Cardiol 2010;55:266-73.

24. Rallidis LS, Lekakis J, Kolomvotsou A, Zampelas A, Vamvakou G, Efstathiou S, et al. Close adherence to a Mediterranean diet improves endothelial function in subjects with abdominal obesity. Am J Clin Nutr 2009;90:263-8.

25. Thomazella MC, Goes MF, Andrade CR, Debbas V, Barbeiro DF, Correia RL, et al. Effects of high adherence to mediterranean or low-fat diets in medicated secondary prevention patients. Am J Cardiol 2011;108:1523-9.

26. Blumenthal JA, Babyak MA, Hinderliter A, Watkins LL, Craighead L, Lin PH, et al. Effects of the DASH diet alone and in combination with exercise and weight loss on blood pressure and cardiovascular biomarkers in men and women with high blood pressure: the ENCORE study. Arch Intern Med 2010;170:126-35.

27. Dod HS, Bhardwaj R, Sajja V, Weidner G, Hobbs GR, Konat GW, et al. Effect of intensive lifestyle changes on endothelial function and on inflammatory markers of atherosclerosis. Am J Cardiol 2010;105:362-7.

28. Pierce GL, Beske SD, Lawson BR, Southall KL, Benay FJ, Donato AJ, et al. Weight loss alone improves conduit and resistance artery endothelial function in young and older overweight/obese adults. Hypertension 2008;52:72-9.

29. Shechter M, Beigel R, Freimark D, Matetzky S, Feinberg MS. Short-term sibutramine therapy is associated with weight loss and improved endothelial function in obese patients with coronary artery disease. Am J Cardiol 2006;97:1650-3.

30. Ades PA, Savage PD, Lischke S, Toth MJ, Harvey-Berino J, Bunn JY, et al. The effect of weight loss and exercise training on flow-mediated dilatation in coronary heart disease: a randomized trial. Chest 2011;140:1420-7.

31. Angelico F, Loffredo L, Pignatelli P, Augelletti T, Carnevale R, Pacella A, et al. Weight loss is associated with improved endothelial dysfunction via NOX2-generated oxidative stress down-regulation in patients with the metabolic syndrome. Intern Emerg Med 2012;7:219-27.

32. Bigornia SJ, Farb MG, Tiwari S, Karki S, Hamburg NM, Vita JA, et al. Insulin status and vascular responses to weight loss in obesity. J Am Coll Cardiol 2013;62:2297-305.

33. Bigornia SJ, Mott MM, Hess DT, Apovian CM, McDonnell ME, Duess MA, et al. Long-term successful weight loss improves vascular endothelial function in severely obese individuals. Obesity (Silver Spring) 2010;18:754-9.

34. Brethauer SA, Heneghan HM, Eldar S, Gatmaitan P, Huang H, Kashyap S, et al. Early effects of gastric bypass on endothelial function, inflammation, and cardiovascular risk in obese patients. Surg Endosc 2011;25:2650-9.

35. Brook RD, Bard RL, Glazewski L, Kehrer C, Bodary PF, Eitzman DL, et al. Effect of shortterm weight loss on the metabolic syndrome and conduit vascular endothelial function in overweight adults. Am J Cardiol 2004;93:1012-6.

36. Buscemi S, Cosentino L, Rosafio G, Morgana M, Mattina A, Sprini D, et al. Effects of hypocaloric diets with different glycemic indexes on endothelial function and glycemic variability in overweight and in obese adult patients at increased cardiovascular risk. Clin Nutr 2013;32:346-52.

37. Buscemi S, Verga S, Tranchina MR, Cottone S, Cerasola G. Effects of hypocaloric verylow-carbohydrate diet vs. Mediterranean diet on endothelial function in obese women. Eur J Clin Invest 2009;39:339-47.

38. Clifton PM, Keogh JB, Foster PR, Noakes M. Effect of weight loss on inflammatory and endothelial markers and FMD using two low-fat diets. Int J Obes (Lond) 2005;29:1445-51. 


\section{CHAPTER 4}

39. Cotie LM, Josse AR, Phillips SM, MacDonald MJ. Endothelial function increases after a 16week diet and exercise intervention in overweight and obese young women. Biomed Res Int 2014;2014:327395.

40. Dengel DR, Kelly AS, Olson TP, Kaiser DR, Dengel JL, Bank AJ. Effects of weight loss on insulin sensitivity and arterial stiffness in overweight adults. Metabolism 2006;55:907-11.

41. Fayh AP, Lopes AL, da Silva AM, Reischak-Oliveira A, Friedman R. Effects of $5 \%$ weight loss through diet or diet plus exercise on cardiovascular parameters of obese: a randomized clinical trial. Eur J Nutr 2013;52:1443-50.

42. Gokce N, Vita JA, McDonnell M, Forse AR, Istfan N, Stoeckl M, et al. Effect of medical and surgical weight loss on endothelial vasomotor function in obese patients. Am J Cardiol 2005;95:266-8.

43. Habib P, Scrocco JD, Terek M, Vanek V, Mikolich JR. Effects of bariatric surgery on inflammatory, functional and structural markers of coronary atherosclerosis. Am J Cardiol 2009;104:1251-5.

44. Hamdy O, Ledbury S, Mullooly C, Jarema C, Porter S, Ovalle K, et al. Lifestyle modification improves endothelial function in obese subjects with the insulin resistance syndrome. Diabetes Care 2003;26:2119-25.

45. Keogh JB, Brinkworth GD, Clifton PM. Effects of weight loss on a low-carbohydrate diet on flow-mediated dilatation, adhesion molecules and adiponectin. Br J Nutr 2007;98:852-9.

46. Keogh JB, Brinkworth GD, Noakes M, Belobrajdic DP, Buckley JD, Clifton PM. Effects of weight loss from a very-low-carbohydrate diet on endothelial function and markers of cardiovascular disease risk in subjects with abdominal obesity. Am J Clin Nutr 2008;87:56776.

47. Khoo J, Piantadosi C, Duncan R, Worthley SG, Jenkins A, Noakes M, et al. Comparing effects of a low-energy diet and a high-protein low-fat diet on sexual and endothelial function, urinary tract symptoms, and inflammation in obese diabetic men. J Sex Med 2011;8:2868-75.

48. Lind L, Zethelius B, Sundbom M, Eden Engstrom B, Karlsson FA. Vasoreactivity is rapidly improved in obese subjects after gastric bypass surgery. Int J Obes (Lond) 2009;33:1390-5.

49. Liu J, Sun N, Yang S, Ma Z, Yang J. Effect of orlistat-assisted weight loss on endotheliumdependent vasodilation in obese Chinese subjects with hypertension. Clin Exp Hypertens 2010;32:395-9.

50. Mavri A, Poredos P, Suran D, Gaborit B, Juhan-Vague I, Poredos P. Effect of diet-induced weight loss on endothelial dysfunction: early improvement after the first week of dieting. Heart Vessels 2011;26:31-8.

51. Mohler ER, 3rd, Sibley AA, Stein R, Davila-Roman V, Wyatt H, Badellino K, et al. Endothelial function and weight loss: comparison of low-carbohydrate and low-fat diets. Obesity (Silver Spring) 2013;21:504-9.

52. Nagamia S, Pandian A, Cheema F, Natarajan R, Khan QA, Patel AD, et al. The role of quinapril in the presence of a weight loss regimen: endothelial function and markers of obesity in patients with the metabolic syndrome. Prev Cardiol 2007;10:204-9.

53. Phillips SA, Jurva JW, Syed AQ, Syed AQ, Kulinski JP, Pleuss J, et al. Benefit of low-fat over low-carbohydrate diet on endothelial health in obesity. Hypertension 2008;51:376-82.

54. Raitakari M, Ilvonen T, Ahotupa M, Lehtimaki T, Harmoinen A, Suominen P, et al. Weight reduction with very-low-caloric diet and endothelial function in overweight adults: role of plasma glucose. Arterioscler Thromb Vasc Biol 2004;24:124-8.

55. Rittig K, Hieronimus A, Thamer C, Machann J, Peter A, Stock J, et al. Reducing visceral adipose tissue mass is essential for improving endothelial function in type 2 diabetes prone individuals. Atherosclerosis 2010;212:575-9.

56. Saleh MH, Bertolami MC, Assef JE, Taha MI, de Freitas W, Jr., Petisco AC, et al. Improvement of atherosclerotic markers in non-diabetic patients after bariatric surgery. Obes Surg 2012;22:1701-7. 


\section{WEIGHT LOSS AND FLOW-MEDIATED VASODILATION}

57. Seligman BG, Polanczyk CA, Santos AS, Foppa M, Junges M, Bonzanini L, et al. Intensive practical lifestyle intervention improves endothelial function in metabolic syndrome independent of weight loss: a randomized controlled trial. Metabolism 2011;60:1736-40.

58. Skilton MR, Sieveking DP, Harmer JA, Franklin J, Loughnan G, Nakhla S, et al. The effects of obesity and non-pharmacological weight loss on vascular and ventricular function and structure. Diabetes Obes Metab 2008;10:874-84.

59. Sturm W, Tschoner A, Engl J, Kaser S, Laimer M, Ciardi C, et al. Effect of bariatric surgery on both functional and structural measures of premature atherosclerosis. Eur Heart $\mathrm{J}$ 2009;30:2038-43.

60. Varady KA, Bhutani S, Klempel MC, Phillips SA. Improvements in vascular health by a lowfat diet, but not a high-fat diet, are mediated by changes in adipocyte biology. Nutr $\mathrm{J}$ 2011;10:8.

61. Wycherley TP, Brinkworth GD, Keogh JB, Noakes M, Buckley JD, Clifton PM. Long-term effects of weight loss with a very low carbohydrate and low fat diet on vascular function in overweight and obese patients. J Intern Med 2010;267:452-61.

62. Wycherley TP, Brinkworth GD, Noakes M, Buckley JD, Clifton PM. Effect of caloric restriction with and without exercise training on oxidative stress and endothelial function in obese subjects with type 2 diabetes. Diabetes Obes Metab 2008;10:1062-73.

63. Ras RT, Streppel MT, Draijer R, Zock PL. Flow-mediated dilation and cardiovascular risk prediction: a systematic review with meta-analysis. Int J Cardiol 2013;168:344-51.

64. Gu P, Xu AM. Interplay between adipose tissue and blood vessels in obesity and vascular dysfunction. Rev Endocr Metab Disord 2013;14:49-58.

65. Shoelson SE, Lee J, Goldfine AB. Inflammation and insulin resistance. J Clin Invest 2006;116:1793-801.

66. Solini A, Stea F, Santini E, Bruno RM, Duranti E, Taddei S, et al. Adipocytokine levels mark endothelial function in normotensive individuals. Cardiovasc Diabetol 2012;11:103.

67. Furukawa S, Fujita T, Shimabukuro M, Iwaki M, Yamada Y, Nakajima Y, et al. Increased oxidative stress in obesity and its impact on metabolic syndrome. J Clin Invest 2004;114:1752-61.

68. Loffredo L, Marcoccia A, Pignatelli P, Andreozzi P, Borgia MC, Cangemi R, et al. Oxidativestress-mediated arterial dysfunction in patients with peripheral arterial disease. Eur Heart $\mathrm{J}$ 2007;28:608-12.

69. Kershaw EE, Flier JS. Adipose tissue as an endocrine organ. J Clin Endocrinol Metab 2004;89:2548-56.

70. Beijers HJ, Ferreira I, Bravenboer B, Henry RM, Schalkwijk CG, Dekker JM, et al. Higher central fat mass and lower peripheral lean mass are independent determinants of endothelial dysfunction in the elderly: the Hoorn study. Atherosclerosis 2014;233:310-8.

71. Green DJ, Maiorana A, O'Driscoll G, Taylor R. Effect of exercise training on endotheliumderived nitric oxide function in humans. J Physiol 2004;561:1-25.

72. Laughlin MH, Newcomer SC, Bender SB. Importance of hemodynamic forces as signals for exercise-induced changes in endothelial cell phenotype. J Appl Physiol 2008;104:588-600.

73. Schwingshackl L, Hoffmann G. Low-carbohydrate diets impair flow-mediated dilatation: evidence from a systematic review and meta-analysis. Br J Nutr 2013;110:969-70.

74. Thijssen DH, Black MA, Pyke KE, Padilla J, Atkinson G, Harris RA, et al. Assessment of flow-mediated dilation in humans: a methodological and physiological guideline. Am J Physiol Heart Circ Physiol 2011;300:H2-12.

75. Montero D, Walther G, Perez-Martin A, Roche E, Vinet A. Endothelial dysfunction, inflammation, and oxidative stress in obese children and adolescents: markers and effect of lifestyle intervention. Obes Rev 2012;13:441-55.

76. Morrison A, Polisena J, Husereau D, Moulton K, Clark M, Fiander M, et al. The effect of English-language restriction on systematic review-based meta-analyses: a systematic review of empirical studies. Int J Technol Assess Health Care 2012;28:138-44. 



\section{CHAPTER 5}

Effects of supplementation with the fat-soluble vitamins $E$ and $D$ on fasting flow-mediated vasodilation in adults: A meta-analysis of randomized controlled trials

Peter J. Joris and Ronald P. Mensink

Nutrients 2015; 7: 1728-1743 


\title{
CHAPTER 5
}

\begin{abstract}
The effects of fat-soluble vitamin supplementation on cardiovascular disease (CVD) risk are not clear. Therefore, we performed a meta-analysis to quantify effects of fat-soluble vitamin supplements on fasting flow-mediated vasodilation (FMD) of the brachial artery, a validated marker to assess CVD risk. Randomized placebo-controlled trials (RCTs) were identified by a systematic search till July 2014. Seven RCTs studying the effects of vitamin E supplements (range: 300 to 1800 IU per day) and nine RCTs examining the effects of vitamin D supplements, that involved, respectively, 303 and 658 adults, were included. No studies with carotenoid or vitamin $\mathrm{K}$ supplements were found. Vitamin $\mathrm{E}$ supplementation increased FMD vs. control by $2.42 \%(95 \% \mathrm{Cl}: 0.46 \%$ to $4.37 \% ; P=0.015)$. No effects of vitamin D supplementation were found $(0.15 \% ; 95 \% \mathrm{Cl}$ : $-0.21 \%$ to $0.51 \% ; P=0.41)$. These effects did not depend on subject characteristics, treatment characteristics or technical aspects of the FMD measurement. However, no dose-response relationship was evident for vitamin $E$, statistical significance depended on one study, while the levels of supplement were far above recommended intakes. The current meta-analysis, therefore, does not provide unambiguous evidence to support the use of fat-soluble vitamin supplements to improve fasting FMD in adults.
\end{abstract}




\section{Introduction}

Observational studies have found inverse associations between the use of fatsoluble vitamin supplements and cardiovascular disease (CVD) risk. However, data from intervention trials are in general disappointing, while for some of the fatsoluble vitamins hardly any data are available [1]. Alternatively, effects of these essential micronutrients on validated markers of CVD, such as vascular function markers can be studied [2]. Measurements of vascular endothelial function, which is a powerful predictor of atherosclerotic disease progression and cardiovascular event rates [3], may indeed be useful to demonstrate CVD benefits [4]. Unfortunately, results of studies on the effects of fat-soluble vitamin supplementation on flow-mediated vasodilation (FMD) of the brachial artery, which is considered as the non-invasive gold standard technique to assess vascular endothelial function [5], were not consistent.

Several papers have therefore summarized the results for vitamin $E$ and vitamin D. Montero and colleagues concluded that longer-term antioxidant vitamin supplementation could improve endothelial function in non-obese adults [6], but (i) only studies involving subjects with type II diabetes were included and (ii) effects of vitamin $\mathrm{E}$ could not be untangled from the known positive relationship between vitamin C and endothelial function [7]. Further, Min [8] and Liu et al. [9] reviewed clinical studies focusing on vitamin $D$ supplementation and endothelial function, but results were equivocal. Also, quantitative estimates of effect sizes were lacking [8, 9] and results of several relevant clinical trials were not included [8]. We therefore performed a meta-analysis of randomized placebo-controlled trials (RCTs) on the effects of fat-soluble vitamin supplementation on fasting FMD in adults. Further, the impact of (i) subject characteristics; (ii) treatment characteristics; and (iii) technical aspects of the FMD measurement on the effects observed on FMD was examined.

\section{Experimental section}

The present meta-analysis was reported according to the Preferred Reporting Items for Systematic reviews and Meta-Analyses (PRISMA) guidelines [10].

\section{Search strategy}

Potentially relevant studies were identified by a systematic search of Medline, Embase and the Cochrane Library database (Cochrane Central Register of Clinical Trials) till July 2014. The following search terms were used to search in titles and abstracts: (vitamin or supplement or calciferol or tocopherol or tocotrienol or retinol or carotenoid or carotene) and (flow mediated vasodilation (or vasodilatation or dilation or dilatation) or endothelial (or endothelium) dependent vasodilation (or vasodilatation or dilation or dilatation) or endothelial (or endothelium) function (or dysfunction) or FMD or vascular reactivity or brachial artery). The search was limited to studies in humans and to the English language. Reference lists from the selected articles were also screened manually for potentially relevant publications. 


\section{CHAPTER 5}

\section{Selection of trials}

Randomized placebo-controlled trials, which investigated the relationship between fat-soluble vitamin supplementation and fasting FMD of the brachial artery with parallel and crossover designs, were selected.

The selection was performed in two steps. First, titles and abstracts were screened. Studies were selected if they met the following inclusion criteria: human intervention study with adults, intervention with fat-soluble vitamin supplements as experimental variable, no intentional co-intervention that made it impossible to estimate the effect of fat-soluble vitamin supplementation, and assessment of fasting vascular endothelial function by measuring FMD. In the second step, fulltexts of the selected articles were read and studies were excluded based on the following criteria: no full text available (conference abstracts), missing data on FMD, no appropriate measures of variability reported, intentional co-intervention and no suitable placebo control treatment (prospective cohort studies). Both authors (Peter J. Joris and Ronald P. Mensink) completed the systematic literature search independently. When inconclusive, eligibility was discussed until consensus was reached.

\section{Data extraction}

For each of the selected studies, data were extracted using a custom-made database including identification of the study (first author's name and year of publication), study design (parallel or crossover), subject characteristics (sample size, age, gender, body mass index (BMI), baseline FMD level, and health status), treatment characteristics (type of vitamin supplements, total supplement dose and duration of follow-up), technical aspects of the FMD measurement (position of cuff and time of occlusion) and FMD values with accompanying measures of variance. For vitamin $\mathrm{E}$, doses in mg were transformed into international units (IU) [11].

\section{Statistical analysis}

Statistical analyses were performed using Stata 12.1 software (Stata Corporation, College Station, TX, USA). The FMD response was quantified as the maximal percentage change in post occlusion arterial diameter relative to baseline diameter, which is the diameter of the brachial artery before the introduction of a flow stimulus in the artery. The post occlusion arterial diameter is the diameter observed within minutes of reperfusion following the release of an inflated cuff.

For crossover trials, the net response in FMD was calculated by subtracting the mean FMD value at the end of the control period from the mean FMD value at the end of the treatment period. For parallel studies, mean changes in the control group were subtracted from mean changes in the intervention group. Mean changes were defined as the difference between measurements before (start-of-the-study values) and after the study (end-of-the-study values). For trials in which different doses of vitamin supplements were supplied or that performed FMD measurements more than one time during the study, multiple study arms were considered. 
As described in [12], summary estimates of weighted mean differences (WMDs) in FMD and $95 \%$ confidence intervals (Cls) were calculated using fixed-effect metaanalyses and visualized using forest plots. The inverse of the variance $\left(1 / \mathrm{SE}^{2}\right)$ (SE $=$ within-study variance) was used as weight factor. Heterogeneity was evaluated using the Cochran's $Q$ test $(P<0.1$ indicates statistical significant heterogeneity) and quantified using the $I^{2}$ statistic [13-15], i.e., the percentage of variability in effect estimate that is due to heterogeneity rather than sampling error. An $I^{2}$ value above $50 \%$ indicates relevant heterogeneity between studies [16]. In case of heterogeneity, random-effect meta-analyses were used as described by DerSimonian and Laird [14].

As it was evident that the type of vitamin supplement was an important source of heterogeneity, first a vitamin $E$ and a vitamin $D$ group were defined. Subgroup analyses were performed within each vitamin group to identify sources of heterogeneity between studies by comparing the summary results of the study arms grouped by subject characteristics (i.e., mean age, gender, baseline BMI, baseline FMD level and health status), treatment characteristics (i.e., type of vitamin supplement, total supplement dose and duration of follow-up) and technical aspects of the FMD measurement (position of cuff and time of occlusion). Median values of continuous variables were used as cutoff values to create the binary variables. Univariate meta-regression analysis was performed to investigate the effect of the dose of the vitamin supplement and other characteristics on the change in FMD. For all statistical analyses, two-sided tests were used. Statistical significance was set at $P<0.05$. Publication bias was finally evaluated visually by inspecting the symmetry of funnel plots. The degree of funnel plot asymmetry was assessed with the Egger's weighted regression test. Absence of publication bias is reflected in an intercept close to 0 with a corresponding $P \geq 0.05$ [17].

\section{Results}

Search results and study selection

A total of 1001 potentially relevant papers were retrieved with the systematic search. Based on the predefined selection criteria, 967 papers were excluded for different reasons [Figure 5.1]. The full texts of the remaining 34 articles were reviewed and eighteen papers were excluded for the following reasons: prospective cohort studies [18-22], missing data on FMD [23-27], no appropriate measures of variability reported [18], intentional co-intervention [28-30], or no full text available (five conference abstracts). A total of sixteen RCTs in adult volunteers with parallel [31-45] or crossover designs [46] met all the inclusion criteria and were finally included [Table 5.1]. In seven studies, effects of vitamin E $[31,32,35,37-39,46]$ were examined and in nine studies, those of vitamin $D[33$, $34,36,40-45]$. No intervention studies were found that examined the effects of carotenoid or vitamin $\mathrm{K}$ supplements.

\section{Study characteristics}

In six parallel studies [31,32, 35, 37-39] and in one crossover [46] trial, effects of vitamin E were examined. These studies provided eight relevant study arms and 


\section{CHAPTER 5}

included 303 subjects. The number of subjects per study ranged from 20 to 70 , the mean age of the participants from 23.0 to 59.8 years, and the mean BMI from 23.1 to $29.2 \mathrm{~kg} / \mathrm{m}^{2}$. The mean baseline FMD was $4.40 \%$ (range: $1.83 \%$ to $6.20 \%$ ). Two studies included only men $[31,37]$, whereas the proportion of men in the remaining studies ranged from $40.0 \%$ to $60.0 \%$. In two studies, healthy elderly [46] or healthy smoking adults [37] were included, in three studies patients with diabetes [32, 38, 39], whereas in two studies subjects had hypercholesterolemia [31] or atypical chest pain [35]. Study duration varied between four weeks and twelve months, and the daily dose of vitamin E from 300 to 1800 IU (mean: 1090 IU/day; Table 5.1).

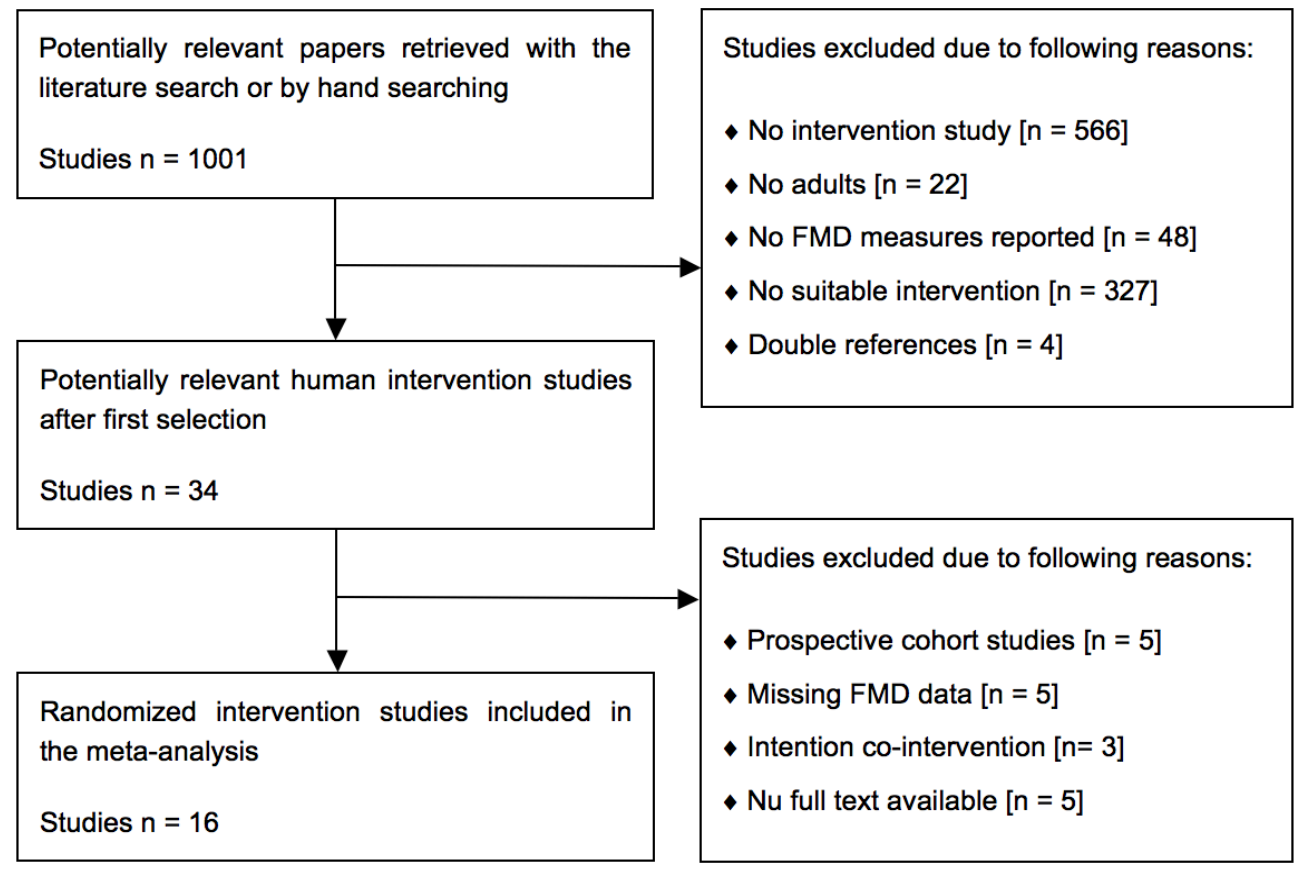

Figure 5.1. Flow diagram showing the study selection procedure of human intervention studies for the meta-analysis of fat-soluble vitamin supplements and endothelial function as measured by flowmediated vasodilation (FMD), with the specification of reasons.

For vitamin D, nine RCTs with parallel designs [33, 34, 36, 40-45] were identified including fifteen study arms. In these studies, 658 subjects participated, 345 in the treatment groups and 313 in the control groups. The mean age of the subjects was 59.8 years (range: 29.0 to 76.9 years), BMI was $28.4 \mathrm{~kg} / \mathrm{m}^{2}$ (range: 24.9 to 31.7 $\mathrm{kg} / \mathrm{m}^{2}$ ), and half of the study population was men. In three studies, healthy women $[33,41]$ or African American adults [34] were included; the other studies included subjects with type II diabetes [40, 42, 45], isolated systolic hypertension [44], HIV infection [36], or a history of stroke [43]. In two trials [40, 43], a single dose of 100,000 IU of vitamin D2 was administered. The dose of the vitamin D3 supplement in the other trials ranged from 2000 to $5000 \mathrm{IU} /$ day [33, 34, 36, 45], or subjects received a total of 100,000 to 200,000 IU once or every three months [41, $42,44]$. Study duration ranged from four weeks to twelve months (Table 5.1). 


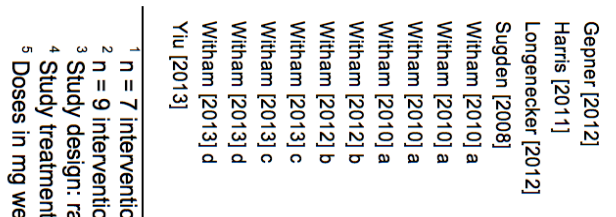

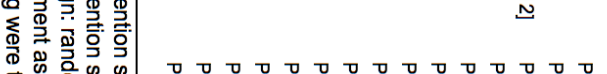

$\stackrel{1}{\circ}$ के 응 @

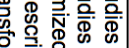

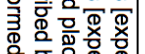

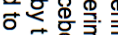

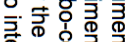

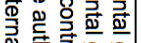

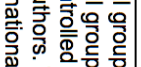

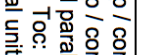

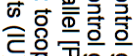

드윰 꾸음

ㅇㅠㅇㅀㅡ으옹응 든

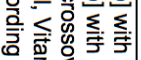

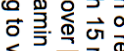

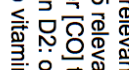

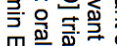

잉

变这

스으

듬

零

굴

గైల్

๙

옹 응

응 홍

음 음

雷

实

จุ๊

3

宾

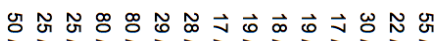
पं

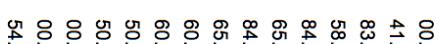

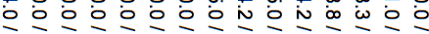

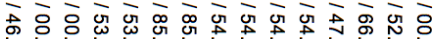

요료

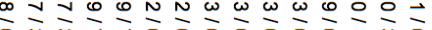

i

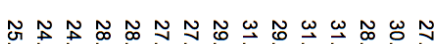

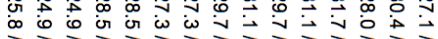

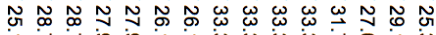

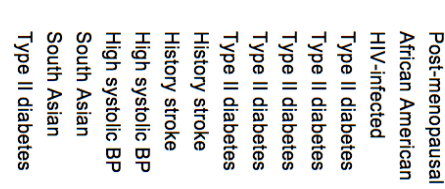

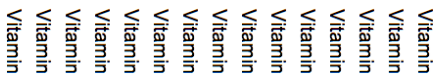

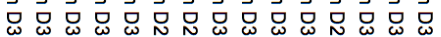

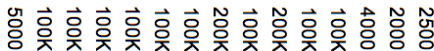

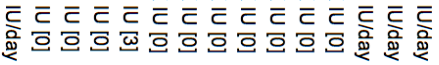

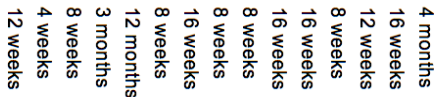

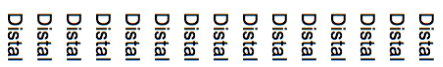

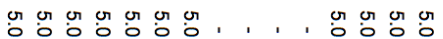
곡 콕 콕 콕 콕 콕 콕

곡 $\frac{3}{5}$ 곡

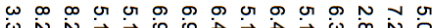

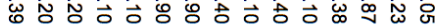
के कo or or or जr or or or or

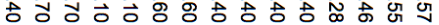

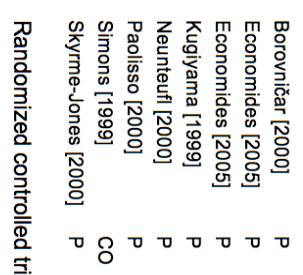

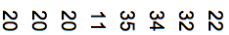
N. $\bar{N} \equiv \bar{\omega} \bar{\omega} \stackrel{\omega}{\omega}$

से जि

N

0 O $\omega$

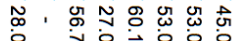

ก

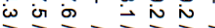
N, N , N

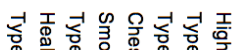

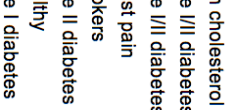
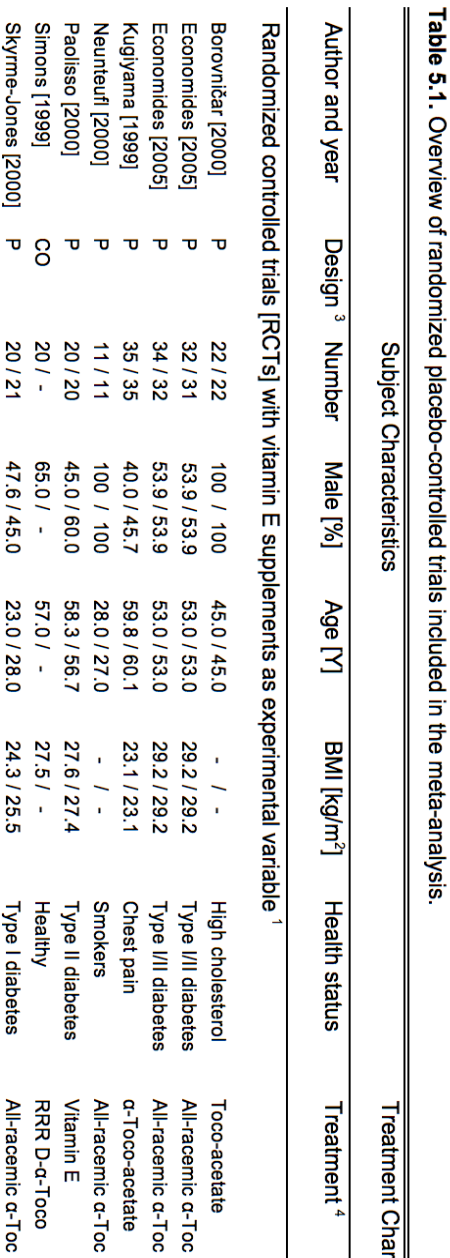

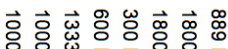

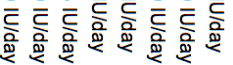

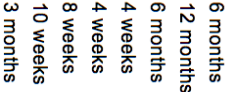

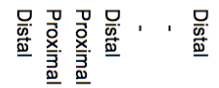

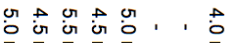
콕 콕 콕 콕 콕 곡

$N \stackrel{N}{N}$ or or or o

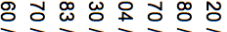
Nं इ के ज़ ज़ ज़

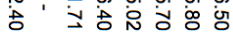




\section{CHAPTER 5}

\section{Effect of vitamin supplementation on FMD}

Vitamin E supplementation increased fasting FMD vs. control by $2.42 \%(95 \% \mathrm{Cl}$ : $0.46 \%$ to $4.37 \% ; P=0.015$ ) [Figure 5.2], corresponding to a relative increase of approximately $50 \%$ compared with baseline FMD values. However, significant heterogeneity was found $\left(I^{2}=92.0 \%, P<0.001\right)$. Results of the meta-regression analysis showed no linear dose-response relationship between the dose of the vitamin E supplement and the change in FMD $(P=0.774$; Supplemental Figure 5.1). Analyses were repeated after excluding the study of Paolisso and colleagues [38], which had the most pronounced effect (10.5\%). The overall WMD in FMD decreased and nearly reached statistical significance $(1.38 \% ; 95 \% \mathrm{Cl}:-0.12 \%$ to $2.87 \% ; P=0.070)$. No linear dose-response relationship was found between the dose of the vitamin $\mathrm{E}$ supplement and the change in FMD $(P=0.161)$. Even though heterogeneity decreased, it remained significant $\left(I^{2}=85.8 \%, P<0.001\right)$.

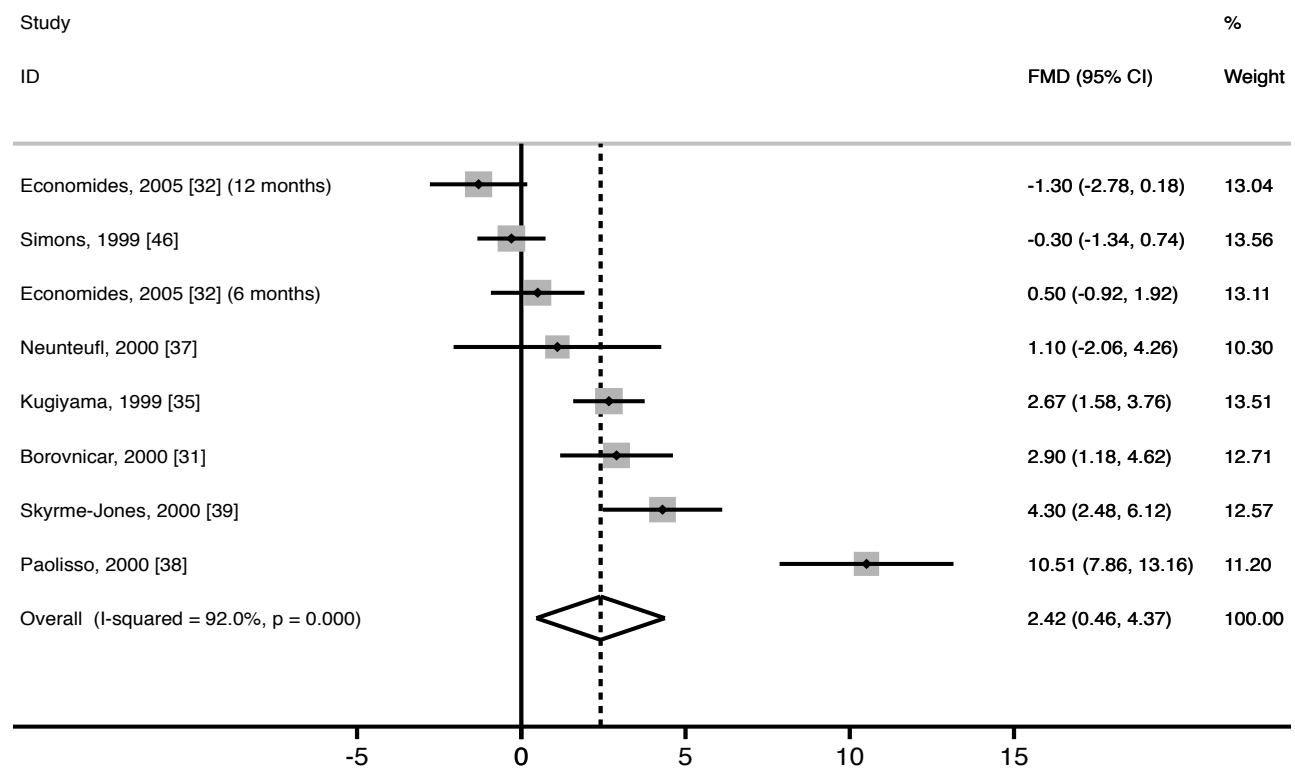

Figure 5.2. Forest plot of random controlled trials (RCTs) that investigated the effect of vitamin $E$ supplements on flow-mediated vasodilation (FMD). The solid squares represent the weight of individual studies and the diamond represents the weighted mean difference (WMD) in FMD (calculated using random-effect meta-analyses). In all studies combined, vitamin $\mathrm{E}$ increased FMD vs. control by $2.42 \%$ (95\% Cl: $0.46 \%$ to $4.37 \% ; P=0.015)$. After excluding the study by Paolisso and colleagues [38], the overall WMD nearly reached statistical significance $(1.38 \% ; 95 \% \mathrm{Cl}:-0.12 \%$ to $2.87 \% ; P=0.070)$.

Vitamin D supplementation did not significantly improve fasting FMD of the brachial artery vs. control $(0.15 \% ; 95 \% \mathrm{Cl}:-0.21 \%$ to $0.51 \% ; P=0.41)$ [Figure 5.3]. Between-study heterogeneity nearly reached statistical significance $\left(I^{2}=40.2 \%, P\right.$ $=0.054$ ). After using only results of the last measurement for trials that performed FMD measurements more than one time during the study [41-44], similar results were found for the overall WMD $(0.33 \% ; 95 \% \mathrm{Cl}:-0.34 \%$ to $1.00 \% ; P=0.34)$. Heterogeneity, however, became statistically significant $\left(I^{2}=52.5 \%, P=0.026\right)$. 


\section{VITAMINS AND FLOW-MEDIATED VASODILATION}

Study

ID

FMD $(95 \% \mathrm{Cl}) \quad$ Weight

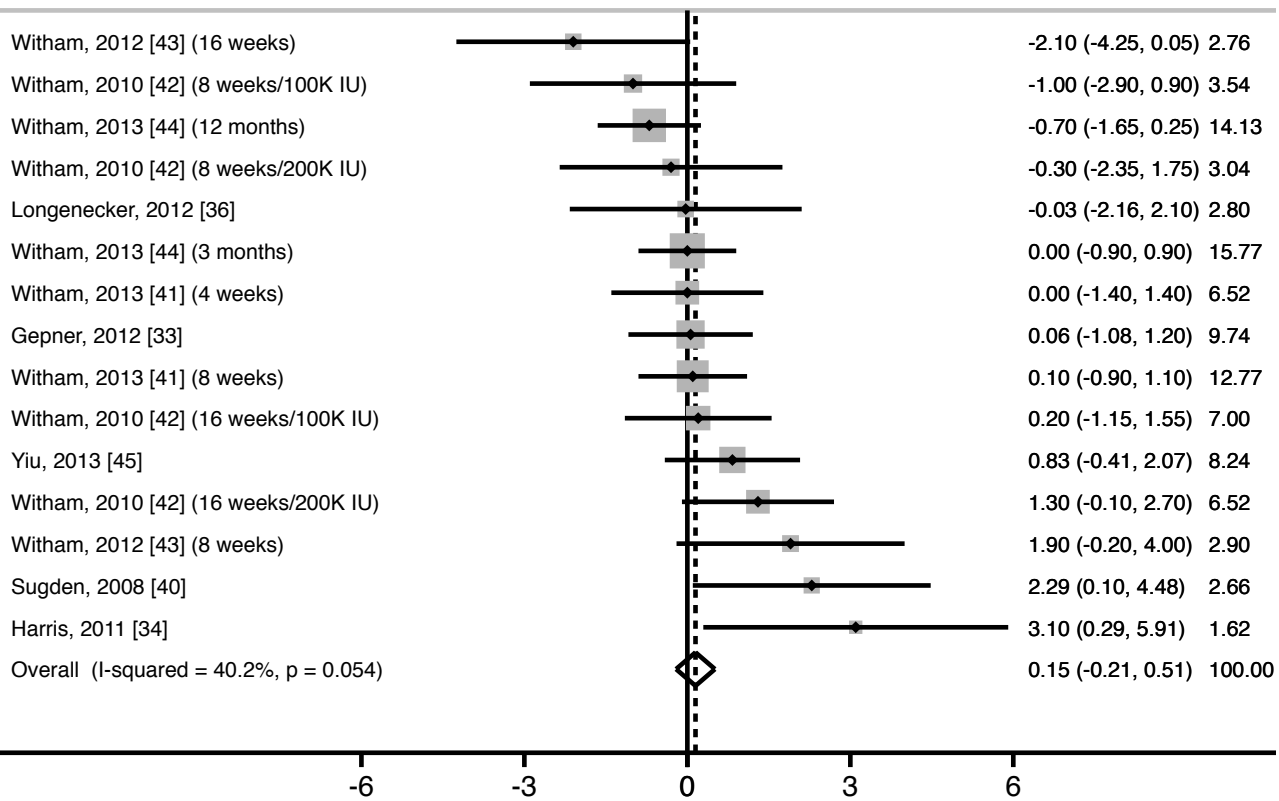

Figure 5.3. Forest plot of random controlled trials (RCTs) that investigated the effect of vitamin $D$ supplements on flow-mediated vasodilation (FMD). The solid squares represent the weight of individual studies and the diamond represents the weighted mean difference (WMD) in FMD (calculated using fixed-effect meta-analyses). In all studies combined, vitamin D did not increase FMD (WMD: 0.15\%; $95 \% \mathrm{Cl}:-0.21 \%$ to $0.51 \% ; P=0.41)$.

\section{Subgroup Analyses}

Subgroup analyses were performed within each vitamin group to evaluate if subject characteristics, treatment characteristics or technical aspects of the FMD measurement were related to the effects observed [Table 5.2]. None of the predefined variables resulted in significantly different effects of fat-soluble vitamin supplement intake on FMD between the subgroups. Further, the impact of baseline plasma 25-hydroxyvitamin D (25(OH)-D) concentrations and vitamin D-induced changes in $25(\mathrm{OH})$-D was investigated, but no association with the change in fasting FMD was found (data not shown).

\section{Publication Bias}

The funnel plot for the effect of vitamin E supplementation did not reveal possible presence of publication bias [Supplemental Figure 5.2] and the Egger's weighted regression test also showed no funnel plot asymmetry $(P=0.20)$. Similar results were found after visual evaluation of the funnel plot for the effect of vitamin $D$ supplementation and the Egger's test $(P=0.24)$ did not reach statistical significance, indicating absence of publication bias [Supplemental Figure 5.3]. 


\section{CHAPTER 5}

Table 5.2. Subgroup analyses for the effect of vitamin supplementation on flow-mediated dilation (FMD)

\begin{tabular}{|c|c|c|c|c|c|c|c|}
\hline Study characteristic & Mean & $\begin{array}{l}\text { Stratification } \\
\text { variable }\end{array}$ & $\begin{array}{l}\text { No of } \\
\text { study arms }\end{array}$ & $\begin{array}{l}\text { WMD } \\
(\%)\end{array}$ & \multicolumn{2}{|c|}{$95 \% \mathrm{Cl}$} & $\begin{array}{l}\text {-value } \\
\text { differen }\end{array}$ \\
\hline \multicolumn{8}{|c|}{ Study arms with vitamin E supplements as experimental variable } \\
\hline \multirow[t]{2}{*}{ Mean age (years) ${ }^{3}$} & 47.1 & $\leq 53.0$ & 5 & 1.48 & -0.59 & 3.55 & 0.372 \\
\hline & & $>53.0$ & 3 & 4.08 & -0.25 & 8.41 & \\
\hline \multirow[t]{2}{*}{ Gender $(\% \text { male })^{3}$} & 63.2 & $\leq 53.9$ & 5 & 3.17 & 0.25 & 6.10 & 0.500 \\
\hline & & $>53.9$ & 3 & 1.17 & -1.14 & 3.49 & \\
\hline \multirow[t]{2}{*}{ Baseline BMI $\left(\mathrm{kg} / \mathrm{m}^{2}\right)^{3}$} & 26.8 & $\leq 27.5$ & 3 & 2.15 & -0.43 & 4.72 & 0.828 \\
\hline & & $>27.5$ & 3 & 3.11 & -2.39 & 8.60 & \\
\hline \multirow[t]{2}{*}{ Baseline FMD $(\%)^{3}$} & 4.40 & $\leq 5.17$ & 4 & 4.10 & 0.71 & 7.50 & 0.219 \\
\hline & & $>5.17$ & 4 & 0.74 & -1.16 & 2.63 & \\
\hline \multirow[t]{2}{*}{ Health status } & - & Healthy & 2 & -0.16 & -1.15 & 0.82 & 0.390 \\
\hline & & Diseased & 6 & 3.10 & 0.67 & 5.54 & \\
\hline \multirow[t]{2}{*}{ Dose (100 IU/day) ${ }^{3}$} & 10.9 & $\leq 10.0$ & 5 & 2.14 & 0.35 & 3.93 & 0.764 \\
\hline & & $>10.0$ & 3 & 3.11 & -2.39 & 8.60 & \\
\hline \multirow[t]{2}{*}{ Study duration (weeks) ${ }^{3}$} & 16.8 & $\leq 11.0$ & 4 & 3.39 & -0.19 & 6.97 & 0.523 \\
\hline & & $>11.0$ & 4 & 1.56 & -0.83 & 3.94 & \\
\hline \multirow[t]{2}{*}{ Position cuff } & - & Distal & 3 & 1.40 & 0.71 & 2.09 & 0.341 \\
\hline & & Proximal & 2 & 6.63 & 4.60 & 8.66 & \\
\hline \multirow[t]{2}{*}{ Occlusion duration $(\min )^{3}$} & 4.67 & $\leq 4.50$ & 3 & 1.17 & -1.14 & 3.49 & 0.158 \\
\hline & & $>4.50$ & 3 & 5.65 & 1.77 & 9.54 & \\
\hline
\end{tabular}

Study arms with vitamin D supplements as experimental variable ${ }^{2}$

\begin{tabular}{|c|c|c|c|c|c|c|c|}
\hline \multirow[t]{2}{*}{ Mean age (years) ${ }^{3}$} & 59.8 & $\leq 64.9$ & 8 & 0.45 & -0.09 & 0.98 & 0.263 \\
\hline & & $>64.9$ & 7 & -0.10 & -0.59 & 0.38 & \\
\hline \multirow[t]{2}{*}{ Gender $(\% \text { male })^{3}$} & 50.4 & $\leq 58.8$ & 8 & 0.14 & -0.28 & 0.56 & 0.805 \\
\hline & & $>58.8$ & 7 & 0.18 & -0.49 & 0.85 & \\
\hline \multirow[t]{2}{*}{ Baseline BMI $\left(\mathrm{kg} / \mathrm{m}^{2}\right)^{3}$} & 28.4 & $\leq 28.5$ & 9 & -0.02 & -0.43 & 0.39 & 0.226 \\
\hline & & $>28.5$ & 6 & 0.68 & -0.05 & 1.40 & \\
\hline \multirow[t]{2}{*}{ Baseline FMD $(\%)^{3}$} & 5.89 & $\leq 6.38$ & 8 & 0.02 & -0.43 & 0.47 & 0.550 \\
\hline & & $>6.38$ & 7 & 0.38 & -0.22 & 0.97 & \\
\hline \multirow[t]{2}{*}{ Health status } & - & Healthy & 4 & 0.23 & -0.42 & 0.87 & 0.820 \\
\hline & & Diseased & 11 & 0.12 & -0.31 & 0.55 & \\
\hline \multirow[t]{2}{*}{ Type of vitamin ${ }^{4}$} & - & $\mathrm{D} 2$ & 3 & 0.70 & -0.54 & 1.94 & 0.521 \\
\hline & & D3 & 12 & 0.10 & -0.27 & 0.47 & \\
\hline \multirow[t]{2}{*}{ Study duration (weeks) ${ }^{3}$} & 13.9 & $\leq 12.0$ & 9 & 0.26 & -0.21 & 0.73 & 0.675 \\
\hline & & $>12.0$ & 6 & -0.01 & -0.56 & 0.55 & \\
\hline \multirow[t]{2}{*}{ Position cuff } & - & Distal & 15 & 0.15 & -0.21 & 0.51 & - \\
\hline & & Proximal & 0 & - & - & - & \\
\hline \multirow[t]{2}{*}{ Occlusion duration $(\mathrm{min})^{3}$} & 5.00 & $\leq 5.00$ & 11 & 0.12 & -0.28 & 0.52 & - \\
\hline & & $>5.00$ & 0 & - & - & - & \\
\hline
\end{tabular}

\footnotetext{
${ }^{1} \mathrm{n}=7$ intervention studies with 8 relevant study arms.

${ }^{2} \mathrm{n}=9$ intervention studies with 15 relevant study arms.

${ }^{3}$ Study arms were divided into subgroups based on their medians.

${ }^{4}$ Vitamin D2: oral ergocalciferol, Vitamin D3: oral cholecalciferol.
} 


\section{Discussion}

In this meta-analysis, data from seven RCTs studying the effects of vitamin E supplements and from nine RCTs examining the effects of vitamin $D$ supplements on fasting FMD in adults were pooled. When all studies were included, we found that vitamin $\mathrm{E}$ supplementation increased FMD of the brachial artery by $2.42 \%$, while no effect of vitamin D supplementation was found. However, significant heterogeneity was found among the vitamin $E$ trials.

The putative positive effects of vitamin E on FMD may be due to increased scavenging of oxygen free radicals by vitamin $E$ or via improved plasma antioxidant defenses [38]. This may lower the quenching effect of free radicals on nitric oxide (NO), thereby improving NO bioavailability and endothelial function. Several studies, but not all $[47,48]$, have further suggested that vitamin E supplementation increases insulin sensitivity $[49,50]$, which may also improve endothelial function [39]. However, based on our results, the use of vitamin E supplements to improve FMD should still be questioned. First, no linear doseresponse relationship was evident, which would have been strong evidence for a causal relationship. Also, the level of vitamin E tested in RCTs included in our meta-analysis ranged from 300 to $1800 \mathrm{IU} /$ day, which is far above recommended intakes of $30 \mathrm{lU} /$ day [51]. In fact, concern has been raised about potential adverse effects. One meta-analysis indeed concluded that high-dose vitamin E supplementation may increase all-cause mortality in trials supplying daily doses over $400 \mathrm{IU}$, that involved adults with chronic diseases [52]. In another metaanalysis, vitamin $\mathrm{E}$ given singly or in combination with other antioxidant supplements was also found to increase mortality in randomized primary and secondary prevention trials when trials with low methodological quality were excluded [53]. Further, the increment in FMD was not longer statistically significant when the study with the most pronounced effect was excluded [38]. The most pronounced effect (10.5\%) substantially differed from the overall WMD in FMD of $2.42 \%$. However, in that study, subjects had the lowest mean baseline FMD $(2.00 \%)$, suggesting that a very specific population was studied. Participants were type II diabetics, but it is not likely that this explains the large effects. Two other studies were also carried out in diabetic patients with both lower (1000 IU) [39] and higher daily doses (1800 IU) of vitamin E [32], but effects were never as large as observed by Paolisso and colleagues [38]. Considering these uncertainties, the present results should therefore not be interpreted as conclusive evidence to support the use of vitamin E supplements to improve FMD.

Prospective cohort studies have reported associations between vitamin $\mathrm{D}$ deficiency [54] or low plasma 25(OH)-D [55] and incident CVD. Although in vitro and animal studies have suggested a role of vitamin $D$ supplements on endothelial function [56], we found no effects of vitamin D supplements on fasting FMD in adults. Another possible explanation for the inverse relation between vitamin $D$ and CVD may be through effects on blood pressure. However, effects of vitamin D on blood pressure are also inconclusive [8]. In addition, calcium intakes may modify possible effects of vitamin D status on associated health benefits [57], and concomitant calcium intake may thus be required to observe positive effects of vitamin $D$ supplementation on fasting vascular endothelial function.

Finally, a number of observational studies have reported an inverse association between carotenoid intake and CVD risk [58]. However, intervention 


\section{CHAPTER 5}

trials using $\beta$-carotene supplements have not supported the hypothesis that $\beta$ carotene reduces CVD $[53,58]$. Unfortunately, we found no studies that examined the effects of carotenoid supplements on FMD. Further, an inverse association between vitamin K2 intake and coronary heart disease was found [59] and an increased dietary intake of vitamin $\mathrm{K}$ was also associated with a reduced risk of cardiovascular mortality [60]. However, results from intervention trials are lacking and none of the included trials investigated the effect of vitamin $\mathrm{K}$ supplementation on brachial reactivity.

Significant heterogeneity was found between vitamin $E$ trials and results of previous studies were indeed inconsistent. It has been speculated that various factors, including the mean age of participants [32, 61], vitamin supplement dose $[23,32,61]$ or duration of the intervention [23, 32, 61], may explain these inconsistent results. However, none of these or other predefined variables accounted for the variable effect of vitamin $\mathrm{E}$ supplementation interventions on FMD. Montero and colleagues found that effects of antioxidant vitamin supplementation on endothelial function did depend on the BMI of subjects [6]. Positive effects were only found in non-obese subjects, which were explained by an insufficient capacity of oral vitamin E intakes to overcome increased levels of oxidative stress [62]. However, only studies involving subjects with type II diabetes were included and effects of antioxidant vitamin $E$ and vitamin $C$ could not be separated in the intervention studies selected. Further, measurements of vascular endothelial function from different vascular regions were pooled and effects on FMD as such were not quantified. After vitamin D supplementation, there were also no predefined characteristics that were significantly related to the effects observed on fasting FMD. In an additional analysis, no association with baseline plasma 25(OH)-D concentrations or vitamin D-induced changes in 25(OH)-D was found. However, heterogeneity among vitamin $D$ studies did not reach statistical significance.

A possible limitation of our meta-analysis is the variability in experimental designs that may have contributed to the heterogeneity observed among the included studies. Further, comparability of FMD measurements between centers is low [63] and may be another source of heterogeneity. Even though technical aspects of the FMD measurement were not significantly related to the effects observed, better standardization of the FMD technique is required to reduce variability between trials included in the meta-analysis.

In conclusion, a causal relationship between high-dose vitamin E supplementation and improved fasting FMD cannot be ascertained from the present meta-analysis, while no effects of vitamin D supplementation were found. Therefore, the current meta-analysis does not provide unambiguous evidence to support the use of fatsoluble vitamin supplements to improve vascular endothelial function in adults and more research is required.

\section{Acknowledgments}

The present study is funded by research grant $\mathrm{CHOO1}$ from the $\mathrm{TI}$ Food and Nutrition, a public-private partnership on precompetitive research in food and 
nutrition. The public partners are responsible for the study design, data collection and analysis, decision to publish, and preparation of the manuscript. The private partners have contributed to the project through regular discussion.

\section{Author contributions}

The authors' responsibilities were as follows; Peter J. Joris: designed the study and conducted the literature review, performed the statistical analyses, interpreted the data, and wrote the manuscript; and Ronald P. Mensink: designed the study and conducted the literature review, interpreted the data, had overall responsibility for the study, and wrote the manuscript. All authors read and approved the final manuscript.

\section{Conflicts of interest}

The authors declare no conflict of interest.

\section{Supplemental data}

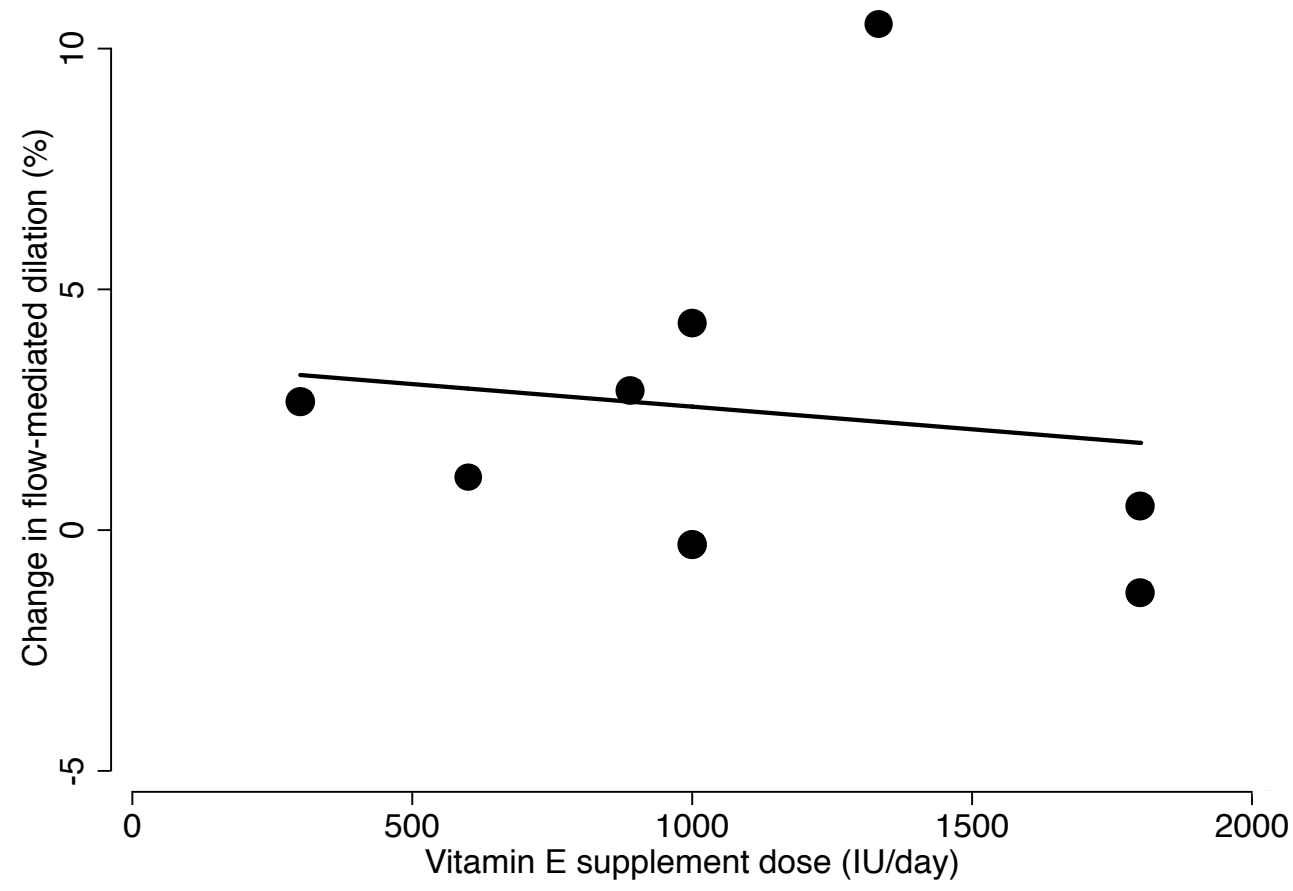

Supplemental Figure 5.1. Dose-response relationship between the dose of the vitamin $\mathrm{E}$ supplement and the change in fasting flow-mediated vasodilation (FMD). The size of each circle is proportional to the inverse of the variance of the change in FMD, and the line represents the regression line determined by meta-regression analysis. The dose of the vitamin E supplement was not associated with the change in $\operatorname{FMD}(P=0.744)$. 


\section{CHAPTER 5}

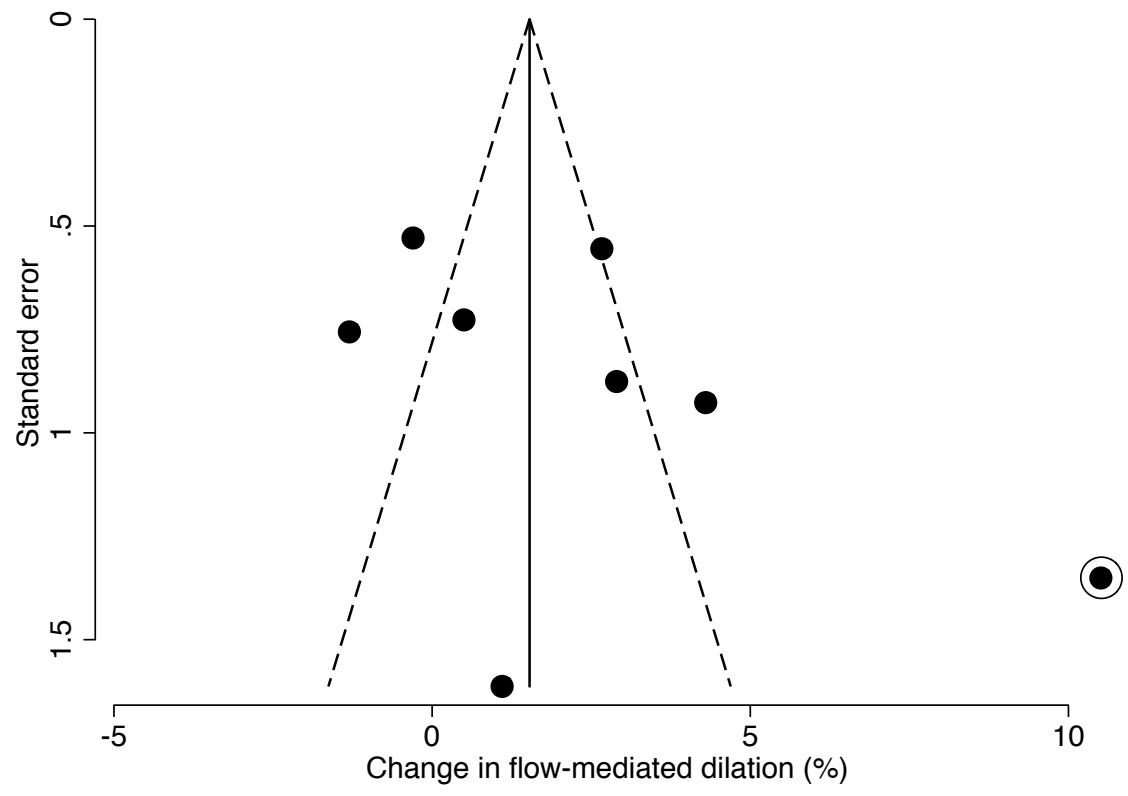

Supplemental Figure 5.2. Funnel plot for the effect of vitamin E supplementation on flow-mediated vasodilation (FMD) in random controlled trials (RCTs). Changes in FMD were plotted on the horizontal axis and the standard errors (s.e.) on the vertical axis. Visual evaluation of the funnel plot did not indicate presence of publication bias. The circle indicates the trial with the most pronounced effect [38].

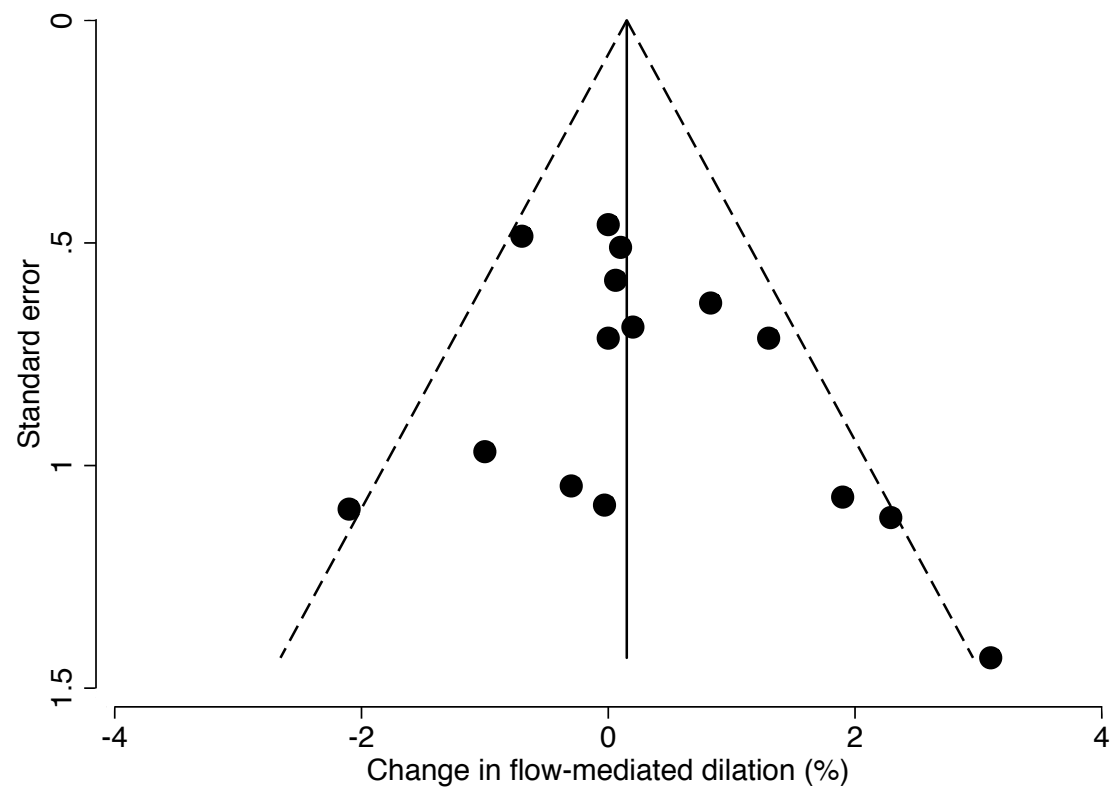

Supplemental Figure 5.3. Funnel plot for the effect of vitamin $D$ supplementation on flow-mediated vasodilation (FMD) in random controlled trials (RCTs). Changes in FMD were plotted on the horizontal axis and the standard errors (s.e.) on the vertical axis. Visual evaluation of the funnel plot did not indicate presence of publication bias. 


\section{VITAMINS AND FLOW-MEDIATED VASODILATION}

\section{References}

1. Lichtenstein AH. Nutrient supplements and cardiovascular disease: A heartbreaking story. J Lipid Res 2009;50:S429-33.

2. Widlansky ME, Gokce N, Keaney JF Jr, Vita JA. The clinical implications of endothelial dysfunction. J Am Coll Cardiol 2003;42:1149-60.

3. Schachinger V, Britten MB, Zeiher AM. Prognostic impact of coronary vasodilator dysfunction on adverse long-term outcome of coronary heart disease. Circulation 2000;101:1899-906.

4. Cohn JN, Quyyumi AA, Hollenberg NK, Jamerson KA. Surrogate markers for cardiovascular disease: Functional markers. Circulation 2004;109:31-46.

5. Ellins EA, Halcox JP. Where are we heading with noninvasive clinical vascular physiology? Why and how should we assess endothelial function? Cardiol Res Pract 2011;2011:870132.

6. Montero D, Walther G, Stehouwer CD, Houben AJ, Beckman JA, Vinet A. Effect of antioxidant vitamin supplementation on endothelial function in type 2 diabetes mellitus: A systematic review and meta-analysis of randomized controlled trials. Obes Rev 2014;15:10716.

7. Ashor AW, Lara J, Mathers JC, Siervo M. Effect of vitamin C on endothelial function in health and disease: A systematic review and meta-analysis of randomised controlled trials. Atherosclerosis 2014;235:9-20.

8. Min B. Effects of vitamin D on blood pressure and endothelial function. Korean J Physiol Pharmacol 2013;17:385-92.

9. Liu ZM, Woo J, Wu SH, Ho SC. The role of vitamin D in blood pressure, endothelial and renal function in postmenopausal women. Nutrients 2013;5:2590-610.

10. Liberati A, Altman DG, Tetzlaff J, Mulrow C, Gotzsche PC, loannidis JP, Clarke M, Devereaux PJ, Kleijnen J, Moher D. The PRISMA statement for reporting systematic reviews and meta-analyses of studies that evaluate healthcare interventions: Explanation and elaboration. BMJ 2009;339:b2700.

11. Arab L, Barr SI, Becking GC. A Report of the Panel on Dietary Antioxidants and Related Compounds. Dietary Reference Intakes for Vitamin C, Vitamin E, Selenium, and Carotenoids; National Academy Press: Washington, DC, USA 2000.

12. Joris PJ, Zeegers MP, Mensink RP. Weight loss improves fasting flow-mediated vasodilation in adults: A meta-analysis of intervention studies. Atherosclerosis 2014;239:2130 .

13. Cochran WG. The combination of estimates from different experiments. Biometrics 1954;10:101-29.

14. DerSimonian R, Laird N. Meta-analysis in clinical trials. Control Clin Trials 1986;7:177-88.

15. Higgins JP, Thompson SG. Quantifying heterogeneity in a meta-analysis. Stat Med 2002;21:1539-58.

16. Higgins JP, Thompson SG, Deeks JJ, Altman DG. Measuring inconsistency in meta-analyses. BMJ 2003;327:557-60.

17. Egger M, Davey SG, Schneider M, Minder C. Bias in meta-analysis detected by a simple, graphical test. BMJ 1997;315:629-34.

18. Can M, Gunes M, Haliloglu OA, Haklar G, Inanc N, Yavuz DG, Direskeneli H. Effect of vitamin $D$ deficiency and replacement on endothelial functions in Behçet's disease. Clin Exp Rheumatol 2012;30:S57-61.

19. Chitalia N, Ismail T, Tooth L, Boa F, Hampson G, Goldsmith D, Kaski JC, Banerjee D. Impact of vitamin D supplementation on arterial vasomotion, stiffness and endothelial biomarkers in chronic kidney disease patients. PLoS One 2014;9:e91363.

20. Koh KK, Blum A, Hathaway L, Mincemoyer R, Csako G, Waclawiw MA, Panza JA, Cannon $\mathrm{RO} 3 \mathrm{rd}$. Vascular effects of estrogen and vitamin $E$ therapies in postmenopausal women. Circulation 1999;100:1851-7. 


\section{CHAPTER 5}

21. Stein JH, Carlsson CM, Papcke-Benson K, Aeschlimann SE, Bodemer A, Carnes M, McBride PE. The effects of lipid-lowering and antioxidant vitamin therapies on flowmediated vasodilation of the brachial artery in older adults with hypercholesterolemia. J Am Coll Cardiol 2001;38:1806-13.

22. Tarcin O, Yavuz DG, Ozben B, Telli A, Ogunc AV, Yuksel M, Toprak A, Yazici D, Sancak S, Deyneli $O$, et al. Effect of vitamin $D$ deficiency and replacement on endothelial function in asymptomatic subjects. J Clin Endocrinol Metab 2009;94:4023-30.

23. Gazis A, White DJ, Page SR, Cockcroft JR. Effect of oral vitamin E (alpha-tocopherol) supplementation on vascular endothelial function in type 2 diabetes mellitus. Diabet Med 1999;16:304-11.

24. Green D, O'Driscoll G, Rankin JM, Maiorana AJ, Taylor RR. Beneficial effect of vitamin $E$ administration on nitric oxide function in subjects with hypercholesterolaemia. Clin Sci (Lond) 1998;95:361-7.

25. Pinkney JH, Downs L, Hopton M, Mackness MI, Bolton CH. Endothelial dysfunction in type 1 diabetes mellitus: Relationship with LDL oxidation and the effects of vitamin $\mathrm{E}$. Diabet Med 1999;16:993-9.

26. Shab-Bidar S, Neyestani TR, Djazayery A, Eshraghian MR, Houshiarrad A, Gharavi A, Kalayi A, Shariatzadeh N, Zahedirad M, Khalaji N, et al. Regular consumption of vitamin D-fortified yogurt drink (Doogh) improved endothelial biomarkers in subjects with type 2 diabetes: A randomized double-blind clinical trial. BMC Med 2011;9:125.

27. Witham MD, Dove FJ, Khan F, Lang CC, Belch JJ, Struthers AD. Effects of vitamin D supplementation on markers of vascular function after myocardial infarction-a randomised controlled trial. Int J Cardiol 2013;167:745-9.

28. Mah E, Pei R, Guo Y, Ballard KD, Barker T, Rogers VE, Parker BA, Taylor AW, Traber MG, Volek JS, et al. y-Tocopherol-rich supplementation additively improves vascular endothelial function during smoking cessation. Free Radic Biol Med 2013;65:1291-9.

29. Motoyama T, Kawano H, Kugiyama K, Hirashima O, Ohgushi M, Tsunoda R, Moriyama Y, Miyao $\mathrm{Y}$, Yoshimura M, Ogawa $\mathrm{H}$, et al. Vitamin $\mathrm{E}$ administration improves impairment of endothelium-dependent vasodilation in patients with coronary spastic angina. J Am Coll Cardiol 1998;32:1672-9.

30. Neunteufl T, Kostner K, Katzenschlager R, Zehetgruber M, Maurer G, Weidinger F. Additional benefit of vitamin $\mathrm{E}$ supplementation to simvastatin therapy on vasoreactivity of the brachial artery of hypercholesterolemic men. J Am Coll Cardiol 1998;32:711-6.

31. Borovnicar A, Keber I, Stavljenic Rukavina A, Yaletel Kragelj L. Improvement of early functional atherosclerotic changes in males with hypercholesterolemia after vitamin $E$ supplementation. Pflugers Arch 2000;440:R126-8.

32. Economides PA, Khaodhiar L, Caselli A, Caballero AE, Keenan H, Bursell SE, King GL, Johnstone MT, Horton ES, Veves A. The effect of vitamin E on endothelial function of micro- and macrocirculation and left ventricular function in type 1 and type 2 diabetic patients. Diabetes 2005;54:204-11.

33. Gepner AD, Ramamurthy R, Krueger DC, Korcarz CE, Binkley N, Stein JH. A prospective randomized controlled trial of the effects of vitamin $\mathrm{D}$ supplementation on cardiovascular disease risk. PLoS One 2012;7:e36617.

34. Harris RA, Pedersen-White J, Guo DH, Stallmann-Jorgensen IS, Keeton D, Huang Y, Shah Y, Zhu H, Dong Y. Vitamin D3 supplementation for 16 weeks improves flow-mediated dilation in overweight African-American adults. Am J Hypertens 2011;24:557-62.

35. Kugiyama K, Motoyama T, Doi H, Kawano H, Hirai N, Soejima H, Miyao Y, Takazoe K, Moriyama $\mathrm{Y}$, Mizuno $\mathrm{Y}$, et al. Improvement of endothelial vasomotor dysfunction by treatment with alpha-tocopherol in patients with high remnant lipoproteins levels. J Am Coll Cardiol 1999;33:1512-8.

36. Longenecker CT, Hileman CO, Carman TL, Ross AC, Seydafkan S, Brown TT, Labbato DE, Storer N, Tangpricha V, McComsey GA. Vitamin D supplementation and endothelial 


\section{VITAMINS AND FLOW-MEDIATED VASODILATION}

function in vitamin D deficient HIV-infected patients: A randomized placebo-controlled trial. Antivir Ther 2012;17:613-21.

37. Neunteufl T, Priglinger U, Heher S, Zehetgruber M, Soregi G, Lehr S, Huber K, Maurer $G$, Weidinger F, Kostner K. Effects of vitamin E on chronic and acute endothelial dysfunction in smokers. J Am Coll Cardiol 2000;35:277-83.

38. Paolisso G, Tagliamonte MR, Barbieri M, Zito GA, Gambardella A, Varricchio G, Ragno E, Varricchio $M$. Chronic vitamin $E$ administration improves brachial reactivity and increases intracellular magnesium concentration in type II diabetic patients. J Clin Endocrinol Metab 2000;85:109-15.

39. Skyrme-Jones RA, O'Brien RC, Berry KL, Meredith IT. Vitamin E supplementation improves endothelial function in type I diabetes mellitus: A randomized, placebo-controlled study. J Am Coll Cardiol 2000;36:94-102.

40. Sugden JA, Davies JI, Witham MD, Morris AD, Struthers AD. Vitamin D improves endothelial function in patients with type 2 diabetes mellitus and low vitamin $D$ levels. Diabet Med 2008;25:320-5.

41. Witham MD, Adams F, Kabir G, Kennedy G, Belch JJ, Khan F. Effect of short-term vitamin D supplementation on markers of vascular health in South Asian women living in the UK-A randomised controlled trial. Atherosclerosis 2013;230:293-9.

42. Witham MD, Dove FJ, Dryburgh M, Sugden JA, Morris AD, Struthers AD. The effect of different doses of vitamin $D(3)$ on markers of vascular health in patients with type 2 diabetes: A randomised controlled trial. Diabetologia 2010;53:2112-9.

43. Witham MD, Dove FJ, Sugden JA, Doney AS, Struthers AD. The effect of vitamin D replacement on markers of vascular health in stroke patients-A randomised controlled trial. Nutr Metab Cardiovas Dis 2012;22:864-70.

44. Witham MD, Price RJ, Struthers AD, Donnan PT, Messow CM, Ford I, McMurdo ME. Cholecalciferol treatment to reduce blood pressure in older patients with isolated systolic hypertension: The VitDISH randomized controlled trial. JAMA Intern Med 2013;173:1672-9.

45. Yiu YF, Yiu KH, Siu CW, Chan YH, Li SW, Wong LY, Lee SW, Tam S, Wong EW, Lau CP, et al. Randomized controlled trial of vitamin D supplement on endothelial function in patients with type 2 diabetes. Atherosclerosis 2013;227:140-6.

46. Simons LA, von Konigsmark M, Simons J, Stocker R, Celermajer DS. Vitamin E ingestion does not improve arterial endothelial dysfunction in older adults. Atherosclerosis 1999;143: 193-9.

47. Shab-Bidar S, Mazloum Z, Mousavi-Shirazifard Z. Daily vitamin E supplementation does not improve metabolic and glycemic control in type 2 diabetic patients: A double blinded randomized controlled trial. J Diabetes 2013;5:57-8.

48. de Oliveira AM, Rondo PH, Luzia LA, D'Abronzo FH, Illison VK. The effects of lipoic acid and alpha-tocopherol supplementation on the lipid profile and insulin sensitivity of patients with type 2 diabetes mellitus: A randomized, double-blind, placebo-controlled trial. Diabetes Res Clin Pract 2011;92:253-60.

49. Paolisso G, D'Amore A, Giugliano D, Ceriello A, Varricchio M, D'Onofrio F. Pharmacologic doses of vitamin $E$ improve insulin action in healthy subjects and non-insulin-dependent diabetic patients. Am J Clin Nutr 1993;57:650-6.

50. Paolisso G, di Maro G, Galzerano D, Cacciapuoti F, Varricchio G, Varricchio M, D'Onofrio F. Pharmacological doses of vitamin $E$ and insulin action in elderly subjects. Am J Clin Nutr 1994;59:1291-6.

51. Monsen ER. Dietary reference intakes for the antioxidant nutrients: Vitamin C, vitamin E, selenium, and carotenoids. J Am Diet Assoc 2000;100:637-40.

52. Miller ER 3rd, Pastor-Barriuso R, Dalal D, Riemersma RA, Appel LJ, Guallar E. Meta-analysis: High-dosage vitamin E supplementation may increase all-cause mortality. Ann Intern Med 2005;142:37-46. 


\section{CHAPTER 5}

53. Bjelakovic G, Nikolova D, Gluud LL, Simonetti RG, Gluud C. Mortality in randomized trials of antioxidant supplements for primary and secondary prevention: Systematic review and meta-analysis. JAMA 2007;297:842-57.

54. Wang TJ, Pencina MJ, Booth SL, Jacques PF, Ingelsson E, Lanier K, Benjamin EJ, D'Agostino RB, Wolf M, Vasan RS. Vitamin D deficiency and risk of cardiovascular disease. Circulation 2008;117:503-11.

55. Dobnig H, Pilz S, Scharnagl H, Renner W, Seelhorst U, Wellnitz B, Kinkeldei J, Boehm BO, Weihrauch G, Maerz W. Independent association of low serum 25-hydroxyvitamin D and 1,25-dihydroxyvitamin D levels with all-cause and cardiovascular mortality. Arch Intern Med 2008;168,1340-9.

56. Dalan R, Liew H, Tan AW, Chew DE, Leow MK. Vitamin D and the endothelium: Basic, translational and clinical research updates. IJC Metab Endocr 2014;4:4-17.

57. Heaney RP. Vitamin D and calcium interactions: Functional outcomes. Am J Clin Nutr 2008;88:541S-4S.

58. Voutilainen S, Nurmi T, Mursu J, Rissanen TH. Carotenoids and cardiovascular health. Am J Clin Nutr 2006;83:1265-71.

59. Geleijnse JM, Vermeer C, Grobbee DE, Schurgers LJ, Knapen MH, van der Meer IM, Hofman A, Witteman JC. Dietary intake of menaquinone is associated with a reduced risk of coronary heart disease: The Rotterdam Study. J Nutr 2004;134:3100-5.

60. Juanola-Falgarona M, Salas-Salvado J, Martinez-Gonzalez MA, Corella D, Estruch R, Ros E, Fito M, Aros F, Gomez-Gracia E, Fiol M, et al. Dietary intake of vitamin K is inversely associated with mortality risk. J Nutr 2014;144:743-50.

61. Lu Q, Bjorkhem I, Wretlind B, Diczfalusy U, Henriksson P, Freyschuss A. Effect of ascorbic acid on microcirculation in patients with type II diabetes: A randomized placebo-controlled crossover study. Clin Sci (Lond) 2005;108:507-13.

62. Sankhla M, Sharma TK, Mathur K, Rathor JS, Butolia V, Gadhok AK, Vardey SK, Sinha M, Kaushik GG. Relationship of oxidative stress with obesity and its role in obesity induced metabolic syndrome. Clin Lab 2012;58:385-92.

63. De Roos NM, Bots ML, Schouten EG, Katan MB. Within-subject variability of flow-mediated vasodilation of the brachial artery in healthy men and women: Implications for experimental studies. Ultrasound Med Biol 2003;29:401-6. 


\section{CHAPTER 6}

\section{Diet-induced weight loss not only improves cardiometabolic risk markers, but also markers of vascular function: A randomized controlled trial in abdominally obese men}

Peter J. Joris, Jogchum Plat, Yvo H.A.M. Kusters, Alfons J.H.M. Houben, Coen D.A. Stehouwer, Casper G. Schalkwijk and Ronald P. Mensink 


\title{
CHAPTER 6
}

\begin{abstract}
Background: Many studies on the effects of diet-induced weight loss on vascular function were performed without a no-weight loss control group and in individuals with obesity-related morbidities. Also, only a limited set of vascular function markers was investigated. In this RCT, we therefore examined [i] effects of dietinduced weight loss on various vascular function markers, and [ii] differences between normal-weight and abdominally obese men at baseline and after weight loss.
\end{abstract}

Design: Apparently healthy normal-weight [ $n=25$; waist circumference: $<94 \mathrm{~cm}]$ and abdominally obese men $[n=54$; waist circumference: $102-110 \mathrm{~cm}$ ] participated. The abdominally obese subjects were randomly allocated to a dietary weight-loss program or a no-weight loss control group. Individuals assigned to the weight-loss program followed a calorie-restricted diet for six weeks to obtain a waist circumference below $102 \mathrm{~cm}$, followed by a weight-maintenance period of two weeks. The control group maintained their habitual diet and physical activity levels.

Results: Weight loss did not affect brachial artery flow-mediated vasodilation [FMD], while carotid-to-femoral pulse wave velocity tended to decrease in the weight-loss compared with the control group by $0.5 \mathrm{~m} / \mathrm{s}(P=0.065)$. The retinal arteriolar diameter increased by $5 \mu \mathrm{m}(P<0.001)$ and the arteriolar-to-venular ratio by $0.02(P<0.01)$, and plasma sE-selectin and sICAM-1 decreased $(P<0.001)$. As expected, total cholesterol, LDL-cholesterol, triacylglycerol, glucose, insulin, Cpeptide, $\mathrm{HOMA}_{\mathrm{IR}}$, and blood pressure improved following weight reduction $(P<$ 0.05 for all variables). Except for FMD, these markers differed at baseline between normal-weight and abdominally obese men, but became comparable after weight reduction, although the waist circumference was still different.

Conclusion: In abdominally obese men, diet-induced weight loss improved retinal microvascular caliber, plasma biomarkers of microvascular endothelial function, and the more conventional cardiometabolic risk markers. Aortic stiffness tended to decrease, but FMD was not changed. 


\section{Introduction}

Abdominal obesity represents a central feature of the metabolic syndrome and is mechanistically linked to various cardiometabolic risk factors, such as hypertension, serum lipid abnormalities, insulin resistance and low-grade systemic inflammation [1]. These risk factors are associated with vascular dysfunction, which may predict longer-term atherosclerotic disease progression and cardiovascular event rates [2, 3]. Many different non-invasive vascular function markers exist, each addressing a different aspect of the vasculature. Brachial artery flow-mediated vasodilation [FMD] is used to assess large artery endothelial function, while other markers can be used to address arterial stiffness, such as carotid-to-femoral pulse wave velocity $\left[\mathrm{PWV}_{\mathrm{c}-\mathrm{f}}\right]$, or retinal microvasculature [e.g. retinal microvascular caliber properties: arteriolar diameter, venular diameter, and the arteriolar-to-venular diameter ratio (AVR)]. Microvascular endothelial function can further be assessed by measuring plasma biomarkers. Many of these markers are associated with future cardiovascular events and are useful to examine effects of life-style interventions on cardiovascular risk [4].

Despite consistent evidence linking abdominal obesity to multiple metabolic disorders [1] and disturbed vascular homeostasis [5], the effects of weight loss on the various vascular function markers are not consistent. Further, in most studies no-weight loss control groups were missing [6]. In addition, physical exercise [7, 8] or weight-loss medication [9] were part of the weight-loss regimes in the very limited randomized controlled trials [RCTs] with a no-weight loss control group, while most studies were performed in participants with obesity-related morbidities [7-9]. Moreover, only a few studies focused on waist circumference as an estimate of visceral fat. An excess of visceral fat, known as abdominal obesity, is the most prevalent manifestation of the metabolic syndrome and more closely linked to metabolic aberrations than BMI [10]. Finally, most studies only used a limited set of vascular function markers. Therefore, the objective of the current RCT was to investigate [i] the effects of diet-induced weight reduction on a panel of vascular function markers and risk markers related to cardiometabolic health, and [ii] differences between normal-weight and abdominally obese men at baseline and after weight loss.

\section{Subjects and methods}

\section{Study population}

Apparently healthy Caucasian individuals were recruited by advertisements in local newspapers or among participants who had participated in earlier trials. To exclude any possible sex effects, women were excluded. Men were invited for a screening visit if they met the following inclusion criteria: aged between 18 and 65 years, stable body weight [weight gain or loss $<3 \mathrm{~kg}$ within the previous three months], no use of medication known to affect lipid or glucose metabolism, no diabetes, not receiving anti-hypertensive medication, and no participation in another biomedical trial during the past 30 days. Twenty-five normal-weight and fifty-four abdominally obese men were included. They had a waist circumference $<94 \mathrm{~cm}$ [normal 


\section{CHAPTER 6}

weight] or between 102 and $110 \mathrm{~cm}$ [abdominally obese]; fasting serum triacylglycerol concentrations $\leq 4.5 \mathrm{mmol} / \mathrm{L}$; no indications for treatment with cholesterol-lowering medications according to the Dutch Cholesterol Consensus [11]; no active cardiovascular disease like congestive heart failure or any cardiovascular event in the past, such as a stroke or an acute myocardial infarction; no inflammatory disease; and no drug or alcohol abuse. All participants gave written informed consent before entering the study. The study was approved by the Medical Ethics Committee of Maastricht University Medical Center and registered at ClinicalTrials.gov as NCT01675401.

\section{Study design}

At the start of the study, all men visited the research facilities twice with an interval of 2 or 3 days to perform baseline measurements. Measurements of normal-weight and abdominally obese individuals were balanced over the 18 months of inclusion. After these measurements, the abdominally obese subjects were divided into two age groups [18-49 years or 50-65 years]. The men from the same age group were assigned to blocks of two or four subjects. Within each block, participants were randomly allocated to either the diet-induced weight-loss group or no-weight loss control group with a randomization ratio of 1:1. Volunteers assigned to the weightloss program visited our research dietician every week and consumed for at least 4 weeks under strict guidance a very low-calorie diet [VLCD] [Modifast; Nutrition et Santé Benelux, Breda, The Netherlands] until the waist circumference was below $102 \mathrm{~cm}$. When the waist circumference was still above $102 \mathrm{~cm}$, the VLCD was continued for another week. This value of $102 \mathrm{~cm}$ was chosen because it is used as cut-off value in the diagnosis of the metabolic syndrome [12]. The proteinenriched VLCD consisted of $2.1 \mathrm{MJ} /$ day [500 kcal/day] and provided $51.9 \mathrm{~g}$ protein, $50.2 \mathrm{~g}$ carbohydrates, $6.9 \mathrm{~g}$ lipids, and a vitamin and mineral content that met the Dutch recommended daily intakes. The VLCD was supplied in powder sachets that had to be dissolved in water to obtain a milkshake [vanilla, chocolate, strawberry or banana], pudding [vanilla, chocolate or caramel] or muesli [cinnamon-apple]. Three sachets had to be consumed daily according to their own preferences. In addition, participants were allowed to eat $250 \mathrm{~g}$ of vegetables or fruit [except bananas] each day. After the VLCD period, subjects were prescribed a mixed solid calorierestricted diet in agreement with the Dutch dietary guidelines. This diet provided $4.2 \mathrm{MJ} /$ day for a period of 1 to 2 weeks. The detailed prescribed mixed solid calorie-restricted diet consisted of the three main meals. In week 7 and week 8 , the participants were kept in energy balance [weight-maintenance period] by prescribing detailed weekly menus that were based on the estimated energy requirements for weight maintenance. Total energy requirement was calculated for each individual based on basal metabolic rate and physical activity levels [13]. Men assigned to the no-weight loss control treatment visited our research dietician two times and maintained their habitual diet, physical activity levels and use of alcohol throughout the total study period. At the end of the intervention periods, the abdominally obese subjects visited the research facilities twice with an interval of 2 to 3 days and follow-up measurements were performed.

Subjects were asked to record in study diaries any signs of illness, medication used, alcohol consumption, any deviations of the study protocol and 


\section{DIETARY WEIGHT LOSS AND VASCULAR FUNCTION}

other complaints. On the day preceding blood drawings, participants were asked not to consume high-fat foods or alcohol, or to perform any strenuous physical exercise. After an overnight fast [from $08.00 \mathrm{PM}$ ], volunteers arrived at the research facilities by public transport or car to standardize vascular measurements as much as possible. After an acclimatization period of 30 minutes in the supine position, vascular measurements were performed. Immediately after performing the measurements, an intravenous cannula was inserted into a vein and fasting blood samples were obtained.

\section{Blood analyses}

After blood sampling through an intravenous catheter, NaF-containing vacutainer tubes [Becton, Dickinson and Company, Franklin Lanes, NY, USA] and EDTAcoated vacutainer tubes [Becton, Dickinson and Company] were kept on ice and centrifuged within 30 minutes. To obtain plasma, the plasma tubes were centrifuged at $1300 \times g$ for 15 minutes at $4{ }^{\circ} \mathrm{C}$. Blood drawn in vacutainer serum tubes [Becton, Dickinson and Company] was allowed to clot for 30 minutes at $21^{\circ} \mathrm{C}$. To obtain serum, serum tubes were centrifuged at $1300 \mathrm{xg}$ for 15 minutes at $21^{\circ} \mathrm{C}$. Following centrifugation, samples were immediately portioned into aliquots and stored at $-80^{\circ} \mathrm{C}$ until analysis at the end of the intervention study.

Fasting plasma glucose [Horiba ABX, Montpellier, France] concentrations were measured in NaF-plasma. Serum fasting samples were analyzed for total cholesterol [CHOD-PAP method; Roche Diagnostics, Mannheim, Germany], HDLcholesterol [precipitation method; Roche Diagnostics, Mannheim, Germany], triacylglycerol [GPO Trinder; Sigma-Aldrich Corp., St. Louis, MO, USA], insulin and C-peptide levels [RIA; Millipore, Billerica, MA, USA]. Triacylglycerol was corrected for free glycerol and LDL-cholesterol was calculated using the Friedewald formula [14]. The degree of insulin resistance was estimated by calculating the $\mathrm{HOMA}_{\mathbb{R}}$, as previously described [15]. Fasting EDTA-plasma samples were used for measurement of biomarkers for low-grade inflammation [interleukin (IL)-6, IL-8, tumor necrosis factor (TNF)- $\alpha$, C-reactive protein (CRP), serum amyloid A (SAA)] and endothelial function [soluble vascular cell adhesion molecule (VCAM)-1, soluble intercellular adhesion molecule (sICAM-1), soluble endothelial selectin (sEselectin)] by using a multi-array detection system based on electrochemiluminescence technology [SECTOR Imager 2400; Meso Scale Discovery, Rockville, MD, USA]. Von Willebrand factor [VWF] was assessed by ELISA in citrate plasma, as previously described [16].

\section{Clinical measurements}

Height was measured during screening visits using a wall-mounted stadiometer. Body weight and fat distribution by measuring the waist-to-hip circumference ratio were determined before the start of the vascular measurements, and every week for men that were assigned to the diet-induced weight-loss intervention. Blood pressure levels [systolic (SBP) and diastolic blood pressure (DBP)] and heart rate were monitored in the supine position using a semi-continuous blood pressure monitoring device [Omron Intellisense M7; Cemex Medische Techniek, Nieuwegein, The Netherlands]. The first measurement was discarded and the 


\section{CHAPTER 6}

average of the last three measurements was reported. After performing the vascular measurements, a Philips Achieva 3.0T TX MRI scanner with a dedicated sixteen-element torso coil [XL Torso coil; Philips Healthcare, Best, The Netherlands] was used to assess subcutaneous and visceral adipose tissue volumes. Two-dimensional (2D) T1W TSE images [nine $5 \mathrm{~mm}$ slices, gap $=10$ $\mathrm{mm}$, repetition time $=526 \mathrm{~ms}$, echo time $=10 \mathrm{~ms}$, turbo spin echo factor $=4$, number of signal averages $=1$, field of view $=400 \mathrm{~mm}^{2} \times 322 \mathrm{~mm}^{2}$, matrix size = $308 \times 164$, resulting in an acquired in-plane voxel size of $1.3 \mathrm{~mm}^{2} \times 1.96 \mathrm{~mm}^{2}$ ] were acquired centered at the top of the L4 vertebral body. Images were analyzed offline with dedicated software [Hippo Fat; IFC CNR, Pisa, Italy].

All vascular measurements were performed in a quiet and darkened room. The room was temperature controlled at $24^{\circ} \mathrm{C}$. Radial artery pulse wave analysis [PWA] was performed, in triplicate, with a tonometer [ShpygmoCor v9; AtCor Medical, West Ryde, Australia] applied to the radial artery near the wrist of the arm. The central arterial waveform was derived from the peripheral arterial waveform using a validated transfer function. Central augmentation indices [CAIxHR75] were defined as the difference between the first and second peak of the central arterial waveform, expressed as a percentage of the pulse pressure and corrected for heart rate. Using the same tonometer $\mathrm{PWV}_{\mathrm{c}-\mathrm{f}}$ was determined [17] in triplicate by measuring the arrival of the pulse wave and the delay to the Rwave of the ECG at the carotid and femoral artery. With use of the direct carotid to femoral distance, $\mathrm{PWV}_{\text {c-f }}$ was calculated automatically by the program of the manufacturer. FMD was assessed by ultrasound echography in dual mode [MyLab ${ }^{\text {TM }}$ 70; Esaote, Maastricht, The Netherlands] and recording of echo images on DVD [18]. After a 5-minute reference period, the pneumatic cuff placed around the participant's forearm was inflated to $200 \mathrm{mmHg}$ for 5 minutes, causing distal hypoxia. Upon cuff-release reactive hyperemia ensued. The echo images were analyzed offline using a custom-written Matlab program [MyFMD; Prof. A.P. Hoeks, Department of Biomedical Engineering, Maastricht University Medical Center, Maastricht, The Netherlands]. The FMD response was then quantified as the maximal percentage change in post occlusion arterial diameter relative to baseline diameter. During brachial artery FMD measurements, the Endo-PAT 2000 [Itamar Medical Ltd, Caesarea, Israel] was used to measure changes in pulse wave amplitude in response to reactive hyperemia. In brief, a pneumatic probe was placed on the index finger of both hands to record the peripheral arterial tone, according to instructions of the manufacturer. The Reactive Hyperemia Index [RHI] was quantified as the post-to-pre occlusion peripheral arterial tone signal ratio in the occluded hand, normalized to the values in the control hand and then further corrected for baseline vascular tone [19]. Finally, retinal vascular images were obtained to assess microvascular diameters in the right eye. During this test, participants were seated with their head resting on a chinrest, looking directly into the non-mydriatic retinal camera [Topcon TRC-NW-300; Topcon Co., Tokyo, Japan]. The camera focused on the optic disc and photographed the retina of the right eye. Images were digitized and analyzed to calculate the mean arteriolar width, mean venular width, and AVR with appropriate software [Generalized DualBootstrap Iterative Closest Point (GDBP-ICP)], as previously described [20]. In brief, the software automatically aligns the retinal images based on detected vascular centerlines by iteratively transforming the algorithm. At least 2 arteriolar 
and 2 venular segments were measured and summarized by using the ParrHubbard formulas [21]. These segments differed between study subjects, but had to be the same segments at each time point for an individual.

\section{Statistical analyses}

Results are presented as means \pm standard deviations [SDs], unless otherwise indicated. Before the start of the study, it was calculated that the statistical power to detect a true difference of at least 2.25 percentage points in FMD with 25 participants per group was $80 \%$ for the weight-loss trial. It was further calculated that the statistical power to detect a true difference of at least 2.25 percentage points in FMD was over $80 \%$ when 25 normal-weight and 50 abdominally obese men were compared cross-sectionally. For these calculations, a within-subject and between-subject variability of 2.82 percentage points in FMD were used [22].

An unpaired Student's $t$ test was used to examine differences at baseline between normal-weight and abdominally obese men. A one-way ANCOVA, using the baseline measurements of the outcome variables as covariates, was conducted to evaluate differences in changes between diet-induced weight-loss and no-weight loss control treatments. When residuals were not normally distributed as assessed with the Kolmogorov-Smirnov test, a Wilcoxon rank-sum was used. Changes were then calculated for each individual as the difference between the values at the end of the study and at the start of the study. Pearson correlation coefficients were determined to investigate [i] cross-sectional relationships between vascular and cardiometabolic risk markers, and [ii] relationships between changes in these markers. Differences were considered statistically significant at $P<0.05$. Analyses were performed using SPSS 21.0 for Mac OS X [SPSS Incorporated, Chicago, IL, USA].

\section{Results}

\section{Study participants}

A consort flow diagram of participants throughout the study is shown in Supplemental Figure 6.1. After screening, 25 normal-weight men were eligible for participation and all completed the study. Baseline measurements were performed in 54 abdominally obese men, but one man dropped out because of personal reasons before completing baseline measurements. A total of 53 abdominally obese men were randomized to dietary weight-loss or no-weight loss control groups. One subject discontinued control treatment because of illness, one man dropped out because of noncompliance with the weight loss program and another participant dropped out because of personal reasons after assignment to the weight-loss program. Thus, 50 abdominally obese men completed the weight-loss study. One of the abdominally obese men from the weigh-loss group was excluded from the statistical analyses due to a fasting SBP $\geq 160 \mathrm{mmHg}$ and fasting DBP $\geq$ $100 \mathrm{mmHg}$ that did not become apparent during the screening visit because of notreported anti-hypertensive medication. Due to technical problems with the recording of echo images on DVD, we were unable to analyze FMD measurements in one normal-weight subject and in five abdominally obese subjects on one test- 


\section{CHAPTER 6}

day [i.e. one measurement at the start of the trial and four measurements at the end of the treatments]. Unclear retinal vascular images were also excluded from the statistical analyses for two normal-weight participants and for eight abdominally subjects on one test-day [i.e. seven retinal images at the start of the study and one image at the end of the weight-loss treatment].

Baseline characteristics of the study participants are shown in Tables 6.16.3 and Supplemental Table 6.1. The median age was comparable between the normal-weight and abdominally obese participants. As expected, the waist circumference $[84.9 \pm 6.3 \mathrm{~cm}$ versus $106.5 \pm 3.6 \mathrm{~cm}$ ] and other anthropometric measures [BMI, waist-to-hip ratio, calculated body fat, visceral and subcutaneous fat volume] were higher in the abdominally obese men $(P<0.001$ for all variables). The mean weight reduction was $10.3 \mathrm{~kg}$ [95\% Cl: 9.2 to $11.4 \mathrm{~kg} ; P<0.001]$ after the dietary weight-loss treatment, while body weight remained stable during the weight-maintenance period [Figure 6.1]. Waist circumference was also reduced $(P$ $<0.001$ ) and body fat decreased by $4.0 \%$ [95\% Cl: 3.2 to $4.8 \% ; P<0.001]$. All study participants obtained a waist circumference below $102 \mathrm{~cm}$, except two men who at the end of the weight-loss intervention period had a waist circumference of $102.5 \mathrm{~cm}$ and $106.3 \mathrm{~cm}$, respectively. Body weight at the start of the no-weight loss control treatment was $95.9 \pm 8.9 \mathrm{~kg}$ and at the end $96.4 \pm 9.1 \mathrm{~kg}$ [Table 6.1]

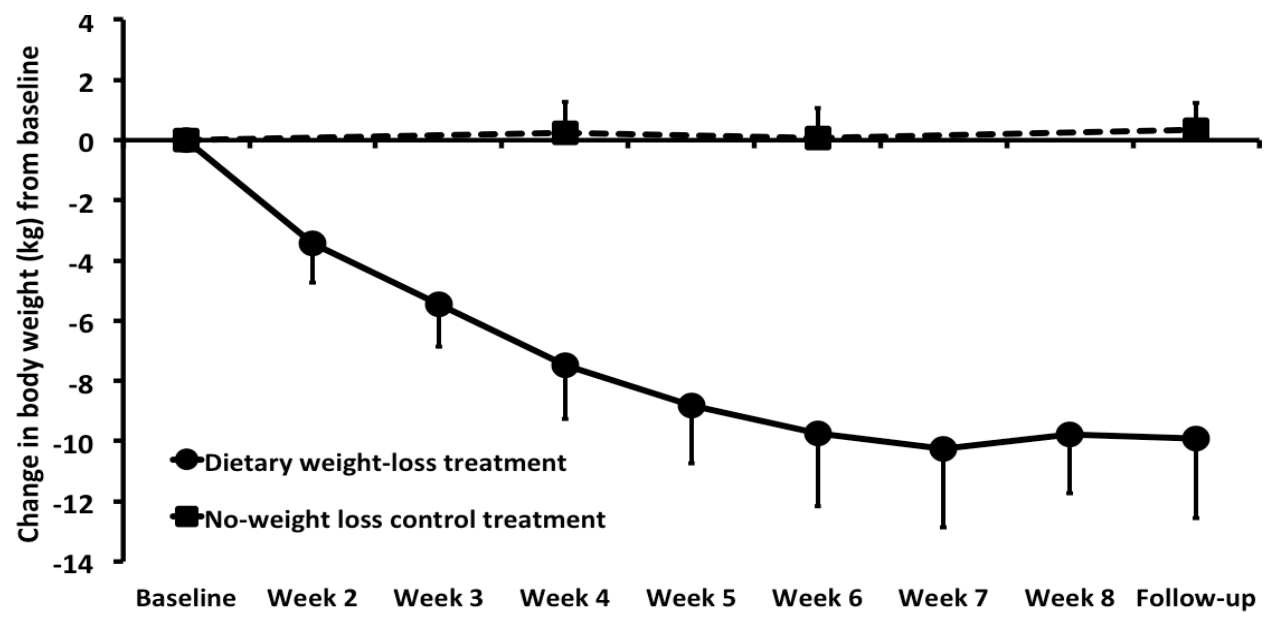

Figure 6.1. Mean changes $( \pm S D)$ in body weight following a dietary weight-loss $(n=23)$ treatment or no-weight loss control treatment $(n=26)$ in a randomized controlled trial with abdominally obese men.

\section{Cardiometabolic risk markers and plasma biomarkers}

Fasting total cholesterol, HDL-cholesterol, LDL-cholesterol, triacylglycerol, glucose, insulin, C-peptide and $\mathrm{HOMA}_{\mathrm{IR}}$ differed at baseline between the normal-weight and abdominally obese men ( $P<0.05$ for all variables) [Table 6.1]. All these metabolic risk markers, except for HDL-cholesterol, significantly improved in the abdominally obese men following dietary weight loss compared with the control treatment $(P<$ 0.05 for all variables) [Table 6.1]. In fact, these metabolic risk markers, except for HDL-cholesterol levels, did not differ significantly between the normal-weight and abdominally obese men at the end of the weight-loss intervention period. 
DIETARY WEIGHT LOSS AND VASCULAR FUNCTION

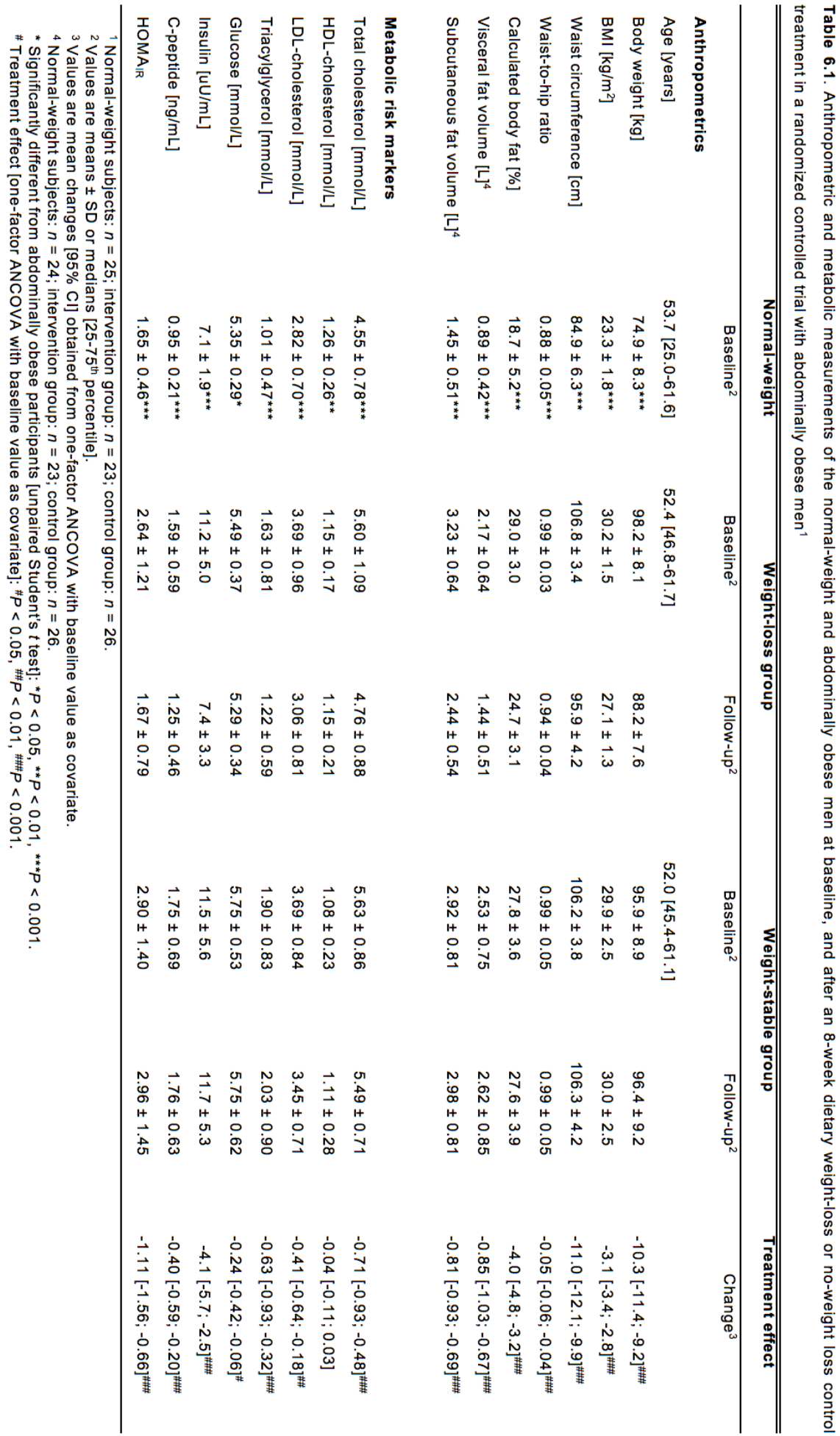




\section{CHAPTER 6}

Table 6.2 shows effects on plasma biomarkers for endothelial function and lowgrade inflammation. Plasma sE-selectin concentrations were lower $(P<0.001)$ and sICAM-1 levels tended to be lower $(P=0.083)$ in the normal-weight compared with abdominally obese men, but significantly improved following dietary weight loss compared with the control treatment by $29 \mathrm{ng} / \mathrm{mL}$ [95\% Cl: 16 to $42 \mathrm{ng} / \mathrm{mL} ; P<$ 0.001 ] and $37 \mathrm{ng} / \mathrm{mL}$ [95\% Cl: 25 to $50 \mathrm{ng} / \mathrm{mL} ; P<0.001$ ], respectively. In addition, sE-selectin levels were associated at baseline with visceral fat volume $[r=0.343 ; P$ $=0.002 ; n=76], \mathrm{HOMA}_{\mathrm{IR}}[\mathrm{r}=0.460 ; P<0.001 ; n=76]$ and fasting triacylglycerol $[\mathrm{r}$ $=0.376 ; P=0.001 ; n=76]$. Moreover, improvements in sE-selectin levels following weight loss were related to changes in visceral fat volume $[r=0.427 ; P=0.042 ; n$ $=23], \mathrm{HOMA}_{\mathrm{IR}}[\mathrm{r}=0.630 ; P=0.001 ; n=23]$ and triacylglycerol $[r=0.428 ; P=$ $0.037 ; n=23]$. Reductions in sICAM-1 and changes in visceral fat volume following weight loss were also correlated $[r=0.557 ; P=0.006 ; n=23]$. No differences in sVCAM-1 and VWF\% were observed. Median TNF- $\alpha$ and CRP concentrations were significantly lower at baseline in the normal-weight men $(P<0.05)$. No significant effects of weight loss were found on IL-6, IL-8, TNF- $\alpha$, CRP and SAA.

\section{Blood pressure and vascular function markers}

At baseline, normal-weight subjects had a significantly lower brachial and aortic SBP, brachial and aortic DBP, mean arterial pressure [MAP], heart rate, brachial artery diameter and $\mathrm{PWV}_{\mathrm{c}-f}$ than the abdominally obese men $(P<0.05$ for all variables). No differences were found for pulse pressure, FMD, RHI and CAIxHR75 [Table 6.3]. Blood pressure and heart rate improved following the weight-loss compared with the control treatment $(P<0.05$ for all variables). At the end of the diet-induced weight-loss period, blood pressure and heart rate did not differ significantly between the normal-weight and abdominally obese men in the weight-loss group.

No differences in changes between treatments were found in baseline brachial artery diameters. Also, FMD did not change. In addition, no effects of weight loss on the RHI were observed. $\mathrm{PWV}_{\mathrm{c}-\mathrm{f}}$ and CAlxHR75 tended to improve by $0.5 \mathrm{~m} / \mathrm{s}$ [95\% Cl: -0.0 to $1.1 \mathrm{~m} / \mathrm{s} ; P=0.065]$ and $3.7 \%$ [95\% Cl: -0.6 to $8.0 \% ; P$ $=0.086]$, respectively. Further, $\mathrm{PWV}_{\mathrm{c}-\mathrm{f}}$ was associated at baseline with visceral fat volume [r=0.517; $P<0.001 ; n=76]$, brachial DBP $[\mathrm{r}=0.552 ; P<0.001 ; n=77]$ and aortic DBP $[\mathrm{r}=0.551 ; P<0.001 ; n=77]$. Moreover, improvements in $\mathrm{PWV}_{\mathrm{c}-\mathrm{f}}$ following weight loss were related to changes in visceral fat volume $[r=0.467 ; P=$ $0.025 ; n=23]$, brachial DBP $[r=0.501 ; P=0.013 ; n=23]$ and aortic DBP $[r=$ $0.500 ; P=0.013 ; n=23$ ]. Finally, arteriolar calibers and retinal AVR were greater in normal-weight compared with abdominally obese men $(P<0.05)$, but improved following weight loss compared with the control treatment by $5 \mu \mathrm{m}$ [95\% Cl: 3 to 8 $\mu \mathrm{m} ; P<0.001$ ] and 0.02 [95\% Cl: 0.01 to $0.04 ; P<0.01$ ], respectively. Mean venular widths were comparable at baseline between normal-weight and abdominally obese men, and did not change following weight loss [Table 6.3]. No statistically significant correlations were observed between mean arteriolar or venular diameters with cardiometabolic risk markers. 


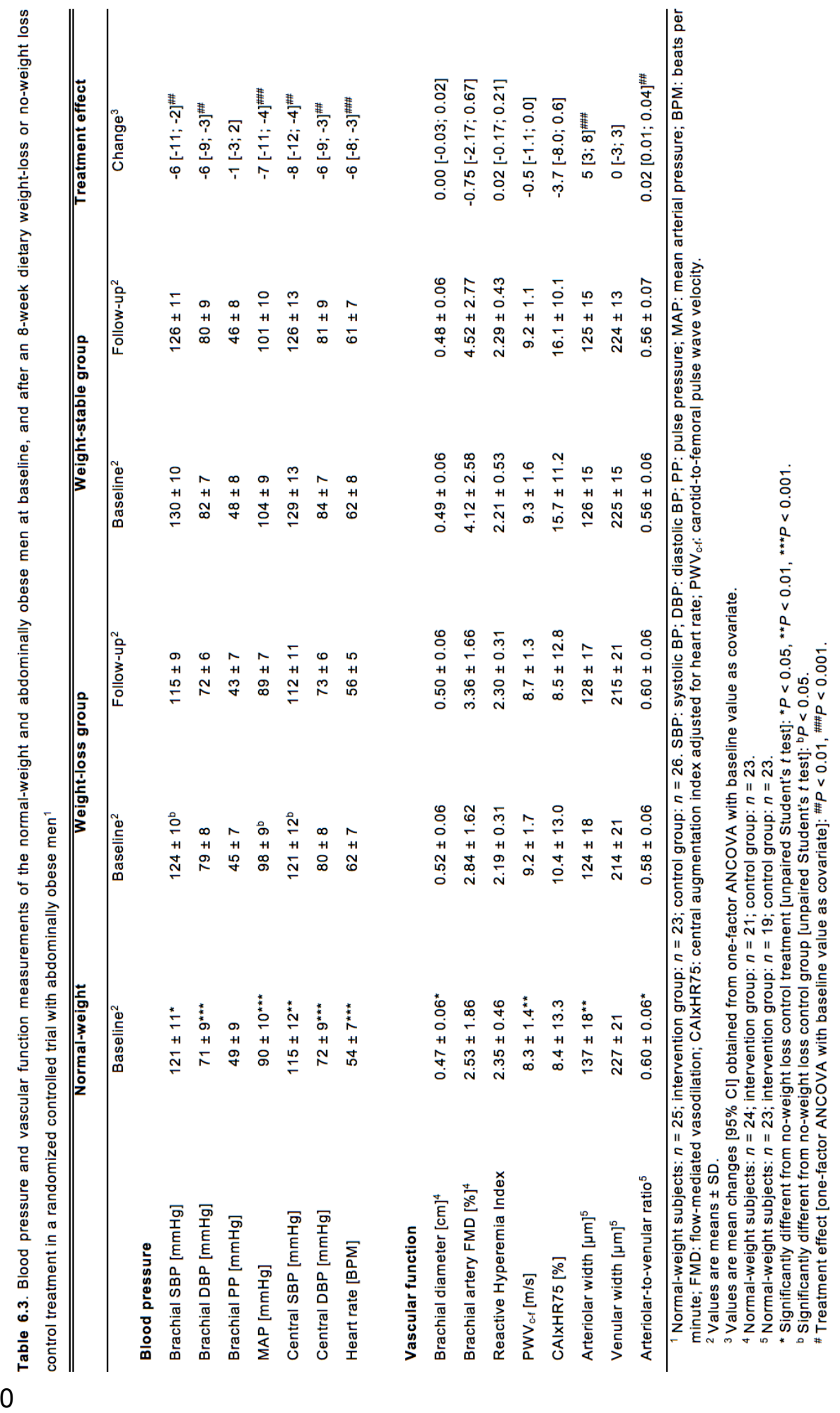




\section{Discussion}

In this randomized study in abdominally obese men, diet-induced weight loss did not affect fasting FMD of the brachial artery, while retinal microvascular caliber and plasma biomarkers of endothelial function improved. Also, aortic stiffness tended to decrease. Improvements in these vascular markers were next to the beneficial effects of weight loss on the more conventional cardiometabolic risk markers. As expected, the cardiometabolic risk profile of the normal-weight participants was more favorable than that of the abdominally obese subjects at baseline. However, values were very comparable at the end of the dietary weight-loss treatment, even if a difference in BMI and waist circumference was still present.

The lack of effect on FMD contrasts findings from several [8, 9, 23], but not all [7], earlier RCTs with a no-weight loss control group. Differences in treatment and subject characteristics may have contributed to these apparently inconsistent results. In our recent meta-analysis, which involved a total of 33 human intervention studies without a no-weight loss control group, it was estimated that each $5 \mathrm{~cm}$ decrease in waist circumference was associated with an increase of 1.17 percentage points [ $95 \% \mathrm{Cl}: 0.45$ to 1.86 ] in FMD [6]. Based on this estimate, we would have expected a 2.57 percentage points improvement in the present study. However, the estimated change was smaller when study participants had no coexisting obesity-related morbidities or received diet-induced weight-loss regimes alone [6], which may partly explain our present results. To our knowledge, only one randomized study with a no-weight loss control group has investigated the effects of dietary weight loss on FMD in overweight and obese adults [23]. In that trial, brachial artery FMD improved by 1.90 percentage points after 12 weeks of reduced energy intake. Like in our RCT, weight loss was about $10 \%$ of initial body weight, but a weight-maintenance period of 4 weeks was used. However, BMI ranged up to $40 \mathrm{~kg} / \mathrm{m}^{2}$ in that study, while none of the male subjects in our study had a baseline BMI above $35 \mathrm{~kg} / \mathrm{m}^{2}$. Indeed, we have previously reported less pronounced effects of weight loss on fasting FMD in trials with study participants who had a mean BMI below $35 \mathrm{~kg} / \mathrm{m}^{2}$ [6]. Moreover, FMD did not differ between normal-weight and abdominally obese volunteers at the start of the study. Taken together, these findings suggest that FMD is not strongly related to BMI when values are below $35 \mathrm{~kg} / \mathrm{m}^{2}$ [24]. As expected, baseline brachial artery diameters were smaller in normal-weight participants, but did not change following weight loss in the abdominally obese men. Lastly, similar results were found for the RHI. The $\mathrm{RHI}$ is a measurement obtained at the fingertips and therefore reflects small artery reactivity, while FMD evaluates a large conduit artery. These findings agree with a previous RCT involving individuals with a similar BMI as our study population [25], but differ from a trial of improved $\mathrm{RHI}$ following dietary weight loss in severely obese patients [26]. Thus, a possible discrepancy may be related to BMI.

The $P W V_{c-f}$, which is considered the gold standard method for measuring arterial stiffness [27], tended to improve by $0.5 \mathrm{~m} / \mathrm{s}$. Results of longitudinal studies have estimated, at a mean follow-up period of about 8 years, that the risk of cardiovascular disease events decreases by $7 \%$ when $\mathrm{PWV}_{\text {c-f }}$ decreases by 0.5 $\mathrm{m} / \mathrm{s}$ [28]. To date, only one randomized trial with a no-weight loss control group has investigated the effects of diet-induced weight loss on arterial stiffness in 


\section{CHAPTER 6}

overweight and obese adults. In agreement, Dengo and colleagues have reported a decrease in $\mathrm{PWV}_{\mathrm{c-f}}$ [29]. Also, effects of weight loss on retinal microvascular caliber were addressed. Improvement in the retinal arteriolar diameters was observed, but not in the venular diameters. Consequently, the retinal AVR improved. McGeechan suggested that the risk of coronary heart disease decreases by $4 \%$ when mean arteriolar calibers increased by $5 \mu \mathrm{m}$ [i.e. the change we found in our study] in women, but not in men [30]. In our study, mean arteriolar calibers did not correlate with blood pressure, as has been observed before [31]. Also, it has been suggested that the retinal venular diameter correlates with conventional cardiometabolic risk markers [31], which we could not confirm. Finally, effects on plasma biomarkers of microvascular endothelial function were studied and positive effects were observed for sE-selectin and sICAM-1, which are both involved in the adhesion of leukocytes to the endothelium [32]. This suggests that endothelial activity is reduced after dietary weight loss.

Vascular function and cardiometabolic risk markers at the end of the dietinduced weight-loss intervention became comparable with those of normal-weight men despite still a large difference in both BMI $\left[30.1 \pm 2.1 \mathrm{~kg} / \mathrm{m}^{2}\right.$ versus $23.3 \pm 1.8$ $\left.\mathrm{kg} / \mathrm{m}^{2}\right]$ and waist circumference $[95.9 \pm 4.2 \mathrm{~cm}$ versus $84.9 \pm 6.3 \mathrm{~cm}]$. Interestingly, study participants assigned to the weight-loss program obtained a waist circumference below $102 \mathrm{~cm}$, which underlines the practical relevance of the cutoff value.

Although the mechanisms for the beneficial effects of dietary weight loss on vascular function have not been fully elucidated, depletions in visceral fat [33] and associated improvements in blood pressure and other cardiometabolic risk markers may be major causes. Excess visceral fat is characterized by abdominal obesity, metabolically more active [34], and closely linked to disturbed vascular homeostasis [5]. In fact, changes in various vascular function markers [i.e. sEselectin, sICAM-1 and $\mathrm{PWV}_{\mathrm{c}-\mathrm{f}}$ ] correlated with reductions in visceral fat volume, but not with subcutaneous fat. The magnitude of the effect on blood pressure found in this study was in agreement with a previous meta-analysis. Reductions of 6.2 $\mathrm{mmHg}$ [95\% Cl: 4.4 to $8.1 \mathrm{mmHg}$ ] and $5.0 \mathrm{mmHg}$ [95\% Cl: 3.3 to $6.6 \mathrm{mmHg}$ in SBP and DBP, respectively, were observed in study populations with an average weight loss above $5.0 \mathrm{~kg}$ [35]. In agreement with others, decreases in DBP correlated with changes in pulse wave velocity [36]. Alternatively, beneficial effects on at least some of the vascular function parameters may also be related to changes in serum triacylglycerol concentrations following weight loss, which were for all lipids comparable to those reported by a previous diet-induced weight-loss intervention study [37]. Interestingly, we found at baseline a positive correlation between plasma sE-selectin and serum concentrations of triacylglycerol. Moreover, changes in sE-selectin correlated significantly with reductions in fasting levels of serum triacylglycerol following weight reduction. The HOMA $\mathrm{IR}_{\mathrm{R}}$ decreased suggesting that insulin sensitivity improved following weight loss. Also, reductions in plasma $s E-s e l e c t i n$ levels correlated significantly with improvements in the $\mathrm{HOMA}_{\mathrm{IR}}$. In fact, previous studies have reported higher levels of sE-selectin and sICAM-1 in individuals with insulin resistance [38], and vascular endothelial dysfunction may be closely related to impaired glucose metabolism [39]. Finally, this trial cannot provide evidence that dietary weight loss decreases plasma markers reflecting low-grade systemic inflammation in abdominally obese men. No 


\section{DIETARY WEIGHT LOSS AND VASCULAR FUNCTION}

effects on pro-inflammatory cytokines were found. As reviewed by Klimcakova and colleagues [40], similar conclusions were reached in many other studies with different weight-loss protocols. Therefore, there is no evidence that improvements in low-grade systemic inflammation have contributed to the beneficial effects on vascular function markers associated with weight loss in our study population.

In conclusion, our data indicate that in abdominally obese men diet-induced weight loss was associated with improvements in retinal microvascular caliber, plasma biomarkers of endothelial function, and more conventional risk markers related to cardiometabolic health. Aortic stiffness tended to decrease following weight loss, but brachial FMD was not affected. Improvements in these vascular markers may relate to the beneficial effects of weight loss on visceral fat volume, blood pressure, serum lipids and plasma glucose. Further, the cardiometabolic risk profile at the end of the dietary weight-loss program became comparable with those of normalweight men, which may underline the practical relevance of the waist circumference cut-off value used in the diagnosis of the metabolic syndrome [12].

\section{Acknowledgments}

The present study is funded by research grant $\mathrm{CH} 001$ from the $\mathrm{Tl}$ Food and Nutrition, a public-private partnership on precompetitive research in food and nutrition. The public partners are responsible for the study design, data collection and analysis, decision to publish, and preparation of the manuscript. The private partners have contributed to the project through regular discussions. We thank Daisy Luiten for dietary assistance, Jos Op't Roodt and Petra Niessen for their practical assistance in performing the study, and Martine Hulsbosch, Maud Beckers and Marjo van de Waarenbrug for performing biochemical analyses. Finally, we thank our volunteers for their enthusiasm and cooperation.

P.J.J., J.P., Y.H.K., A.J.H., C.D.S., C.G.S., and R.P.M. designed the study and interpreted the results. P.J.J. and Y.H.K. conducted the study and P.J.J. performed the statistical analyses. P.J.J. and R.P.M. drafted the first version of the manuscript. All authors critically read and commented on the manuscript. 
CHAPTER 6

\section{Supplemental data}

\section{Enrollment}

Subjects assessed for eligibility $(n=171)$

Excluded $(n=93)$

- Not meeting inclusion criteria $(n=79)$

- Declined to participate $(n=13)$

- Discontinued baseline measurements $(n=1)$

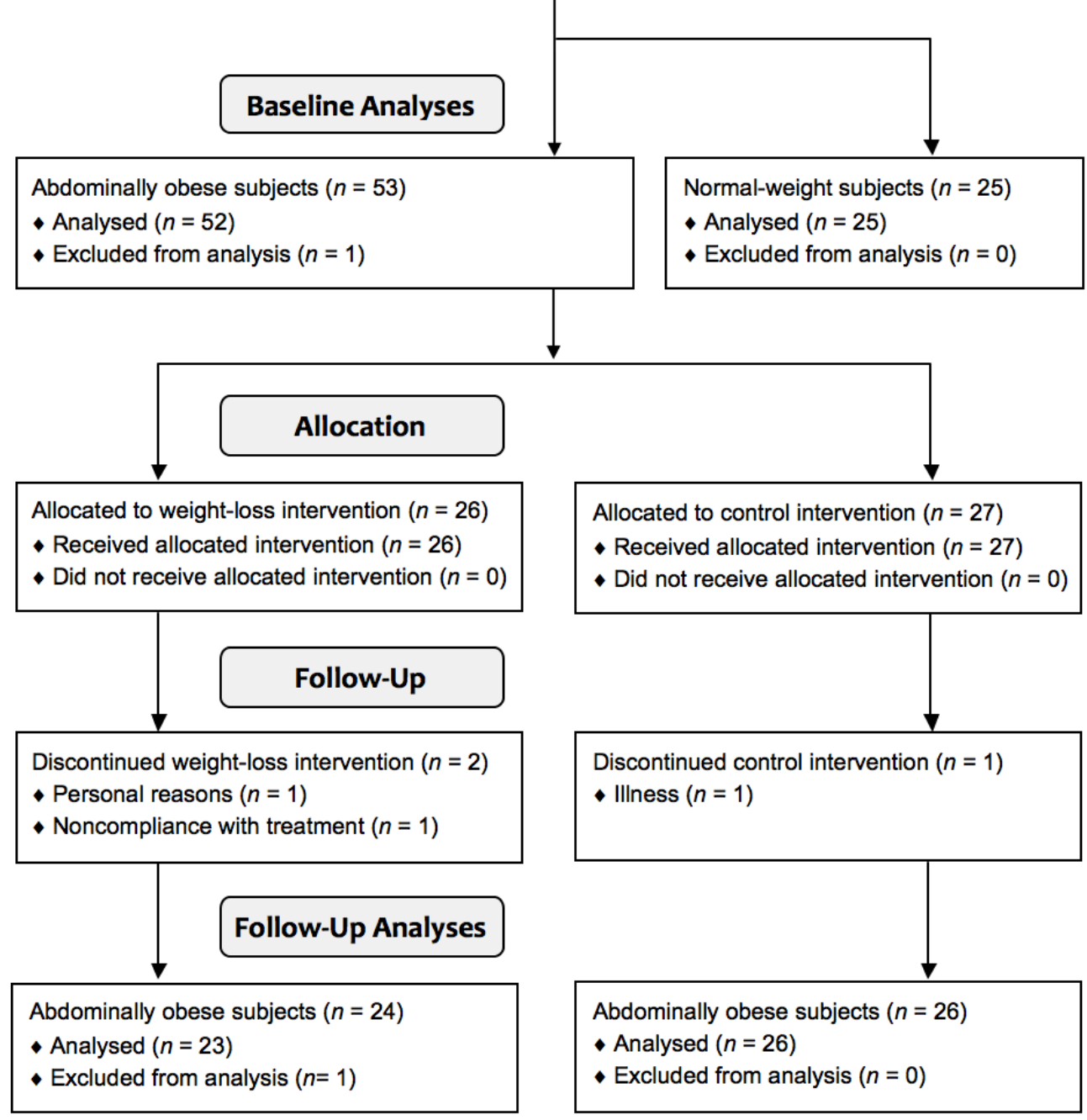

Supplemental Figure 6.1. Consort flow diagram. Diagram of the progress through the phases of this randomized parallel trial with two treatment groups. 


\section{DIETARY WEIGHT LOSS AND VASCULAR FUNCTION}

Supplemental Table 6.1. Measurements of the abdominally obese men at baseline ${ }^{1}$

\begin{tabular}{|c|c|c|c|}
\hline \multicolumn{2}{|r|}{ Abdominally obese } & & Abdominally obese \\
\hline & Baseline $^{2}$ & & Baseline $^{2}$ \\
\hline Anthropometrics & & Blood pressure & \\
\hline Age [years] & $51.8[45.7-60.7]$ & Brachial SBP [mmHg] & $127 \pm 10$ \\
\hline Body weight $[\mathrm{kg}]$ & $96.9 \pm 8.4$ & Brachial DBP [mmHg] & $81 \pm 7$ \\
\hline BMI $\left[\mathrm{kg} / \mathrm{m}^{2}\right]$ & $30.1 \pm 2.1$ & Brachial PP [mmHg] & $46 \pm 8$ \\
\hline Waist circumference $[\mathrm{cm}]$ & $106.5 \pm 3.6$ & MAP [mmHg] & $101 \pm 9$ \\
\hline Waist-to-hip ratio & $0.99 \pm 0.04$ & Central SBP [mmHg] & $125 \pm 13$ \\
\hline Calculated body fat [\%] & $28.0 \pm 3.5$ & Central DBP [mmHg] & $82 \pm 7$ \\
\hline Visceral fat volume $[\mathrm{L}]$ & $2.34 \pm 0.72$ & Heart rate $[\mathrm{BPM}]$ & $62 \pm 8$ \\
\hline Subcutaneous fat volume [L] & $3.09 \pm 0.78$ & & \\
\hline Metabolic risk markers & & Vascular function & \\
\hline Total cholesterol $[\mathrm{mmol} / \mathrm{L}]$ & $5.56 \pm 0.97$ & Brachial diameter $[\mathrm{cm}]^{3}$ & $0.51 \pm 0.06$ \\
\hline HDL-cholesterol [mmol/L] & $1.11 \pm 0.21$ & Brachial artery FMD $[\%]^{3}$ & $3.54 \pm 2.16$ \\
\hline LDL-cholesterol $[\mathrm{mmol} / \mathrm{L}]^{3}$ & $3.67 \pm 0.88$ & Reactive Hyperemia Index & $2.20 \pm 0.42$ \\
\hline TAG $[\mathrm{mmol} / \mathrm{L}]$ & $1.82 \pm 0.91$ & CAlxHR75 [\%] & $12.5 \pm 12.5$ \\
\hline Glucose [mmol/L] & $5.64 \pm 0.48$ & $\mathrm{PWV}_{\mathrm{c-f}}[\mathrm{m} / \mathrm{s}]$ & $9.2 \pm 1.7$ \\
\hline Insulin $[\mathrm{uU} / \mathrm{mL}]$ & $11.6 \pm 5.4$ & Arteriolar width $[\mu \mathrm{m}]^{4}$ & $124 \pm 17$ \\
\hline C-peptide $[\mathrm{ng} / \mathrm{mL}]$ & $1.69 \pm 0.67$ & Venular width $[\mu \mathrm{m}]^{4}$ & $219 \pm 20$ \\
\hline $\mathrm{HOMA}_{\mathrm{IR}}$ & $2.84 \pm 1.38$ & Arteriolar-to-venular ratio ${ }^{4}$ & $0.57 \pm 0.06$ \\
\hline Endothelial dysfunction & & Low-grade inflammation & \\
\hline sVCAM-1 [ng/mL] & $413 \pm 79$ & $\mathrm{IL}-6[\mathrm{pg} / \mathrm{mL}]^{3}$ & $0.62[0.47-0.87]$ \\
\hline sICAM-1 [ng/mL] & $255 \pm 52$ & IL-8 [pg/mL] & $3.57[2.83-3.95]$ \\
\hline sE-selectin [ng/mL] & $108 \pm 45$ & TNF- $\alpha[p g / m L]$ & $2.03[1.67-2.44]$ \\
\hline vWf [\%] & $125 \pm 44$ & $\mathrm{CRP}[\mu \mathrm{g} / \mathrm{mL}]^{5}$ & $1.44[0.54-2.95]$ \\
\hline
\end{tabular}

${ }^{1}$ Abdominally obese subjects: $n=52$. TAG: triacylglycerol; sVCAM: soluble vascular cell adhesion molecule; sICAM: soluble intercellular adhesion molecule; sE-selectin: soluble endothelial selectin; vWf: von Willebrand factor; IL: interleukin; TNF: tumor necrosis factor; CRP: C-reactive protein; SAA: serum amyloid A; SBP: systolic BP; DBP: diastolic BP; PP: pulse pressure; MAP: mean arterial pressure; BPM: beats per minute; FMD: flow-mediated vasodilation; CAIxHR75: central augmentation index adjusted for heart rate; $\mathrm{PWV}_{\mathrm{c} \text {-f: }}$ carotid-to-femoral pulse wave velocity. ${ }^{2}$ Values are means $\pm S D$ or medians $\left[25-75^{\text {th }}\right.$ percentile]. ${ }^{3}$ Abdominally obese subjects: $n=51 .{ }^{4}$ Abdominally obese subjects: $n=45 .{ }^{5}$ Abdominally obese subjects: $n=49 .{ }^{6}$ Abdominally obese subjects: $n=47$. 


\section{CHAPTER 6}

\section{References}

1. Despres JP, Lemieux I. Abdominal obesity and metabolic syndrome. Nature 2006;444:8817.

2. Schachinger V, Britten MB, Zeiher AM. Prognostic impact of coronary vasodilator dysfunction on adverse long-term outcome of coronary heart disease. Circulation 2000;101:1899-906.

3. Van Gaal LF, Mertens IL, De Block CE. Mechanisms linking obesity with cardiovascular disease. Nature 2006;444:875-80.

4. Cohn JN, Quyyumi AA, Hollenberg NK, Jamerson KA. Surrogate markers for cardiovascular disease: functional markers. Circulation 2004;109:IV31-46.

5. Beijers HJ, Ferreira I, Bravenboer B, Henry RM, Schalkwijk CG, Dekker JM, Nijpels G, Stehouwer CD. Higher central fat mass and lower peripheral lean mass are independent determinants of endothelial dysfunction in the elderly: the Hoorn study. Atherosclerosis 2014;233:310-8.

6. Joris PJ, Zeegers MP, Mensink RP. Weight loss improves fasting flow-mediated vasodilation in adults: a meta-analysis of intervention studies. Atherosclerosis 2015;239:2130 .

7. Blumenthal JA, Babyak MA, Hinderliter A, Watkins LL, Craighead L, Lin PH, Caccia C, Johnson J, Waugh R, Sherwood A. Effects of the DASH diet alone and in combination with exercise and weight loss on blood pressure and cardiovascular biomarkers in men and women with high blood pressure: the ENCORE study. Arch Intern Med 2010;170:126-35.

8. Dod HS, Bhardwaj R, Sajja V, Weidner G, Hobbs GR, Konat GW, Manivannan S, Gharib W, Warden BE, Nanda NC, et al. Effect of intensive lifestyle changes on endothelial function and on inflammatory markers of atherosclerosis. Am J Cardiol 2010;105:362-7.

9. Shechter M, Beigel R, Freimark D, Matetzky S, Feinberg MS. Short-term sibutramine therapy is associated with weight loss and improved endothelial function in obese patients with coronary artery disease. Am J Cardiol 2006;97:1650-3.

10. Walton C, Lees B, Crook D, Worthington M, Godsland IF, Stevenson JC. Body fat distribution, rather than overall adiposity, influences serum lipids and lipoproteins in healthy men independently of age. Am J Med 1995;99:459-64.

11. Nederlands Huisartsen Genootschap. Multidisciplinaire richtlijn cardiovasculair risicomanagement, Herziening 2011. Houten: Bohn Stafleu van Loghum 2011.

12. National Cholesterol Education Program Expert Panel on Detection E, Treatment of High Blood Cholesterol in A. Third Report of the National Cholesterol Education Program (NCEP) Expert Panel on Detection, Evaluation, and Treatment of High Blood Cholesterol in Adults (Adult Treatment Panel III) final report. Circulation 2002;106:3143-421.

13. Seale JL. Predicting total energy expenditure from self-reported dietary records and physical characteristics in adult and elderly men and women. Am J Clin Nutr 2002;76:52934.

14. Friedewald WT, Levy RI, Fredrickson DS. Estimation of the concentration of low-density lipoprotein cholesterol in plasma, without use of the preparative ultracentrifuge. Clin Chem 1972;18:499-502.

15. Matthews DR, Hosker JP, Rudenski AS, Naylor BA, Treacher DF, Turner RC. Homeostasis model assessment: insulin resistance and beta-cell function from fasting plasma glucose and insulin concentrations in man. Diabetologia 1985;28:412-9.

16. Stam F, van Guldener C, Schalkwijk CG, ter Wee PM, Donker AJ, Stehouwer CD. Impaired renal function is associated with markers of endothelial dysfunction and increased inflammatory activity. Nephrol Dial Transplant 2003;18:892-8.

17. Van Bortel LM, Laurent S, Boutouyrie P, Chowienczyk P, Cruickshank JK, De Backer T, Filipovsky J, Huybrechts S, Mattace-Raso FU, Protogerou AD, et al. Expert consensus 


\section{DIETARY WEIGHT LOSS AND VASCULAR FUNCTION}

document on the measurement of aortic stiffness in daily practice using carotid-femoral pulse wave velocity. J Hypertens 2012;30:445-8.

18. Corretti MC, Anderson TJ, Benjamin EJ, Celermajer D, Charbonneau F, Creager MA, Deanfield J, Drexler H, Gerhard-Herman M, Herrington D, et al. Guidelines for the ultrasound assessment of endothelial-dependent flow-mediated vasodilation of the brachial artery: a report of the International Brachial Artery Reactivity Task Force. J Am Coll Cardiol 2002;39:257-65.

19. Axtell AL, Gomari FA, Cooke JP. Assessing endothelial vasodilator function with the EndoPAT 2000. J Vis Exp 2010.

20. Stewart CV, Tsai CL, Roysam B. The dual-bootstrap iterative closest point algorithm with application to retinal image registration. IEEE Trans Med Imaging 2003;22:1379-94.

21. Hubbard LD, Brothers RJ, King WN, Clegg LX, Klein R, Cooper LS, Sharrett AR, Davis MD, Cai J. Methods for evaluation of retinal microvascular abnormalities associated with hypertension/sclerosis in the Atherosclerosis Risk in Communities Study. Ophthalmology 1999;106:2269-80.

22. De Roos N, Bots M, Schouten E, Katan M. Within-subject variability of flow-mediated vasodilation of the brachial artery in healthy men and women: implications for experimental studies. Ultrasound Med Biol 2003;29:401-6.

23. Pierce GL, Beske SD, Lawson BR, Southall KL, Benay FJ, Donato AJ, Seals DR. Weight loss alone improves conduit and resistance artery endothelial function in young and older overweight/obese adults. Hypertension 2008;52:72-9.

24. Juonala M, Viikari JS, Laitinen T, Marniemi J, Helenius H, Ronnemaa T, Raitakari OT. Interrelations between brachial endothelial function and carotid intima-media thickness in young adults: the cardiovascular risk in young Finns study. Circulation 2004;110:2918-23.

25. Olsen RH, Pedersen LR, Jurs A, Snoer M, Haugaard SB, Prescott E. A randomised trial comparing the effect of exercise training and weight loss on microvascular function in coronary artery disease. Int J Cardiol 2015;185:229-35.

26. Merino J, Megias-Rangil I, Ferre R, Plana N, Girona J, Rabasa A, Aragones G, Cabre A, Bonada $A$, Heras $M$, et al. Body weight loss by very-low-calorie diet program improves small artery reactive hyperemia in severely obese patients. Obes Surg 2013;23:17-23.

27. Laurent S, Cockcroft J, Van Bortel L, Boutouyrie P, Giannattasio C, Hayoz D, Pannier B, Vlachopoulos C, Wilkinson I, Struijker-Boudier H, et al. Expert consensus document on arterial stiffness: methodological issues and clinical applications. Eur Heart J 2006;27:2588605.

28. Vlachopoulos C, Aznaouridis K, Stefanadis C. Prediction of cardiovascular events and allcause mortality with arterial stiffness: a systematic review and meta-analysis. J Am Coll Cardiol 2010;55:1318-27.

29. Dengo AL, Dennis EA, Orr JS, Marinik EL, Ehrlich E, Davy BM, Davy KP. Arterial destiffening with weight loss in overweight and obese middle-aged and older adults. Hypertension 2010;55:855-61.

30. Liew G, Sharrett AR, Wang JJ, Klein R, Klein BE, Mitchell P, Wong TY. Relative importance of systemic determinants of retinal arteriolar and venular caliber: the atherosclerosis risk in communities study. Arch Ophthalmol 2008;126:1404-10.

31. McGeechan K, Liew G, Macaskill P, Irwig L, Klein R, Klein BE, Wang JJ, Mitchell P, Vingerling JR, Dejong PT, et al. Meta-analysis: retinal vessel caliber and risk for coronary heart disease. Ann Intern Med 2009;151:404-13.

32. Calder PC, Ahluwalia N, Albers R, Bosco N, Bourdet-Sicard R, Haller D, Holgate ST, Jonsson LS, Latulippe ME, Marcos A, et al. A consideration of biomarkers to be used for evaluation of inflammation in human nutritional studies. Br J Nutr 2013;109:S1-34.

33. Goodpaster BH, Kelley DE, Wing RR, Meier A, Thaete FL. Effects of weight loss on regional fat distribution and insulin sensitivity in obesity. Diabetes 1999;48:839-47.

34. Kershaw EE, Flier JS. Adipose tissue as an endocrine organ. J Clin Endocrinol Metab 2004;89:2548-56. 


\section{CHAPTER 6}

35. Neter JE, Stam BE, Kok FJ, Grobbee DE, Geleijnse JM. Influence of weight reduction on blood pressure: a meta-analysis of randomized controlled trials. Hypertension 2003;42:87884.

36. Petersen KS, Blanch N, Keogh JB, Clifton PM. Effect of weight loss on pulse wave velocity: systematic review and meta-analysis. Arterioscler Thromb Vasc Biol 2015;35:243-52.

37. Chan DC, Watts GF, Ng TW, Yamashita S, Barrett PH. Effect of weight loss on markers of triglyceride-rich lipoprotein metabolism in the metabolic syndrome. Eur $\mathrm{J}$ Clin Invest 2008;38:743-51.

38. Hak AE, Pols HA, Stehouwer CD, Meijer J, Kiliaan AJ, Hofman A, Breteler MM, Witteman JC. Markers of inflammation and cellular adhesion molecules in relation to insulin resistance in nondiabetic elderly: the Rotterdam study. J Clin Endocrinol Metab 2001;86:4398-405.

39. Esper RJ, Nordaby RA, Vilarino JO, Paragano A, Cacharron JL, Machado RA. Endothelial dysfunction: a comprehensive appraisal. Cardiovasc Diabetol 2006;5:4.

40. Klimcakova E, Kovacikova M, Stich V, Langin D. Adipokines and dietary interventions in human obesity. Obes Rev 2010;11:446-56. 


\section{CHAPTER 7}

Long-term magnesium supplementation improves arterial stiffness in overweight and obese adults: Results of a randomized, double-blind, placebocontrolled intervention trial

Peter J. Joris, Jogchum Plat, Stephan J.L. Bakker and Ronald P. Mensink

The American Journal of Clinical Nutrition 2016; 103: 1260-1266 


\section{CHAPTER 7}

\section{Abstract}

Background: Epidemiological studies have suggested a protective effect of magnesium intake on cardiovascular risk. However, intervention trials of magnesium supplementation on blood pressure and conventional cardiometabolic risk markers are inconsistent. Effects on vascular function markers related to cardiovascular risk have hardly been studied.

Objective: The objective was to evaluate the effects of long-term magnesium supplementation on arterial stiffness.

Design: We performed a 24-week, randomized, double-blind, placebo-controlled intervention study. Fifty-two overweight and slightly obese individuals (30 men and 22 postmenopausal women, age $62 \pm 6$ years) were randomized to receive either three times daily magnesium ( $3 \times 117 \mathrm{mg}$ or $350 \mathrm{mg} /$ day) or placebo capsules. Twenty-four hour urine collections and 24-hour ambulatory blood pressure assessments were performed at the start and at the end of the study. Carotid-tofemoral pulse wave velocity $\left(\mathrm{PWV}_{\mathrm{c}-\mathrm{f}}\right)$ was assessed at baseline, after 12 weeks, and at week 24 .

Results: Serum magnesium concentrations did not differ after 12 weeks, but tended to increase after 24-week magnesium supplementation compared with placebo by $0.02 \mathrm{mmol} / \mathrm{L}(95 \% \mathrm{Cl}$ : 0.00 to $0.04 \mathrm{mmol} / \mathrm{L} ; P=0.09)$. Twenty-four hour urinary magnesium excretion increased by $2.01 \mathrm{mmol}(95 \% \mathrm{Cl}: 1.22$ to $2.93 \mathrm{mmol}$; $P<0.001)$ at week 24 . $\mathrm{PWV}_{\text {c-f }}$ was not changed after 12 weeks $(0.0 \mathrm{~m} / \mathrm{s} ; 95 \% \mathrm{Cl}$ : 0.6 to $0.5 \mathrm{~m} / \mathrm{s} ; P=0.90)$, but was improved in the magnesium compared with the placebo group by $1.0 \mathrm{~m} / \mathrm{s}(95 \% \mathrm{Cl}: 0.4$ to $1.6 \mathrm{~m} / \mathrm{s} ; P=0.001)$ after 24 weeks. Office and 24-hour ambulatory blood pressure levels were not changed. No adverse events were observed.

Conclusion: Our data indicate that a daily magnesium supplement of $350 \mathrm{mg}$ for 24 weeks in overweight and obese adults reduces arterial stiffness, as estimated by a decrease in $\mathrm{PWV}_{\mathrm{c}-\mathrm{f}}$, suggesting a potential mechanism by which an increased dietary magnesium intake beneficially affects cardiovascular health. 


\section{Introduction}

A meta-analysis of 16 prospective cohort studies involving 313,041 subjects found an inverse association between dietary magnesium and cardiovascular disease (CVD) risk [1]. Each $200 \mathrm{mg}$ per day increment in dietary magnesium intake was associated with a $22 \%$ lower risk of ischemic heart disease (IHD). Another approach to estimate dietary magnesium intake is to measure 24-hour urinary magnesium excretion. In a prospective cohort study involving 7,664 adults, low urinary magnesium excretion was associated with an increased risk of IHD [2]. Results of these epidemiological studies underline the need for well-designed intervention trials to examine a potential causal role of magnesium intake in the prevention of CVD. However, randomized controlled trials (RCTs) with cardiovascular events as endpoints are missing, while results from intervention studies investigating the effects of magnesium intake on blood pressure [3] and other conventional cardiometabolic risk markers [4-8] are inconsistent and showed in general no clear effects. An alternative approach is to investigate the effect of magnesium supplementation on non-invasive vascular function markers that are related to cardiovascular risk. Arterial stiffness is a validated marker to demonstrate cardiovascular health benefits [9]. In this respect, carotid-to-femoral pulse wave velocity $\left(P W V_{c-f}\right)$, a non-invasive method that measures the propagation of the forward pressure wave travelling along the aorta, is considered the gold standard method for quantifying arterial stiffness [10]. A recently published meta-analysis of individual participant data from 16 studies involving a total of 17,635 participants showed that $\mathrm{PWV}_{\mathrm{c}-\mathrm{f}}$ was a predictor of IHD, CVD risk and CVD mortality, independent of other established cardiovascular risk factors [11]. To date, one RCT addressed the effect of oral magnesium supplementation on arterial stiffness, but found no effect [8]. Of note, this study was carried out with only 14 healthy young men and lasted only 8 weeks, which may have been to short to induce changes in arterial stiffness. Therefore, the objective of this randomized, double-blind, placebo-controlled intervention trial was to investigate the effects of magnesium supplementation for a 24 weeks period in a large group of subjects. The trial was performed in overweight and obese middle-aged and elderly adults, because they may be expected to have an increased arterial stiffness at baseline [12], allowing for improvement by the intervention.

\section{Subjects and methods}

\section{Study population}

Apparently healthy overweight and slightly obese men and women were recruited via posters in university and hospital buildings or by advertisements in local newspapers. In addition, volunteers who had participated in earlier studies were approached. To avoid any possible variations in the study outcomes due to hormonal effects, only postmenopausal (two or more years after last menstruation) women were included. Volunteers were invited for a screening visit if they met the following inclusion criteria: aged between 45 and 70 years, stable body weight (weight gain or loss $<3 \mathrm{~kg}$ within three months prior to the screening visit), non- 


\section{CHAPTER 7}

smoker, willing to abstain from dietary supplements one month prior to the study and during the study, no current use of proton pump inhibitors or medication known to affect lipid or glucose metabolism, no diabetes, not receiving anti-hypertensive medication, and no participation in another biomedical study within one month prior to the screening visit. Fifty-two overweight and slightly obese adults were included. They had a BMI between 25 and $35 \mathrm{~kg} / \mathrm{m}^{2}$; fasting serum triacylglycerol concentrations $\leq 4.5 \mathrm{mmol} / \mathrm{L}$; serum creatinine concentrations $<116 \mu \mathrm{mol} / \mathrm{L}$ for men and $<101 \mu \mathrm{mol} / \mathrm{L}$ for women; no indications for treatment with cholesterollowering medications according to Dutch Cholesterol Consensus [13]; no active cardiovascular disease like congestive heart failure or any cardiovascular event in the past, such as an acute myocardial infarction or cerebrovascular accident; no active inflammatory disease; and no drug or alcohol abuse. All study participants gave written consent before entering the study. The study was conducted according to the guidelines laid down in the Declaration of Helsinki, approved by the Medical Ethics Committee of Maastricht University Medical Center, and registered on September $8^{\text {th }}, 2014$ at ClinicalTrials.gov as NCT02235805.

\section{Study design and products}

The study had a randomized, double-blind, placebo-controlled, parallel design with a 24-week experimental period. Subjects were allocated to receive either magnesium or placebo capsules using a computer generated randomization scheme stratified by gender. Study participants were requested to take for 24 weeks daily one capsule after breakfast, one capsule after lunch and one capsule after dinner. On the days of blood sampling, the first capsule was taken after all measurements were completed. Each capsule provided $116.7 \mathrm{mg}$ magnesium (Magnesium Citrate Complex [Mg 16\%]; AMT Labs Inc., North Salt Lake, UT, USA). Thus, daily magnesium intake provided by the three capsules was $350 \mathrm{mg}$. Placebo capsules contained starch (Amylum Solani). All the capsules were kindly provided by Laboratorium Medisan B.V. (Heerenveen, The Netherlands). DRcaps (Capsugel, Cambridge, UK) acid-resistant hypromellose capsules were used. The capsules were prepared in one batch. A total daily dose of $350 \mathrm{mg}$ was administered as this is considered the tolerable upper intake level (UL) of supplemental magnesium for adults [14]. Magnesium citrate was deliberately chosen, since this type of supplement has a higher bioavailability as compared with other magnesium formulations [15]. Capsules were provided in blister strips that contained 15 capsules. The blisters were number-coded so as to blind both study subjects and investigators. Our research dietician provided six blister strips to the volunteers every four weeks. Participants were kindly requested to return all blisters at the next visit including any unused capsules that were counted as a measure of compliance. Study volunteers maintained their habitual diet, physical activity levels and consumption of alcohol throughout the total study period.

Measurements were performed at the start of the study, after 12 weeks, and at the end of the study. Twenty-four hour ambulatory blood pressure was monitored (Mobil-O-Graph; I.E.M., Stolberg, Germany) and all subjects collected 24-hour urine samples at baseline (day -3) and at week 24 (day 165). Blood pressure recordings were taken every 15 minutes during daytime (from $07.00 \mathrm{AM}$ till $11.00 \mathrm{PM}$ ) and every 30 minutes at night (from 11.00 PM till $07.00 \mathrm{AM}$ ) on the 
non-dominant arm. Subjects were asked to maintain their normal daily activities during all the recording periods and to avoid intensive exercise. The first recording was discarded and a 24-hour mean ambulatory blood pressure was calculated, as well as daytime (from 07.00 AM till 11.00 PM) and nighttime (from 11.00 PM till 07.00 AM) means. Variabilities were quantified as the SD of 24 -hour, daytime and nighttime values. Nocturnal blood pressure reductions were calculated as continuous variables ([the mean daytime blood pressure - the mean nighttime blood pressure] / the mean daytime blood pressure) $\times 100$ [16]. For 24-hour urine collection, study volunteers were instructed to discard the first morning urine samples and to collect all urine for the following 24 hours. A separate container was used to collect all urine during the night and the first morning urine sample of the next morning after arousal. Participants were requested to empty their bladder completely before going to sleep. In addition, they completed at the start and at the end of the trial a food-frequency questionnaire (FFQ) to estimate food intake from the previous four weeks. FFQs were immediately checked by a research dietician in the presence of the participants. Energy and nutrient intakes were calculated using the Dutch Food Composition Tables [17]. Individuals were requested to record daily in study diaries any signs or symptoms of illnesses, use of medication, consumption of alcohol, any deviations of the study protocol and any other complaints.

\section{Blood sampling and analyses}

Fasting blood samples were taken at the start of the study (days -3 and 0 ), at week 12 (day 84), and at the end of the study (days 165 and 168) from a forearm vein by venipuncture. On the days preceding blood sampling, participants were requested not to consume alcohol or to perform any strenuous physical exercise. On the morning of blood sampling, subjects arrived after an overnight fast (no food or drink after 08.00 PM, except for water) at the Metabolic Research Unit Maastricht (MRUM) research facilities by public transport or by car to the standardize measurements as much as possible. After blood sampling, NaF-containing vacutainer tubes (Becton, Dickinson and Company, Franklin Lanes, NY, USA) and EDTA-coated vacutainer tubes (Becton, Dickinson and Company) were immediately kept on ice and centrifuged within 30 minutes. To obtain plasma, plasma separator tubes were centrifuged at $1300 \times \mathrm{g}$ for 15 minutes at $4{ }^{\circ} \mathrm{C}$. Blood drawn in vacutainer serum tubes (Becton, Dickinson and Company) was first allowed to clot for at least 30 minutes at $21^{\circ} \mathrm{C}$. To obtain serum, serum separator tubes were centrifuged at $1300 \times g$ for 15 minutes at $21^{\circ} \mathrm{C}$. Following centrifugation, plasma and serum samples were immediately portioned into aliquots and stored at $-80^{\circ} \mathrm{C}$ until analysis at the end of the study.

Serum and urinary magnesium and calcium concentrations were determined photometrically with Magnesium and Calcium Gen.2 (COBAS; Roche Diagnostics $\mathrm{GmbH}$, Mannheim, Germany) by the Central Diagnostic Laboratory Maastricht University Medical Center. Sodium and potassium concentrations were assessed with the indirect ion-selective electrode (ISE) method Na-K-Cl for Gen.2 (COBAS; Roche Diagnostics $\mathrm{GmbH}$ ). In addition, hematological parameters were determined, including hemoglobin, red blood cells count, hematocrit, white blood 


\section{CHAPTER 7}

cell count, differential leukocyte count and platelet count. Technicians were not aware of the treatments of the participants.

\section{Clinical measurements}

Height was measured during the screening using a wall-mounted stadiometer. Weight and the waist-to-hip circumference ratio as a measure of body fat distribution were determined before the start of the vascular measurements at the start of the trial (day 0), at week 12, and at the end of the trial (day 168). After placement of the tonometer leads and an acclimatization period of 30 minutes in the supine position, office blood pressure (systolic [SBP] and diastolic blood pressure [DBP], and pulse pressure) and heart rate (HR) were measured using a semi-continuous blood pressure monitoring device (Omron M7; CEMEX Medische Techniek, Nieuwegein, The Netherlands). The first measurement was discarded and the average of the last three measurements is reported.

Vascular measurements were performed in a quiet, darkened, temperature-controlled room at $22^{\circ} \mathrm{C}$. Radial artery pulse wave analysis (PWA) was performed in triplicate, with a tonometer (SphygmoCor v9; AtCor Medical, West Ryde, Australia) that was applied to the radial artery near the wrist of the arm. The central arterial waveform was derived from the peripheral waveform using a validated transfer function. Central augmentation indices (CAlxHR75) were defined as the difference between the first peak and second peak of the arterial waveform, expressed as a percentage of the pulse pressure and corrected for heart rate. Using the same tonometer, $\mathrm{PWV}_{\mathrm{c}-\mathrm{f}}$ was determined, in triplicate, by measuring the arrival of the pulse wave and the delay to the R-wave of the electrocardiogram at the carotid and femoral artery. $\mathrm{PWV}_{\mathrm{c}-\mathrm{f}}$ was calculated automatically by the program of the manufacturer after entering $80 \%$ of the direct straight carotid-to-femoral distance [18].

\section{Statistical analyses}

Results are presented as means \pm SDs, unless otherwise indicated. Before the start of the study, it was calculated that the statistical power to detect a true difference of at least $1.2 \mathrm{~m} / \mathrm{s}$ in $\mathrm{PWV}_{\mathrm{c}-\mathrm{f}}$ with 25 participants per treatment group was $80 \%$. For these power calculations, an $\alpha$ of 0.05 and within-subject variability of $1.5 \mathrm{~m} / \mathrm{s}$ in $\mathrm{PWV}_{\mathrm{c-f}}$, that we found in a previous trial, were used [19]. Differences in baseline values between both treatment groups were tested using an unpaired Student's $t$ test. A one-way ANCOVA, using the baseline measurements of the outcome variables as covariates, was conducted to evaluate differences in responses between magnesium and placebo treatments. $A<0.05$ was considered statistically significant. Analyses were performed using SPSS 23.0 for Mac OS X (SPSS Incorporated, Chicago, IL, USA). 


\section{MAGNESIUM AND ARTERIAL STIFFNESS}

\section{Results}

\section{Study participants}

A consort flow diagram of subjects throughout the study is shown in Supplemental Figure 7.1. After screening, 52 subjects were eligible for participation and started the trial. One male subject from the magnesium group dropped out in week 6 because of personal reasons. A total of 51 individuals (29 men and 22 postmenopausal women) completed the trial. FFQ data at the start of the study were missing for one woman from the placebo group. Baseline characteristics of the adults who completed the study are shown in Table 7.1. The mean age of the study participants was $62 \pm 6$ years and their mean BMI was $29.6 \pm 2.8 \mathrm{~kg} / \mathrm{m}^{2}$.

Energy and nutrient intakes, as estimated with FFQs, did not change during the study (Supplemental Table 7.1). BMI $\left(29.3 \pm 2.6 \mathrm{~kg} / \mathrm{m}^{2}\right.$ versus $29.9 \pm$ $3.1 \mathrm{~kg} / \mathrm{m}^{2} ; P=0.40$ ) and fat distribution (waist-to-hip circumference ratio; $0.95 \pm$ 0.07 versus $0.96 \pm 0.09 ; P=0.59$ ) were comparable at baseline between the magnesium and placebo groups (Table 7.1). At the end of the study, these values were respectively $29.4 \pm 2.9 \mathrm{~kg} / \mathrm{m}^{2}$ and $0.95 \pm 0.07$ versus $30.2 \pm 3.4 \mathrm{~kg} / \mathrm{m}^{2}$ and $0.97 \pm 0.08$ for the magnesium and placebo groups. Changes were not different between the two groups. No effects on hematological parameters were observed.

As evidenced from capsule count, overall compliance ranged between $86 \%$ and $102 \%$, and was on average $99 \%$ and $98 \%$ for the magnesium and placebo groups, respectively. No serious adverse events were reported in individuals' diaries. Only one woman from the magnesium group reported mild headache and mild gastrointestinal complaints for seven days during the $11^{\text {th }}$ week of the study.

Table 7.1. Baseline characteristics of the overweight and obese adults who completed the study ${ }^{1,2}$

\begin{tabular}{lcc}
\hline \hline & Magnesium Group & Placebo Group \\
\hline Men / women, $n$ & $14 / 12$ & $15 / 10$ \\
Age, years & $62 \pm 5$ & $62 \pm 6$ \\
BMI, kg/m & $29.3 \pm 2.6$ & $29.9 \pm 3.1$ \\
Waist circumference, cm & $100 \pm 9$ & $104 \pm 11$ \\
Waist-to-hip circumference ratio & $0.95 \pm 0.07$ & $0.96 \pm 0.09$ \\
Total cholesterol, mmol/L & $6.08 \pm 0.88$ & $5.70 \pm 0.81$ \\
TAG, mmol/L & $1.34 \pm 0.63$ & $1.37 \pm 0.50$ \\
Glucose, mmol/L & $5.53 \pm 0.52$ & $5.49 \pm 0.60$ \\
Serum creatinine, $\mu \mathrm{mol} / \mathrm{L}$ & $80.1 \pm 11.3$ & $82.1 \pm 13.3$ \\
Brachial SBP, mmHg & $130 \pm 15$ & $126 \pm 14$ \\
Brachial DBP, mmHg & $82 \pm 8$ & $81 \pm 7$ \\
HR, b.p.m. & $58 \pm 7$ & $61 \pm 6$
\end{tabular}

${ }^{1}$ Magnesium group: $n=26$; placebo group: $n=25$. BMI: body mass index; TAG: triacylglycerol; SBP: systolic blood pressure; DBP: diastolic blood pressure; HR: heart rate; b.p.m.: beats per minute. ${ }^{2}$ Values are means \pm SDs. 


\section{CHAPTER 7}

Vascular function markers and blood pressure

After 12 weeks of supplementation, changes in $\mathrm{PWV}_{\text {c-f }}$ were not statistically different between the two treatment groups (Table 7.2). At the end of the study, $\mathrm{PWV}_{\text {c-f }}$ was significantly improved in the oral magnesium supplementation group compared with the placebo group by $1.0 \mathrm{~m} / \mathrm{s}(95 \% \mathrm{Cl}: 0.4$ to $1.6 \mathrm{~m} / \mathrm{s} ; P=0.001)$. No effects were observed on CAlxHR75.

The effects of dietary magnesium supplementation on blood pressure are presented in Table 7.2 and Supplemental Table 7.2. Office SBP, DBP, pulse pressure and HR did not change after 12 weeks and 24 weeks of supplementation. There were also no significant effects on mean 24-hour, mean daytime and mean nighttime ambulatory blood pressure levels. Variabilities and nocturnal reductions in SBP and DBP did not differ between the two treatment groups.

\section{Serum and urinary parameters}

Serum magnesium concentrations did not differ at 12 weeks, but tended to increase after oral magnesium supplementation compared with the placebo treatment by $0.02 \mathrm{mmol} / \mathrm{L}(95 \% \mathrm{Cl}: 0.00$ to $0.04 \mathrm{mmol} / \mathrm{L} ; P=0.09)$ at the end of the study. Magnesium intake resulted in increased serum potassium concentrations of $0.24 \mathrm{mmol} / \mathrm{L}(95 \% \mathrm{Cl}: 0.07$ to $0.42 \mathrm{mmol} / \mathrm{L} ; P=0.007)$ at 12 weeks, while no significant differences were observed compared with placebo after 24 weeks. No effects on serum calcium and sodium concentrations were found (Table 7.3). Serum mineral concentrations were within normal range at baseline, at week 12, and at the end of the trial [20].

Table 7.3 shows the effects of 24-week magnesium citrate supplementation on urinary parameters. Twenty-four hour urinary magnesium excretion increased by $2.01 \mathrm{mmol}(95 \% \mathrm{Cl}: 1.22$ to $2.93 \mathrm{mmol} ; P<0.001)$. In fact, all individuals from the magnesium group had increased 24-hour urinary magnesium concentrations at the end of the trial. No differences in other urinary parameters were observed. No differences in other urinary parameters were observed. 
MAGNESIUM AND ARTERIAL STIFFNESS

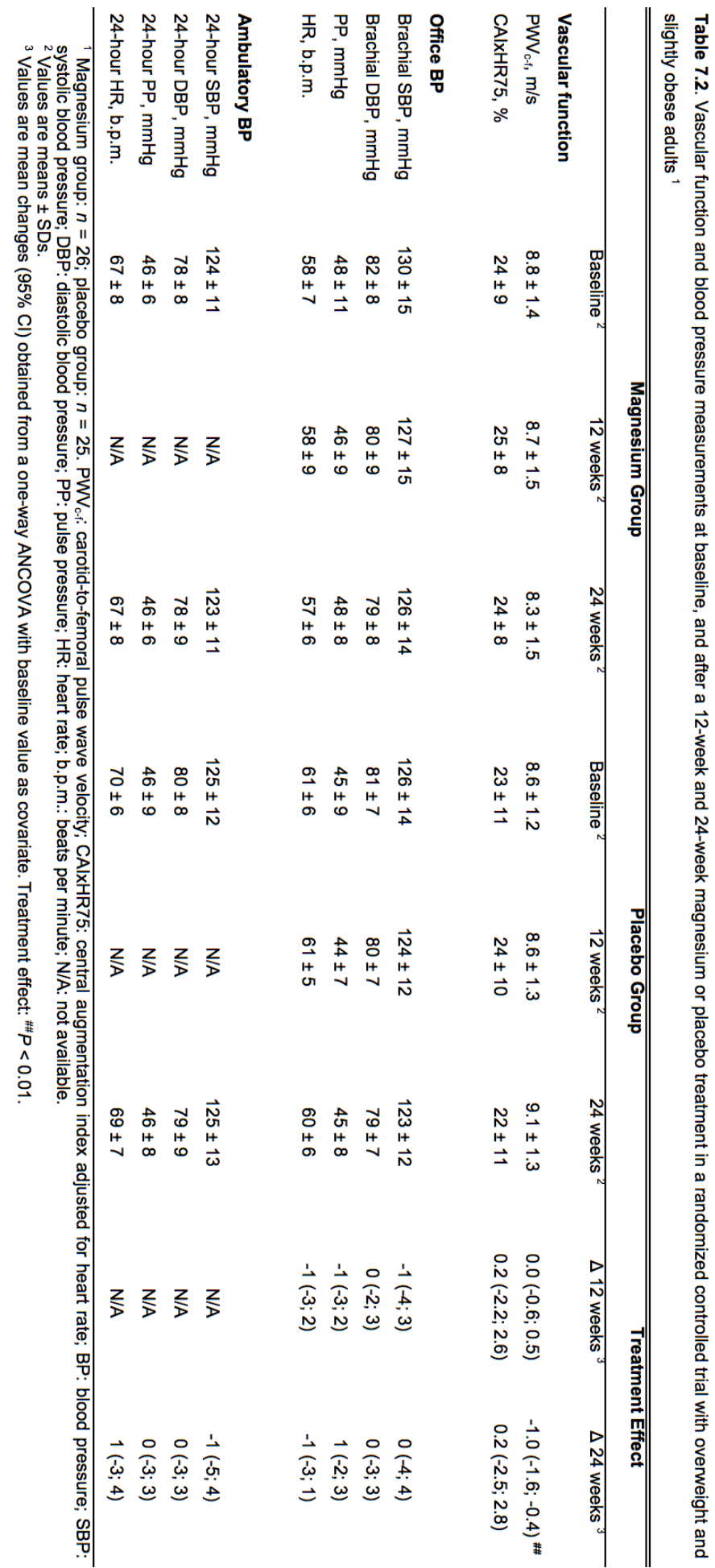




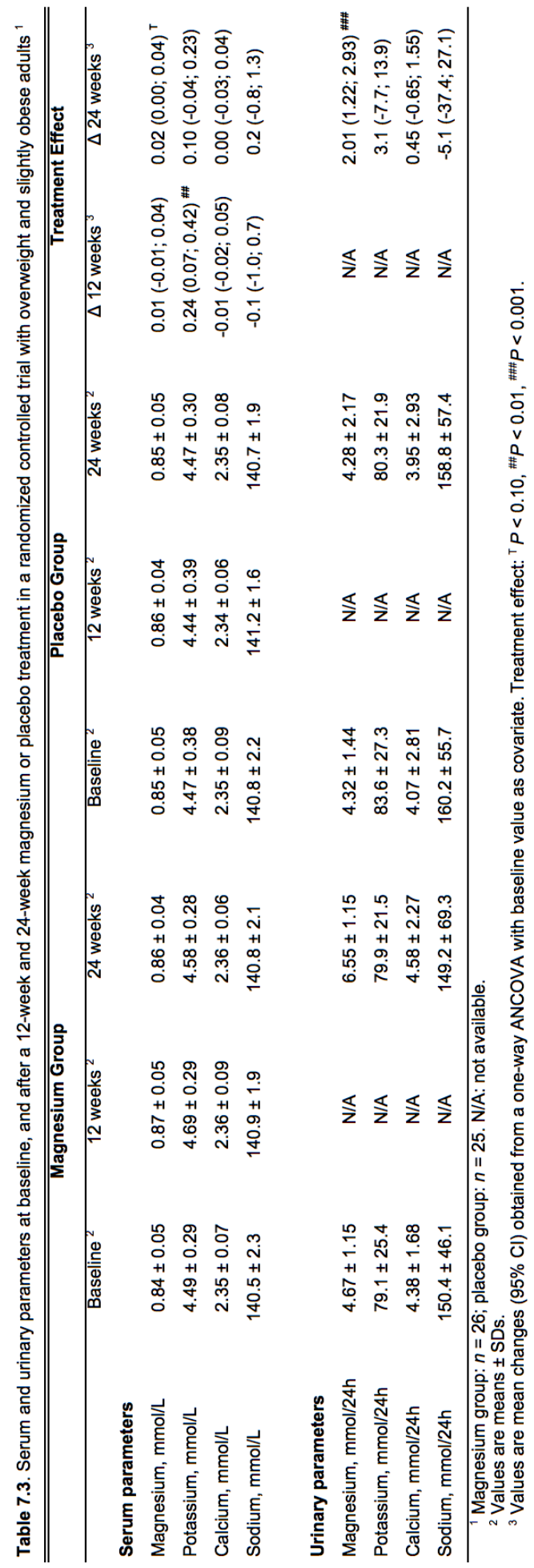




\section{Discussion}

In this RCT with overweight and obese men and postmenopausal women, we found a decrease in $P W V_{c-f}$ after 24-weeks of daily supplementation with $350 \mathrm{mg}$ magnesium, indicating an improvement in arterial stiffness. The $P W V_{c-f}$, which is considered the current gold standard method for measuring arterial stiffness [10], was reduced by $1.0 \mathrm{~m} / \mathrm{s}$. Results of longitudinal epidemiological studies have estimated that the risk of cardiovascular events decreases by $14 \%$ when $\mathrm{PWV}_{\mathrm{c} \text {-f }}$ improves by $1.0 \mathrm{~m} / \mathrm{s}$ [21], underlining the potential clinical relevance of these findings.

To the best of our knowledge, this is the first human intervention trial to demonstrate an improvement in arterial stiffness following magnesium supplementation. Only in one other intervention study, effects of magnesium supplementation (368 $\mathrm{mg}$ per day) on arterial stiffness have been examined, but no effects were reported [8]. However, arterial stiffness was estimated by a method, which is not considered to be the gold standard [22] and correlated poorly with $\mathrm{PWV}_{\mathrm{c-f}}$ [23]. Moreover, the number of participants was limited and the trial lasted only 8 weeks [8]. In fact, we also did not observe an improvement in $\mathrm{PWV}_{\mathrm{c} \text {-f }}$ at week 12 of the trial, while $\mathrm{PWV}_{\mathrm{c}-\mathrm{f}}$ was improved after 24 weeks of magnesium supplementation.

Blood pressure is a major determinant of arterial stiffness. In fact, a systematic review of observational studies showed that blood pressure was an independent predictor of the PWV response in $90 \%$ of the published studies involving both outcomes [24]. In contrast, we found an improved $P W V_{c-f}$ without any change in blood pressure levels or variability. A lack of effect on blood pressure is in agreement with the findings of a meta-analysis of 20 RCTs, that involved a total of 1,220 adult participants. In that meta-analysis, no overall effect of magnesium supplementation on SBP and DBP was reported [3]. However, significant heterogeneity between included studies was found and subgroup analyses suggested a beneficial effect of magnesium supplementation on blood pressure at total daily doses above $370 \mathrm{mg}$, which is slightly above the daily supplement of $350 \mathrm{mg}$ we have used [25]. In contrast to the $P W V_{\text {c-f }}$, we observed no effects on CAIxHR75. The CAIxHR75 is a non-invasive measurement of the arterial pressure waveform that depends on the tone of peripheral resistance arteries, while $P W V_{\text {-f }}$ is a direct indicator of arterial stiffness depending on the longer-term structural remodeling of large elastic arteries [10]. Previous trials showed that vascular stiffness and wave reflection indices do not necessarily change in parallel $[26,27]$. Therefore, it is possible that long-term magnesium supplementation has an impact on the aorta, but not on peripheral muscular arteries. Also other longer-term dietary interventions have been shown to improve markers of arterial stiffness without any apparent effects on brachial blood pressure levels [28], possibly through improvements in structural characteristics of large elastic arterial walls [10]. In fact, as compared with muscular arteries, a much more pronounced age-related decline in arterial wall properties of the aorta has been found allowing for improvement of this large elastic artery by interventions. These differences are probably related to differences in elastin-collagen smoothmuscle proportions [29]. 


\section{CHAPTER 7}

Even though we did not address underlying mechanisms, magnesium may improve arterial structure by blocking the deposition of calcium in the human arterial wall $[30,31]$. Serum and urinary calcium concentrations did not differ following magnesium supplementation, while serum potassium concentrations were higher after 12 weeks. Other studies have reported that magnesium supplementation for 4 weeks [32] and 6 weeks [33] also increased serum potassium concentrations. However, we observed no effects on serum potassium concentrations after 24 weeks of oral magnesium supplementation, suggesting that it takes a few months for potassium concentrations to reach a new steady-state. Also, serum concentrations of sodium did not change significantly. Therefore, it is not likely that the observed effects on $\mathrm{PWV}_{\mathrm{c}-\mathrm{f}}$ are due to homeostatic changes in these minerals. Alternative possible mechanisms to explain the beneficial effects of magnesium may relate to the postulated actions of magnesium on vascular tone, endothelial function, inflammation and oxidative stress [34].

Intervention studies have shown that oral magnesium bioavailability varies between different formulations [15]. Magnesium citrate supplementation in our study tended to increase serum magnesium concentrations by $0.02 \mathrm{mmol} / \mathrm{L}$, while 24-hour urinary magnesium excretion increased by $2.01 \mathrm{mmol}$. These findings are in agreement with those of a recent meta-analysis of magnesium supplementation studies. Increases of $0.05 \mathrm{mmol} / \mathrm{L}(95 \% \mathrm{Cl}: 0.02$ to $0.07 \mathrm{mmol} / \mathrm{L})$ in serum and of $1.52 \mathrm{mmol}$ ( $95 \% \mathrm{Cl}: 1.20$ to $1.83 \mathrm{mmol}$ ) in urinary magnesium were observed [35), when total daily doses of magnesium varied between 197 and $884 \mathrm{mg}$ (median: $360 \mathrm{mg}$ ). Increases in serum and urinary magnesium concentrations were more pronounced at higher intakes and longer study duration. Because $2 \mathrm{mmol}$ is equivalent to $49 \mathrm{mg}$ of magnesium, the observed urinary increment appears to be rather low. This may be due to a lower rate of gastrointestinal absorption than the $30 \%$, which is usually assumed for magnesium absorption from the gut [36, 37], possibly due to the relatively high magnesium intake in our trial [38]. All subjects that received the magnesium capsules had higher urinary magnesium concentrations at the end of the study. This indicates that the compliance was excellent, as also evidenced from capsule count. Urinary magnesium excretion did not increase in the previous RCT that found no effect of magnesium supplementation on arterial stiffness [8). In that study, magnesium pidolate was administered to healthy young men, aged 23 to 33 years, with a family history of the metabolic syndrome. These results could not relate to total daily magnesium dose, as they also used about $350 \mathrm{mg}$ as we did. Thus, except for subject characteristics and study duration, the magnesium formulation used may also at least partly explain the lack of effects in that study. We deliberately chose to supply magnesium citrate as this type of supplement has a higher bioavailability as compared with other formulations [15].

In conclusion, our data indicate that an oral magnesium intervention for 24 weeks in overweight and slightly obese adults results in a clinically relevant reduction in arterial stiffness, suggesting a potential mechanism by which an increased magnesium intake beneficially affects cardiovascular health outcomes. 


\section{Acknowledgments}

The present study is funded by research grant $\mathrm{CH} 001$ from Top Institute of Food and Nutrition (TIFN), a public-private partnership on precompetitive research in food and nutrition. The public partners are responsible for the study design, data collection and analysis, decision to publish, and preparation of the manuscript. The private partners have contributed to the project through regular discussion. We thank D. Luiten and C. Op't Eyndt for dietary assistance, and M. Hulsbosch for technical support. Finally, we thank our volunteers for their enthusiasm and cooperation.

The authors' responsibilities were as follows; P.J.J.: designed and conducted the trial, performed the statistical analyses, interpreted the data, and wrote the manuscript; J.P.: interpreted the data and wrote the manuscript; S.J.L.B.: interpreted the data and wrote the manuscript; and R.P.M.: designed the trial, interpreted the data, had overall responsibility for the study, and wrote the manuscript. All authors read and approved the final manuscript. The authors state no conflict of interest.

\section{Supplemental data}

Supplemental Table 7.1. Energy and nutrient intakes at baseline and after a 24-week magnesium or placebo treatment in a randomized controlled trial with overweight and slightly obese adults ${ }^{1}$

\begin{tabular}{|c|c|c|c|c|c|}
\hline & \multicolumn{2}{|c|}{ Magnesium Group } & \multicolumn{2}{|c|}{ Placebo Group } & \multirow{2}{*}{$\begin{array}{c}\text { Treatment Effect } \\
\Delta 24 \text { weeks }^{3}\end{array}$} \\
\hline & Baseline $^{2}$ & 24 weeks $^{2}$ & Baseline & 24 weeks $^{2}$ & \\
\hline Energy, MJ/day & $9.7 \pm 1.9$ & $9.3 \pm 2.5$ & $10.7 \pm 3.5$ & $10.2 \pm 3.1$ & $-0.1(-1.1 ; 0.9)$ \\
\hline Energy, kcal/day & $2317 \pm 454$ & $2223 \pm 594$ & $2546 \pm 837$ & $2435 \pm 748$ & $-29(-270 ; 212)$ \\
\hline Carbohydrate, En\% & $41.8 \pm 6.9$ & $41.9 \pm 7.3$ & $40.1 \pm 8.3$ & $41.2 \pm 6.7$ & $-0.3(-3.3 ; 2.7)$ \\
\hline Protein, En\% & $15.6 \pm 2.8$ & $15.6 \pm 2.7$ & $16.2 \pm 3.0$ & $16.0 \pm 2.7$ & $-0.1(-1.4 ; 1.1)$ \\
\hline Total fat, En\% & $37.4 \pm 5.4$ & $37.3 \pm 6.1$ & $39.5 \pm 7.6$ & $38.7 \pm 5.9$ & $0.0(-2.6 ; 2.5)$ \\
\hline SFA, En\% & $12.4 \pm 2.6$ & $12.2 \pm 2.4$ & $12.8 \pm 3.4$ & $12.8 \pm 2.8$ & $-0.3(-1.1 ; 0.4)$ \\
\hline MUFA, En\% & $13.2 \pm 3.0$ & $13.7 \pm 3.7$ & $14.6 \pm 4.5$ & $14.6 \pm 3.9$ & $0.1(-1.4 ; 1.7)$ \\
\hline PUFA, En\% & $8.1 \pm 2.0$ & $8.0 \pm 2.3$ & $8.3 \pm 2.1$ & $7.8 \pm 1.9$ & $0.3(-0.6 ; 1.3)$ \\
\hline Alcohol, En\% & $2.9 \pm 2.7$ & $2.9 \pm 2.8$ & $1.9 \pm 1.9$ & $1.8 \pm 1.9$ & $0.1(-0.4 ; 0.6)$ \\
\hline Dietary fiber, g/day & $27.1 \pm 6.3$ & $25.3 \pm 8.0$ & $28.3 \pm 8.8$ & $27.4 \pm 9.1$ & $-1.2(-4.8 ; 2.5)$ \\
\hline Cholesterol, mg/day & $234 \pm 83$ & $231 \pm 91$ & $255 \pm 119$ & $254 \pm 93$ & $-9(-44 ; 26)$ \\
\hline
\end{tabular}




\section{CHAPTER 7}

Supplemental Table 7.2. Ambulatory blood pressure measurements at baseline and after a 24-week magnesium or placebo treatment in a randomized controlled trial with overweight and obese adults ${ }^{1}$

\begin{tabular}{lccccc}
\hline \hline & \multicolumn{2}{c}{ Magnesium Group $^{2}$ Placebo Group } & Treatment Effect \\
\hline & Baseline $^{2}$ & 24 weeks $^{2}$ & Baseline $^{2}$ & 24 weeks $^{2}$ & $\Delta 24$ weeks $^{3}$ \\
& & & & & \\
Daytime SBP, mmHg & $127 \pm 12$ & $126 \pm 11$ & $129 \pm 13$ & $128 \pm 13$ & $0(-5 ; 5)$ \\
Daytime DBP, mmHg & $81 \pm 8$ & $80 \pm 8$ & $83 \pm 8$ & $81 \pm 9$ & $0(-3 ; 3)$ \\
Daytime PP, mmHg & $46 \pm 7$ & $46 \pm 7$ & $46 \pm 9$ & $46 \pm 8$ & $0(-3 ; 3)$ \\
Daytime HR, b.p.m. & $69 \pm 8$ & $70 \pm 9$ & $73 \pm 6$ & $71 \pm 8$ & $1(-3 ; 5)$ \\
Nighttime SBP, mmHg & $114 \pm 12$ & $114 \pm 11$ & $116 \pm 12$ & $116 \pm 13$ & $-2(-6 ; 3)$ \\
Nighttime DBP, mmHg & $70 \pm 9$ & $70 \pm 10$ & $71 \pm 9$ & $72 \pm 9$ & $0(-3 ; 3)$ \\
Nighttime PP, mmHg & $45 \pm 5$ & $44 \pm 6$ & $44 \pm 9$ & $45 \pm 8$ & $-1(-4 ; 2)$ \\
Nighttime HR, b.p.m. & $62 \pm 9$ & $60 \pm 6$ & $64 \pm 6$ & $62 \pm 6$ & $-2(-4 ; 1)$ \\
SD 24-hour SBP, mmHg & $14 \pm 3$ & $14 \pm 4$ & $15 \pm 4$ & $14 \pm 4$ & $1(-2 ; 3)$ \\
SD 24-hour DBP, mmHg & $11 \pm 2$ & $11 \pm 3$ & $11 \pm 2$ & $11 \pm 3$ & $0(-1 ; 2)$ \\
SD 24-hour HR, b.p.m. & $9 \pm 2$ & $9 \pm 3$ & $10 \pm 3$ & $9 \pm 4$ & $0(-2 ; 2)$ \\
SD Daytime SBP, mmHg & $13 \pm 3$ & $13 \pm 4$ & $14 \pm 5$ & $13 \pm 4$ & $0(-2 ; 3)$ \\
SD Daytime DBP, mmHg & $10 \pm 2$ & $10 \pm 4$ & $10 \pm 3$ & $10 \pm 3$ & $0(-2 ; 2)$ \\
SD Daytime HR, b.p.m. & $9 \pm 3$ & $9 \pm 3$ & $10 \pm 3$ & $9 \pm 4$ & $0(-2 ; 2)$ \\
SD Nighttime SBP, mmHg & $11 \pm 3$ & $12 \pm 4$ & $12 \pm 5$ & $12 \pm 5$ & $0(-2 ; 3)$ \\
SD Nighttime DBP, mmHg & $8 \pm 2$ & $9 \pm 3$ & $10 \pm 2$ & $9 \pm 3$ & $1(-1 ; 2)$ \\
SD Nighttime HR, b.p.m. & $5 \pm 2$ & $5 \pm 3$ & $5 \pm 2$ & $6 \pm 3$ & $0(-1 ; 2)$ \\
Dipping SBP, \% & $10 \pm 7$ & $10 \pm 5$ & $10 \pm 5$ & $9 \pm 5$ & $0(-4 ; 3)$ \\
Dipping DBP, \% & $14 \pm 8$ & $13 \pm 7$ & $14 \pm 7$ & $12 \pm 6$ & $1(-3 ; 4)$
\end{tabular}

1 Magnesium group: $n=26$; placebo group: $n=25$. BP: blood pressure; SBP: systolic blood pressure; DBP: diastolic blood pressure; PP: pulse pressure; HR: heart rate; b.p.m.: beats per minute; SD: standard deviation of individual 24-hour, daytime or nighttime values (within-subject variability). ${ }^{2}$ Values are means \pm SDs. ${ }^{3}$ Values are mean changes $(95 \% \mathrm{Cl})$ obtained from a oneway ANCOVA with baseline value as covariate. 


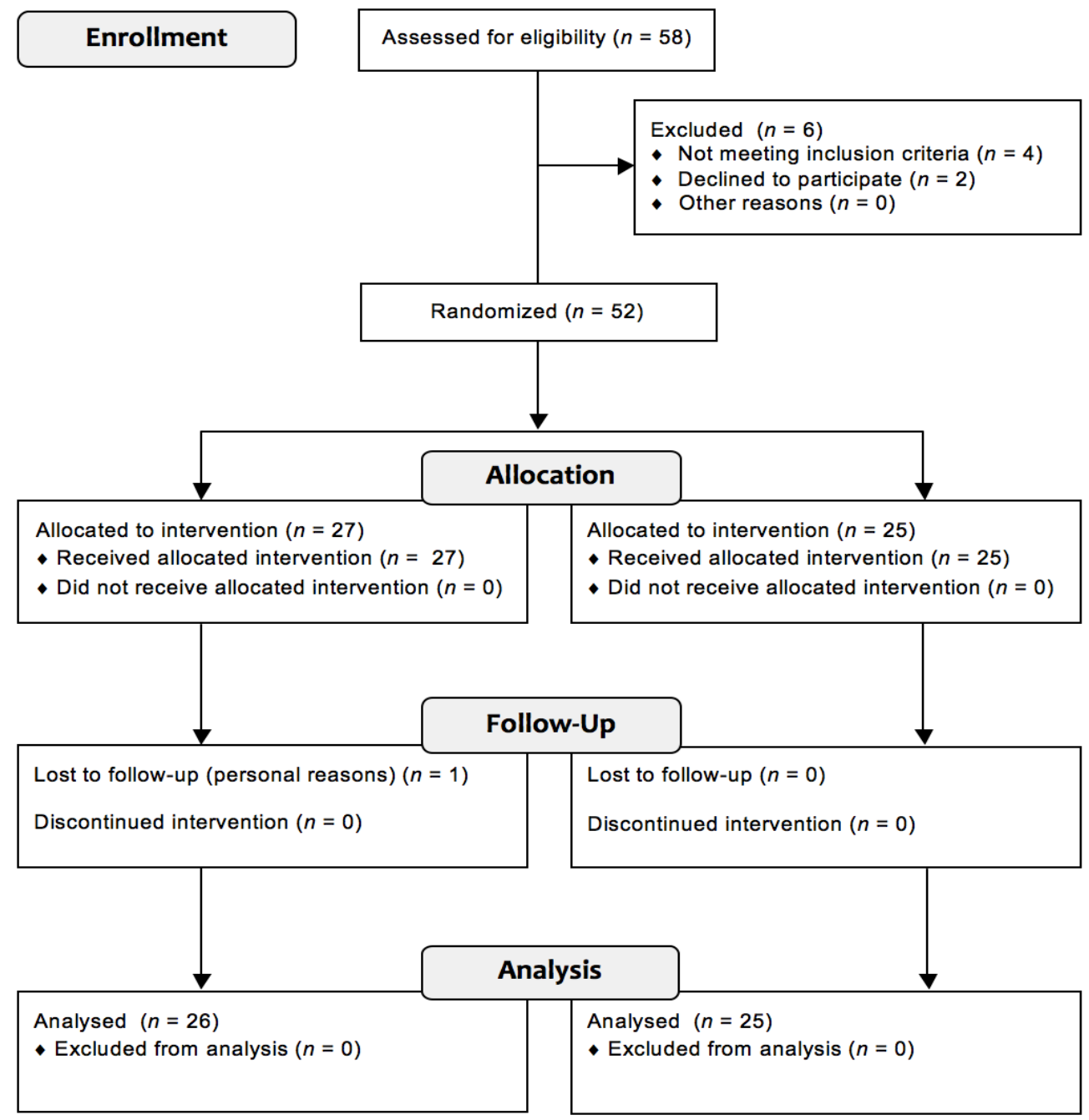

Supplemental Figure 7.1. Consort flow diagram. Diagram of the progress through the phases of this randomized parallel trial with two treatment groups. 


\section{CHAPTER 7}

\section{References}

1. Del Gobbo LC, Imamura F, Wu JH, de Oliveira Otto MC, Chiuve SE, Mozaffarian D. Circulating and dietary magnesium and risk of cardiovascular disease: a systematic review and meta-analysis of prospective studies. Am J Clin Nutr 2013;98:160-73.

2. Joosten MM, Gansevoort RT, Mukamal KJ, van der Harst P, Geleijnse JM, Feskens EJ, Navis G, Bakker SJ, Group PS. Urinary and plasma magnesium and risk of ischemic heart disease. Am J Clin Nutr 2013;97:1299-306.

3. Jee SH, Miller ER 3rd, Guallar E, Singh VK, Appel LJ, Klag MJ. The effect of magnesium supplementation on blood pressure: a meta-analysis of randomized clinical trials. Am J Hypertens 2002;15:691-6.

4. Guerrero-Romero F, Tamez-Perez HE, Gonzalez-Gonzalez G, Salinas-Martinez AM, Montes-Villarreal J, Trevino-Ortiz JH, Rodriguez-Moran M. Oral magnesium supplementation improves insulin sensitivity in non-diabetic subjects with insulin resistance. A double-blind placebo-controlled randomized trial. Diabetes Metab 2004;30:253-8.

5. Paolisso G, Sgambato S, Gambardella A, Pizza G, Tesauro P, Varricchio M, D'Onofrio F. Daily magnesium supplements improve glucose handling in elderly subjects. Am J Clin Nutr 1992;55:1161-7.

6. Marken PA, Weart CW, Carson DS, Gums JG, Lopes-Virella MF. Effects of magnesium oxide on the lipid profile of healthy volunteers. Atherosclerosis 1989;77:37-42.

7. Chacko SA, Sul J, Song Y, Li X, LeBlanc J, You Y, Butch A, Liu S. Magnesium supplementation, metabolic and inflammatory markers, and global genomic and proteomic profiling: a randomized, double-blind, controlled, crossover trial in overweight individuals. Am J Clin Nutr 2011;93:463-73.

8. Cosaro E, Bonafini S, Montagnana M, Danese E, Trettene MS, Minuz P, Delva P, Fava C. Effects of magnesium supplements on blood pressure, endothelial function and metabolic parameters in healthy young men with a family history of metabolic syndrome. Nutr Metab Cardiovasc Dis 2014;24:1213-20.

9. Cohn JN, Quyyumi AA, Hollenberg NK, Jamerson KA. Surrogate markers for cardiovascular disease: functional markers. Circulation 2004;109:IV31-46.

10. Laurent S, Cockcroft J, Van Bortel L, Boutouyrie P, Giannattasio C, Hayoz D, Pannier B, Vlachopoulos C, Wilkinson I, Struijker-Boudier H, et al. Expert consensus document on arterial stiffness: methodological issues and clinical applications. Eur Heart J 2006;27:2588605.

11. Ben-Shlomo Y, Spears M, Boustred C, May M, Anderson SG, Benjamin EJ, Boutouyrie P, Cameron J, Chen $\mathrm{CH}$, Cruickshank JK, et al. Aortic pulse wave velocity improves cardiovascular event prediction: an individual participant meta-analysis of prospective observational data from 17,635 subjects. J Am Coll Cardiol 2014;63:636-46.

12. Wildman RP, Mackey RH, Bostom A, Thompson T, Sutton-Tyrrell K. Measures of obesity are associated with vascular stiffness in young and older adults. Hypertension 2003;42:46873.

13. Nederlandse Huisarten Genootschap. Multidisciplinaire richtlijn cardiovasculair risicomanagement, Herziening 2011. Houten: Bohn Stafleu van Loghum, 2011.

14. Food and Nutrition Board, Institute of Medicine. Magnesium. Dietary Reference Intakes: Calcium, Phosphorus, Magnesium, Vitamin D, and Fluoride. Washington DC: National Academy Press 1997:190-249.

15. Walker AF, Marakis G, Christie S, Byng M. Mg citrate found more bioavailable than other Mg preparations in a randomised, double-blind study. Magnes Res 2003;16:183-91.

16. Muxfeldt ES, Cardoso CR, Salles GF. Prognostic value of nocturnal blood pressure reduction in resistant hypertension. Arch Intern Med 2009;169:874-80.

17. Nederlands Voedingsstoffenbestand (NEVO). Dutch food consumption database. Bilthoven, The Netherlands: National Institute for Public Health and the Environment 2013. 
18. Van Bortel L, Laurent S, Boutouyrie P, Chowienczyk P, Cruickshank J, De Backer T, Filipovsky J, Huybrechts S, Mattace-Raso F, Protogerou A, et al. Expert consensus document on the measurement of aortic stiffness in daily practice using carotid-femoral pulse wave velocity. J Hypertens 2012;30:445-8.

19. Joris PJ, Mensink RP. Beetroot juice improves in overweight and slightly obese men postprandial endothelial function after consumption of a mixed meal. Atherosclerosis 2013;231:78-83.

20. Heil W, Ehrhardt V. Reference ranges for adults and children. Pre-analytical considerations. Mannheim: Roche Diagnostics, 9th Edition 2008.

21. Vlachopoulos C, Aznaouridis K, Stefanadis C. Prediction of cardiovascular events and allcause mortality with arterial stiffness: a systematic review and meta-analysis. J Am Coll Cardiol 2010;55:1318-27.

22. Gunarathne A, Patel JV, Hughes EA, Lip GY. Measurement of stiffness index by digital volume pulse analysis technique: clinical utility in cardiovascular disease risk stratification. Am J Hypertens 2008;21:866-72.

23. Salvi P, Magnani E, Valbusa F, Agnoletti D, Alecu C, Joly L, Benetos A. Comparative study of methodologies for pulse wave velocity estimation. J Hum Hypertens 2008;22:669-77.

24. Cecelja M, Chowienczyk P. Dissociation of aortic pulse wave velocity with risk factors for cardiovascular disease other than hypertension: a systematic review. Hypertension 2009;54:1328-36.

25. Kass L, Weekes J, Carpenter L. Effect of magnesium supplementation on blood pressure: a meta-analysis. Eur J Clin Nutr 2012;66:411-8.

26. Vlachopoulos C, Dima I, Aznaouridis K, Vasiliadou C, Loakeimidis N, Aggeli C, Toutouza $M$, Stefanadis $C$. Acute systemic inflammation increases arterial stiffness and decreases wave reflections in healthy individuals. Circulation 2005;112:2193-200.

27. Kelly RP, Millasseau SC, Ritter JM, Chowienczyk PJ. Vasoactive drugs influence aortic augmentation index independently of pulse-wave velocity in healthy men. Hypertension 2001;37:1429-33.

28. Pase MP, Grima NA, Sarris J. The effects of dietary and nutrient interventions on arterial stiffness: a systematic review. Am J Clin Nutr 2011;93:446-54.

29. van der Heijden-Spek JJ, Staessen JA, Fagard RH, Hoeks AP, Boudier HA, van Bortel LM. Effect of age on brachial artery wall properties differs from the aorta and is gender dependent: a population study. Hypertension 2000;35:637-42.

30. Iseri LT, French JH. Magnesium: nature's physiologic calcium blocker. Am Heart J 1984;108:188-93.

31. Shechter M, Kaplinsky E, Rabinowitz B. The rationale of magnesium supplementation in acute myocardial infarction. A review of the literature. Arch Intern Med 1992;152:2189-96.

32. Cohen N, Alon I, Almoznino-Sarafian D, Zaidenstein R, Weissgarten J, Gorelik O, Berman S, Modai D, Golik A. Metabolic and clinical effects of oral magnesium supplementation in furosemide-treated patients with severe congestive heart failure. Clin Cardiol 2000;23:4336.

33. Bashir Y, Sneddon JF, Staunton HA, Haywood GA, Simpson IA, McKenna WJ, Camm AJ. Effects of long-term oral magnesium chloride replacement in congestive heart failure secondary to coronary artery disease. Am J Cardiol 1993;72:1156-62.

34. Cunha AR, Umbelino B, Correia ML, Neves MF. Magnesium and vascular changes in hypertension. Int J Hypertens 2012;2012:754250.

35. Zhang X, Del Gobbo LC, Hruby A, Rosanoff A, He K, Dai Q, Costello RB, Zhang W, Song $\mathrm{Y}$. The circulating concentration and 24-h urine excretion of magnesium dose- and timedependently respond to oral magnesium supplementation in a meta-Analysis of randomized controlled trials. J Nutr 2016.

36. Joosten MM, Gansevoort RT, Mukamal KJ, Kootstra-Ros JE, Feskens EJ, Geleijnse JM, Navis G, Bakker SJ, Group PS. Urinary magnesium excretion and risk of hypertension: the prevention of renal and vascular end-stage disease study. Hypertension 2013;61:1161-7. 


\section{CHAPTER 7}

37. Bohn T, Walczyk T, Davidsson L, Pritzkow W, Klingbeil P, Vogl J, Hurrell RF. Comparison of urinary monitoring, faecal monitoring and erythrocyte analysis of stable isotope labels to determine magnesium absorption in human subjects. $\mathrm{Br} J$ Nutr 2004;91:113-20.

38. Bohn T. Dietary factors influencing magnesium absorption in humans. Curr Nutr Food Sci 2008;4:53-72. 


\section{CHAPTER 8}

General discussion 


\section{CHAPTER 8}

\section{Introduction}

Improving diet is instrumental for the prevention of cardiovascular disease (CVD) [1], which is already for many decades a leading cause of morbidity and mortality worldwide [2]. However, the number of large randomized controlled trials (RCTs) with appropriate follow-up periods and with cardiovascular events as endpoints is limited, as they require inclusion of thousands of participants with very long followup periods. As an alternative approach, the effects of dietary interventions on noninvasive vascular function markers as surrogate risk markers of CVD can be investigated. These markers are associated with future cardiovascular events and can also be used to demonstrate CVD benefits [3]. However, there is an urgent need to know which of these vascular function markers are sensitive to dietary changes, as vascular dysfunction is a key mechanism whereby a healthy diet improves cardiovascular health [1]. The research described in the present thesis therefore focused on (i) three well-defined nutritional intervention studies and (ii) two meta-analyses of intervention studies, which were specifically designed to assess the specific effects of various dietary factors on the many different noninvasive vascular function markers in adult individuals [Table 8.1].

\section{Relevance of vascular function markers}

Many different non-invasive vascular function markers exist, each addressing a different aspect of the vasculature. Flow-mediated vasodilation (FMD) of the brachial artery is used to assess endothelial function, while other markers can be used to address arterial stiffness, such as pulse wave velocity (PWV), or microvascular structure (e.g. arteriolar-to-venular ratio [AVR] in retinal vessels). The relation between various vascular function markers and the risk of CVD is briefly summarized in chapter 2. Vascular endothelial dysfunction and arterial stiffening are key mechanisms whereby a healthy diet improves cardiovascular risk [1]. The present dissertation therefore primarily focused on the effects of dietary changes on markers of endothelial function and arterial stiffness. In fact, FMD of the brachial artery was the primary study outcome parameter in two dietary intervention studies [chapters 3 and 6] and in both meta-analyses [chapters 4 and 5], while the randomized intervention trial described in chapter 7 was specially designed to address the long-term effects of oral magnesium citrate supplementation on carotid-to-femoral PWV $\left(\mathrm{PWV}_{\mathrm{c}-\mathrm{f}}\right)$. The relevance of the various non-invasive vascular function measurements is further discussed in the sections described below.

\section{Markers of vascular endothelial function}

Celermajer and colleagues introduced the measurement of FMD in 1992 [4] and up till now it has been a study outcome in more than 3500 publications. The assessment of FMD is the most accepted and established non-invasive method to measure endothelial function and has been shown to correlate with invasively assessed endothelial function in coronary arteries [5]. However, ultrasound measures of FMD are complex and require careful training of the operator and 
well-defined analysis protocols. FMD of the brachial artery was measured according to the guidelines [6] in all nutritional intervention studies described in the thesis [chapters 3, 6 and 7]. In 2005, an extensive meta-analysis was conducted on 250 studies, which revealed that technical aspects of the measurement (i.e. position of pneumatic cuff and duration of occlusion) affect the FMD response [7]. In the intervention trials we performed [chapters 3,6 and 7], the cuff was placed around the participant's forearm and inflated for 5 minutes, since this approach gives an FMD response that is predominantly endothelium mediated. In contrast, positioning the cuff proximal to the imaging site may provoke a response that may partly be related to ischemia-induced hypoxia in the area being imaged [8].

Brachial FMD is inversely associated with future CVD events and a recent meta-analysis of prospective epidemiologic studies has suggested that each $1.0 \%$ increase in FMD is associated with a $8 \%$ lower risk of overall CVD [9]. Therefore, studies with FMD as an outcome variable may give insight into the effects of dietary interventions on CVD risk. However, treatment differences of $1.0 \%$ in brachial FMD are relatively large compared with absolute FMD values, which are usually between $2 \%$ and $8 \%$. This means that a strong intervention is needed to observe physiologically relevant effects on fasting FMD. In combination with a within-subject variability of $2.8 \%$ in FMD [10], power calculations showed that large numbers of participants were needed to detect relevant treatment differences of $1.8 \%$ [chapter 3] and $2.3 \%$ [chapter 6], respectively. Importantly, trials described in this dissertation were adequately powered, since observed within-subject variabilities were less than the $2.8 \%$ used for the sample size calculations. In fact, a within-subject variability of $2.3 \%$ in fasting FMD was found in chapter 3 , while we found a within-subject variability of $2.6 \%$ in the weight-loss intervention trial that is described in chapter 6 . To improve reproducibility of FMD measurements, all tests were performed at the same time of the day for a particular study subject [11] in a quiet, darkened, and temperature-controlled room. Many other factors are also known to affect endothelial function, such as habitual dietary intake, consumption of alcohol and physical exercise [12]. On the days preceding the vascular measurements, individuals were therefore requested not to consume high-fat foods or alcoholic beverages, or to perform any strenuous physical exercise. Further, on the morning of the measurements, volunteers arrived after an overnight fast (no foods or drinks after 08.00 PM, except for water) at the research facilities by public transport or by car to standardize FMD measurements as much as possible [chapters 3, 6 and 7].

Even though some claim the contrary [13], baseline brachial diameters (Dbase) can be changed by some interventions, such as red wine consumption and physical exercise [14]. Changes in Dbase are important because a change in Dbase affect the quantification of the FMD response. Therefore, we do agree with Atkinson and Batterham that it is preferable that Dbase, as an important confounder of the FMD, is reported in all studies on flow-mediated responses [15]. We have already reported these data in one study [chapter 6], and no changes in response to diet-induced weight reduction were found. Further, Dbase did not differ between test days in the study described in chapter 3 (data not shown) and did not change from fasting values at two hours after consumption of the meal with beetroot juice $(0.53 \mathrm{~mm}$ versus $0.52 \mathrm{~mm})$ or control drink $(0.52 \mathrm{~mm}$ versus 0.53 $\mathrm{mm}$ ). Consequently, changes in Dbase do not explain our study results. Finally, 


\section{CHAPTER 8}

dependency on Dbase may also affect meta-analyses of intervention studies on FMD of the brachial artery. Unfortunately, in both meta-analyses described in the present thesis [chapters 4 and 5], Dbase data were in general missing in the included trials to analyze into more detail whether baseline diameters may also have contributed to the significant heterogeneity found among the included studies.

Peripheral arterial tonometry (PAT) is another functional measure of vascular endothelial function, which is easier to use and provides better reproducibility as compared with ultrasound assessments of FMD. This technique also adds to the predictive value of the Framingham risk score [16]. In addition, several EndoPAT studies have demonstrated an improvement in endothelial function as a result of dietary changes [17]. EndoPAT assessments of vascular endothelial function were performed according to guidelines [18] during brachial FMD measurements in the nutritional intervention studies described in chapters 6 and 7. In agreement with the majority of studies applying both brachial ultrasound and PAT, we found no correlation between FMD and the reactive hyperemia index $(\mathrm{RHI})$. The $\mathrm{RHI}$ is the primary outcome of the EndoPAT measurement and defined as the post-to-pre occlusion PAT signal ratio obtained at the fingertips. However, the utility and predictive value of EndoPAT measurements in terms of future CVD risk have been less established than of FMD measurements [19]. Furthermore, the flow increase and subsequent increase of the PAT signal during reactive hyperemia is a complex response, that is only partly mediated by the endothelium and partly dependent on the gas nitric oxide (NO) [20]. In contrast, the flowmediated response, which is measured in a large peripheral muscular artery, is primarily mediated by NO [21]. More research is thus required to evaluate the relevance of the $\mathrm{RHI}$, as a valuable marker of vascular endothelial function in dietary intervention trials.

\section{Markers of arterial stiffness}

The most valid and reliable measure of arterial stiffness is $\mathrm{PWV}_{\mathrm{c}-\mathrm{f}}$, which is relatively easy to measure and predictive of future CVD events and mortality. The predictive value is superior to that of brachial artery stiffness (carotid-to-radial PWV), the augmentation index (Alx), and central pulse pressure [22]. In fact, $\mathrm{PWV}_{\mathrm{c}-\mathrm{f}}$ is now considered the gold standard for arterial stiffness assessments and a meta-analysis has suggested that the risk of CVD events decreases by $14 \%$ when $\mathrm{PWV}_{\mathrm{c}-f}$ improves by $1.0 \mathrm{~m} / \mathrm{s}$ [23]. $\mathrm{PWV}_{\mathrm{c}-\mathrm{f}}$ values depend on both the algorithm applied on the waveforms and the estimate of the carotid-to-femoral distance. In fact, different algorithms applied on the same waveform can lead to differences in calculated values between $5 \%$ and $15 \%$, while differences in carotidto-femoral distance alone can lead to differences in PWV values of up to $30 \%$ [24]. In all dietary intervention trials described in the present thesis [chapters 3, 6 and 7], we used the most frequently used algorithm (i.e. the intersecting tangent algorithm) to standardize our PWV measurements. Furthermore, we used $80 \%$ of the direct carotid-to-femoral distance, because this appears to be the most accurate body surface distance estimate. In fact, these and other procedures were performed according to the recommendations, which were recently described in an expert consensus document on arterial stiffness [25]. To improve the reproducibility of PWV measurements, repeated measures were recommended 
[25]. In the intervention trials described in chapters 3,6 and 7 , we performed at least three measurements. If the most extreme $P W V_{c-f}$ values differed by more than $1.0 \mathrm{~m} / \mathrm{s}$, a fourth measurement was performed. The reported PWV values were the average of all $P W V_{c-f}$ measurements. A within-subject variability of 1.2 $\mathrm{m} / \mathrm{s}$ in $P W V_{\text {c-f }}$ was found in the randomized study described in chapter 3 , while we found a within-subject variability of $1.4 \mathrm{~m} / \mathrm{s}$ in the diet-induced weight-loss intervention study [chapter 6]. Based on these study results, a conservative estimate for the within-subject variability of $1.5 \mathrm{~m} / \mathrm{s}$ in $P W V_{c-f}$ was finally used for our sample size calculation when designing the long-term magnesium citrate intervention trial, which is described in chapter 7 of the present dissertation.

Even though dietary factors may improve arterial stiffness by targeting the functional mechanisms that regulate arterial stiffness such as the bioavailability of NO [26], long-term dietary intervention trials (i.e. several months) may also reduce arterial stiffness by altering arterial structure [27]. Blood pressure is a major determinant of arterial stiffness. In fact, a systematic review of observational studies showed that blood pressure was an independent predictor of the PWV response in $90 \%$ of the published trials involving both outcomes, although causality could not be established [28]. We found that reductions in diastolic blood pressure following diet-induced weight loss correlated with changes in $\mathrm{PWV}_{\text {c-f }}$ [chapter 6]. Based on a meta-analysis of 13 longitudinal trials that had a mean follow-up of 45 months, measurements of arterial stiffness, such as Alx, have predictive value for future cardiovascular outcomes independently of blood pressure levels [29]. Furthermore, we have reported that magnesium supplementation improved $\mathrm{PWV}_{\mathrm{c}-\mathrm{f}}$ in overweight and obese men and postmenopausal women, without any change in office or ambulatory blood pressure [chapter 7]. This suggests that magnesium supplementation for 24 weeks may improve $P W V_{c-f}$ by altering the structure of large elastic arteries [30]. Therefore, to establish the potential of longer-term nutritional interventions to improve cardiovascular health, it is useful to quantify effects on measures of arterial stiffness in addition to assessments of blood pressure levels.

\section{Markers of microvascular structure}

The microcirculation in retina is accessible to non-invasive measurement and retinal images were obtained to assess microvascular structure of the eye. In the intervention trials described in chapters 3, 6 and 7, retinal vascular calibers were determined using a 45-degree digital camera (Topcon TRC-NW-300). The nonmydriatic retinal camera focused on the optic disc and photographed the retina of the right eye. All Images were digitized and analyzed with the appropriate software, as described earlier [31]. At least 2 arteriolar and 2 venular segments were measured at all time points for an individual, and summarized as the central retinal artery and central retinal vein equivalent by using the Parr and Hubbard formulas [32]. These equivalents are projected calibers for the central retinal vessels, measured away from the optic disc. Beneficial changes in retinal vessel diameters are associated with a decreased risk of CVD outcomes [33, 34]. McGeechan and colleagues have suggested that the risk of coronary heart disease (CHD) decreases by $17 \%$ when mean arterial diameters increase by $20 \mu \mathrm{m}$ in women, but 
not in men. In that meta-analysis, it was further found that the risk of CHD was reduced by $16 \%$ when venular diameters decrease by $20 \mu \mathrm{m}$ in women [34].

Table 8.1. Overview of the main results of the studies presented in this thesis ${ }^{1}$

\section{Type of research Exposure Main results and clinical relevance}

$\begin{array}{llll}\text { Chapter } 3 & \begin{array}{l}\text { A randomized } \\ \text { crossover study } \\ \text { with } 20 \text { healthy } \\ \text { overweight and } \\ \text { obese men }\end{array} & \begin{array}{l}\text { Effects of a single } \\ \text { dose of beetroot } \\ \text { juice (providing } 500 \\ \text { mg dietary nitrate }) \\ \text { on postprandial } \\ \text { endothelial function }\end{array} & \begin{array}{l}\text { After consumption of beetroot juice, the } \\ \text { postprandial impairment in FMD following } \\ \text { a standardized mixed meal was improved } \\ (P=0.030) \text { compared with the control } \\ \text { drink }(-0.37 \pm 2.92 \% \text { vs. }-1.56 \pm 2.90 \%) .\end{array} \\ & \begin{array}{l}\text { Whether these postprandial changes in } \\ \text { FMD are related to health outcomes, }\end{array} \\ & \text { remains to be determined. }\end{array}$

Chapter 4 A meta-analysis of 7 (vitamin E) and 9 (vitamin D) randomized controlled trials
Chapter 5 A meta-analysis of intervention studies with experimental $(n=$ 4) and quasiexperimental $(n=$ 33) designs

\section{Chapter 6 A randomized parallel trial with 50 abdominally obese male subjects}

Effects of supplementation with the fat-soluble vitamins $E$ and $D$ on endothelial function
Effects of weight loss on vascular endothelial function
A causal relationship between vitamin $E$ supplementation and improved FMD could not be ascertained, while no effects of vitamin D supplementation were found $(0.15 \% ; 95 \% \mathrm{Cl}:-0.21 \%$ to $0.51 \% ; P=$ 0.41). Effects did not depend on subject characteristics, treatment characteristics or technical aspects of the brachial artery FMD measurement.

Each $10 \mathrm{~kg}$ decrease in body weight was associated with an increase of $1.11 \%$ (95\% Cl: 0.47 to $1.76 \% ; P=0.001)$ in FMD, which has been related to a $9 \%$ decrease in the risk to develop CVD. Effects were larger when subjects received low-fat energy-restricted diets or weightreduction regimens including exercise therapy or weight-loss medication.

Effects of dietinduced weight loss on endothelial function and arterial stiffness

No effects on fasting FMD were observed, while markers of arterial stiffness (Alx and $\left.\mathrm{PWV}_{\mathrm{c}-\mathrm{f}}\right)$ tended to improve by $3.7 \%(P=$ $0.086)$ and $0.5 \mathrm{~m} / \mathrm{s} \quad(P=0.065)$, respectively. In fact, results of longitudinal studies have suggested that the risk of CVD decreases by $7 \%$ when PWV improves by $0.5 \mathrm{~m} / \mathrm{s}$.

Long-term magnesium supplementation improved $\mathrm{PWV}_{\mathrm{c}-\mathrm{f}}$ compared with placebo by $1.0 \mathrm{~m} / \mathrm{s}$, which has been related with a $14 \%$ decrease in the risk to develop CVD. No significant effects on blood pressure levels were found.
Effects of oral with magnesium citrate (350 mg per day) for 24 weeks on arterial stiffness supplementation

\footnotetext{
${ }^{1}$ FMD: flow-mediated vasodilation; $\mathrm{PWV}_{\text {c-f: }}$ carotid-to-femoral pulse wave velocity.

${ }^{2}$ Some analyses (markers of endothelial function and microvascular structure) are still ongoing.
} 


\section{Dietary factors and vascular function}

The results presented in this thesis show that nutritional interventions can beneficially affect vascular function. An overview of the main outcomes and the clinical relevance of these findings is presented [Table 8.1]. Beetroot juice improved in overweight and slightly obese men postprandial FMD after consumption of a standardized mixed meal [chapter 3]. We found no unambiguous evidence to support the use of the fat-soluble vitamins $E$ and $D$ to improve fasting FMD in adults [chapter 4], while a linear relationship between weight loss and fasting FMD of the brachial artery was found in overweight and obese adults [chapter 5]. Diet-induced weight loss improved markers of endothelial function and arterial stiffness in abdominally obese men [chapter 6]. Furthermore, long-term oral magnesium supplementation reduced $\mathrm{PWV}_{\mathrm{c}-\mathrm{f}}$ in overweight and slightly obese men and postmenopausal women, which indicates an improvement in arterial stiffness [chapter 7]. The section below discusses the effects of these dietary factors on the various non-invasive vascular function markers in adult individuals.

\section{Beetroot juice supplementation}

In healthy overweight and slightly obese men, a single dose of beetroot juice attenuated the postprandial impairment of FMD following a mixed meal, possibly through increases in NO levels. The beetroot juice $(140 \mathrm{~mL})$ provided approximately $500 \mathrm{mg}$ dietary nitrate. The present study [chapter 3] was recently included in a systemic review and meta-analysis of RCTs, that was conducted to examine the effects of inorganic nitrate and beetroot supplementation on vascular function measurements [35]. Nine crossover and three parallel trials, including a total of 246 participants, were included. As expected, improvements in vascular function were reported following inorganic nitrate and beetroot consumption. Higher nitrate doses induced more pronounced vascular effects, whereas aging, increased BMI and raised systolic blood pressure were associated with a reduced effect. In addition, their analyses showed that inorganic nitrate supplementation had a similar effect on vascular function compared with beetroot juice supplementation. These results, however, should be interpreted with caution. If studies included more than one method to assess vascular health, results from each method were entered and a pooled estimate for each trial was calculated. Even though beetroot juice improved postprandial FMD, the pooled effect size for our trial was $0.14(95 \% \mathrm{Cl}:-0.30$ to 0.59$)$ since we found no differences between interventions for PWV and the Alx. In agreement, the authors of the meta-analysis reported a non-significant effect on PWV after performing a stratified analysis by method (FMD versus PWV). Also, fasting and postprandial effects were combined. In one trial, beetroot improved in healthy men postprandial vascular function after the consumption of bread [36], and we found that a single dose of beetroot juice attenuated the postprandial impairment of FMD following a mixed meal [chapter 3]. In fact, these postprandial challenge tests may be useful to detect early perturbations in vascular health, possibly even before changes in the vasculature can be found under fasting conditions. Finally, significant heterogeneity was found among the trials included in the meta-analysis [35] that may be partly due to 


\section{CHAPTER 8}

differences in duration of the dietary interventions. Study duration ranged from several hours (i.e. acute effects) to days (i.e. chronic effects), but meta-regression analyses suggested that effects on vascular health were not significantly related to duration of the studies.

Table 8.2. Energy content and macronutrient composition of the test meals ${ }^{1}$

\begin{tabular}{lccc}
\hline \hline & Two muffins & Low-fat milk & Control drink \\
\hline Energy (kJ) & 4095 & 503 & 600 \\
Energy (kcal) & 980 & 120 & 142 \\
Protein (g) & 14.5 & 12.0 & 0.0 \\
Carbohydrates (g) & 103.0 & 18.0 & 35.5 \\
Total fat (g) & 56.6 & 0.0 & 0.0 \\
Saturated FA (g) & 33.9 & & \\
Trans FA (g) & 2.2 & & \\
Monounsaturated FA (g) & 14.5 & & \\
Polyunsaturated FA (g) & 2.7 & & \\
Cholesterol (mg) & 349 & & \\
\hline FA: fatty acids. & & &
\end{tabular}

\section{Postprandial challenge tests}

We have found a postprandial impairment of FMD two hours after the consumption of a standardized mixed meal. The test meal consisted of two muffins (containing $57 \mathrm{~g}$ fat) and $140 \mathrm{~mL}$ of a carbohydrate control drink [chapter 3]. Interestingly, a postprandial decrease in brachial FMD was not observed in the weight-loss trial described in chapter 6 (data not shown). In that study, individuals also received a mixed-meal challenge to investigate whether body weight modifies postprandial vascular responses. FMD of the brachial artery was also measured two hours following the meal, but the macronutrient composition [Table 8.2] of the meal (fat/carbohydrate/protein: $28 \mathrm{En} \% / 59 \mathrm{En} \% / 13 \mathrm{En} \%$ or $57 \mathrm{~g} / 121 \mathrm{~g} / 26 \mathrm{~g}$ ) was different as compared with the test meal used in chapter $\mathbf{3}$ (fat/carbohydrate/protein: $27 \mathrm{En} \% / 66 \mathrm{En} \% / 7 \mathrm{En} \%$ or $57 \mathrm{~g} / 138 \mathrm{~g} / 14 \mathrm{~g}$ ). In fact, we deliberately chose to use a standardized mixed meal consisting of two muffins with $300 \mathrm{~mL}$ low-fat milk, as its composition more closely matched the compositions of daily diets consumed in real life. Differences regarding the postprandial effects on brachial artery FMD between both studies may thus relate to the amount or source of dietary proteins present in the mixed meal. In fact, the postprandial impairment in FMD of the brachial artery was not observed when caseinate proteins were added to the mixed meal [37], which was explained by an increased supply of the amino acid L-arginine. Irrespective of the intervention, we did observe postprandial decreases in DBP and Alx [chapter 3], that were probably due to fast neuronal- and hormonal-mediated peripheral vasodilation in response to food intake [38]. In addition, food intake involves other vascular changes, such as a decreased blood flow in peripheral muscle [39]. This may 
affect brachial blood pressure levels and the Alx, which is deduced from a pulse wave analysis of the radial artery pressure waveform. Finally, fasting Alx is a noninvasive measurement of arterial stiffness and a lower Alx is significantly associated with a lower risk of CVD [29]. Even though these frequent but transient postprandial decreases in Alx may not reflect true improvements in arterial stiffness, it still remains to be investigated whether they are of clinical importance for long-term cardiovascular health.

Study

ID
$\%$

FMD $(95 \% \mathrm{Cl}) \quad$ Weight
Witham, 2012 (16 weeks)

Witham, 2010 (8 weeks/100K IU)

Witham, 2013 (12 months)

Witham, 2010 (8 weeks/200K IU)

Longenecker, 2012

Witham, 2013 (3 months)

Witham, 2013 (4 weeks)

Gepner, 2012

Witham, 2013 (8 weeks)

Witham, 2010 (16 weeks/100K IU)

Yiu, 2013

Witham, 2010 (16 weeks/200K IU)

Zoccali, 2014

Witham, 2012 (8 weeks)

Sugden, 2008

Harris, 2011

Overall (I-squared $=46.5 \%, p=0.021)$

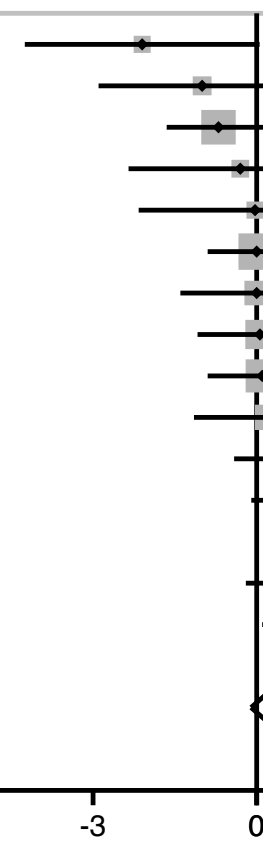

$-2.10(-4.25,0.05) 2.60$

$-1.00(-2.90,0.90) 3.34$

$-0.70(-1.65,0.25) 13.32$

$-0.30(-2.35,1.75) 2.86$

$-0.03(-2.16,2.10) 2.64$

$0.00(-0.90,0.90) \quad 14.88$

$0.00(-1.40,1.40) \quad 6.15$

$0.06(-1.08,1.20) \quad 9.19$

$0.10(-0.90,1.10) \quad 12.05$

$0.20(-1.15,1.55) \quad 6.60$

$0.83(-0.41,2.07) \quad 7.77$

$1.30(-0.10,2.70) \quad 6.15$

$1.80(0.34,3.26) \quad 5.68$

$1.90(-0.20,4.00) \quad 2.73$

$2.29(0.10,4.48) \quad 2.51$

$3.10(0.29,5.91) \quad 1.53$

$0.24(-0.10,0.59) \quad 100.00$

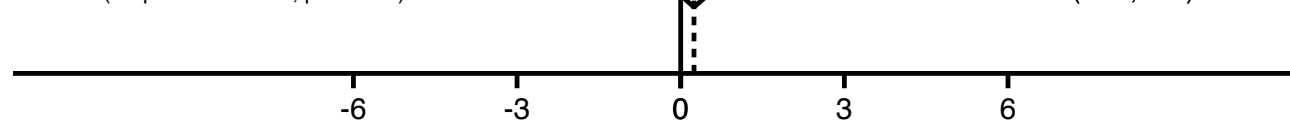

Figure 8.1. Forest plot of random controlled trials (RCTs) that investigated the effect of vitamin D supplements on fasting flow-mediated vasodilation (FMD) of the brachial artery. The solid squares represent the weight of individual studies and the diamond represents the weighted mean difference (WMD) in FMD (calculated using fixed-effect meta-analyses). In all randomized studies combined, vitamin D did not increase FMD (WMD: $0.24 \%$; $95 \% \mathrm{Cl}:-0.10 \%$ to $0.59 \% ; P=0.17$ ).

\section{Fat-soluble vitamin supplements}

The lack of effect of fat-soluble vitamin D supplements on fasting FMD [chapter 4] were in agreement with a more recently published meta-analysis of randomized trials [40]. The authors reported that vitamin D supplementation did not improve FMD and results did not depend on various subject or treatment characteristics. However, the weighted mean difference (WMD) was different in both metaanalyses $(0.15 \%$ [95\% Cl: $-0.21 \%$ to $0.51 \%]$ versus $0.96 \%[95 \% \mathrm{Cl}:-0.14 \%$ to $2.06 \%])$. This is explained by (i) two relevant trials $[41,42]$ that were not included in the more recently published meta-analysis and (ii) one study published in August 


\section{CHAPTER 8}

2014 that was not included in our meta-analysis as the literature search was updated till July 2014. In that trial, Zoccali and colleagues reported a significant improvement of $1.8 \%$ in fasting FMD after 12 weeks of paricalcitrol (i.e. a synthetic and biologically active form of vitamin D) treatment in participants with chronic kidney disease [43]. We repeated the analyses performed in chapter 4, but inclusion of that trial [43]did not alter the conclusions of our meta-analysis [Figure 8.1]. In case the recent study was included in our subgroup analyses, there were also no predefined subject or treatment characteristics related to the effects observed on fasting brachial artery FMD. In the more recently published metaanalysis, the methodological quality of the included studies was determined by the Jadad scoring system by evaluating the correctness of randomization, blinding, and reporting of withdrawals [44]. However, the quality of the trials did not influence the overall effect of vitamin $D$ administration on FMD and may therefore not explain the observed lack of effect in our analysis.

\section{Weight-loss intervention studies}

A significant linear relationship between weight loss and fasting FMD was found in our meta-analysis of 33 intervention trials without a no-weight loss control group, indicating an improvement in endothelial function [chapter 5]. The results of the meta-regression analyses were comparable after excluding intervention trials involving exercise therapy of weight-loss medication. In fact, we estimated that each $10 \mathrm{~kg}$ decrease in body weight was associated with a significant increase of $1.25 \%(95 \% \mathrm{Cl}: 0.57$ to $1.94 \%)$ in fasting FMD. In addition, it was estimated that each $5 \mathrm{~cm}$ decrease in waist circumference was associated with an improvement of $1.28 \%(95 \% \mathrm{Cl}: 0.47$ to $2.09 \%)$ in FMD. However, no linear relationship was found between weight loss and fasting FMD after excluding trials involving volunteers with obesity-related morbidities. As effects may depend on both the type of weight-loss treatment and subject characteristics, we performed a welldesigned RCT including a no-weight loss control group to investigate the effects of dietary weight loss on various markers of endothelial function in men [chapter 6]. Even though some plasma biomarkers of endothelial function improved following dietary weight loss, fasting FMD did not change. These apparently inconsistent outcomes have been thoroughly discussed in chapter 6 of the present dissertation.

Effects on plasma biomarkers of endothelial function were studied and beneficial effects were observed on both sE-selectin and sICAM. These biomarkers were also combined into overall $z$ scores and diet-induced weight loss significantly reduced the overall score for biomarkers of endothelial dysfunction (data not shown). However, these calculations have some limitations because they are based on the assumption that each biomarker carries a similar weight, which may not be true because some plasma markers may be more strongly related to CVD risk than others [45]. In addition, the various biomarkers address different aspects of the vasculature, which should also be considered. Finally, retinal arteriolar diameters were significantly higher in the normal-weight compared with abdominally obese men, but improved following dietary weight loss compared with the no-weight los control treatment by $5.0 \mu \mathrm{m}$ [chapter 6]. McGeechan has suggested that the risk of $\mathrm{CHD}$ decreases by $4 \%$ when mean arteriolar calibers 
increase by $5.0 \mu \mathrm{m}$ [34], underlining the potential practical relevance of these findings. To the best of our knowledge, this is the first intervention study to demonstrate an improvement in retinal AVR following diet-induced weight loss. In a meta-analysis of observational trials a lower BMI was also significantly associated with wider retinal arteriolar calibers [46]. Based on our results, a causal relationship between weight loss and retinal microvascular changes can now be ascertained for the first time. Therefore, examining retinal vascular calibers may provide useful information about microvascular network alterations in nutritional intervention trials with abdominally obese individuals.

In the intervention study described in chapter 6, Pearson correlation coefficients were determined to examine cross-sectional relationships between many different vascular function markers and more traditional cardiometabolic risk markers (e.g. blood pressure, serum lipids, inflammatory markers, plasma glucose and insulin sensitivity). In addition, relationships between improvements in these markers were assessed, but hardly any significant relationships were observed. One potential explanation may be the complex relationship between dietary factors and CVD outcomes. In fact, both vascular function and cardiometabolic risk markers exist on the pathway between diet and CVD risk, but they may relate to different and partly independent mechanisms.

\section{Magnesium supplementation}

In the third dietary intervention study described in this thesis [chapter 7], we found that magnesium citrate supplementation for 24 weeks significantly reduced $\mathrm{PWV}_{\mathrm{c}-\mathrm{f}}$ in healthy overweight and slightly obese adults. A total daily dose of $350 \mathrm{mg}$ was administered as this was the tolerable upper intake level for supplemental magnesium for adults set by the Food and Nutrition Board (FNB) of the Institute of Medicine (IOM) [47]. Furthermore, magnesium citrate was chosen as it has a higher bioavailability as compared with other magnesium formulations [48]. No adverse events related to oral magnesium intake were observed and no differences in various hematological parameters, including differential leukocyte counts, were found between treatment groups (data not shown). Interestingly, in contrast to $P W V_{c-f}$, we did not observe effects on the Alx. This difference may arise from the fact that these measures reflect different aspects of arterial stiffness. The Alx is a non-invasive measure of the arterial pressure waveform that depends on the tone of resistance arteries, while $P W V_{c-f}$ is a direct indicator of arterial stiffness that depends on the longer-term structural remodeling of large elastic arteries [30]. Previous trials also showed that vascular stiffness and wave reflection indices do not necessarily change in parallel $[49,50]$. Therefore, the observed decrease in $\mathrm{PWV}_{\text {c-f, }}$, but not in Alx, may be due to a more pronounced impact of long-term magnesium supplementation on the aorta than on the peripheral muscular arterioles and arteries.

\section{Conclusion and future directions}

The research described in the present thesis focused on three well-defined nutritional intervention studies and two meta-analyses that were designed to 


\section{CHAPTER 8}

assess the effects of dietary factors and weight loss on vascular function markers predicting the risk for CVD. We provide further evidence that dietary changes improve cardiovascular health based on beneficial effects on endothelial function and arterial stiffness. An overview of the main results of the studies presented in the present thesis and the clinical relevance of these findings is presented [Table 8.1]. Even though the various non-invasive vascular function measurements described in the present thesis are used for research purposes worldwide, none of these functional measurements are routinely used in clinical practice. Further research is therefore warranted to evaluate the clinical application of FMD of the brachial artery, while $P W V_{\text {c-f }}$ has already been depicted as a promising future tool for cardiovascular risk prediction in clinical practice [51, 52].

From industrial, academic, and public health perspective, there is an urgent need to know which of the many different vascular function markers are sensitive to dietinduced changes as vascular dysfunction is a key mechanism whereby a healthy diet improves cardiovascular health [1]. The present thesis provides evidence that endothelial function, as estimated by FMD, is impaired following a dietary stressor (i.e. a standardized mixed-meal challenge) as reported in chapter 3 , while FMD of the brachial artery is improved after the consumption of dietary components, such as inorganic nitrate [chapter 3], or following defined lifestyle changes leading to weight reduction [chapter 5]. Conversely, no fasting or postprandial differences were observed in the weight-loss study described in chapter 6, which suggests that FMD is not strongly related to BMI when values are below $35 \mathrm{~kg} / \mathrm{m} 2$ [53]. Even though these measurements of flow-mediated responses are complex and have several important shortcomings as discussed, brachial FMD may be considered as a valuable vascular function marker to examine cardiovascular health effects of nutritional interventions known to affect NO bioavailability. PAT is another noninvasive vascular function measurement, which is more easy to use and provides better reproducibility than the ultrasound assessment of FMD. EndoPAT results were only reported in chapter 6 and no differences in RHI were observed. This thesis therefore does not provide relevant evidence on the sensitivity of EndoPAT measurements to dietary changes, while more research is required to evaluate the relevance of the $\mathrm{RHI}$ as a valuable marker of endothelial function in individuals. In addition, plasma biomarkers were measured as an indirect approach to determine endothelial function and dietary weight loss improved both sE-selectin and sICAM concentrations [chapter 6]. Plasma biomarkers of endothelial function are valuable outcome measures in addition to, but not instead of functional markers such as FMD. To identify potential improvements in arterial stiffness, $P_{\text {C.f }}$ was measured in all intervention studies described in this dissertation [chapters 3, 6 and 7]. Oral magnesium citrate supplementation for 24 weeks improved $P W V_{c-f}$ in overweight and slightly obese adults [chapter 7], while arterial stiffness, as estimated by $P W V_{c-f}$, tended to decrease by $0.5 \mathrm{~m} / \mathrm{s}$ following diet-induced weight loss [chapter 6]. Based on these data, $P W V_{c-f}$ is considered as a valuable non-invasive functional marker to examine longer-term effects of dietary changes on the risk of CVD. Besides $P W V_{c-f}$ as measurement of arterial stiffness, the Alx was investigated. There are few nutritional intervention studies in which Alx was measured. In the weight-loss clinical trial described in chapter 6, Alx tented to improve by $3.7 \%$, while no differences were found following magnesium 
supplementation [chapter 7]. Further, postprandial changes in Alx did not differ between both test meals in chapter 3 . More research is thus warranted to evaluate the sensitivity of the Alx to diet-induced changes. Finally, retinal arteriolar calibers improved following weight loss as compared with the control treatment by $5.0 \mu \mathrm{m}$ [chapter 6]. As a result, non-invasive assessments of the retinal microvascular structure may be relevant to demonstrate potential cardiovascular health benefits in well-defined nutritional intervention studies.

As a next step, the postprandial vascular response should be further characterized. Even though effects of dietary weight loss on vascular function have been demonstrated in the fasting state [chapter 6], postprandial vascular effects are not clear. This is of particular interest, since abdominally obese participants have a disturbed postprandial metabolism [54]. We also reported postprandial differences in FMD responses, possibly due to differences in the macronutrient composition of the mixed-meal challenges [37]. Therefore, future research should focus on effects of diet macronutrients on postprandial vascular function. Further, beneficial effects of magnesium supplementation on arterial stiffness were reported in chapter 7 . Next, the effects of a daily intake of magnesium on other vascular function measurements should be investigated, including markers of endothelial function and microvascular structure.

The primary target is the large part of the population that is at increased cardiovascular risk. Therefore, future research should also be performed in subjects with the metabolic syndrome. Finally, this thesis focused on the potential of diet and weight loss to improve peripheral vascular function and metabolic health. However, effects of dietary changes on the vasculature of the brain are largely unknown. This is of particular interest, since neurovascular dysfunction is a key pathological event that precedes the development of impaired cognitive function $[55,56]$. Future research should now broaden its focus on implementing new-concepts for healthy living at a whole body level. In particular, the interaction between brain and periphery regarding the effects of diet and weight loss on both vascular and metabolic heath is of great relevance. 


\section{CHAPTER 8}

\section{References}

1. Lichtenstein AH, Appel LJ, Brands M, Carnethon M, Daniels S, et al. Diet and lifestyle recommendations revision 2006: a scientific statement from the American Heart Association Nutrition Committee. Circulation 2006;114:82-96.

2. World Health Organization. Cardiovascular diseases (CVDs) fact sheet No. 317, January 2015. Available from: http://www.who.int/mediacentre/factsheets/fs317/en/.

3. Cohn JN, Quyyumi AA, Hollenberg NK, Jamerson KA. Surrogate markers for cardiovascular disease: functional markers. Circulation 2004;109:IV31-46.

4. Celermajer DS, Sorensen KE, Gooch VM, Spiegelhalter DJ, Miller OI, Sullivan ID, Lloyd JK, Deanfield JE. Non-invasive detection of endothelial dysfunction in children and adults at risk of atherosclerosis. Lancet 1992;340:1111-5.

5. Anderson TJ, Uehata A, Gerhard MD, Meredith IT, Knab S, Delagrange D, Lieberman EH, Ganz P, Creager MA, Yeung AC, et al. Close relation of endothelial function in the human coronary and peripheral circulations. J Am Coll Cardiol 1995;26:1235-41.

6. Corretti MC, Anderson TJ, Benjamin EJ, Celermajer D, Charbonneau F, Creager MA, Deanfield J, Drexler H, Gerhard-Herman M, Herrington D, et al. Guidelines for the ultrasound assessment of endothelial-dependent flow-mediated vasodilation of the brachial artery: a report of the International Brachial Artery Reactivity Task Force. J Am Coll Cardiol 2002;39:257-65.

7. Bots ML, Westerink J, Rabelink TJ, de Koning EJ. Assessment of flow-mediated vasodilatation (FMD) of the brachial artery: effects of technical aspects of the FMD measurement on the FMD response. Eur Heart J 2005;26:363-8.

8. Harris RA, Nishiyama SK, Wray DW, Richardson RS. Ultrasound assessment of flowmediated dilation. Hypertension 2010;55:1075-85.

9. Ras RT, Streppel MT, Draijer R, Zock PL. Flow-mediated dilation and cardiovascular risk prediction: a systematic review with meta-analysis. Int J Cardiol 2013;168:344-51.

10. De Roos NM, Bots ML, Schouten EG, Katan MB. Within-subject variability of flow-mediated vasodilation of the brachial artery in healthy men and women: implications for experimental studies. Ultrasound Med Biol 2003;29:401-6.

11. Otto ME, Svatikova A, Barretto RB, Santos S, Hoffmann M, Khandheria B, Somers V. Early morning attenuation of endothelial function in healthy humans. Circulation 2004;109:250710.

12. Abularrage CJ, Sidawy AN, Aidinian G, Singh N, Weiswasser JM, Arora S. Evaluation of macrocirculatory endothelium-dependent and endothelium-independent vasoreactivity in vascular disease. Perspect Vasc Surg Endovasc Ther 2005;17:245-53.

13. Charakida M, de Groot E, Loukogeorgakis SP, Khan T, Luscher T, Kastelein JJ, Gasser T, Deanfield JE. Variability and reproducibility of flow-mediated dilatation in a multicentre clinical trial. Eur Heart J 2013;34:3501-7.

14. Atkinson G, Batterham AM. The percentage flow-mediated dilation index: a large-sample investigation of its appropriateness, potential for bias and causal nexus in vascular medicine. Vasc Med 2013;18:354-65.

15. Atkinson G, Batterham AM. The clinical relevance of the percentage flow-mediated dilation index. Curr Hypertens Rep 2015;17:4.

16. Rubinshtein R, Kuvin JT, Soffler M, Lennon RJ, Lavi S, Nelson RE, Pumper GM, Lerman LO, Lerman A. Assessment of endothelial function by non-invasive peripheral arterial tonometry predicts late cardiovascular adverse events. Eur Heart J 2010;31:1142-8.

17. Moerland M, Kales AJ, Schrier L, van Dongen MG, Bradnock D, Burggraaf J. Evaluation of the EndoPAT as a Tool to Assess Endothelial Function. Int J Vasc Med 2012;2012:904141.

18. Liu J, Wang J, Jin Y, Roethig HJ, Unverdorben M. Variability of peripheral arterial tonometry in the measurement of endothelial function in healthy men. Clin Cardiol 2009;32:700-4. 
19. Poredos $\mathrm{P}$, Jezovnik MK. Testing endothelial function and its clinical relevance. J Atheroscler Thromb 2013;20:1-8.

20. Nohria A, Gerhard-Herman M, Creager MA, Hurley S, Mitra D, Ganz P. Role of nitric oxide in the regulation of digital pulse volume amplitude in humans. J Appl Physiol 2006;101:5458.

21. Meredith IT, Currie KE, Anderson TJ, Roddy MA, Ganz P, Creager MA. Postischemic vasodilation in human forearm is dependent on endothelium-derived nitric oxide. Am J Physiol 1996;270:H1435-40.

22. Mitchell GF, Hwang SJ, Vasan RS, Larson MG, Pencina MJ, Hamburg NM, Vita JA, Levy D, Benjamin EJ. Arterial stiffness and cardiovascular events: the Framingham Heart Study. Circulation 2010;121:505-11.

23. Vlachopoulos C, Aznaouridis K, Stefanadis C. Prediction of cardiovascular events and allcause mortality with arterial stiffness: a systematic review and meta-analysis. J Am Coll Cardiol 2010;55:1318-27.

24. Reference Values for Arterial Stiffness C. Determinants of pulse wave velocity in healthy people and in the presence of cardiovascular risk factors: 'establishing normal and reference values'. Eur Heart J 2010;31:2338-50.

25. Van Bortel LM, Laurent S, Boutouyrie P, Chowienczyk P, Cruickshank JK, De Backer T, Filipovsky J, Huybrechts S, Mattace-Raso FU, Protogerou AD, et al. Expert consensus document on the measurement of aortic stiffness in daily practice using carotid-femoral pulse wave velocity. J Hypertens 2012;30:445-8.

26. Wilkinson IB, Qasem A, McEniery CM, Webb DJ, Avolio AP, Cockcroft JR. Nitric oxide regulates local arterial distensibility in vivo. Circulation 2002;105:213-7.

27. Pase MP, Grima NA, Sarris J. The effects of dietary and nutrient interventions on arterial stiffness: a systematic review. Am J Clin Nutr 2011;93:446-54.

28. Cecelja M, Chowienczyk P. Dissociation of aortic pulse wave velocity with risk factors for cardiovascular disease other than hypertension: a systematic review. Hypertension 2009;54:1328-36.

29. Vlachopoulos C, Aznaouridis K, O'Rourke MF, Safar ME, Baou K, Stefanadis C. Prediction of cardiovascular events and all-cause mortality with central haemodynamics: a systematic review and meta-analysis. Eur Heart J 2010;31:1865-71.

30. Laurent S, Cockcroft J, Van Bortel L, Boutouyrie P, Giannattasio C, Hayoz D, Pannier B, Vlachopoulos C, Wilkinson I, Struijker-Boudier H, et al. Expert consensus document on arterial stiffness: methodological issues and clinical applications. Eur Heart J 2006;27:2588605.

31. Stewart CV, Tsai CL, Roysam B. The dual-bootstrap iterative closest point algorithm with application to retinal image registration. IEEE Trans Med Imaging 2003;22:1379-94.

32. Hubbard LD, Brothers RJ, King WN, Clegg LX, Klein R, Cooper LS, Sharrett AR, Davis MD, Cai J. Methods for evaluation of retinal microvascular abnormalities associated with hypertension/sclerosis in the Atherosclerosis Risk in Communities Study. Ophthalmology 1999;106:2269-80.

33. McGeechan K, Liew G, Macaskill P, Irwig L, Klein R, Klein BE, Wang JJ, Mitchell P, Vingerling JR, de Jong PT, et al. Prediction of incident stroke events based on retinal vessel caliber: a systematic review and individual-participant meta-analysis. Am J Epidemiol 2009;170:1323-32.

34. McGeechan K, Liew G, Macaskill P, Irwig L, Klein R, Klein BE, Wang JJ, Mitchell P, Vingerling JR, Dejong PT, et al. Meta-analysis: retinal vessel caliber and risk for coronary heart disease. Ann Intern Med 2009;151:404-13.

35. Lara J, Ashor AW, Oggioni C, Ahluwalia A, Mathers JC, Siervo M. Effects of inorganic nitrate and beetroot supplementation on endothelial function: a systematic review and meta-analysis. Eur J Nutr 2015.

36. Hobbs DA, Goulding MG, Nguyen A, Malaver T, Walker CF, George TW, Methven L, Lovegrove JA. Acute ingestion of beetroot bread increases endothelium-independent 


\section{CHAPTER 8}

vasodilation and lowers diastolic blood pressure in healthy men: a randomized controlled trial. J Nutr 2013;143:1399-405.

37. Westphal S, Taneva E, Kastner S, Martens-Lobenhoffer J, Bode-Boger S, Kropf S, Dierkes J, Luley C. Endothelial dysfunction induced by postprandial lipemia is neutralized by addition of proteins to the fatty meal. Atherosclerosis 2006;185:313-9.

38. Ahuja KD, Robertson IK, Ball MJ. Acute effects of food on postprandial blood pressure and measures of arterial stiffness in healthy humans. Am J Clin Nutr 2009;90:298-303.

39. Kelbaek H, Munck O, Christensen NJ, Godtfredsen J. Autonomic nervous control of postprandial hemodynamic changes at rest and upright exercise. J Appl Physiol 1987;63:1862-5.

40. Stojanovic M, Radenkovic M. Vitamin d versus placebo in improvement of endothelial dysfunction: a meta-analysis of randomized clinical trials. Cardiovasc Ther 2015;33:145-54.

41. Witham MD, Adams F, Kabir G, Kennedy G, Belch JJ, Khan F. Effect of short-term vitamin $D$ supplementation on markers of vascular health in South Asian women living in the UK--a randomised controlled trial. Atherosclerosis 2013;230:293-9.

42. Witham MD, Price RJ, Struthers AD, Donnan PT, Messow CM, Ford I, McMurdo ME. Cholecalciferol treatment to reduce blood pressure in older patients with isolated systolic hypertension: the VitDISH randomized controlled trial. JAMA Intern Med 2013;173:1672-9.

43. Zoccali C, Curatola G, Panuccio V, Tripepi R, Pizzini P, Versace M, Bolignano D, Cutrupi S, Politi R, Tripepi G, et al. Paricalcitol and endothelial function in chronic kidney disease trial. Hypertension 2014;64:1005-11.

44. Jadad AR, Moore RA, Carroll D, Jenkinson C, Reynolds DJ, Gavaghan DJ, McQuay HJ. Assessing the quality of reports of randomized clinical trials: is blinding necessary? Control Clin Trials 1996;17:1-12.

45. van Bussel BC, Soedamah-Muthu SS, Henry RM, Schalkwijk CG, Ferreira I, Chaturvedi N, Toeller M, Fuller JH, Stehouwer CD, Group EPCS. Unhealthy dietary patterns associated with inflammation and endothelial dysfunction in type 1 diabetes: the EURODIAB study. Nutr Metab Cardiovasc Dis 2013;23:758-64.

46. Boillot A, Zoungas S, Mitchell P, Klein R, Klein B, Ikram MK, Klaver C, Wang JJ, Gopinath $B$, Tai ES, et al. Obesity and the microvasculature: a systematic review and meta-analysis. PLoS One 2013;8:e52708.

47. Food and Nutrition Board (Institute of Medicine). Dietary Reference Intakes: Calcium, Phosphorus, Magnesium, Vitamin D, and Fluoride. Washington DC: National Academy Press 1997:190-249.

48. Walker AF, Marakis G, Christie S, Byng M. Mg citrate found more bioavailable than other Mg preparations in a randomised, double-blind study. Magnes Res 2003;16:183-91.

49. Vlachopoulos C, Dima I, Aznaouridis K, Vasiliadou C, loakeimidis N, Aggeli C, Toutouza M, Stefanadis C. Acute systemic inflammation increases arterial stiffness and decreases wave reflections in healthy individuals. Circulation 2005;112:2193-200.

50. Kelly RP, Millasseau SC, Ritter JM, Chowienczyk PJ. Vasoactive drugs influence aortic augmentation index independently of pulse-wave velocity in healthy men. Hypertension 2001;37:1429-33.

51. Holewijn S, den Heijer M, Stalenhoef AF, de Graaf J. Non-invasive measurements of atherosclerosis (NIMA): current evidence and future perspectives. Neth J Med 2010;68:388-99.

52. Ter Avest E, Stalenhoef AF, de Graaf J. What is the role of non-invasive measurements of atherosclerosis in individual cardiovascular risk prediction? Clin Sci (Lond) 2007;112:50716.

53. Juonala M, Viikari JS, Laitinen T, Marniemi J, Helenius H, Ronnemaa T, Raitakari OT. Interrelations between brachial endothelial function and carotid intima-media thickness in young adults: the cardiovascular risk in young Finns study. Circulation 2004;110:2918-23. 
54. Couillard C, Bergeron N, Prud'homme D, Bergeron J, Tremblay A, Bouchard C, Mauriège $\mathrm{P}$, Després J. Postprandial triglyceride response in visceral obesity in men. Diabetes 1998;47:953-60.

55. Kelleher RJ, Soiza RL. Evidence of endothelial dysfunction in the development of Alzheimer's disease: Is Alzheimer's a vascular disorder? Am J Cardiovasc Dis 2013;3:197226.

56. Grove T, Taylor S, Dalack G, Ellingrod V. Endothelial function, folate pharmacogenomics, and neurocognition in psychotic disorders. Schizophr Res 2015;164:115-21. 

Summary 


\section{SUMMARY}

A healthy diet is a cornerstone for the prevention or delay of cardiovascular disease (CVD), which is the leading cause of morbidity and mortality in many parts of the world. However, the number of large randomized controlled trials (RCTs) with appropriate follow-up periods and with CVD events as endpoints is limited, as they require inclusion of thousands of study participants with very long follow-up periods. As an alternative approach, the effects of dietary interventions on surrogate risk markers of CVD can be studied. In this respect, vascular function markers are of interest, as some of these markers are associated with future cardiovascular events. From industrial, academic, and public health perspective, there is an urgent need to know which of the many different vascular function markers are sensitive to diet-induced changes. The research presented in this thesis therefore focused on (i) three well-defined dietary intervention trials and (ii) two meta-analyses of intervention studies, which were specifically designed to assess the specific effects of various dietary factors and weight loss on different non-invasive vascular function markers in adult individuals.

The relation between various vascular function markers and the risk of CVD is briefly summarized in chapter 2 . Then, effects of dietary fatty acids on these cardiovascular risk markers and on CVD risk itself are discussed. We concluded that replacement of dietary saturated fatty acids (SFAs) by cis-polyunsaturated fatty acids lowers the risk of CVD. However, more research is warranted to evaluate the effects of replacing SFAs with carbohydrates or cis-monounsaturated fatty acids. The intake of trans fatty acids from hydrogenated oils should be as low as possible independent of the macronutrient that is replacing. The next two chapters describe the effects of specific dietary components on vascular endothelial function. In chapter 3 it was investigated in healthy overweight and obese men whether beetroot juice, which is rich in inorganic nitrate, could counteract the postprandial impairment of brachial artery flow-mediated vasodilation (FMD) induced by a mixed meal. For this, twenty men participated in a randomized crossover trial and consumed in random order a mixed meal providing $57 \mathrm{~g}$ of fat cominbed with either beetroot juice (providing $500 \mathrm{mg}$ of dietary nitrate) or a control drink. After consumption of beetroot juice, the postprandial impairment in FMD following a mixed meal was significantly improved compared with the control drink $(-0.37 \pm 2.92 \%$ versus $-1.56 \pm 2.90 \% ; P=0.030$ for the difference in changes). Plasma concentrations of nitric oxide (NO), which is a potent vasodilator, were significantly higher following beetroot juice consumption. From this study, we concluded that a single dose of beetroot juice attenuates the postprandial impairment of FMD following a mixed meal, possibly through increases in plasma NO concentrations. In chapter 4, a meta-analysis was performed to quantify effects of supplementation with the fat-soluble vitamin $E$ and vitamin D on fasting FMD in adults. Randomized placebo-controlled trials were identified by a systematic search till July 2014 . Seven RCTs studying the effects of vitamin E supplements (range: 300 to $1800 \mathrm{IU}$ per day) and nine RCTs examining the effects of vitamin D supplements, that involved respectively 303 and 658 adults, were included. A causal relationship between vitamin $\mathrm{E}$ supplementation and improved FMD could not be ascertained, while we found no effects of vitamin D supplementation. The current meta-analysis, therefore, did not provide unambiguous evidence to support the use of fat-soluble vitamin supplements to improve fasting FMD in adults. The effects of weight loss on vascular function 
markers were investigated in the next two chapters. In a meta-analysis, effects of weight loss on fasting FMD in adults were quantified [chapter 5]. Studies with experimental (RCTs) and quasi-experimental designs published before June 2014 were identified by a systematic search. Four RCTs involving 265 subjects were included. Weight loss increased fasting FMD vs. control by $3.29 \%$. A total of 1517 individuals participated in 33 studies with a quasi-experimental design. Forty-nine relevant study arms were included. Results of the meta-regression analysis suggested that each $10 \mathrm{~kg}$ decrease in body weight was associated with an increase of $1.11 \%$ in FMD. Further, it was estimated that each $5 \mathrm{~cm}$ decrease in waist circumference increased fasting FMD by $1.17 \%$. Effects were more pronounced when participants had coexisting obesity-related morbidities. Also, effects may be larger when study volunteers received low-fat diets or weightreduction regimens including exercise therapy or weight-loss medication. Then, a randomized intervention trial was performed, which was specially designed to investigate (i) effects of dietary weight loss on different vascular function markers and (ii) differences between normal-weight and abdominally obese men at baseline and after weight loss [chapter 6]. For this, apparently healthy normal-weight $(n=$ 25; waist circumference below $94 \mathrm{~cm})$ and abdominally obese men $(n=54$; waist circumference: $102-110 \mathrm{~cm}$ ) participated. Abdominally obese men were randomly allocated to a diet-induced weight-loss program or a no-weight loss control group. Men assigned to the weight-loss program obtained a waist circumference below $102 \mathrm{~cm}$, that is the cut-off value used in the diagnosis of the metabolic syndrome. Weight loss did not affect FMD, which suggests that FMD is not strongly related to BMI when values are below $35 \mathrm{~kg} / \mathrm{m}^{2}$. Carotid-to-femoral pulse wave velocity $\left(P W V_{c-f}\right)$ tended to decrease, while the retinal microvascular caliber, plasma biomarkers of endothelial function and the more conventional cardiometabolic risk markers improved. These markers differed at baseline between normal-weight and abdominally obese individuals, but became very comparable following the weightloss program, although the waist circumference was still different. Finally chapter 7 describes the results of a long-term intervention study in which the effects of magnesium supplementation on arterial stiffness were investigated. Fifty-two overweight and slightly obese individuals (30 men and 22 women) participated in a 24-week, randomized, double-blind, intervention trial and received either three times daily magnesium (350 mg/day) or placebo capsules. $\mathrm{PWV}_{\text {c-f }}$ was not changed after 12 weeks, but was improved in the magnesium compared with the placebo group by $1.0 \mathrm{~m} / \mathrm{s}$ after 24 weeks. Office and 24-hour ambulatory blood pressure were not changed. We concluded from this trial that a daily magnesium supplement of $350 \mathrm{mg}$ for 24 weeks in overweight and slightly obese middle-aged and elderly individuals may reduce arterial stiffness, suggesting a potential mechanism by which an increased magnesium intake beneficially affects cardiovascular health outcomes.

In conclusion, the present dissertation provides further evidence that dietary changes affect cardiovascular health by improving vascular endothelial function and arterial stiffness. FMD is considered the current non-invasive gold standard technique to assess vascular endothelial function. Even though measurements of flow-mediated responses are complex and have several important shortcomings, FMD may be considered as a valuable marker to examine cardiovascular health effects of dietary interventions known to affect NO bioavailability. The most valid 


\section{SUMMARY}

and reliable measure of arterial stiffness is $P W V_{c-f}$, which is the current gold standard for arterial stiffness assessments. Based on the results reported in this thesis, $\mathrm{PWV}_{\text {c-f }}$ is considered as a valuable non-invasive vascular function marker to examine the effects of longer-term dietary changes on the risk of adverse cardiovascular health outcomes. 


\section{Samenvatting}


Hart- en vaatziekten (HVZ) zijn de belangrijkste oorzaak van ziekte en sterfte. Het risico om HVZ te ontwikkelen kan worden verlaagd door het voedingspatroon te veranderen. Het aantal gerandomiseerde studies met een controle groep (RCT) naar de effecten van voeding op cardiovasculaire ziekten is echter beperkt. Echter, in plaats daarvan, kunnen effecten van voedingsinterventies op risicomarkers voor HVZ, zoals non-invasieve markers voor vaatfunctie, worden onderzocht. Deze vaatfunctiemarkers voorspellen toekomstige cardiovasculaire uitkomsten en kunnen ook gebruikt worden om eventuele gunstige effecten op het cardiovasculaire risico te bestuderen. Het identificeren van vaatfunctiemarkers, die veranderen als gevolg van een veranderd voedingspatroon, is echter van groot belang aangezien een verslechterde vaatwandfunctie een belangrijk mechanisme is waarlangs een gezonde voeding het cardiovasculair risico verlaagt. Het onderzoek, dat in dit proefschrift staat beschreven, heeft zich dan ook gericht op (i) drie RCTs en (ii) twee meta-analyses van interventiestudies, die specifiek zijn opgezet om de effecten van voedingsfactoren en gewichtsverlies op verschillende non-invasieve vaatfunctiemarkers te bepalen in volwassenen.

Het verband tussen verschillende markers voor vaatfunctie en het risico op HVZ is samengevat in hoofdstuk 2. Vervolgens zijn de effecten van verschillende vetzuren in de voeding op cardiovasculaire risicomarkers en ziekten besproken. We concludeerden dat het vervangen van verzadigde vetzuren door cismeervoudig onverzadigde vetzuren het risico op HVZ verlaagt, terwijl verder onderzoek verricht moet worden om het vervangen van verzadigde vetzuren door cis-enkelvoudig onverzadigde vetzuren en koolhydraten goed in kaart te brengen. De inname van trans-vetzuren moet zo laag mogelijk zijn. De volgende twee hoofdstukken beschrijven het effect van enkele voedingsfactoren op endotheelfunctie. In de voedingsinterventiestudie beschreven in hoofdstuk 3 onderzochten we in twintig mannen met overgewicht of matige obesitas de effecten van nitraatrijk bietwortelsap op de postprandiale verslechtering van de flow-gemedieerde vasodilatatie van de arteria brachialis (FMD), die optreedt na het nuttigen van een maaltijd. De mannen consumeerden in een willekeurige volgorde een maaltijd ( $57 \mathrm{~g}$ vet) met bietwortelsap (500 mg nitraat) of een controle drankje. In vergelijking met het controle drankje, nam de FMD na de maaltijd minder sterk af na de consumptie van bietwortelsap $(-1.56 \pm 2.90 \%$ versus $-0.37 \pm 2.92 \%$;) Plasma stikstofmonoxide (NO) concentraties waren verhoogd na de inname van bietwortelsap. $\mathrm{NO}$ is een stof, die een een belangrijke rol speelt bij het verwijden van bloedvaten. Uit deze studie konden we concluderen dat een éénmalige inname van bietwortelsap de afname in de FMD na een maaltijd voorkomt door verhoging van de plasmaconcentraties van NO. In hoofdstuk 4 werd een metaanalyse uitgevoerd om de effecten van suppletie met de vetoplosbare vitaminen $\mathrm{E}$ en D op FMD te kwantificeren. RCTs gepubliceerd voor juli 2014 werden op systematische wijze verzameld. In totaal werden zeven onderzoeken met vitamine $D$ en negen interventiestudies naar de effecten van vitamine E (300-1800 IU/dag) gevonden, waaraan respectievelijk 303 en 658 volwassenen deelnamen. Een oorzakelijk verband tussen vitamine $E$ suppletie en een verbetering van FMD kon niet worden vastgesteld, terwijl er geen effecten van suppletie met vitamine $D$ werden gevonden. Deze meta-analyse kon derhalve geen éénduidig bewijs leveren dat in volwassenen suppletie met deze twee vetoplosbare vitaminen een positief effect heeft op FMD. De volgende twee hoofdstukken beschrijven de 
effecten van gewichtsverlies op vaatmarkers. De effecten van gewichtsverlies op FMD werden gekwantificeerd in een meta-analyse [hoofdstuk 5]. Interventiestudies gepubliceerd voor juni 2014 werden op systematische wijze verzameld en vier RCTs met 265 volwassenen werden geïncludeerd. Gewichtsverlies verbeterde de FMD ten opzichte van de controlegroep met 3,29\%. In totaal hebben 1517 volwassenen deelgenomen in 33 afvalstudies met een quasi-experimentele onderzoeksopzet. Er waren 49 relevante studiearmen. Metaregressieanalyses lieten zien dat een daling van het lichaamsgewicht met $10 \mathrm{~kg}$ samenging met een verbetering van $1,11 \%$ in FMD. Een afname van de buikomtrek met $5 \mathrm{~cm}$ ging samen met een verbetering van 1,17\% in FMD. Dit effect was significant groter in deelnemers met obesitas-gerelateerde aandoeningen of na gewichtsreductie-interventies, die mede werden bewerkstelligd door een verhoogde lichamelijke activiteit of het gebruik van geneesmiddelen voor de behandeling van obesitas. Vervolgens werd een RCT uitgevoerd om enerzijds de effecten van gewichtsverlies als gevolg van een energiebeperkt dieet op verschillende vaatmarkers te identificeren en anderzijds om verschillen te onderzoeken tussen mannen met een normaal lichaamsgewicht en met abdominale obesitas bij aanvang van het onderzoek en na gewichtsverlies [hoofdstuk 6]. Vijfentwintig mannen met een normaal lichaamsgewicht (tailleomtrek < $94 \mathrm{~cm}$ ) en vierenvijftig mannen met abdominale obesitas (tailleomtrek: $102-110 \mathrm{~cm}$ ) namen deel aan deze studie. Mannen met abdominale obesitas werden willekeurig toegewezen aan een groep die middels een energiebeperkt dieet gewicht moest verliezen (interventiegroep) of aan een groep die hun voedingspatroon niet veranderde zodat hun gewicht constant bleef (controlegroep). Deelnemers in de interventiegroep hadden na acht weken een buikomtrek kleiner dan de grenswaarde die gehanteerd wordt bij de diagnose van het metabool syndroom $(102 \mathrm{~cm})$. Er werden geen effecten gevonden op FMD. Gewichtsverlies als gevolg van een energiebeperkt dieet verbeterde echter wel de polsgolfsnelheid in de aorta $\left(P W V_{c-f}\right)$, de diameters van de bloedvaatjes van het netvlies, plasmaconcentraties van biomarkers van endotheelfunctie en de meer bekende cardiometabole risicomarkers, zoals het serum cholesterolgehalte, het plasma glucosegehalte en de bloeddruk. Deze markers verschilden bij aanvang van de RCT tussen mannen met een normaal lichaamsgewicht en met abdominale obesitas, maar waren bijna vergelijkbaar na de gewichtsreductie. Hoofdstuk 7 beschrijft tenslotte de resultaten van een lange-termijn studie naar de effecten van magnesiumsuppletie op de arteriële stijfheid. Tweeënvijftig volwassen met overgewicht of matige obesitas (30 mannen en 22 vrouwen) namen deel aan een gerandomiseerd, dubbelblind, placebo-gecontroleerd interventieonderzoek. Hierin werd het effect van een dagelijkse inname van $350 \mathrm{mg}$ magnesium $(3 \times 117 \mathrm{mg})$, gedurende 24 weken, op de $P W V_{c-f}$ onderzocht. Er werd geen effect gevonden na 12 weken, terwijl de $P W V_{c-f}$ was verbeterd met $1 \mathrm{~m} / \mathrm{s}$ aan het einde van de studie. De bloeddruk, die door ons 's ochtend voorafgaande aan de bloedafname werd gemeten alsmede de bloeddruk die gedurende 24-uur werd gemeten, veranderden niet. Uit deze interventiestudie concludeerden we dat een dagelijks magnesiumsupplement van $350 \mathrm{mg}$ gedurende 24 weken de arteriële stijfheid verbetert, hetgeen een mogelijk mechanisme is waarlangs een verhoogde inname van magnesium het risico op HVZ verlaagt. 


\section{SAMENVATTING}

In conclusie, dit proefschrift levert verder bewijs dat veranderingen in samenstelling van de voeding het risico op cardiovasculaire aandoeningen kunnen verminderen door een gunstige werking op vasculaire endotheelfunctie en arteriële stijfheid. FMD is de huidige gouden standaard om endotheelfunctie te onderzoeken. Ondanks enkele belangrijke tekortkomingen kan FMD toch beschouwd worden als een waardevolle marker om de risico's op het krijgen van HVZ te beoordelen van voedingsinterventies, die het NO metabolisme beïnvloeden. De meest valide en betrouwbare marker voor arteriële stijfheid is $\mathrm{PWV}_{\text {c-f. }} \mathrm{Op}$ basis van de resultaten beschreven in dit proefschrift kan $P W V_{c-f}$ beschouwd worden als een waardevolle vaatfunctiemarker om de effecten van lange-termijn voedingsinterventies op het risico van HVZ te voorspellen. 


\section{Valorisation}




\section{VALORISATION}

\section{Valorisation}

The medical, societal and economic consequences of cardiovascular disease (CVD) combined with the growing world population over the age of 60 years requires multilevel assessments and multidimensional solutions. The World Health Organization (WHO) has estimated that by the year 2050 the world population aged 60 or over will be two billion. Human ageing is associated with an increased risk of cardiovascular problems and effective intervention strategies are highly needed for the prevention or delay of CVD. The research described in the present dissertation focused on three well-defined intervention studies and two metaanalyses of intervention trials, which were specially designed to assess the specific effects of various dietary factors and weight loss on vascular function markers predicting the risk for CVD. We provided further evidence that dietary changes improve cardiovascular health based on beneficial effects on vascular endothelial function and arterial stiffness. Besides the scientific value of the research described in this dissertation, the study findings can also be presented in terms of societal and economic relevance, which is known as valorisation. Valorisation has been defined by the Dutch National Valorisation Commission as "the process of creating value from knowledge by making knowledge suitable and/or available for societal and/or economic use, and by translating that knowledge into competitive products, services, processes and commercial activities". In other words: "How can the findings described in this thesis be translated into practice?". The societal and economic relevance of these findings will be first addressed. The next question that needs to be addressed is how the generated scientific knowledge can be translated into practice.

\section{Societal and economic relevance}

Various vascular function markers are associated with future cardiovascular events and can also be used to demonstrate CVD benefits. We found that a single dose of beetroot juice improved the postprandial impairment in flow-mediated vasodilation of the brachial artery (FMD) after consumption of a mixed meal [reported in chapter 3]. In our meta-analysis described in chapter 5, it was estimated that each $10 \mathrm{~kg}$ decrease in body weight was associated with an increase of about $1 \%$ in FMD. Results from prospective epidemiological studies have suggested that the risk of CVD decreases by $8 \%$ when FMD increases by $1 \%$ [1]. In abdominally obese men, diet-induced weight-loss tended to decrease carotid-to-femoral pulse wave velocity $\left(P W V_{c-f}\right)$ by $0.5 \mathrm{~m} / \mathrm{s}$ [chapter 6]. A decrease of this magnitude at the population level would lead to a $7 \%$ risk reduction of CVD [2]. Furthermore, as reported in chapter $\mathbf{7}$, long-term magnesium supplementation in overweight and slightly obese adults improved $P W V_{c-f}$ as compared with placebo by $1 \mathrm{~m} / \mathrm{s}$, which has been related with a $14 \%$ decrease in the risk to develop CVD [2]. The relevance of these nutritional interventions in promoting public health can thus be found in the prevention of CVD in the large part of the population that is at increased cardiovascular risk, but not yet diagnosed with disease or under medical treatment. In addition, high-risk patients such as subjects already diagnosed with 
CVD may also benefit from these intervention strategies, but this warrants further studies.

Identifying effective intervention strategies to prevent or postpone conditions such as CVD associated with human aging will also have an enormous economic impact. In fact, nutritional interventions described in the present dissertation, such as oral magnesium supplementation [chapter 7], which can be easily achieved at low costs, could scale down medical costs, revalidation and medication, and would therefore be of significant economic relevance. This would also have a great societal impact, since CVD is the leading cause of death worldwide [3]. However, potential risks that may be associated with the consumption of dietary components described in this dissertation should also be kept in mind. For instance, concern has been raised about potential adverse effects of vitamin E supplementation. One meta-analysis indeed concluded that high-dose vitamin $E$ supplementation may increase all-cause mortality in trials supplying daily doses $>400 \mathrm{IU}$, that involved adults with chronic diseases [4]. In another thorough meta-analysis, vitamin E given singly or in combination with other antioxidant supplements was also found to increase mortality in randomized primary and secondary prevention trials when trials with low methodological quality were excluded [5].

The various vascular function measurements described in this dissertation may also function as future screening tools to determine the specific components, either from nutritional or pharmacological origin, that will be beneficial to reduce the risk to develop CVD. Measurement of these validated vascular markers may also give physicians the opportunity in the future to early diagnose and follow the progression of cardiovascular complications. In fact, $\mathrm{PWV}_{\text {c-f }}$ has already been depicted as a promising future tool for cardiovascular risk prediction in clinical practice $[6,7]$. This is of the great importance, as it has been shown that various treatments are more effective if they are given early in the disease process. Furthermore, more information on the development and natural progression of age-related conditions such as CVD will be provided. Overall, the present thesis provides further data on the sensitivity of various vascular markers to diet-induced changes. From industrial, academic and public health perspective, these results may be of great relevance as vascular dysfunction is a key mechanism whereby a healthy diet and healthy lifestyle improve cardiovascular health [8].

\section{Translation into practice}

The results described in this thesis have been presented at national and international conferences to colleagues inside and outside the field with the purpose to increase the awareness of the medical, societal and economic consequences of CVD and to highlight the potential impact of diet and weight loss. Results have also been discussed with experts for possible explanations or innovative ways to look at the data. For instance, experts of the industrial partners within this project have contributed to the described research projects through regular discussions at tri-annual expert meetings. Moreover, research findings have been published or submitted to international peer-reviewed scientific journals in the categories "nutrition and dietetics" and "peripheral vascular disease". 


\section{VALORISATION}

Published research data are therefore accessible to scientists worldwide, and will drive other research groups for further investigation with the purpose to further broaden current knowledge.

The research described in the present thesis was funded by research grant $\mathrm{CH}-001$ from the Top Institute of Food and Nutrition (TIFN). TIFN is a publicprivate partnership between knowledge institutes, industry and government conducting strategic research in food and nutrition. Further, magnesium and placebo capsules were kindly provided by Laboratorium Medisan B.V. (Heerenveen, The Netherlands). These interactions and cooperation's are crucial for the optimal valorisation of findings extracted from scientific research. In fact, scientists have a good insight into existing knowledge from scientific publications and they can use that knowledge to design promising trials. Scientists know how to perform well-designed intervention studies and academia have state-of-the-art facilities to investigate health effects of the most promising products. On the other hand, industries focus on the innovative and practical use of research, and the translation into products that can be marketed, while the Dutch government supports science and industry to transfer scientific knowledge for the benefit of society and the economy. Close collaborations between these partners will have societal and economic impact as they facilitate both the translation of research findings into commercial products that may lead to an improvement in quality of life and the application of generated knowledge for governmental policy-making.

Research findings reported in the present dissertation should be confirmed in additional studies. The effects of dietary interventions may also differ between target groups. While we focused on the large part of the population that is at increased cardiovascular risk, but not yet diagnosed with disease or under drug treatment, future research should now broaden its focus on different target groups (e.g. subjects with the metabolic syndrome or CVD patients). Only when results are confirmed in several independent scientific trials, these study findings can be considered univocal. The generated scientific knowledge can be used by different policy makers. One group may be the Health Council of the Netherlands, which is an independent scientific advisory body informing the Dutch government and parliament on public health. Health agencies such as the Netherlands Nutrition Centre (Voedingscentrum) are valuable in providing scientific evidence-based information on healthy and safe food to the Dutch population. In addition, the European Food and Safety Authority (EFSA) is the agency of the European Union that provides highly valuable scientific advice on the use of foods and food components. EFSA protects European consumers from scientifically unfunded advice regarding healthy nutrition, which has a negative impact on nutritional science and also threatens the credibility of nutritional scientists. 


\section{VALORISATION}

\section{References}

1. Ras RT, Streppel MT, Draijer R, Zock PL. Flow-mediated dilation and cardiovascular risk prediction: a systematic review with meta-analysis. Int J Cardiol 2013;168:344-51.

2. Vlachopoulos C, Aznaouridis K, Stefanadis C. Prediction of cardiovascular events and allcause mortality with arterial stiffness: a systematic review and meta-analysis. J Am Coll Cardiol 2010;55:1318-27.

3. World Health Organization. Cardiovascular diseases (CVDs) fact sheet No. 317, January 2015. Available from: http://www.who.int/mediacentre/factsheets/fs317/en/.

4. Miller ER 3rd, Pastor-Barriuso R, Dalal D, Riemersma RA, Appel LJ, Guallar E. Meta-analysis: High-dosage vitamin $\mathrm{E}$ supplementation may increase all-cause mortality. Ann Intern Med 2005;142:37-46.

5. Bjelakovic G, Nikolova D, Gluud LL, Simonetti RG, Gluud C. Mortality in randomized trials of antioxidant supplements for primary and secondary prevention: Systematic review and meta-analysis. JAMA 2007;297:842-57.

6. Holewijn S, den Heijer M, Stalenhoef AF, de Graaf J. Non-invasive measurements of atherosclerosis (NIMA): current evidence and future perspectives. Neth $J$ Med 2010;68:388-99.

7. Ter Avest E, Stalenhoef AF, de Graaf J. What is the role of non-invasive measurements of atherosclerosis in individual cardiovascular risk prediction? Clin Sci (Lond) 2007;112:50716.

8. Lichtenstein AH, Appel LJ, Brands M, Carnethon M, Daniels S, et al. Diet and lifestyle recommendations revision 2006: a scientific statement from the American Heart Association Nutrition Committee. Circulation 2006;114:82-96. 



\section{Dankwoord}




\section{DANKWOORD}

De afgelopen jaren heb ik met veel plezier gewerkt aan dit proefschrift en ik kan terugblikken op een prachtige tijd. Uiteraard hebben erg veel mensen bijgedragen aan de totstandkoming van mijn proefschrift en ik wil graag iedereen bedanken, die op welke manier dan ook, betrokken is geweest.

Allereerst wil ik mijn promotoren, Prof. dr. ir. R.P. Mensink en Prof. dr. J. Plat, bedanken voor al hun steun en de goede begeleiding tijdens mijn promotietraject. Beste Ronald, ik wil je bedanken voor de plezierige samenwerking en de kans die je me hebt gegeven om humaan voedingsonderzoek uit te voeren. Ik heb enorm veel van je geleerd en ik heb je betrokkenheid altijd weten te appreciëren. Een betere werkbaas had ik me niet kunnen wensen! Jogchum, je drive en passie voor voedingsonderzoek heeft mijn enthousiasme voor deze tak van wetenschappelijke onderzoek verder versterkt. Ik heb veel van je geleerd en ik wil je bedanken voor de fijne samenwerking, en de leerzame en gezellige congresbezoeken.

De leden van de beoordelingscommissie, Prof. dr. M.K.C. Hesselink, Prof. dr. A. Bast, Dr. R. Draijer, Prof. dr. J.M. Geleijnse en Prof. dr. A.A. Kroon, wil ik graag bedanken voor het lezen en beoordelen van dit proefschrift.

Ik wil eveneens Prof. dr. C.G. Schalkwijk, Dr. A.J.H.M. Houben en Prof. dr. C.D.A. Stehouwer van de afdeling Interne Geneeskunde van het MUMC+ bedanken voor de prettige samenwerking. Ik hoop dat we in de toekomst deze samenwerking kunnen verderzetten. Yvo en Jos, bedankt voor de goede samenwerking bij het uitvoeren van de testdagen voor de Afvalstudie. Samen zijn we erin geslaagd om de studie tot een goed einde te brengen.

De TI Food and Nutrition partners in het thema "Cardiovascular Health", bedankt voor de vruchtbare samenwerking en jullie interesse, en voor de nuttige suggesties en discussies tijdens onze bijeenkomsten.

Prof. dr. T.T. Liu, thank you so much for giving me the opportunity to visit your lab at the University of California, San Diego. It was really a great experience and I am looking forward to collaborate in the future! I also would like to thank Dr. D.D. Shin for all his invaluable help, support and patience. Maryam and Xing, we really had a good time and I wish you both the best.

Het uitvoeren van voedingsinterventies kan uiteraard niet zonder de medewerking van gemotiveerde en enthousiaste deelnemers. Daarom wil ik graag deze mensen van harte bedanken voor hun interesse en deelname aan één of meerdere studies die beschreven staan in dit proefschrift.

Ik heb een erg leuke tijd gehad op zowel de universiteit als daarbuiten. De dagjes uit, weekenden weg, kerstdiners, carnavalfeestjes in de Perroen, etentjes, borrels en ontelbare koffiepauzes waren erg leuk.

Martine, Maud en Maurice, bedankt voor jullie belangstelling in mijn onderzoek en de labanalyses die jullie hebben uitgevoerd voor de studies die hier beschreven staan. Zonder jullie hulp had ik dit nooit allemaal kunnen opschrijven! Onze diëtistes, Nina, Daisy en Cara, bedankt voor de waardevolle hulp bij het uitvoeren 
van de voedingsinterventies en de gezelligheid op onze kamer. Jullie hebben mij bergen werk uit handen genomen. Verder wil ik de secretaresses, Claudia, Désirée B., Desiree M. en Yolanda, en onze computerspecialisten, Loek, Marc en Paul, bedanken voor hun hulp. Tenslotte wil ik ook de stagiaires, Roel, Gonny, Mandy, Cheryl en Vincent, bedanken voor de hulp tijdens de testdagen.

Lotte en Charlotte T., we hebben enerzijds heel wat afgelachen op jullie kamer, maar ik kon ook steeds bij jullie terecht voor een serieus gesprek. Bedank voor alles! Cyril, je bent één van de meest oprechte personen die ik ken. We hebben erg veel plezier gehad en ik ben blij dat ik je nu een landgenoot kan noemen. Rudi, ik vond het erg leuk om samen met jou achter Els te staan bij haar promotie. Tanja, je enthousiasme werkt erg aanstekelijk en ik wil je erg bedanken om me te helpen bij het regelen van een bezoek aan het Center for Functional MRI in San Diego. Dirk, Guy, Max en Roel, dank voor de gezellige pokeravonden. Ik hoop dat we deze traditie verderzetten in de toekomst.

Natuurlijk wil ik Chris, Dorien P., Florence, Herman, José, Nadine, Resy, Sabine en Sanne bedanken voor de hulp en gezelligheid, koffie- en theepauzes, luchtige gesprekken en ontelbare wetenschappelijke discussies. Ik wil ook graag andere collega's en oud-collega's bedanken voor alle gezelligheid in de afgelopen vijf jaar: Alex, Bernard, Birgitta, Boris, Bram, Charlotte B., Dorien R., Eline, Elke, Emanuel, Emmani, Esther, Eva, Eveline, Freek, Gabby, Gijs, Jan, Jasper, Jesse, Jonathan, Joris, Jos, Kylie, Lena, Lucas, Mark, Marlies, Mathijs, Mieke, Nuria, Pilou, Rick, Silvie, Stefan C., Stefan G., Tineke en Yvonne. Ik wens jullie allemaal veel succes en geluk in de toekomst.

Uiteraard verdienen mijn twee paranimfen een aparte vermelding. Els, wij leerden elkaar snel kennen aan het begin van mijn promotietraject. Ik wil je bedanken voor alle hulp, advies en leuke gesprekken. Joris, hartelijk dank voor het ontwerpen van deze cover. Ik wens jullie veel geluk samen met jullie kindje! Sophie, wij hebben het langst samen een kamer gedeeld. Als ik nood had aan afleiding, kon ik altijd bij je terecht en ik wil je bedanken voor de gezelligheid en leuke gesprekken.

Hoewel ik jullie heb leren kennen als collega's, zie ik jullie nu steeds meer als vriendinnen en ik ben blij dat jullie achter mij staan tijdens mijn verdediging.

De mannen, Davy, Gary, Jochen en Niels, wil ik speciaal bedanken voor de nodige ontspanning buiten het werk. Ik vind het super dat we een hechte groep zijn, één grote passie delen en steeds op elkaar kunnen rekenen!

Mijn familie alsook die van Geertrui wil ik heel erg bedanken voor alle support en aanmoedigingen. Mama en papa, ik wil jullie bedanken voor mij steeds alle kansen te bieden en me altijd onvoorwaardelijk te steunen. Mede door jullie heb ik dit punt kunnen bereiken, ik ben jullie heel erg dankbaar!

Last, but definitely not least, Geertrui. Ik ben blij dat je me de ruimte hebt gegeven om onderzoekservaring op te doen in de Verenigde Staten. Jij bent mijn grootste steun en toeverlaat, en ik wil je bedanken voor je eindeloze liefde en geduld de afgelopen jaren. Ik kijk uit naar onze toekomst samen! 

Curriculum Vitae 


\section{CURRICULUM VITAE}

Peter Jozef Joris was born on March $3^{\text {rd }}, 1988$ in Hasselt, Belgium. He completed secondary school at the Sint-Jozefinsituut Bokrijk, Genk in 2006. From 2006 till 2011, he studied Biomedical Sciences at Hasselt University. In 2011, he graduated Magna Cum Laude as Master in Biomedical Sciences, specialization Environmental Health Sciences at Hasselt University. His senior internship was spent at the Centre for Environmental Sciences, Hasselt University. Under supervision of Prof. dr. Tim Nawrot, he investigated the effects of air pollution on cardiovascular health. Since the end of 2011, he worked on his PhD project "relevance of vascular function markers" at the department of Human Biology and Movement Sciences at Maastricht University under supervision of Prof. dr. ir. Ronald Mensink and Prof. dr. Jogchum Plat. This project was part of a project funded by the Top Institute for Food and Nutrition (TIFN) and was carried out in close collaboration with the Department of Internal Medicine. During his PhD project, he investigated the effects of diet and weight loss on vascular function and metabolic health. He was also involved in teaching and supervising students during their thesis. From November 2015 until April 2016, he worked as a Visiting Graduate Student at the Center for Functional MRI at the University of California, San Diego. Under supervision of Prof. dr. Thomas Liu, Peter obtained theoretical knowledge and practical skills on advanced magnetic resonance imaging (MRI) methodology regarding vascular function and physiology in the human brain. In July 2016, he starts as a tenure-track assistant professor at the department of Human Biology and Movement Sciences at Maastricht University. 


\section{List of publications}




\section{LIST OF PUBLICATIONS}

\section{Published manuscripts}

Joris PJ, Plat J, Bakker SJ, Mensink RP. Long-term magnesium supplementation improves arterial stiffness in overweight and obese adults: Results of a randomized, double-blind, placebo-controlled, intervention trial. Am J Clin Nutr 2016; 103: 1260-1266.

Joris PJ, Mensink RP. Role of cis-monounsaturated fatty acids in the prevention of coronary heart disease. Curr Atheroscler Rep 2016; 18: 38.

Joris PJ, Mensink RP. Effects of supplementation with the fat-soluble vitamins E and $D$ on fasting flow-mediated vasodilation in adults: A meta-analysis of randomized controlled trials. Nutrients 2015; 7: 1728-1743.

Joris PJ, Zeegers MP, Mensink RP. Weight loss improves fasting flow-mediated vasodilation in adults: A meta-analysis of intervention studies. Atherosclerosis 2015; 239: 21-30.

Joris PJ, Mensink RP. Beetroot juice improves in overweight and slightly obese men postprandial endothelial function after consumption of a mixed meal. Atherosclerosis 2013; 231: 78-83.

\section{Book chapters}

Joris PJ, Mensink RP. Effect of dietary fatty acid intake on cardiovascular disease - Chapter 7. In: Functional Dietary Lipids, $1^{\text {st }}$ Edition: Food formulation, Consumer Issues and Innovation for Health. Woodhead Publishing 2015: 177-191.

\section{Submitted manuscripts}

Joris PJ, Plat J, Kusters YH, Houben AJ, Stehouwer CD, Schalkwijk CG, Mensink RP. Diet-induced weight loss not only improves cardiometabolic risk markers, but also markers of vascular function: A randomized controlled trial in abdominally obese men. Submitted

Joris PJ, Mensink RP, Adam TC, Liu TT. Relevance of cerebral blood flow measurements in adults: Effects of diet and exercise. In preparation

Brouwers B, Joris PJ, Hesselink MK, Schrauwen P, Schrauwen-Hinderling VB. Combined aerobic and resistance exercise training improves the cardio-metabolic profile in overweight and obese men with the metabolic syndrome. Submitted 
Severins N, Mensink RP, Joris PJ, Plat J. Effects of protein hydrolysate on blood pressure, serum lipids and vascular function: A meta-analysis and systematic review. Submitted

Kusters YH, Schalkwijk CG, Houben AJ, Kooi ME, Lindeboom L, op 't Roodt J, Joris PJ, Plat J, Mensink RP, Barrett EJ, Stehouwer CD. Visceral and subcutaneous adipose tissue, intrahepatic lipid and muscle microvasculature contribute independently to obesity-associated insulin resistance: implications for treatment strategies. Submitted 
